\title{
ELEMENTOS ESTRUTURAIS DE PLÁSTICO RECICLADO
}

\author{
Dissertação apresentada à Escola \\ de Engenharia de São Carlos da \\ Universidade de São Paulo, como \\ parte dos requisitos para a \\ obtenção do Título de Mestre em \\ Engenharia de Estruturas.
}

Orientador: Libânio Miranda Pinheiro

São Carlos

17 de março de 2006 
Dedico este trabalho aos meus pais e à minha irmã, pelo apoio e amor incondicionais, e à Jaciara, pelo amor, por existir e estar ao meu lado. 
Não se iludam. A ciência não está alicerçada na rocha. A vasta estrutura de suas teorias ergue-se sobre um pântano. É como um edificio sustentado por estacas que mergulham num terreno movediço, mas não atingem nenhuma base natural. Muitas questões fundamentais para a ciência continuam em aberto. Se não queremos nos ver reduzidos a meras fatias do conhecimento oficial, precisamos manter abertas também as nossas mentes. 


\section{Agradecimentos}

Ao professor Libânio Miranda Pinheiro, pela orientação e pela amizade.

Ao professor Benedito de Moraes Purquério, pela amizade, pelo apoio intelectual e pela ajuda financeira, tornando viável o trabalho e agregando-lhe valor.

Aos professores Carlos Alberto Fortulan e Jonas de Carvalho, pelo tempo gasto na discussão do projeto de pesquisa e pelas tão valiosas contribuições, sem as quais o trabalho não seria o mesmo.

Ao empresário João Dimas Rodrigues Martins, pelas conversas tão pertinentes sobre a problemática dos plásticos reciclados e pela prestatividade em ceder tempo, dinheiro e as instalações da empresa para o usufruto da pesquisa.

À CAPES, pela bolsa de estudos concedida.

À Universidade de São Paulo, por colocar à disposição a sua estrutura.

Aos funcionários do Departamento de Engenharia de Estruturas da Escola de Engenharia de São Carlos, pela disposição permanente em ajudar.

Aos amigos do Departamento de Estruturas, pelas conversas e momentos de descontração, onde quase tudo se discutia, menos sobre plásticos, viscoelasticidade, fluência, relaxação e coisas do gênero.

À Jaciara, por sua doçura, apoio integral, compreensão e amor.

Aos meus pais, simplesmente por tudo. 


\section{Sumário}

LISTA DE SÍMBOLOS i

RESUMO iii

ABSTRACT iv

CAPÍTULO 1 - INTRODUÇÃO 1

1.1. APRESENTAÇÃO DO TEMA

1.2. IMPORTÂNCIA DA PESQUISA 3

1.3. OBJETIVOS 6

1.4. CONTEÚDO DO TRABALHO

CAPÍTULO 2 - EVOLUÇÃO DOS PLÁSTICOS 9

2.1. HISTÓRIA DOS MATERIAIS DE CONSTRUÇÃO 9

2.2. A HISTÓRIA DO PLÁSTICO 12

2.3. ESTADO DA ARTE 16

CAPÍTULO 3 - OS PLÁSTICOS E SUAS APLICAÇÕES 26

3.1. ESTRUTURA QUÍMICA DOS PLÁSTICOS 27

3.1.1. MONÔMEROS 27

3.1.2. HOMOPOLÍMEROS 27

3.1.3. COPOLÍMEROS 28

3.1.4. TERPOLÍMEROS 28

3.2. MECANISMOS MOLECULARES 29

3.3. CLASSIFICAÇÃO DOS POLÍMEROS 32

3.3.1. POLÍMEROS TERMOPLÁSTICOS 32

3.3.2. POLÍMEROS TERMOFIXOS 36

3.3.3. ESTRUTURAS POLIMÉRICAS LAMINADAS 37

3.3.4. ELASTÔMEROS 37

3.4. CARACTERÍSTICAS GERAIS DOS PLÁSTICOS 38

3.4.1. PESO MOLECULAR 38

3.4.2. POLÍMEROS CRISTALINOS E AMORFOS 38

3.4.3. PROPRIEDADES TÉRMICAS 39

3.4.4. PROPRIEDADES ELÉTRICAS $\quad 40$

3.4.5. PROPRIEDADES ÓTICAS 40

3.5. ALTERAÇÃO DAS PROPRIEDADES DOS PLÁSTICOS 41

3.5.1. ADITIVOS 41 
3.5.2. REFORÇOS 41

3.5.3. CORANTES 42

CAPÍTULO 4 - FUNDAMENTOS TEÓRICOS 43

4.1. PROPRIEDADES MECÂNICAS 45

4.1.1. O FENÔMENO DA FLUÊNCIA 50

4.1.2. O FENÔMENO DA RELAXAÇÃO 52

4.1.3. COMPARAÇÃO COM OUTROS MATERIAIS 54

4.2. MODELOS DE PREVISÃO DO COMPORTAMENTO VISCOELÁSTICO 57

4.2.1. REPRESENTAÇÃO DIFERENCIAL DA VISCOELASTICIDADE LINEAR 57

4.2.2. MODELOS SIMPLES UNIDIMENSIONAIS 58

4.2.3. MODELOS MECÂNICOS GENERALIZADOS 67

4.2.4. O PRINCÍPIO DA SUPERPOSIÇÃO DE WILLIAMS, LANDEL E FERRY 69

4.2.5. SÉRIES DE PRONY 73

4.2.6. REPRESENTAÇÃO DAS SÉRIES DE PRONY 73

CAPÍTULO 5 - ANÁLISE DOS MODELOS DE PREVISÃO 75

5.1. MODELO DE MAXWELL 76

5.1.1. OBTENÇÃO DAS CONSTANTES DO MODELO DE MAXWELL 76

5.1.2. CURVAS REPRESENTATIVAS DO MODELO DE MAXWELL 78

5.2. MODELO DE KELVIN-VOIGT 79

5.2.1. OBTENÇÃO DAS CONSTANTES DO MODELO DE KELVIN-VOIGT 79

5.2.2. CURVAS REPRESENTATIVAS DO MODELO DE KELVIN-VOIGT 80

5.3. MODELO ASSOCIADO: MAXWELL E KELVIN-VOIGT EM SÉRIE 81

5.3.1. OBTENÇÃO DAS CONSTANTES DO MODELO ASSOCIADO 82

5.3.2. CURVAS REPRESENTATIVAS DO MODELO ASSOCIADO 84

5.4. COMPARAÇÃO: MODELOS DE MAXWELL, KELVIN E ASSOCIADO 85

CAPÍTULO 6 - CONSIDERAÇÕES SOBRE AS ESTRUTURAS DE PLÁSTICO 88

6.1. O PROJETO DE ENGENHARIA 88

6.2. A DINÂMICA DE UM PROJETO DE ENGENHARIA 88

6.3. O CONCEITO DE MATERIAL ESTRUTURAL 89

6.4. A ESCOLHA DO MATERIAL ESTRUTURAL 89

6.5. O PROJETO DE ENGENHARIA DE ESTRUTURAS 90

6.6. O PROJETO DE ESTRUTURAS DE MATERIAL PLÁSTICO 91

6.6.1. PROPRIEDADES MECÂNICAS DO MATERIAL PLÁSTICO

RELEVANTES A UM PROJETO ESTRUTURAL 92

6.6.2. LIMITAÇÕES DE UMA ESTRUTURA DE MATERIAL PLÁSTICO 92 
CAPÍTULO 7 - CONFORMAÇÃO DOS PLÁSTICOS

7.1. MOLDAGEM POR COMPRESSÃO

7.2. MOLDAGEM POR TRANSFERÊNCIA

7.3. MOLDAGEM DOS PLÁSTICOS REFORÇADOS

7.4. MOLDAGEM POR INJEÇÃO

7.5. MOLDAGEM POR EXTRUSÃO

7.6. MOLDAGEM POR PULTRUSÃO

7.7. CONFORMAÇÃO DE CHAPAS PLÁSTICAS

7.7.1. CONFORMAÇÃO EM MOLDES COMBINADOS

7.7.2. CONFORMAÇÃO POR ESCORREGAMENTO

7.7.3. MOLDAGEM A AR COMPRIMIDO

7.7.4. MOLDAGEM A VÁCUO

CAPÍTULO 8 - RECICLAGEM DOS PLÁSTICOS

8.1. O QUE É RECICLAGEM?

8.2. CLASSIFICAÇÃO DOS PLÁSTICOS

8.3. TIPOS DE RECICLAGEM

8.3.1. RECICLAGEM QUÍMICA

8.3.2. RECICLAGEM MECÂNICA

8.3.3. RECICLAGEM ENERGÉTICA

8.4. PERSPECTIVAS DA RECICLAGEM DOS PLÁSTICOS NO BRASIL

E MUNDO

CAPÍTULO 9 - CONSIDERAÇÕES FINAIS E CONCLUSÕES

9.1. CONSIDERAÇÕES FINAIS

9.2. CONCLUSÕES

9.3. SUGESTÕES PARA PESQUISAS FUTURAS

ANEXO A - ROTEIRO BÁSICO DE ENSAIOS EXPERIMENTAIS E PROJETO DAS MATRIZES PARA EXTRUSÃO DOS CORPOS-DE-PROVA

A.1. CONSIDERAÇÕES FINAIS

A.1.1. ENSAIO DE COMPRESSÃO: D695-96

A.1.2. ENSAIO DE TRAÇÃO: D638-96

A.1.3. ENSAIO DE FLEXÃO: D5943-96 


\section{Lista de Símbolos}

$\mathrm{a}_{\mathrm{T}}$

dS

$\mathrm{dU}$

E

fdx

$\mathrm{F}(\mathrm{t})=\mathrm{F}_{\text {crp }}(\mathrm{t})$

$\mathrm{F}_{\mathrm{d}}(\mathrm{t})$

$\mathrm{F}_{\mathrm{e}}\left(0^{+}\right)$

$\mathrm{F}_{\mathrm{g}}$

$\mathrm{F}_{\mathrm{i}}$

$\mathrm{F}_{\mathrm{v}}(\mathrm{t})$

$\mathrm{N}$

$\mathrm{P}, \mathrm{Q}$

$\mathrm{R}$

$\mathrm{t}$

$\mathrm{T}$

$\mathrm{T}_{\mathrm{g}}$

$\mathrm{T}_{\text {ref }}$

$\alpha$

$\dot{\gamma}=\dot{\varepsilon}$

$\varepsilon$

$\varepsilon_{0}$

$\varepsilon(\mathrm{t})$

$\varepsilon_{\mathrm{d}}(\mathrm{t})$

$\varepsilon_{\mathrm{e}}=\varepsilon_{\mathrm{e}}\left(0^{+}\right)$

$\varepsilon_{\mathrm{v}}(\mathrm{t})$

$\eta$ fator de correção do tempo (WLF)

incremento da medida da entropia do sistema

incremento da energia interna do sistema

energia de ativação aparente

incremento de trabalho mecânico

função de conformação da fluência ou função de flexibilidade

parcela elástica retardada da função de conformação da fluência

parcela elástica da função de conformação da fluência

função de conformação vítrea (Série de Prony)

retardação da resistência (Série de Prony)

parcela viscosa da função de conformação da fluência

densidade de interconexão molecular

operadores lineares diferenciais

constante do gás

tempo

temperatura

temperatura de transição vítrea

temperatura de referência

coeficiente de expansão térmica

taxa de deformação

deformação

deformação inicial

deformação dependente do tempo

deformação elástica retardada

deformação elástica instantânea

fluidez viscosa

constante referida com a viscosidade do fluido 
$\lambda$

$\rho$

$\sigma$

$\sigma_{0}=\sigma\left(0^{+}\right)$

$\tau$

$\xi_{\mathrm{g}}$

$\xi_{\text {r }}$

$\xi_{\text {rel }}(\mathrm{t})$

$\xi_{\infty}=\xi(\infty)$ quociente dos parâmetros $\eta$ e $\xi$

massa específica

tensão

tensão inicial

tempo de relaxação

módulo de elasticidade vítrea

módulo de elasticidade emborrachado

módulo da relaxação das tensões

módulo relaxado no tempo infinito 


\section{Resumo}

PARENTE, R. A. (2006). Elementos Estruturais de Plástico Reciclado. Dissertação (Mestrado) - Escola de Engenharia de São Carlos, Universidade de São Paulo, São Carlos, 2006.

Nesta pesquisa, fez-se uma abrangente reunião da literatura existente, apresentando um resumo histórico da evolução dos plásticos, enfocando o estado da arte e os avanços obtidos com o emprego desses materiais na construção civil, com função estrutural. É feita uma revisão sobre a estrutura química dos plásticos mais conhecidos, apresentando os mecanismos moleculares que provocam os fenômenos dependentes do tempo, e de que forma as suas propriedades podem ser alteradas. Este trabalho também analisa os diversos modelos de previsão do comportamento viscoelástico, além de fazer uma comparação entre os modelos de Maxwell, Kelvin-Voigt e Associado e os dados experimentais, mostrando aqueles que mais se adequam ao comportamento do material plástico. São discutidos alguns aspectos pertinentes a um Projeto de Engenharia e, posteriormente, apresentados alguns conceitos e considerações específicos a um projeto de estruturas de material plástico. Os tipos de processamento mais utilizados são apresentados e, para cada um deles, quais as aplicações a que se destinam e qual a sua influência nas características do produto final. Tratando-se do plástico reciclado, é de fundamental importância o conhecimento e o entendimento do processo de reciclagem. Além da apresentação dos tipos de reciclagem, é feita uma análise do cenário local e global do mercado dos plásticos reciclados. Ao fim deste trabalho, pôde-se concluir que o mercado dos elementos estruturais de plástico reciclado é um nicho a ser explorado e, como a pesquisa sobre o tema é ainda incipiente, há muito a ser estudado, pesquisado e, posteriormente, desenvolvido. Pode-se afirmar que a baixa rigidez do plástico reciclado frente aos materiais de construção tradicionais é a sua maior deficiência. O seu comportamento viscoelástico, dependente do tempo, e a sua sensibilidade à variação de temperatura tornam complexo o dimensionamento com esse material, desencorajando o seu emprego pelos projetistas de estruturas. Desde que sejam desenvolvidas formas de se contornar essas deficiências, como a adição de fibras, o emprego de armaduras de protensão nos elementos estruturais e a aplicação de aditivos, o emprego do plástico reciclado como elemento estrutural mostra-se não só tecnicamente viável, como bastante também promissor.

Palavras-chave: elementos estruturais, plásticos, reciclagem, processamento, viscoelasticidade, propriedades mecânicas, fluência, relaxação, sustentabilidade. 


\section{Abstract}

PARENTE, R. A. (2006). Structural Elements of Recycled Plastic. M.Sc. Dissertation Escola de Engenharia de São Carlos, Universidade de São Paulo, São Carlos, 2006.

This work deals with the employment of plastic materials in structures of civil construction. First, a reunion of existent literature is performed, emphasizing the state of art and the obtained advances in this area. A resume about the chemical structures of plastics is done, presented, considering the molecular mechanisms that cause the time-dependent behavior. This work also analyzes the several prediction models of viscoelasticity and compares the models of Maxwell, Kelvin-Voigt, Associated and experimental data, looking for those that best adequate with the plastic behavior. Some aspects involving an engineering project are discussed and, after, some specific concepts and ideas about plastic structures are presented. This work also considers the processing of plastics and its influence on the characteristics of manufactured product. Beyond the ways of plastic recycling, a local and global analysis of recycled plastic market are presented. It can be concluded that the recycled plastic structures market needs to be explored and as the research is novel, there is a lot to be studied, researched and, after, developed. The low stiffness is the worst characteristic of plastics and the time-dependent behavior and the temperature sensibility make the design complex, not encouraging the employment by engineers. If these problems are crossed, with fibers, additions or the pos-tension of reinforcement, the recycled plastic as structural element become technically viable and a reality in a brief future.

Keywords: plastics, structural elements, recycling, plastic processing, viscoelasticity, mechanical properties, creep, relaxation, sustainability. 


\section{Introdução}

\subsection{APRESENTAÇÃO DO TEMA}

É difícil imaginar o mundo moderno sem o uso dos plásticos. Desde a descoberta do primeiro plástico sintético da história, no início do século $\mathrm{XX}$, eles vêm sendo aperfeiçoados e aplicados com sucesso, nas mais diversas atividades do ser humano.

O termo "plástico", exaustivamente repetido neste trabalho, será empregado para todo material constituído por resinas sintéticas que tem, por sua vez, a sua matéria-prima de origem natural, como o álcool, o petróleo, o gás natural e o carvão, pois todas são ricas em carbono, o átomo principal que constitui os materiais poliméricos (MARCZAK, 2004).

A palavra plástico vem do grego plastikós, que, em latim, originou o adjetivo plasticus, que define a propriedade de um material de adquirir diversas formas, devido a uma ação exterior.

Formados a partir de longas cadeias de macromoléculas, ou polímeros, os plásticos possuem propriedades que os tornam atrativos em relação a outros materiais: são leves, resilientes (resistem ao impacto sem se deformar definitivamente), indiferentes à deterioração por decomposição e ataque de microorganismos, resistentes à corrosão, de fácil processamento e com um custo reduzido de manutenção.

O plástico coletado do resíduo urbano para reciclagem e reuso é composto basicamente por termoplásticos. A figura 1.1 mostra a distribuição média dos tipos de plásticos encontrados nos resíduos descartados. No entanto, o universo dos materiais plásticos é bastante amplo, podendo ser dividido em quatro categorias básicas (CRAWFORD, 1987; PRINGLE e BARKER, 2000):

a) Termoplásticos: serão aqueles enfocados neste trabalho. O seu aquecimento provoca o enfraquecimento das forças intermoleculares, tornando-os flexíveis. Quando resfriado, o material enrijece novamente. Esse ciclo de aquecimento e resfriamento pode ser repetido indefinidamente, sendo essa a maior de suas vantagens. Exemplos desses materiais são: polietileno (PE), cloreto de polivinila (PVC), poliestireno (PS), poliamida e polipropileno (PP); 
b) Termofixos ou termorrígidos: devido a seu processo de fabricação e moldagem, os termofixos são os plásticos que não podem ser amolecidos e moldados novamente. Quando aquecidos, esses materiais queimam e se degradam. Exemplos: formaldeídos, resinas epóxicas e alguns poliésteres;

c) Elastômeros: são polímeros que possuem propriedades elásticas que permitem duplicar ou triplicar o seu comprimento, recuperando o seu tamanho quando se interrompe a tensão. Exemplos de aplicação: pneus;

d) Polímeros naturais: materiais como a celulose e as proteínas, que provêem a base mecânica para a maioria dos vegetais e vida animal. Recentemente, materiais plásticos biodegradáveis têm sido desenvolvidos.

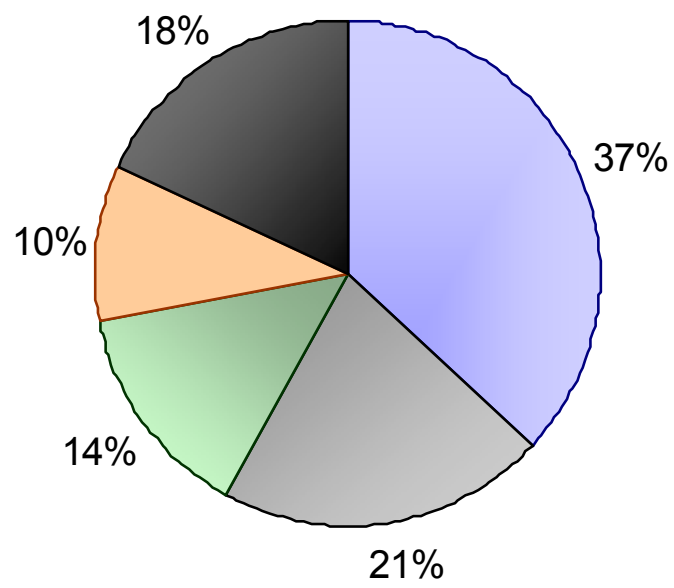

$$
\square \text { PE - Polietileno }
$$

$\square$ PET - Tereftalato de Polietileno

$\square$ PVC - Cloreto de Polivinila

$\square$ PP - Polipropileno

$\square$ Outros Plásticos Rígidos

Figura 1.1. Distribuição dos plásticos nos resíduos descartados Fonte: PIVA \& WIEBECK, 2004

A escassez de matéria-prima como a madeira, o alto consumo energético na produção do aço e do cimento juntamente com a abundância de material plástico a baixo custo estimularam, nas últimas décadas, a pesquisa relacionada às propriedades físicas do plástico reciclado, bem como o seu uso em estruturas.

Segundo Nielsen e Landel (1994), a maioria dos materiais plásticos é aplicada em função das características mecânicas desejáveis e da viabilidade do custo econômico. Por essa razão, as propriedades mecânicas são consideradas as mais importantes das propriedades físicas e químicas consideradas. Projetar elementos de plástico exige, ao menos, um conhecimento elementar do comportamento mecânico e de que forma esse comportamento pode variar em função de fatores estruturais que podem ser modificados nos polímeros.

No entanto, essa liberdade possibilitada pelos materiais plásticos é vista como uma confusa complexidade (NIELSEN e LANDEL, 1994). É importante a necessidade de uma avaliação dos diversos aspectos que afetam o comportamento estrutural, bem como a reunião e a organização do conhecimento existente e o estado da arte. Dessa 
maneira, uma das contribuições deste trabalho consiste na desmistificação e a na divulgação dos elementos estruturais de termoplásticos reciclados, junto à comunidade acadêmica e à sociedade.

A dependência do tempo e da temperatura nas propriedades mecânicas dos plásticos é bastante acentuada. Isto se deve à sua natureza viscoelástica, que implica no comportamento dual de um líquido viscoso e de um sólido elástico. Nos sistemas viscosos, o trabalho feito pelo sistema é dissipado sob a forma de calor, enquanto que nos sistemas elásticos, o trabalho realizado é acumulado sob a forma de energia potencial de deformação, como uma mola comprimida (NIELSEN e LANDEL, 1994).

É função do engenheiro de estruturas o estudo dos materiais que constituem a estrutura a ser projetada, para que haja uma concepção racional e uso otimizado dos recursos disponíveis. Em paralelo, com o avanço da ciência dos materiais e o empenho do homem em buscar melhorias, novos materiais foram desenvolvidos. Com essa diversidade, a escolha do material tem se tornado, no projeto, um aspecto crítico na busca pela solução estrutural mais adequada.

Por se tratar de um campo de pesquisa e de aplicação recente - elementos estruturais de material termoplástico reciclado -, é requerido todo esforço no sentido de complementar e renovar a literatura sobre o tema. A comparação com outros materiais também se faz premente para que o projetista possa decidir sobre qual material utilizar, balizado em informações técnicas.

\subsection{IMPORTÂNCIA DA PESQUISA}

A tecnologia aplicada ao desenvolvimento dos plásticos tem modificado o uso desses materiais, tornando-os cada vez mais resistentes e versáteis. O caráter antes descartável foi substituído por vantagens como: boa resistência mecânica, resiliência, durabilidade e baixo custo de manutenção.

A utilização do plástico na construção civil, como elemento de suporte primário, tem se tornado uma tendência verificada nos países desenvolvidos, como nos Estados Unidos, Canadá, Japão e diversos países europeus. O Brasil está se inserindo aos poucos, havendo algumas pesquisas sobre esses materiais e poucas empresas se iniciando nesse nicho de mercado, que aparenta ser bastante promissor.

Um outro aspecto a ser levantado é a necessidade de crescimento econômico do País. O Brasil possui sérias deficiências em infra-estrutura que precisam ser sanadas, caso contrário se tornarão um entrave ao desenvolvimento. No entanto, esse crescimento deve vir acompanhado de um desenvolvimento sustentável, do ponto de vista ecológico. As leis ambientais sinalizam essa tendência, cada vez mais rígidas, restringindo e direcionando o uso dos recursos naturais e o descarte de resíduos. 
Dentre os diversos problemas de infra-estrutura no País, a precariedade das rodovias, a inexistência de uma rede hidroviária eficiente e a escassez de ferrovias estão entre os maiores entraves ao crescimento da economia. Um passo para a melhoria desse cenário pode ser dado pelo projeto de parcerias público-privadas (PPP's), aprovado em 2004 pelo governo federal. A PPP é uma modalidade de contrato que será desenvolvida em paralelo aos contratos de concessão já existentes, e permite um amplo leque de atividades que incluem, principalmente, projetos de infraestrutura (Sítio eletrônico do Ministério do Planejamento, Orçamento e Gestão, 30/12/2004).

A substituição da madeira por outros materiais é justificável em aplicações como: mourões, caibros, vigotas, terças, tesouras, pontes, passarelas, marinas e, principalmente, dormentes de ferrovias, devido a sua enorme demanda. Segundo a FIP (FÉDÉRATION INTERNATIONALE DE LA PRÉCONTRAINTE, 1987) apud BASTOS (1999), o número total de dormentes instalados nas ferrovias no mundo é de três bilhões. Parte integrante da operação ferroviária, a manutenção de via permanente é responsável por significativa parcela de seus custos. Alguns trabalhos recentes quantificaram seu valor entre $12 \%$ e $30 \%$ do custo total da operação. No caso das ferrovias brasileiras, isto representou, em 2000, uma despesa da ordem de US\$ 300 milhões, que tende a aumentar, ano a ano, com a alta contínua dos custos de mão-de-obra e dos materiais (Ministério dos Transportes, 2001 apud RODRIGUES, 2001).

STOPATTO (1987) apud BASTOS (1999) afirma que, no Brasil, o problema da aquisição de dormentes de madeira está atingindo as ferrovias nacionais há muito tempo, e não se pode negar as crescentes dificuldades encontradas na solução desse problema. A cada dia, a matéria-prima está mais distante e as madeiras de boa qualidade vão se tornando mais raras.

O Brasil, apesar de figurar como o primeiro colocado na reciclagem de papelão e alumínio, é considerado um dos países onde mais se desperdiça no mundo. O percentual de resíduo urbano reciclado no Brasil é de apenas $5 \%$, enquanto nos Estados Unidos e na Europa esse percentual é de 40\%. O resultado desses números é o aumento do volume de resíduos descartados nos lixões e aterros sanitários, provocando um maior desequilíbrio ambiental (Folha Online Ciência, 05/06/2003). O plástico reciclado no Brasil representa apenas $21 \%$ do total produzido. O quadro acima piora quando se considera que somente $20 \%$ dos municípios possuem aterros sanitários dentro dos padrões definidos pela legislação, como mostra diagnóstico divulgado pelo Ministério das Cidades (Folha Online Cotidiano, 03/12/2004). 
O estudo dos materiais termoplásticos reciclados em elementos estruturais estimulará o aumento da reciclagem dos plásticos no País, dando um uso mais nobre ao material e agregando maior valor ao produto da reciclagem. Dessa forma, desoneram-se os aterros sanitários e lixões de um material que pode levar até 450 anos para se degradar. Ao mesmo tempo, esse novo mercado poderá criar diversos postos de trabalho, nos mais diversos níveis, desde a coleta seletiva do resíduo, o processamento e produção, o desenvolvimento de novos produtos e aplicações, até a venda do produto final.

No Brasil, a pesquisa a respeito do tema deste trabalho ainda é incipiente, estando aquém da tecnologia já dominada por alguns países desenvolvidos. Uma revisão da literatura existente, no País e no exterior, se faz necessária. Uma comparação do plástico com os diversos materiais de construção, sob a luz da engenharia de estruturas, deve ser feita, para que se possam sugerir as prováveis aplicações desse material.

De acordo com a norma D5592-94, da ASTM, os plásticos estão crescentemente sendo utilizados em aplicações permanentes, como componentes estruturais, em uma base comparável com os materiais tradicionais, tais como o aço, o alumínio, e alguns compósitos de alto desempenho. Ao contrário das aplicações em bens de consumo, em que os plásticos servem tipicamente como embalagens, essas aplicações permanentes envolvem componentes de suporte de carga, expostos a uma diversidade de condições ao longo do ciclo de vida do produto. Em tempo, para se projetar com plásticos, o projetista deve levar em consideração os efeitos do tempo, da temperatura, da velocidade de carregamento e o ambiente de exposição do plástico, bem como as causas e as prováveis conseqüências de uma ruína.

Um aspecto crítico do plástico é a sua rigidez, considerada baixa frente a outros materiais estruturais, como a madeira. Esse fator é, atualmente, o limitante do uso do plástico em aplicações estruturais. No entanto, estudos têm mostrado que a adição de fibras naturais ou sintéticas torna factível o uso estrutural, revertendo o problema da rigidez (NOSKER e RENFREE, 1999(a,b); CARROLL et al., 2001; CORREA et al., 2003). A descoberta de blendas, a partir de plásticos imiscíveis, cuja composição tem resultado num material denso e rígido, tem sido uma alternativa na utilização de materiais plásticos descartados (NOSKER et al., 1993 e 1994; JOSHI, et al, 2004).

Os elementos estruturais de termoplásticos reciclados são um substituto a diversas aplicações de concreto, aço e madeira, com a vantagem de ser uma alternativa que exige muito menos consumo de energia no seu processo industrial, em comparação ao cimento e ao aço. Além disso, surge como um aliado na preservação das florestas. 
A tabela 1.1 mostra, para diversos materiais, a comparação dos custos de energia, devido à matéria-prima, ao combustível e ao processamento. Não é recomendado, como pode ser observado, levar em consideração somente o custo da matéria-prima.

Tabela 1.1. Energia de manufatura para materiais com espessuras típicas de projeto. Fonte: CRAWFORD, 1987

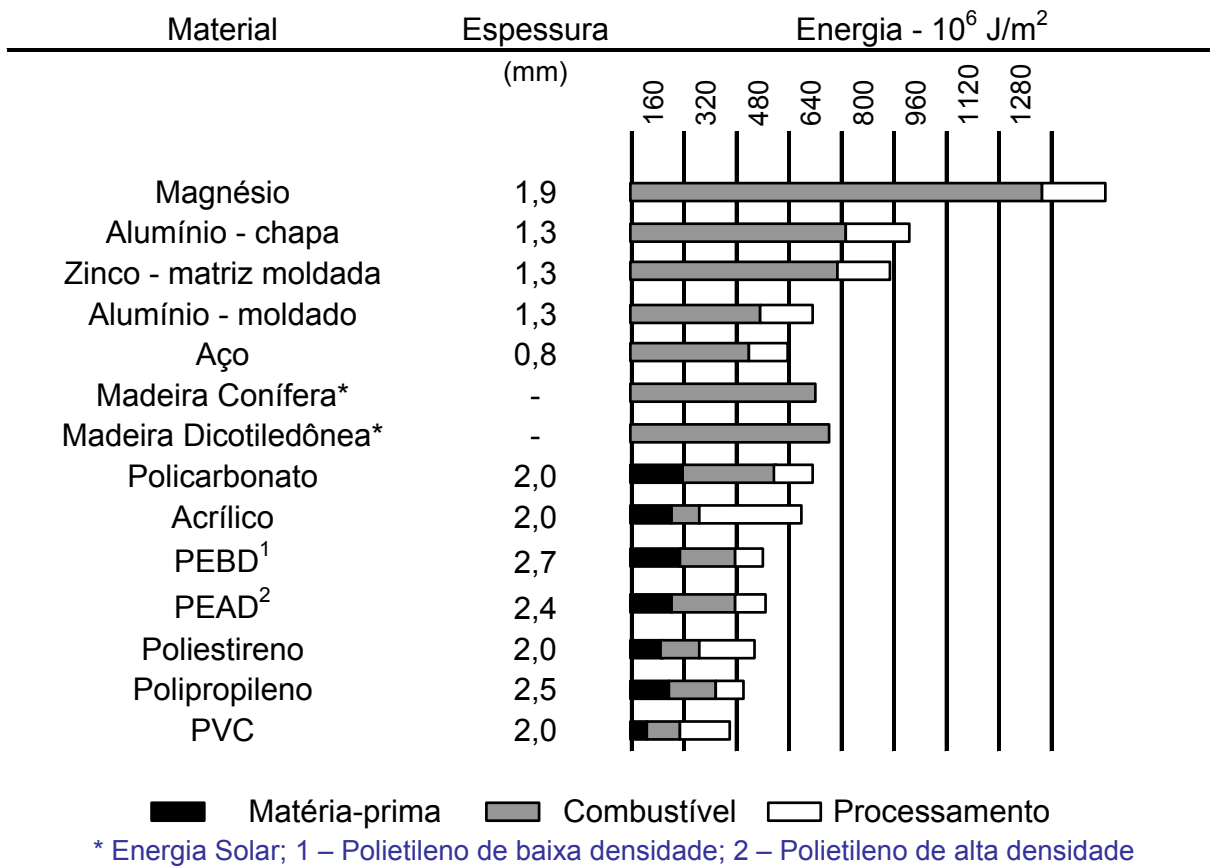

O desenvolvimento de uma dissertação, cujo tema é inédito no Departamento de Engenharia de Estruturas da EESC, possibilita a criação de uma nova linha de pesquisa e proporciona o desenvolvimento de trabalhos futuros e aprofunda estudos sobre o tema.

A importância desta pesquisa como uma colaboração ao tema, na literatura acadêmica e técnica no Brasil, pode ser sintetizada pelas palavras a seguir:

Solucionar é, desde sempre, a função da investigação científica. Nós acreditamos que qualquer resultado encontrado em uma investigação, por mais significativo e promissor que fosse, teria permanecido inútil se não fosse comunicado e transferido. Comunicar é, pois, a condição básica do desenvolvimento e é também a idéia central deste trabalho. (PIVA \& WIEBECK, 2004).

\subsection{OBJETIVOS}

Os objetivos principais desta pesquisa são os seguintes:

a) Reunir, analisar e interpretar o conhecimento da literatura existente sobre a utilização de termoplásticos e compósitos poliméricos, reciclados ou não, como material estrutural; 
b) Estudar, analisar e interpretar as equações constitutivas e os diversos modelos teóricos de previsão do comportamento do material termoplástico, que tratam das relações entre tensão e deformação, das formas de ruptura e da influência da fadiga;

c) Situar o plástico entre os principais materiais estruturais existentes - madeira, aço e concreto armado;

d) Discutir alguns conceitos e considerações específicos a um projeto de estruturas de material plástico, suas vantagens e deficiências;

e) Apresentar conceitos e definições sobre a reciclagem do plástico, bem como dados técnicos que sejam relevantes à viabilidade de um projeto estrutural de plástico reciclado;

f) Esquematizar o processo de fabricação dos elementos estruturais de plástico - máquinas, equipamentos, moldes, matrizes e materiais utilizados;

g) Como se trata de trabalho inaugural sobre o tema no Departamento de Engenharia de Estruturas da EESC, obter, como resultados e conclusões, dados e evidências técnicas que indiquem ou não a viabilidade do plástico reciclado como material estrutural.

\subsection{CONTEÚDO DO TRABALHO}

Este trabalho consiste em estudo teórico, compreendendo esta Introdução e um total de nove capítulos. As demais etapas realizadas durante a pesquisa estão na descrição do conteúdo dos capítulos indicadas a seguir:

Capítulo 2: revisão bibliográfica sobre os plásticos na história, sua descoberta, evolução e primeiras aplicações, até a sua inserção como material de construção. São apresentados também o estado da arte, os trabalhos e as conquistas recentes da aplicação dos plásticos como material constituinte de elementos estruturais;

Capítulo 3: apresentação dos plásticos existentes, a partir de sua classificação e características gerais. Uma introdução à sua estrutura química também é feita, relacionando-a com o comportamento dos diferentes tipos de plásticos;

Capítulo 4: propriedades mecânicas e características físicas dos plásticos, com ênfase nos aspectos que são necessários a um projeto estrutural. Uma comparação dos plásticos com os diversos tipos de material é feita e os fenômenos intrínsecos à viscoelasticidade são apresentados e interpretados. Os diversos modelos de previsão são descritos, analisados e interpretados;

Capítulo 5: comparação entre três modelos matemáticos de previsão apresentados no capítulo 4: Maxwell, Kelvin-Voigt e Associado. A partir da análise de 
um mesmo material, uma análise geral desses modelos de previsão é feita, enfocando a sensibilidade aos fenômenos da fluência, relaxação e recuperação;

Capítulo 6: aspectos mais importantes de um projeto estrutural, a sua concepção e o seu desenvolvimento. O tema é particularizado para o caso de estruturas de material plástico, as suas peculiaridades e características a serem consideradas num projeto;

Capítulo 7: os mais utilizados tipos de conformação dos plásticos e, para cada um deles, quais aplicações a que se destinam e qual a sua influência nas características do produto final;

Capítulo 8: conceitos e definições sobre a reciclagem do plástico, bem como dados técnicos que sejam relevantes à viabilidade de um projeto estrutural de plástico reciclado;

Capítulo 9: conclusões e sugestões para pesquisas futuras. 


\section{Evolução dos Plásticos}

O uso dos plásticos em elementos estruturais, aplicados à construção civil ou não, é resultado da busca incessante, principalmente após a Segunda Guerra Mundial, do entendimento do comportamento dos materiais poliméricos.

Apesar disso, Wigotsky, em 1993, citando o exemplo da indústria automobilística, afirmou que o volume dos plásticos utilizados neste mercado - ainda bastante inferior ao dos metais - não reflete o seu verdadeiro potencial de utilização.

Atualmente, mais de 10 anos depois, a declaração de Wigotsky se tornou pouco condizente com a realidade. Com o desenvolvimento de novos plásticos, a descoberta de blendas e o investimento da indústria na produção de elementos de plástico com utilização estrutural, configurou-se um novo paradigma: materiais poliméricos, compósitos ou não, passaram a competir e superar em desempenho os materiais metálicos e as madeiras.

O resumo da história dos materiais de construção e dos plásticos ajuda a entender essa mudança de paradigma, que não ocorreu de maneira abrupta. O desenvolvimento das ciências e da tecnologia, sempre acompanhando os anseios e as necessidades do homem, ocorreu de maneira lenta e gradual, e, neste contexto, se encontra a história da evolução e da utilização dos plásticos.

\subsection{HISTÓRIA DOS MATERIAIS DE CONSTRUÇÃO}

A história do homem se confunde com a evolução dos materiais. A busca por ferramentas que o auxiliassem em suas tarefas e por tecnologias que aumentassem $o$ conforto e a segurança proporcionou um grande avanço no uso dos materiais. Inicialmente, a matéria-prima para a confecção de ferramentas, peças e materiais de construção foi retirada da própria natureza. Pedras, madeira, couro, barro são exemplos desses usos.

Com o avanço das ciências e o domínio da natureza, o homem passou a modificar e a criar materiais, a partir de suas necessidades. Ferro, aço, vidros, plásticos, materiais compósitos, enfim, uma variedade limitada, apenas, pelos anseios do homem e o avanço das ciências. A figura 2.1 mostra, qualitativamente, o progresso das propriedades mecânicas dos materiais de construção, nos últimos séculos. 


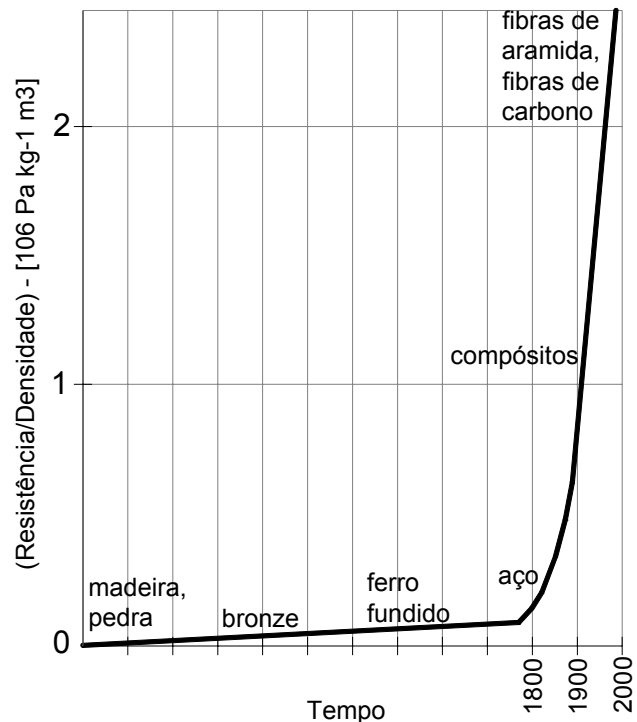

Figura 2.1. Relação resistência/densidade dos materiais na história Fonte: http://www.people.virginia.edu/ Iz2n/mse209

Os primeiros materiais utilizados pelo homem, para a construção de abrigos, foram pedras, madeiras, ossos e couro de animais. Os primeiros vestígios datam de 12.000 a.C. e eram estruturas bastante simples. Varas de madeira ou ossos de animais eram utilizados para erguer tendas, que eram cobertas por folhagens ou couro. Para o homem da época, devido a seu caráter nômade, as estruturas não necessitavam durar por longos períodos. Esses abrigos, no entanto, protegiam o homem de intempéries como chuvas, neve, ventos fortes e calor excessivo (Enciclopédia virtual About.com, 23/02/2005).

Com o advento da agricultura, as estruturas incorporaram maior espaço, segurança e privacidade. Formas de construções permanentes foram desenvolvidas. Materiais compósitos também foram utilizados. O método consistia em construir paredes de madeira e barro. Erguiam-se postes de madeira juntamente com fibras (raízes ou galhos) e aplicava-se lama ou reboco como vedação (ELLIOTT, 1994). Infelizmente, esse método construtivo ainda persiste, sendo comum no sertão nordestino brasileiro, como pode ser observardo na figura 2.2.

Dentre os diversos materiais, a madeira se destaca por ser utilizada pelo homem desde os seus primórdios até os dias de hoje. Templos gregos, até o século XVI a.C., eram construídos de madeira com terracota. Posteriormente, passaram a utilizar blocos de pedra para a sua construção, com exceção da cobertura, que continuou a ser feita de madeira. As construções européias, até o século XIX, foram baseadas no uso intensivo da madeira, por meio das vastas florestas do continente. Devido às suas características únicas, a madeira é um material natural que ainda é utilizado na construção de casas e de outras estruturas, ferramentas, mobílias e objetos decorativos (Enciclopédia virtual About.com, 23/02/2005). 


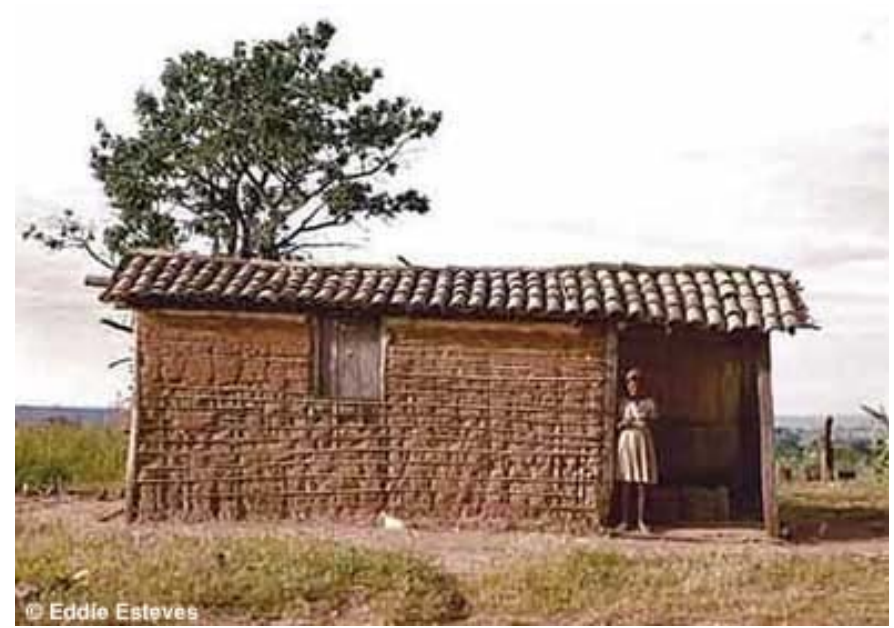

Figura 2.2. Casa de pau à pique típica do sertão nordestino brasileiro Fonte: http://www.cactos.com.br

Os romanos se destacaram como grandes construtores, desenvolvendo e aperfeiçoando três diferentes métodos construtivos: a alvenaria, as construções em concreto e as treliças de madeira.

Um belo exemplo do uso inovador do concreto e da alvenaria estrutural pelos romanos é o Panteão, construído entre os anos de 118 a 126 (ver figura 2.3). Apesar de ter sido destruído por incêndios duas vezes, o prédio foi recuperado e hoje é um dos maiores pontos turísticos de Roma, na Itália.
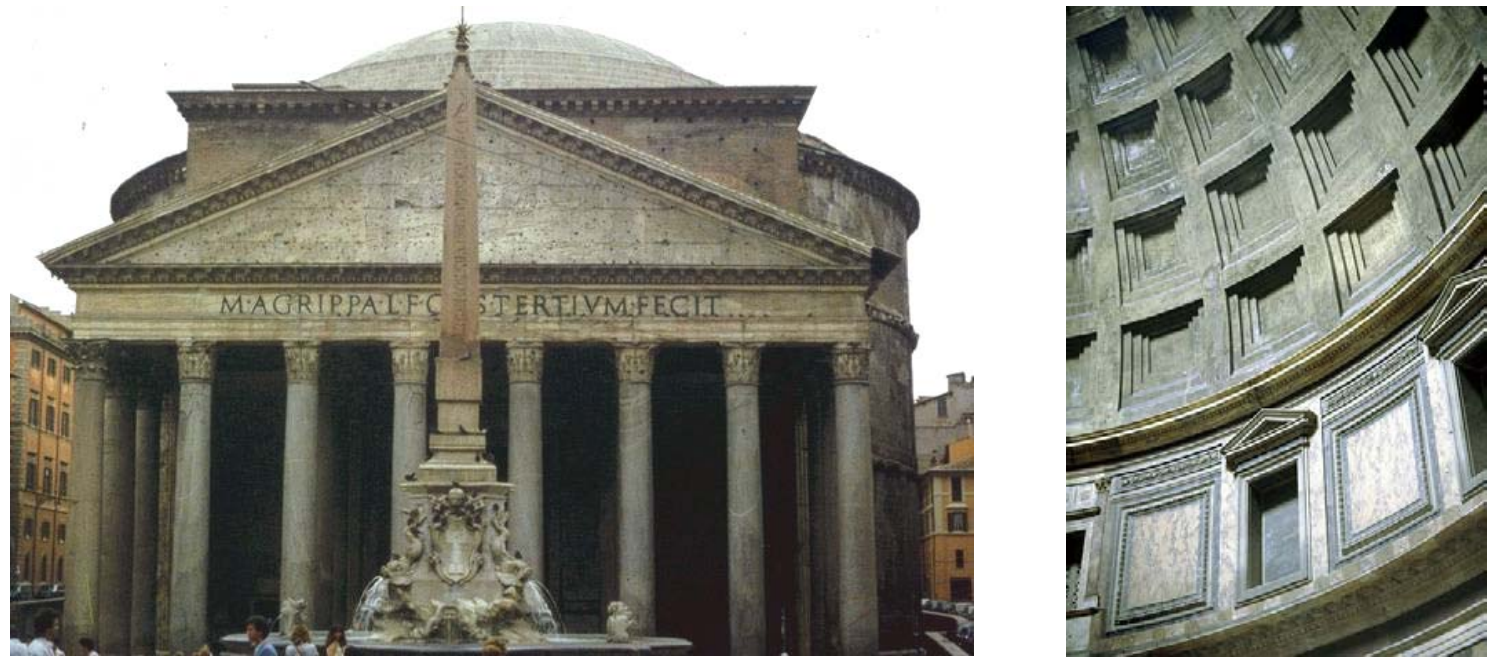

Figura 2.3. Detalhes da abóbada em concreto do Panteão. Fonte: http://harpy.uccs.edu/roman/

Sua cobertura, uma abóbada esférica apoiada em paredes de alvenaria, possui mais de 43 metros de altura no ponto mais alto. Em seu topo, existe um óculo ou abertura em forma de anel, que permite a entrada de iluminação e ventilação.

Durante a Era Industrial, as inovações tecnológicas aperfeiçoaram os materiais e os métodos construtivos. Com o advento da máquina a vapor e os conhecimentos sobre fundição, o ferro foi largamente utilizado como material de construção. Com a produção em massa de elementos estruturais de ferro, as estruturas foram 
padronizadas. Inicialmente utilizadas como vigas de ferro suportadas pela alvenaria, os elementos de ferro passaram a ser utilizados na estrutura como um todo.

O aço, uma liga de ferro e carbono em proporções variadas, não demorou muito a ser desenvolvido. No entanto, somente na segunda metade do século XIX, quando passou a se entender melhor seu comportamento, é que foi largamente utilizado. Um exemplo da utilização do aço é a construção da Torre Eiffel, em 1888, na França (vide figura 2.4). Com 324 metros, foi considerada a estrutura mais alta durante a sua construção (Sítio eletrônico oficial da Torre Eiffel).

A utilização do cimento, como concreto simples ou reforçado, é um capítulo à parte na história da humanidade. Os antigos egípcios, há 4.500 anos, já utilizavam um ligante a partir do gesso calcinado. Segundo Brunauer e Copeland (1964) apud Mehta e Monteiro (1994): "O material mais largamente usado em construção é o concreto, normalmente feito com a mistura de cimento Portland com areia, pedra e água [...]". Estima-se que o atual consumo de concreto é da ordem de 5,5 bilhões de toneladas por ano (MEHTA e MONTEIRO, 1994).

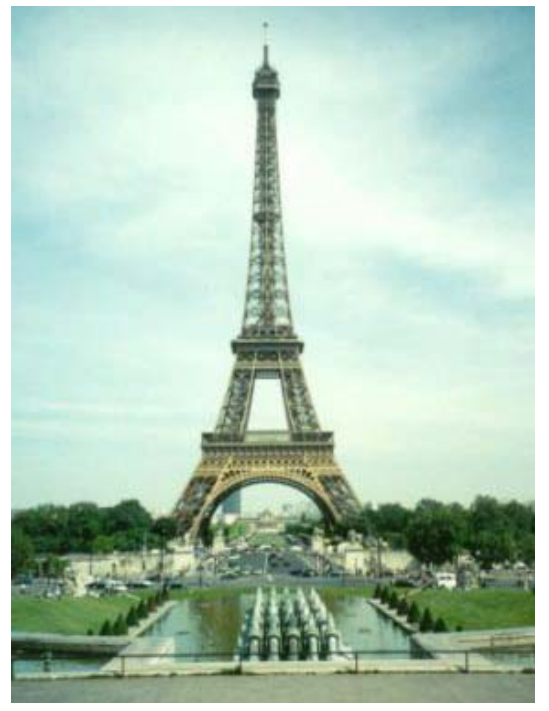

Figura 2.4. Vista frontal da Torre Eiffel em Paris (França)

São três as razões expostas por Mehta e Monteiro (1994) para o concreto ser o material mais usado na engenharia: o concreto possui uma excelente impermeabilidade, a facilidade de execução, em diferentes formas e tamanhos, e normalmente é o mais barato e mais facilmente disponível no canteiro de obras.

\subsection{A HISTÓRIA DO PLÂSTICO}

A escassez e a finitude dos recursos naturais e a convergência entre ciência e tecnologia impulsionaram o homem a criar materiais sintéticos, que atendessem a determinados fins, mas que não eram encontrados na natureza. Os plásticos, 
denominação dada aos materiais formados por macromoléculas, copiaram a estrutura química das resinas naturais, após observações e experiências das mais diversas, e acabaram por superá-las, quanto ao uso e capacidade de atender às demandas do mundo moderno (DONATO, 1972).

Pouco mais de um século atrás, a indústria dos polímeros estava na sua infância. O primeiro plástico manufaturado, uma forma de nitrato celulósico, foi apresentado na Grande Exibição Internacional de Londres, em 1862. Foram apresentadas 36 classes de plásticos. Em meio a 14000 exibidores da seção $C$ da classe 4 (substâncias animais e vegetais utilizadas em manufatura), era um pequeno conjunto de moldagens feitos por Alexander Parkes, a partir de um material chamado Parkesine. Foi apresentado na feira como um substituto de materiais naturais como o marfim e o casco de tartaruga, que estavam se tornando raros e caros (MCCRUM, 1987). No entanto, o Parkesine não foi viável comercialmente por causa de seu alto custo. Parkes empregou uma grande quantidade de solventes que não era reaproveitado.

O primeiro processo verdadeiramente comercial para a produção de material plástico a partir de nitrato celulósico deve-se a John Hyatt de Albany, no estado de New York. Em 1863, Hyatt, que era um tipógrafo com 26 anos, procurou ganhar um prêmio, oferecido pela companhia Phelan e Collander para a descoberta de um novo material sintético para fazer bolas de bilhar. Ele estudou na literatura a respeito do nitrato celulósico e conheceu a descoberta de Parkes de que a combinação de piroxilina e cânfora produzia um plástico semelhante ao marfim.

Hyatt formulou a idéia de usar uma pequena quantidade de solvente e suplementou com temperatura e pressão. Depois de alguns experimentos conduzidos na cozinha de sua casa, ele foi expulso para um barracão. Celulóide é um dos menores nitratos de celulóide existentes. Hyatt obteve sucesso em seu processo e o patenteou em 1870. A importância do celulóide não se deve somente ao fato de ser o primeiro plástico, mas este ele foi o único por quarenta anos, até o desenvolvimento da baquelita, o único (MCCRUM, 1987).

Parkes, Hancock, Goodyear e Hyatt foram homens práticos e em cujas mãos os plásticos e a indústria da borracha se desenvolveram no século XIX. Seus métodos de trabalho eram totalmente diferentes dos métodos que seriam utilizados após 1920 . Antes disso, não havia um entendimento da estrutura molecular dos polímeros. Para a borracha natural, Faraday em 1826 deduziu a fórmula empírica $\mathrm{C}_{5} \mathrm{H}_{8}$. Mas não havia a apreciação do fato de que a borracha natural abrangia moléculas enormemente longas (MCCRUM, 1987). 
A confusão predominante foi finalmente dissipada por Staudinger em 1920. Sua idéia revolucionária sofreu acalorada resistência, mas em 1930 foi aceito que todos os plásticos e borrachas eram polímeros, ou macromoléculas, como Staudinger denominou-as. No caso da borracha, por exemplo, unidades idênticas de $\mathrm{C}_{5} \mathrm{H}_{8}$ são ligadas umas às outras, numa cadeia imensamente longa. Tudo começava a se encaixar: por exemplo, o efeito de vulcanização era, meramente, a união de uma molécula longa com outra por pontes de átomos de enxofre, -S-S-S- (MCCRUM, 1987).

A hipótese de Staudinger (pela qual ele ganhou o prêmio Nobel em 1953) surtiu enorme efeito: permitiu uma interpretação racional do ensaio e deu aos químicos das indústrias a luz da verdade para guiar seus trabalhos (MCCRUM, 1987).

O primeiro plástico inteiramente sintético foi a baquelita, obtida pelo belga Leo Hendrik Baekland, em 1909. Desde então a família dos plásticos não parou de crescer: durante a Segunda Guerra Mundial surgiram o nylon, o polietileno e o acrílico. Antes, já haviam sido descobertos o poliestireno, o cloreto de polivinila, ou PVC, o acetato de polivinilo, ou PVA, o polipropileno e muitos outros (CRAWFORD, 1987).

As chapas de acrílico, recém-descobertas, foram largamente empregadas para fabricação de carlingas (aberturas no dorso da fuselagem) de aviões durante a Segunda Guerra (MARCZAK, 2004).

No começo, os plásticos eram considerados materiais baratos e descartáveis. Essa reputação foi superada e, atualmente, as suas propriedades específicas e versatilidade são apreciadas e o seu uso tem sido cada vez mais amplo, tornando-se um material essencial para os mais diversos setores da indústria.

A história do desenvolvimento dos materiais poliméricos, naturais ou sintéticos, é marcada pelo pioneirismo de homens que deixaram o nome na história. Sua utilização é mais antiga do que se imagina e algumas passagens são mostradas na tabela 2.1.

Tabela 2.1. Síntese histórica do desenvolvimento dos polímeros. Fonte: MARCZAK, 2004

\begin{tabular}{|l|l|}
\hline 1000 a.C & $\begin{array}{l}\text { Os chineses descobrem o verniz extraído de uma árvore (Rhus vernicflua), aplicado } \\
\text { na forma de revestimentos impermeáveis e duráveis. Ele seria usado em móveis } \\
\text { domésticos até a década de 1950. }\end{array}$ \\
\hline 1550 & $\begin{array}{l}\text { Numa viagem à América Central, Valdes faz a primeira menção à borracha natural, } \\
\text { usada pelos nativos. }\end{array}$ \\
\hline 1835 & Regnault relata a produção de cloreto de vinila, monômero do PVC. \\
\hline 1839 & $\begin{array}{l}\text { Goodyear (EUA) descobre a vulcanização, a adição de enxofre à borracha natural, } \\
\text { tornando-a mais forte e resiliente. Isso viabilizou o uso como material de engenharia. }\end{array}$ \\
\hline 1876 & $\begin{array}{l}\text { Sir Wickham contrabandeia sementes de seringueiras brasileiras para a Ásia, onde } \\
\text { constituiu-se a base da indústria mundial de borracha. }\end{array}$ \\
\hline
\end{tabular}




\begin{tabular}{|c|c|}
\hline 1909 & $\begin{array}{l}\text { Leo Baekland, nos EUA, patenteia a baquelita, a primeira resina termofixa sintética, } \\
\text { substituindo materiais tradicionais como a madeira e o marfim. }\end{array}$ \\
\hline 1922 & Hermann Staudinger, alemão, sintetiza a borracha. \\
\hline 1930 & A BASF alemã desenvolve o poliestireno (PS), mas a produção só ocorreu em 1937. \\
\hline 1933 & Descoberta do processo de polimerização do polietileno - PE sob alta pressão. \\
\hline 1934 & $\begin{array}{l}\text { Wallace Hume Carothers, da Du Pont (EUA), desenvolve o nylon, que foi patenteado } \\
\text { no ano seguinte. }\end{array}$ \\
\hline 1950 & Iniciada a produção comercial do poliestireno de alto impacto. \\
\hline 1973 & $\begin{array}{l}\text { A produção mundial de plástico supera a de aço, tomando como base o volume de } \\
\text { material fabricado. }\end{array}$ \\
\hline 2000 & $\begin{array}{l}\text { É dada uma ênfase na formulação de polímeros já existentes, com propriedades } \\
\text { otimizadas. A preocupação com a reciclagem torna-se assunto de máxima } \\
\text { importância, uma vez que seu desenvolvimento e uso serão inviáveis caso esse } \\
\text { problema não seja resolvido. Começa a reciclagem em larga escala de garrafas de } \\
\text { poliéster e de PEAD. }\end{array}$ \\
\hline
\end{tabular}

A inserção dos plásticos na indústria da construção foi apenas mais um passo. Seu uso, porém, é mais freqüente em elementos não estruturais: revestimento, iluminação, isolamento térmico e acústico, impermeabilização, adesivos e acessórios. Segundo Menezes (1989), a indústria da construção é a segunda maior consumidora de plásticos do mercado mundial. Em países subdesenvolvidos, seu uso é menos intenso devido ao custo da matéria-prima, mas nos países desenvolvidos, cerca de um quarto da produção é destinada à construção civil.

Algumas experiências foram feitas, utilizando o plástico como material de construção. Tanto no continente europeu como nos Estados Unidos, na década de 30, diversas casas modulares foram construídas com plástico, segundo Quarmby (1976) apud Menezes (1989).

$\mathrm{Na}$ Grã-Bretanha, devido à escassez de material de construção durante a Segunda Guerra, e por motivações comerciais, iniciou-se a construção de casas essencialmente a partir do plástico. No entanto, o sistema estrutural encontrou entraves por causa das limitações dos plásticos disponíveis na época.

Uma empresa escocesa, a Buildings Plastics Research Corporations de Glasgow, em 1941, desenvolveu o projeto de casas modulares de plástico, de montagem rápida, que exigiam precisão na montagem e no acabamento interno e externo.

Vários modelos de construções modulares com plástico foram propostos e construídos posteriormente, mas todos sem a implantação da produção em larga escala, fazendo com que, à época, o sistema construtivo entrasse em desuso. 


\subsection{ESTADO DA ARTE}

O uso dos materiais poliméricos tem se intensificado nas últimas décadas, principalmente devido ao avanço da ciência dos materiais, às melhorias agregadas ao processamento dos plásticos e ao desenvolvimento dos materiais compósitos.

Os plásticos reforçados ou compósitos poliméricos são materiais de engenharia constituídos por dois ou mais componentes. Um deles é, normalmente, uma fibra resistente, como a fibra de vidro, a aramida ou a fibra de carbono, que confere a parcela da resistência à tração. O outro componente - chamado de matriz - é geralmente uma resina que liga as fibras e promove a transferência de carga. São utilizados na fabricação de peças em setores que exigem uma resistência mecânica, dielétrica, corrosiva, abrasiva, dentre outras. (Plástico Reforçado e Compósitos, Nov/Dez 2004).

Desde 1988, nos Estados Unidos, estudos têm sido desenvolvidos com o intuito de entender o comportamento do plástico reciclado, para a substituição em diversas aplicações na construção civil que, anteriormente, eram exclusivas da madeira. $O$ progresso obtido reflete-se nas normas da ASTM, nos métodos de ensaios desenvolvidos e nos diversos produtos que surgiram: mourões, postes, dormentes de ferrovias e estruturas de portos, marinas e pontes (LAMPO e NOSKER, 2001).

Krishnaswamy et al. (1997), a pedido do Departamento de Recursos Naturais de Ohio, nos Estados Unidos, realizaram ensaios em paletes de plástico reciclado (PPR). No relatório que descreve desde a concepção da forma do palete, a sua comparação com outros materiais, a análise do comportamento mecânico e o estudo de viabilidade econômica, Krishnaswamy et al. obtém as seguintes conclusões:

- Os PPR's são uma opção viável e, dependendo da capacidade de carga requerida no projeto, podem ser dimensionados para casos particulares;

- A performance dos PPR's em laboratório e em campo alcançam e até excedem a de paletes de madeira e de aço galvanizado disponíveis no mercado. A integridade estrutural e as características de durabilidade dos paletes projetados são excelentes;

- Apesar do custo inicial ser maior que o dos outros materiais, a performance e a análise da vida útil viabilizam a implementação dos PPR's, tornando-os comercialmente aceitáveis.

As figuras $2.5 \mathrm{a}$ e $2.5 \mathrm{~b}$ ilustram os paletes de plástico reciclado utilizados nos ensaios de laboratório e em campo. 


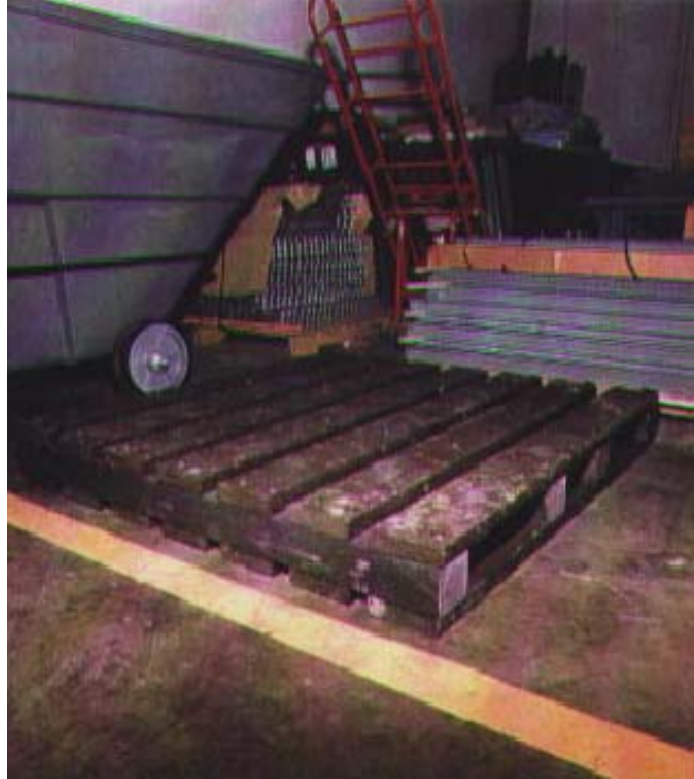

(a)

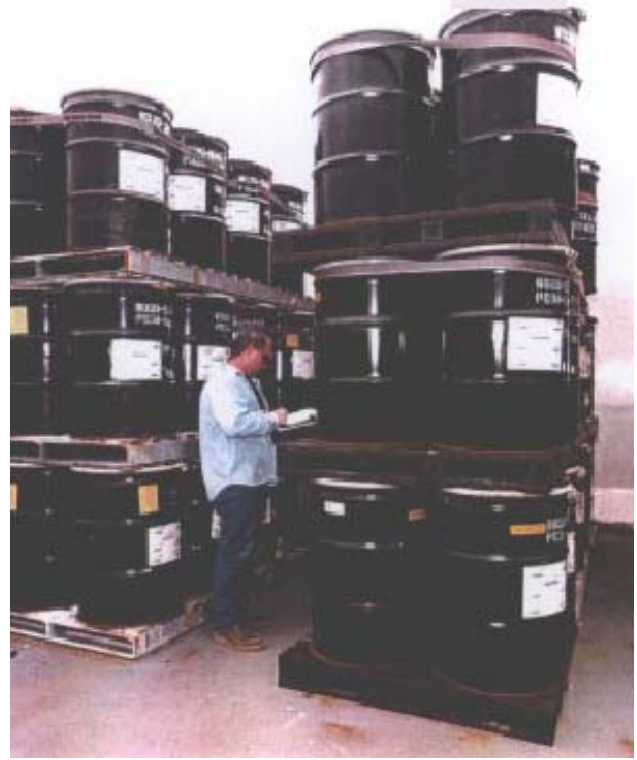

(b)

Figura 2.5. Paletes de plástico reciclado

Sullivan et al. (United States Patent, $\left.\mathrm{n}^{\circ} 5.886 .078,1999\right)$ desenvolveram um compósito polimérico a partir de material plástico reciclado, um componente polimérico emborrachado e um componente de preenchimento contendo mica. O material resultante é sugerido aos mais diversos usos na construção: dormentes de ferrovias, meio-fios de estacionamentos e estacas em marinas. Ainda, segundo os autores, um dos benefícios do uso do plástico é a combinação de baixo peso e resistência mecânica. As propriedades químicas, elétricas e físicas podem ser modificadas de acordo com o critério de utilização dos diversos materiais componentes.

Pesquisadores da AMIPP, Centro de Materiais Avançados via Processamento de Polímeros Imiscíveis, da Universidade Rutgers, de New Jersey/EUA, têm conseguido sucesso no desenvolvimento e na aplicação de plásticos reciclados em estruturas.

Nosker e Renfree são exemplos da inovação na AMIPP. Eles desenvolveram uma blenda, composta por $35 \%$ de poliestireno, PS, e $65 \%$ de polietileno de alta densidade, PEAD, obtendo um material mais resistente que o PEAD e mais rígido que o PS. A grande rigidez alcançada deve-se à densa estrutura molecular, resultado do preenchimento dos vazios e da interconexão entre o PS e o PEAD (GUTERMAN, 2003).

A descoberta da blenda, a partir de dois polímeros imiscíveis, ocorreu em 1988, havendo pouco reconhecimento da comunidade científica por, aproximadamente, uma década. Em 1996, Nosker e Renfree iniciaram um projeto de construção de pequenas pontes, com o material desenvolvido. Em 1999, construiu-se uma ponte mista, de plástico e aço, no Missouri (EUA) e dois anos depois, uma ponte em New York (EUA), de plástico e fibra de vidro. 
Nosker e Renfree (1999a) desenvolveram um dormente para ferrovias a partir de um compósito com plástico reciclado. De acordo com os autores, vários fatores limitam o uso dos dormentes tradicionais de madeira: a reduzida vida útil, devido à ação de microorganismos e da umidade; a maior rigidez das normas de controle e preservação, pois grandes áreas de florestas são necessárias para suprir o mercado de dormentes, além do uso de preservativos químicos na madeira.

O dimensionamento do dormente de compósito com plástico reciclado (DCPR) baseou-se nas propriedades do tradicional dormente de madeira. Apesar da comprovada performance demonstrada empiricamente através dos tempos, foi considerada a possibilidade de que as propriedades mecânicas da madeira não fossem otimizadas. Ensaios de flexão foram realizados com o DCPR e a resistência última e o módulo de elasticidade foram, respectivamente, $28 \mathrm{MPa}$ e $2069 \mathrm{MPa}$ (aproximadamente). Os DCPR's foram instalados em várias ferrovias e os resultados foram satisfatórios: não houve evidências de fraturas, laminação ou quaisquer outros sinais de degradação.

A empresa Polywood Plastic Lumber, de New Jersey/EUA, está utilizando a tecnologia desenvolvida pela AMIPP, na fabricação de dormentes e de outros elementos estruturais. A figura 2.6 mostra os dormentes produzidos pela empresa.

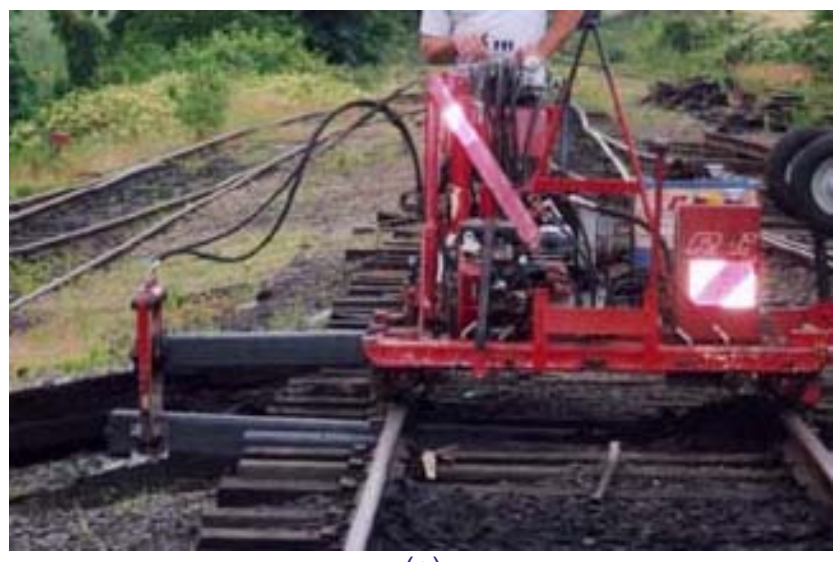

(a)

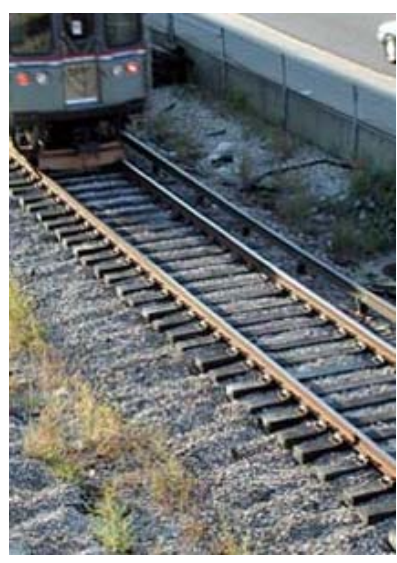

(b)

Figura 2.6. Dormentes de plástico reciclado produzidos pela Polywood Plastic Lumber

Além da Polywood Plastic Lumber, duas outras empresas estão investindo na fabricação de dormentes de material plástico reciclado: a TieTek e a U.S. Plastic Lumber (USPL), ambas nos Estados Unidos. A produção das três empresas difere, mas todas partem do polietileno de alta densidade (HDPE) reciclado, misturado e não lavado, utilizam um sistema de extrusão e realizam uma moldagem sob pressão em moldes fechados, com a finalidade de evitar vazios no interior dos dormentes. A maioria dos processos utiliza maquinário pesado e são bastante lentos. Após o preenchimento dos moldes, eles são levados para uma banheira de resfriamento e, 
posteriormente, são desmoldados hidraulicamente e deixados ao ar livre para o resfriamento total.

A partir do projeto e da fabricação de dormentes de compósito com plástico reciclado, Nosker e Renfree (1999b) continuaram a estudar as diversas aplicações do uso desse material como substituto da madeira. Compararam-se as propriedades mecânicas dos elementos estruturais de plástico com as de madeira e observou-se que o módulo de elasticidade do plástico ainda é bastante deficiente. Isso é evidenciado quando se comparam os módulos de elasticidade do pinho, cerca de 8.300MPa a 11.000MPa, com o mais alto valor obtido com o plástico, de 2.000MPa.

A solução encontrada foi a adição e a disposição de forma aproximadamente orientada de fibras de vidro, obtendo melhores resultados: o máximo aumento de resistência foi de $68 \%$, enquanto o módulo de elasticidade teve um aumento de até $176 \%$.

Albano e Sanchez (1999) estudaram as propriedades mecânicas e térmicas da blenda composta por polipropileno (PP) virgem e polietileno de alta densidade (PEAD), sendo este último reciclado ou não. Verificou-se que, para o módulo de elasticidade, há um pequeno sinergismo entre os materiais constituintes. Observou-se, com microscópio eletrônico, que a grande quantidade de moléculas interligadas na interface, resultado da adição do PEAD, somado ao processo de decomposição do PEAD (ruptura e conseqüentes reações de intertravamento), tornam a blenda mais rígida. Os autores mostraram a possibilidade do aproveitamento do resíduo plástico, desde que fosse verificada a influência nas propriedades térmicas e mecânicas da proporção dos plásticos constituintes.

Produtos poliolefínicos reciclados com desempenho superior aos materiais virgens correspondentes foram obtidos por Martins et al. (1999). Utilizando as palavras dos autores: "O balanço das reações de reticulação e cisão em cadeias poliolefínicas, quando expostas a condições ambientais de radicais livres, pode resultar em boas propriedades e novas aplicações". O comportamento mecânico da madeira plástica por eles desenvolvida, denominada IMAWOOD (constituída basicamente por polietileno), foi melhorado por efeito da radiação gama. Outro produto desenvolvido, o IMACAR (constituído de pára-choques descartados de carros), revelou alta resistência ao impacto, muito superior ao material virgem de composição correspondente.

Uma explicação para esse comportamento é que a exposição de polímeros às radiações ionizantes altera a sua estrutura molecular e as suas propriedades. Ocorre a formação de ligações cruzadas entre as cadeias, paralelamente à cisão entre átomos. A reticulação provoca um aumento do peso molecular, que geralmente ocasiona melhoria das propriedades, enquanto que a cisão de cadeias reduz o seu peso, tendo 
como resultado a deterioração das propriedades. Como o polietileno apresenta reticulação após a irradiação, pode-se esperar uma melhoria nas suas propriedades mecânicas (MARTINS et al., 1999).

Após a irradiação ao ar em intensidade crescente de exposição, o IMAWOOD apresentou um aumento na resistência à tração da ordem de $15 \%$ e uma diminuição no alongamento na ruptura de aproximadamente $80 \%$. Houve também um aumento crescente no módulo de elasticidade no ensaio de compressão, o que indica maior rigidez do plástico reciclado com o prolongamento do tempo de exposição (MARTINS et al., 1999).

Carroll et al. (2001) estudaram as propriedades estruturais dos elementos de plástico reciclado com adição de farinha de madeira. Os autores concluíram que o material é estruturalmente satisfatório, mas não se deve simplesmente substituir o elemento de madeira pelo de plástico, com as mesmas dimensões. Eles enfatizam que as estruturas de compósitos plásticos devem ser projetadas como tal, e não utilizando parâmetros e conhecimentos teóricos e empíricos de outros materiais.

Krishnaswamy et al. (2001a) desenvolveram um compósito polimérico, projetaram e construíram uma ponte sobre o rio Hudson, em New York/EUA. O comprimento total e largura da ponte são, respectivamente, $9 \mathrm{~m}$ e $3,35 \mathrm{~m}$. O projeto consumiu um total de $5.000 \mathrm{~kg}$ de plástico (polietileno de alta densidade) reforçado com fibra de vidro e $2.500 \mathrm{~kg}$ de aço para as conexões e tirantes utilizados (KRISHNASWAMY et al., 2001b). As figuras 2.7 e 2.8 mostram a ponte já construída.

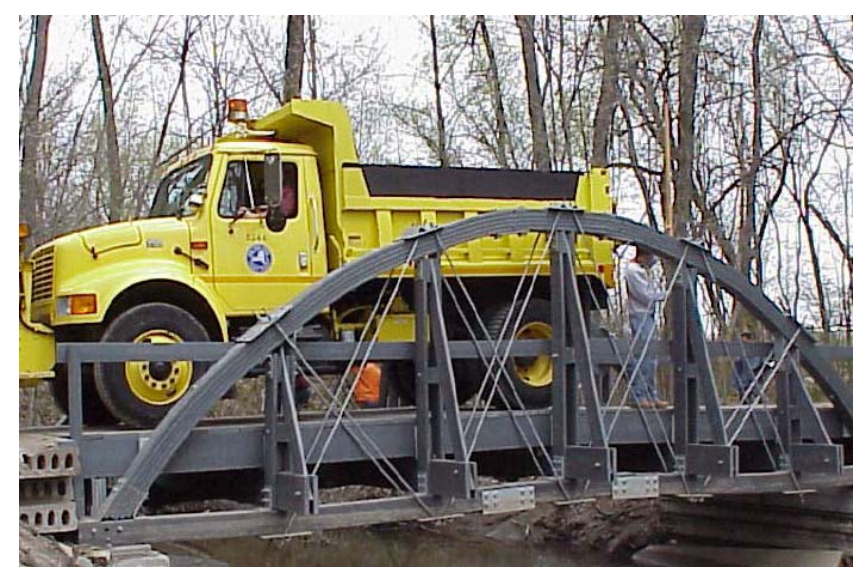

Figura 2.7. Ponte sobre o rio Hudson construída com plástico reforçado com fibra de vidro

O monitoramento da ponte sob a ação das cargas de projeto é feito continuamente, por meio de dez pontos de observação. Utilizando uma referência fixa, são medidos os deslocamentos, por meio de uma estação total, com GPS (Sistema de Posicionamento Global) (KRISHNASWAMY et al., 2001b). 
Por meio de teste de carga padronizado pela AASHTO (American Association of State Highway and Transportation Officials), em abril de 2001, a uma temperatura de $13^{\circ} \mathrm{C}$, o maior deslocamento, medido na parte inferior da ponte, foi de $32,5 \mathrm{~mm}$, denunciando a baixa rigidez do material utilizado, cerca de $20 \%$ a $30 \%$ da rigidez da madeira (KRISHNASWAMY et al., 2001b).

De acordo com Krishnaswamy et al. (2001b), o uso de elementos estruturais de plástico reciclado reforçado com fibras, utilizado na ponte, oferece uma alternativa economicamente viável para a construção de pontes com pequenos vãos. As vantagens apontadas pelos autores são: não é um material biodegradável e não sofre corrosão de qualquer espécie. Materiais ensaiados após 10 anos de utilização mostraram um aumento na rigidez e na resistência. Além de ser um material ambientalmente responsável, quando se considera o custo em função da sua vida útil, o sistema construtivo se torna competitivo.

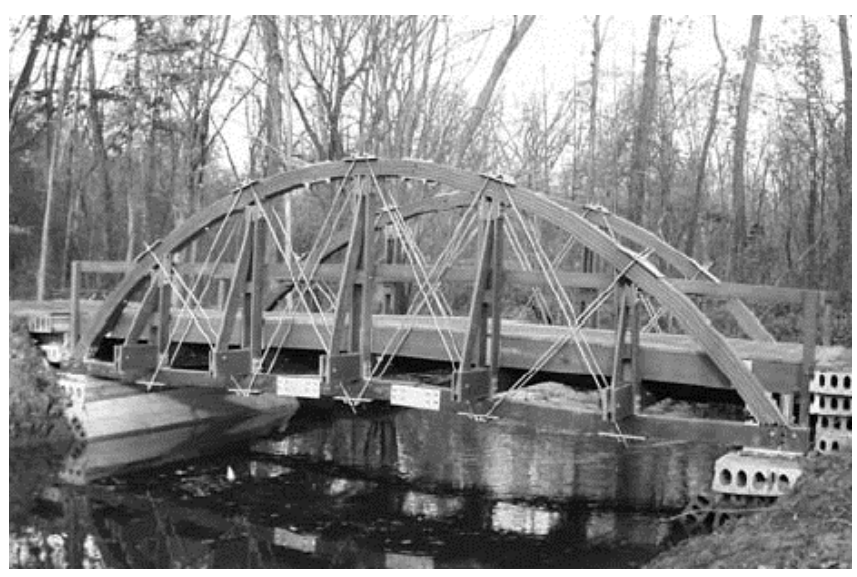

Figura 2.8. Outra vista da ponte sobre o rio Hudson (New York/EUA)

Em 2002, os pesquisadores da AMIPP, Nosker et al., construíram uma ponte inteiramente de plástico - guarda-corpos, vigas de sustentação e plataforma - com exceção dos pilares de madeira, que foram aproveitados da estrutura anterior. Com $14 \mathrm{~m}$ de comprimento e pesando, aproximadamente, 14t, estima-se que a ponte, construída inteiramente de material reciclado, tenha consumido 250.000 garrafas plásticas (PEAD) e 750.000 copos de café (PS) (DOWNS, 2002; JACOBSON, 2003; SAWYER, 2003; GUTERMAN, 2003; GALIOTO, 2004). As figuras 2.9 (a, b) e 2.10 ilustram a ponte e sua construção.

As vigas "l" utilizadas na ponte que transpõe o rio Mullica, em New Jersey, possuem uma seção transversal de $41 \mathrm{~cm}$ x $43 \mathrm{~cm}$ (16" x 17"). A ponte foi projetada para suportar o peso de caminhão de até 18t. Além do apelo ecológico, com a reciclagem dos resíduos plásticos, o material constituinte da ponte é resistente à ação da água, corrosão e ataque por microorganismos. 


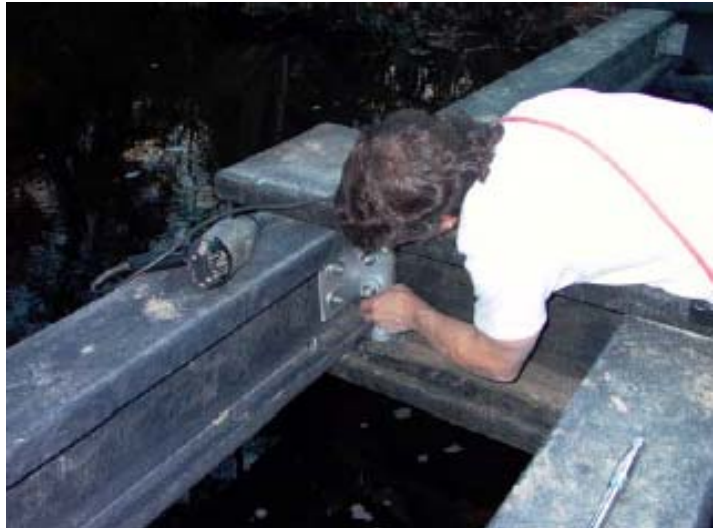

(a)

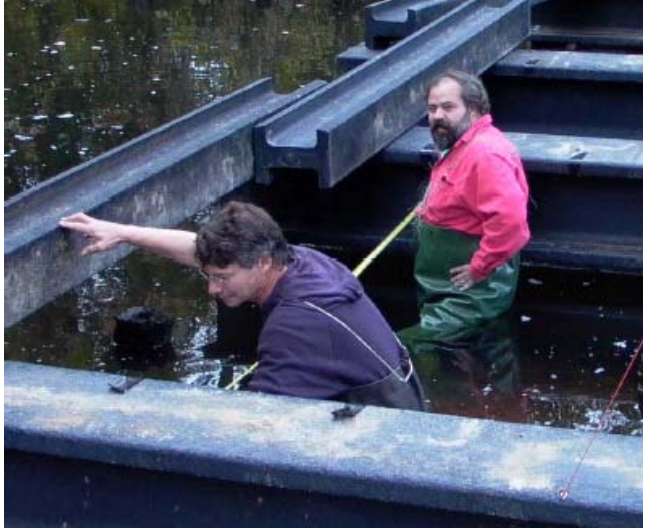

(b)

Figura 2.9. Detalhes das vigas I utilizadas na construção da ponte sobre o rio Mullica

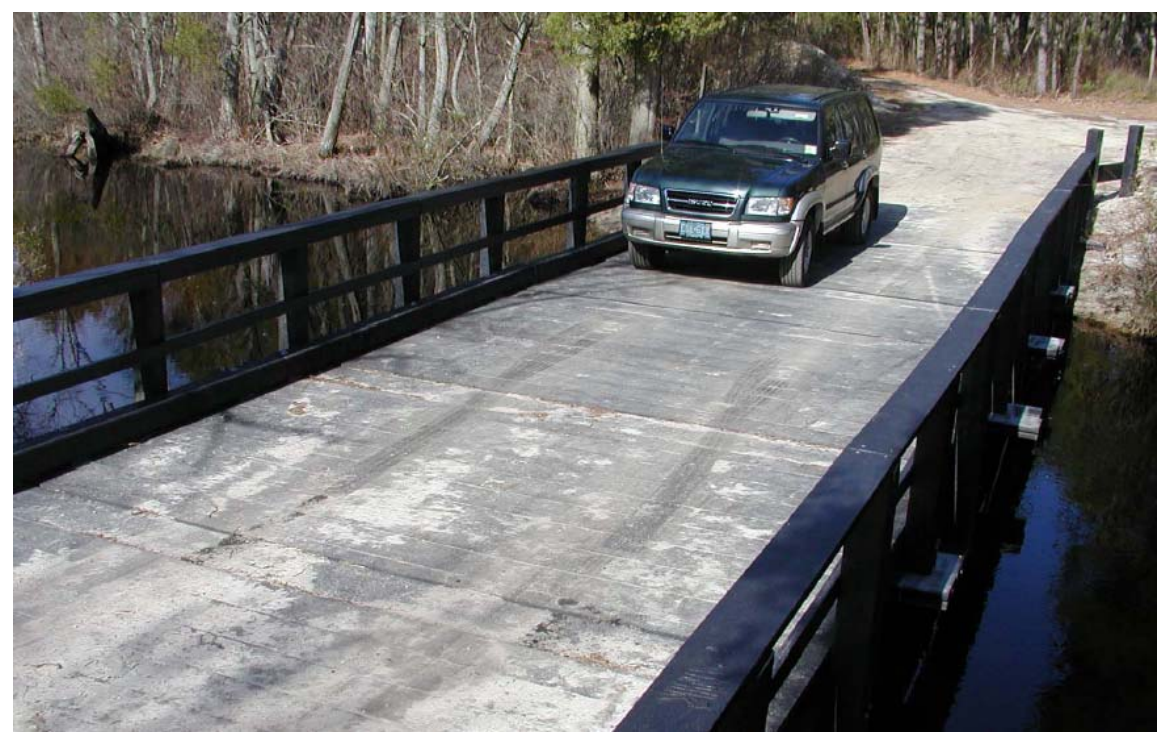

Figura 2.10. Ponte sobre o rio Mullica construída inteiramente de plástico

A pesquisa aplicada ao desenvolvimento de novos materiais pelo grupo de pesquisadores da AMIPP e o sucesso por eles alcançado é retratado pelas patentes registradas de novos materiais e novas metodologias de reciclagem de plásticos.

A primeira delas, a patente $n^{0} 5.298 .214$ de 29/03/1994 (United States Patent), trata do processamento de plásticos. Mais especificamente, a patente discorre sobre o método de obtenção de compósitos de poliestireno (PS) e outras poliolefinas a partir de plásticos reciclados. Apesar da crença comum de que a composição de plásticos imiscíveis não produz bons resultados, os pesquisadores da AMIPP descobriram que a adição de poliestireno, um plástico com um alto módulo de elasticidade quando comparado com outros plásticos, a outras poliolefinas produzia bons resultados.

Em seguida, as patentes $\mathrm{n}^{0} 5.789 .477$ de 04/08/1998 e $\mathrm{n}^{0} 5.916 .932$ de 29/06/1999 (United States Patent) registram um material compósito destinado à construção civil obtido a partir de materiais reciclados. O compósito é obtido do polietileno de alta densidade (HDPE) reciclado e fibras, como exemplo, a fibra de vidro. A união resultou num material cujas propriedades tinham seu máximo de 
eficiência quando a proporção de fibras em peso era de $35 \%$. Com essa composição, - material possuía uma resistência à compressão de $26 \mathrm{MPa}$ e um módulo de elasticidade à compressão de 2952MPa.

A patente no 5.951 .940 de 14/09/1999 (United States Patent) fornece subsídios para o processamento adequado dos plásticos reciclados. De acordo com os inventores, todo o esforço tem sido direcionado no sentido de tornar o processo de reciclagem do plástico pós-consumo economicamente viável, sem que haja a necessidade de uma triagem, ou seja, tornar exeqüível a reciclagem de plásticos misturados, poliolefinas ou não, juntamente com as impurezas. Tradicionalmente, o produto resultante dessa reciclagem era um plástico de baixa qualidade. Mas, com a metodologia descrita, levando em consideração a lavagem do material pós-consumo, os compatibilizadores intrínsecos aos plásticos descartados e a adição de outros, esse tipo de reciclagem torna-se viável.

A partir dos materiais desenvolvidos na AMIPP, diversos produtos e aplicações foram propostas e, inclusive, produzidas comercialmente, a partir de licenças obtidas por outras empresas, desde produtos que necessitam de um baixo desempenho (mourões, cercas, deques, bancos) até elementos estruturais de alta solicitação como pilares de marinas, embarcadouros e paletes.

A construção com elementos de plástico reciclado é uma realidade, principalmente nos Estados Unidos e, em menor escala, no Canadá e na Inglaterra. A tecnologia desenvolvida nas universidades já ultrapassou a escala experimental de laboratório e chegou aos pátios das fábricas, com a produção em grande escala. As figuras 2.11 e 2.12 apresentam uma amostra do que está sendo feito no mundo, comercialmente, e indicam um cenário que não deve ser ignorado, o dos elementos estruturais de material plástico reciclado.

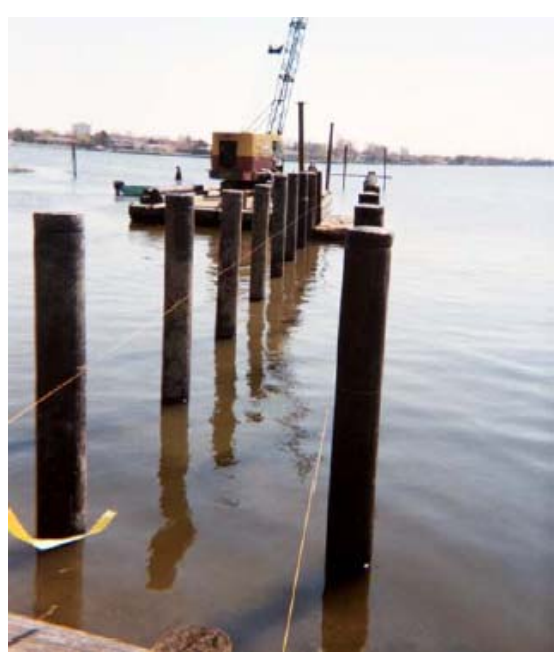

(a)

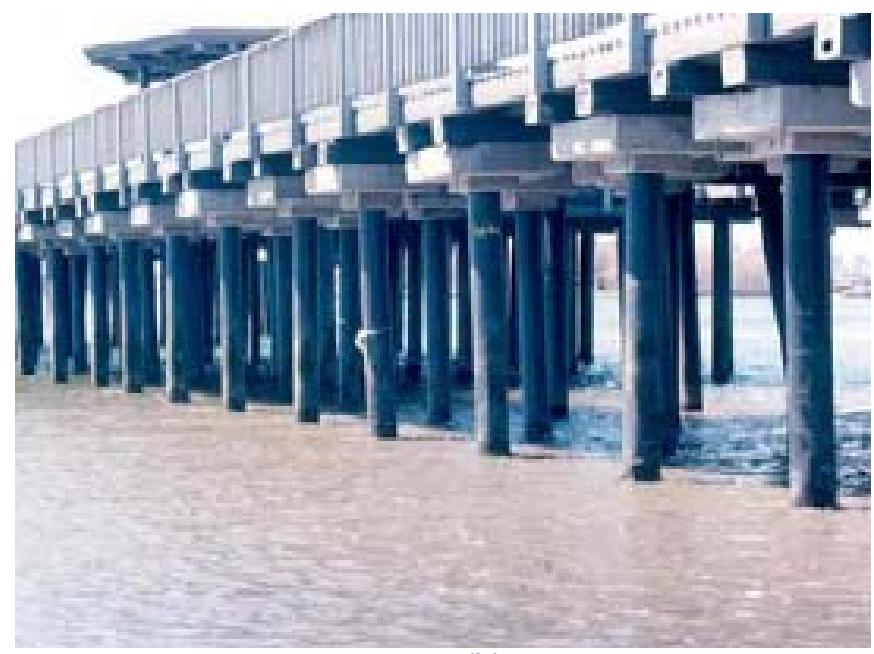

(b)

Figura 2.11. Marina construída com pilares de plástico reciclado desenvolvido na AMIPP 


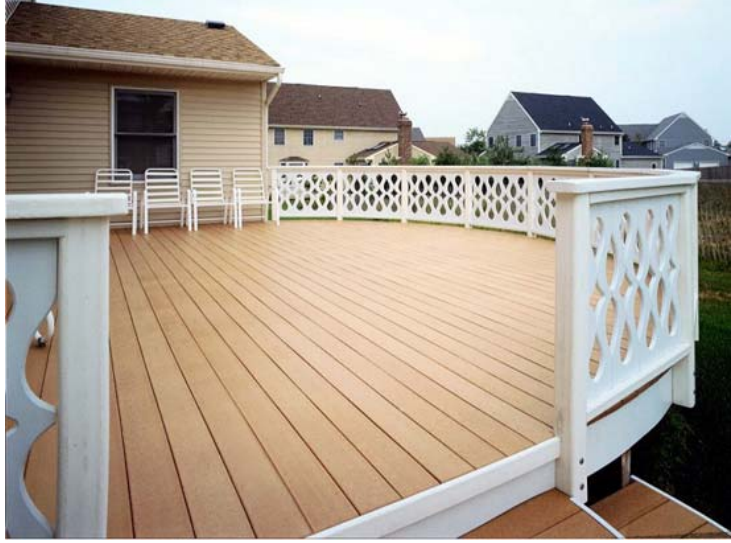

(a)

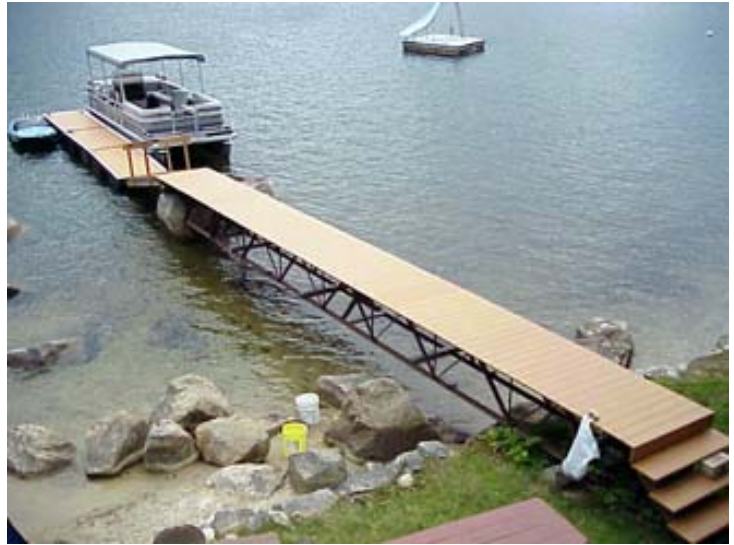

(b)

Figura 2.12. Construção de píeres ou deques com elementos de plástico reciclado da empresa Plastic Lumber Yard (EUA)

Há outros compósitos plásticos que acenam como uma alternativa aos materiais de construção, constituídos por plásticos e pó ou farinha de madeira, que são utilizados pelo setor automobilístico desde a década de 70 . A adição da farinha de madeira agrega ao compósito um ganho significativo de rigidez, em relação aos materiais termoplásticos não modificados. Obtém-se, portanto, um elemento estrutural suficientemente rígido, uma maior resistência à tração e à flexão, com uma maior temperatura de uso e baixo peso específico (CORREA et al., 2003).

Dentre os tipos de processamento, o que mais se adequa à produção de perfis com fins estruturais é a pultrusão. Correia et al. (2005a) fizeram ensaios experimentais de perfis pultrusados e verificaram as mudanças ocorridas nas propriedades físicas, químicas, mecânicas e estéticas, quando submetidos à exposição acelerada de umidade, temperatura e radiação ultravioleta. O material estudado que compunha os perfis é o poliéster reforçado com fibra de vidro (GFRP). A partir dos resultados dos ensaios, concluiu-se que a resistência e a deformação na ruptura diminuíram com a umidade e este efeito foi acelerado pelo aumento da temperatura.

Correia et al. (2005a) salientaram que a degradação ocorreu devido a um fenômeno físico, como a plastificação da matriz polimérica, não havendo uma degradação química passível de ser considerada. Apesar da redução das propriedades mecânicas observada nos ensaios de durabilidade, a pesquisa confirmou que os perfis pultrusados de GFRP apresentaram um excelente desempenho estrutural, oferecendo uma durabilidade superior quando comparados com os materiais tradicionais.

Como o projeto e o dimensionamento dos perfis de GRFP são governados pelos fenômenos da deformabilidade e da instabilidade, Correia et al. (2005b) estudaram o comportamento de vigas híbridas, compostas por perfis pultrusados (tipo I) e uma 
mesa de concreto. Os resultados obtidos demonstram a viabilidade das vigas de concreto-GFRP, podendo ser utilizadas em reparos ou reforços e até mesmo em novas construções, apresentado uma rigidez razoável, uma alta resistência à flexão e um baixo peso próprio. A resistência e os deslocamentos nas vigas foram previstos com um razoável grau de precisão, pelos métodos propostos. Foi verificada a importância da consideração, durante o projeto, da deformação cisalhante e do escorregamento na interface dos materiais. 


\section{Os Plásticos e suas Aplicações}

O avanço contínuo da ciência dos materiais, impulsionando e sendo impulsionado pela demanda do mercado por novos materiais para atender a necessidades específicas, levou ao aumento exponencial das famílias dos plásticos e de seus derivados. A sintetização desses materiais tem direta influência nesse crescimento. É uma tarefa quase impossível catalogar todos os plásticos existentes, haja vista que constantemente novos materiais são criados. Um aspecto que mostra a sua abragência nas mais diversas áreas é que, em 1973, sua produção superou a do aço, em volume (MARCZAK, 2004).

Por muito tempo as características dos materiais utilizados na construção foram aferidas por suas propriedades macroscópicas. O aspecto visual da rocha, o número de nós ou defeitos numa peça de madeira, a granulometria da areia e a finura de um aglomerante eram parâmetros (e ainda continuam sendo) que os engenheiros dispunham para balizar seus projetos. No entanto, com a investigação em nível molecular, no caso específico dos plásticos, a descoberta de sua estrutura (um conjunto de monômeros - os polímeros) tornou possível o entendimento de suas propriedades, tão distintas das relativas a outros materiais.

Segundo Marczak (2004), apesar da produção industrial de plásticos ter iniciado em 1909, com o desenvolvimento da baquelita pelo belga L. H. Baekeland, a indústria de materiais plásticos só avançou seriamente a partir de 1930 , com os processos químicos para produção do nylon, uretanos e fluorcarbonos (Teflon). Nessa mesma época iniciou-se a produção da celulose, do acetato e dos compostos moldáveis à base de estireno. Simultaneamente, aparecem também as primeiras máquinas voltadas à produção industrial de peças plásticas baseadas em injeção, sopro e vácuo.

As possibilidades de combinação dos elementos químicos para o desenvolvimento de novos plásticos são virtualmente infinitas. É justamente esse o desafio em se trabalhar com esse tipo de material - a seleção do plástico mais adequado para uma dada aplicação. Nesse variado grupo, que consiste, basicamente, de carbono, oxigênio, hidrogênio, nitrogênio e outros elementos orgânicos e inorgânicos, existem mais de 50 famílias distintas e comercialmente disponíveis, com cada família abragendo dezenas ou centenas de variações (MARCZAK, 2004). 


\subsection{ESTRUTURA QUÍMICA DOS PLÁSTICOS}

A palavra polímero é a combinação de uma palavra de origem grega, "mero", que significa parte e "poli" que significa muitos, vários. A parte de um plástico é uma combinação única dos átomos para formar uma molécula denominada monômero. Os plásticos são formados a partir da união de vários monômeros em longas cadeias que resultam num material com um conjunto de propriedades, os polímeros.

Os monômeros são unidos numa cadeia polimérica por grandes forças de atração entre as moléculas, ao contrário das forças que unem as cadeias moleculares, que são mais fracas. Os polímeros podem ser construídos das mais diversas maneiras, como pode ser exemplificado a seguir.

\subsubsection{Monômeros}

Exemplos de monômeros são o estireno, o cloreto de vinila e o propileno. A figura 3.1 mostra, de maneira ilustrativa, três tipos de monômeros quaisquer: $A, B$ e $C$ (podem ser o estireno, o etileno, o cloreto de vinila ou o propileno, por exemplo). Será usada essa nomenclatura para se exemplificar os tipos de polímeros a seguir.

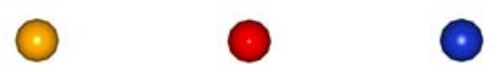

Figura 3.1. Monômeros A, B e C

\subsubsection{Homopolímeros}

Os homopolímeros, como a própria origem do nome diz, são os polímeros construídos a partir da união de polímeros iguais. Como exemplos, têm-se o polietileno (PE), o poliestireno (PS), o polipropileno (PP) e o cloreto de polivinila (PVC). A figura 3.2 ilustra, de maneira esquemática, o cloreto de polivinila.

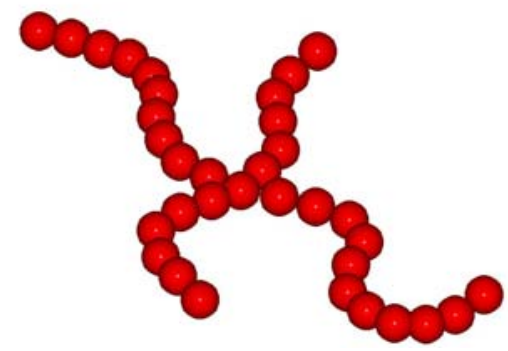

Figura 3.2. Cloreto de Polivinila (PVC)

Uma forma de representar os homopolímeros é utilizando a nomenclatura anteriormente adotada, por exemplo: A-A-A-A-A-A-A-A-A-A-A-A-A. 


\subsubsection{Copolímeros}

Os copolímeros, por sua vez, são assim chamados por serem constituídos de dois diferentes monômeros. Um exemplo é o etileno-acrílico.

Um tipo alternativo de representação dos copolímeros, com a nomenclatura adotada, é: A-A-A-B-B-A-A-A-B-B-A-A-A-B-B. A figura 3.3 ilustra este exemplo.

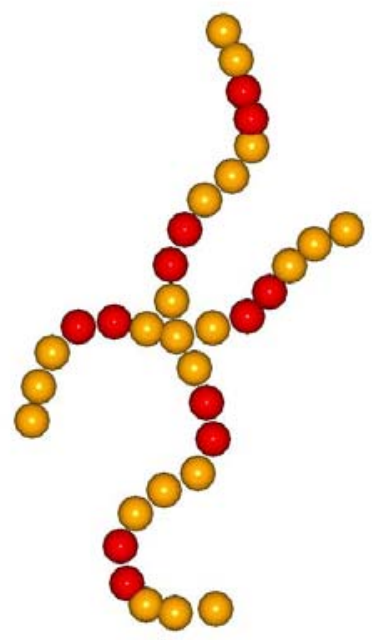

Figura 3.3. Exemplo esquemático de um copolímero

\subsubsection{Terpolímeros}

Os terpolímeros são aqueles que possuem três tipos de monômeros. De uma maneira representativa: A-A-A-B-C-C-A-A-A-B-C-C-A-A-A. A figura 3.4 ilustra este tipo de terpolímero.

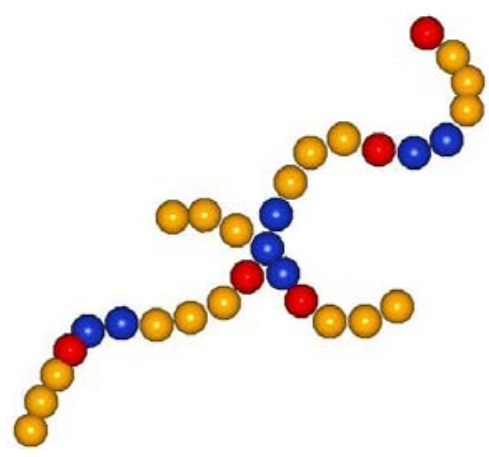

Figura 3.4. Exemplo esquemático de um terpolímero

Dois monômeros formando um copolímero são combinados durante uma reação de polimerização, que é a síntese de um polímero ou o conjunto das reações que provocam a união de pequenas moléculas, por ligação covalente, para a formação das muitas cadeias macromoleculares que compõem um material polimérico (AGNELLI, 200?). Os materiais chamados ligas são produzidos a partir de uma mistura simples de dois ou mais polímeros, resultando numa blenda, com propriedades geralmente 
melhores do que as do material individual. Neste caso, não existe reação química. Exemplos de ligas são o óxido de polifenileno + estireno de alto impacto, o policarbonato + ABS (sigla padronizada pela IUPAC - International Union of Pure and Applied Chemistry - para representar o plástico principalmente baseado em terpolímeros de acrilonitrila-butadieno-estireno) e o ABS + PVC.

\subsection{MECANISMOS MOLECULARES}

Quando sujeito às tensões aplicadas, os polímeros podem se deformar por dois mecanismos atomísticos fundamentais. O comprimento e a angulação das ligações químicas conectando os átomos se distorcem, movendo os átomos para novas posições de maior energia interna. Isto é um movimento bastante sutil e ocorre muito rapidamente, requerendo somente cerca de $10^{-12}$ segundos.

Se o polímero tiver suficiente mobilidade molecular, rearranjos em larga escala dos átomos podem também ser possíveis. Por exemplo, a rotação relativa em torno das ligações simples da estrutura carbono-carbono pode produzir mudanças consideráveis na conformação da molécula. Dependendo da mobilidade, uma molécula polimérica pode se estender na direção das tensões aplicadas, que faz diminuir sua entropia conformacional (a molécula é menos desordenada). Os elastômeros respondem quase em sua totalidade por meio desse mecanismo de entropia, com pequenas distorções em suas ligações covalentes ou mudança na sua energia interna (ROYLANCE, 2001).

A primeira e a segunda lei da termodinâmica combinadas estabelecem como um incremento de trabalho mecânico $\mathrm{fdx}$ no sistema pode produzir um aumento da energia interna $\mathrm{dU}$ ou uma redução na entropia $\mathrm{dS}$ :

$$
\mathrm{fdx}=\mathrm{dU}-\mathrm{TdS}
$$

Claramente, a importância relativa da contribuição entrópica aumenta com a temperatura $\mathrm{T}$, e isto fornece um meio conveniente de determinar experimentalmente se a rigidez do material está relacionada com a energia interna ou com a entropia. A força necessária para tracionar uma borracha com uma deformação constante aumentará com o aumento da temperatura, assim como a agitação térmica tornará a estrutura interna mais robusta, em sua tentativa natural de restaurar a aleatoriedade. Mas essa força trativa num corpo-de-prova de aço - que demonstra pouca elasticidade entrópica - diminuirá com o aumento da temperatura, como resultado de uma expansão térmica que agirá para aliviar as tensões internas (ROYLANCE, 2001).

Em contraste a essa natureza instantânea da elasticidade energeticamente controlada, as mudanças conformacionais ou entrópicas são processos cujas 
velocidades são sensíveis à mobilidade molecular local. Essa mobilidade é influenciada por uma variedade de fatores físicos e químicos, como a arquitetura molecular, a temperatura ou a presença de fluidos absorvidos que podem dilatar 0 polímero. Geralmente, uma simples figura mental de um volume livre aproximadamente, o espaço disponível para segmentos moleculares agirem cooperativamente para realizar o movimento ou reação em questão - é utilizável na intuição dessas velocidades.

Essas taxas de mudança conformacional podem geralmente ser descritas com razoável acurácia por expressões do tipo Arrhenius, na seguinte forma:

$$
\operatorname{taxa} \propto \exp (-\mathrm{E} / \mathrm{RT})
$$

em que E é uma energia de ativação aparente no processo e $\mathrm{R}$ é a constante dos gases. Quando a temperaturas muito acima da temperatura de transição vítrea, representada pelo símbolo $\mathrm{T}_{\mathrm{g}}$ (o índice $g$ origina-se do inglês glass, que significa vidro) na figura 3.5, as taxas são tão rápidas como são essencialmente instantâneas, e o polímero age de uma maneira emborrachada, exibindo deformações grandes, instantâneas e completamente reversíveis em resposta às tensões aplicadas.

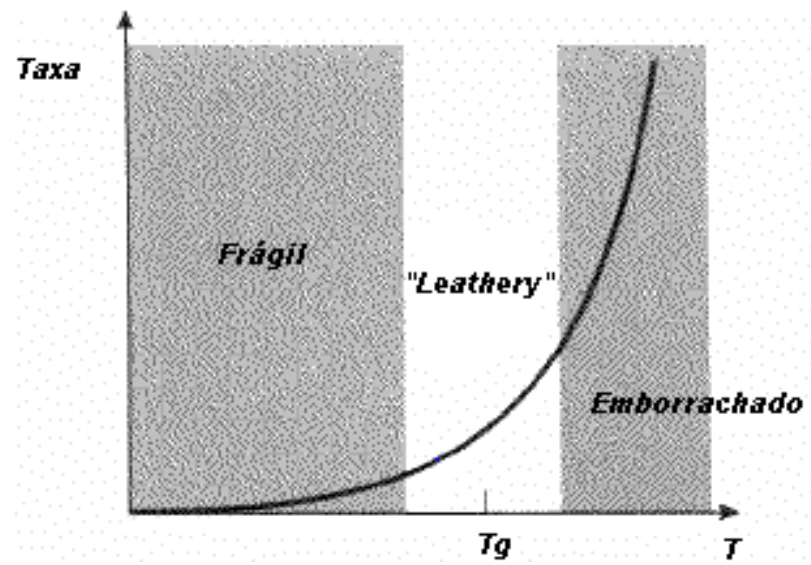

Figura 3.5. Influência da temperatura na taxa de deformação. Fonte: ROYLANCE, 2001

Para temperaturas muito menores que $T_{g}$, as taxas são tão baixas que são negligenciadas. Neste caso, o processo de "destravamento" das cadeias moleculares está essencialmente congelado. Então, os polímeros são capazes de responder somente por meio da deformação das ligações. O polímero responde de maneira vítrea, agindo instantaneamente e reversivelmente, mas sendo incapaz de ser deformado além de um percentual sem antes fraturar de maneira frágil.

Em um valor próximo de $T_{g}$, o material age de maneira dual, entre os regimes vítreo e emborrachado. Esta resposta é uma combinação da fluidez viscosa e a solidez elástica, e esta região é denominada "leathery" ou, mais tecnicamente, 
viscoelástica. $\mathrm{O}$ valor de $\mathrm{T}_{\mathrm{g}}$ é um importante parâmetro para descrever a resposta termomecânica do plástico. Fatores que ressaltam a mobilidade, como diluentes absorvidos, estados de tensão expansivos e um vazio nas cadeias moleculares, tendem a produzir valores menores de $\mathrm{T}_{\mathrm{g}}$. O filme transparente de polivinil utilizado em pára-brisas automotivos é um exemplo de um material que é utilizado no regime viscoelástico. A resposta viscoelástica é um recurso de dissipação substancial de energia durante o impacto.

Com temperaturas bem abaixo de $\mathrm{T}_{\mathrm{g}}$, quando os movimentos entrópicos estão congelados e somente as deformações elásticas das ligações são possíveis, os polímeros exibem um módulo de elasticidade relativamente alto, denominado "módulo vítreo" $\xi_{\mathrm{g}}$, da ordem de $3 \mathrm{GPa}$. Como a temperatura aumentada além de $\mathrm{T}_{\mathrm{g}}$, a rigidez cai dramaticamente, por duas ordens de magnitude talvez, para um valor chamado de "módulo emborrachado" $\xi_{\mathrm{r}}$ (o índice $r$ origina-se do inglês rubber, que significa borracha). Em elastômeros, que foram permanentemente interconectados por vulcanização e outros meios, o valo de $\xi_{\mathrm{r}}$ é determinado, primordialmente, pela densidade de interconexões; a teoria cinética da elasticidade das borrachas fornece a expressão abaixo.

$$
\sigma=\operatorname{NRT}\left(\varepsilon-\frac{1}{\varepsilon^{2}}\right)
$$

em que $\sigma$ é a tensão, $N$ é a densidade de interconexões $\left(\mathrm{mol} / \mathrm{m}^{3}\right)$, e $\varepsilon=\Delta \mathrm{L} / \mathrm{L}_{0}$ é a deformação específica. A diferenciação da expressão acima fornece a curva da tensão-deformação, com $\varepsilon_{\mathrm{r}}=3 \mathrm{NRT}$.

Se o material não está interconectado, a rigidez exibe um curto platô devido à habilidade de emaranhamento molecular que age como junções de encadeamento. Sob altas temperaturas o emaranhamento deixa de atuar, havendo um escorregamento, e o material torna-se um líquido viscoso. Os módulos vítreo e emborrachado não dependem fortemente do tempo, mas na região de transição próxima de $\mathrm{T}_{\mathrm{g}}$, os efeitos do tempo podem ser importantes. Um diagrama do módulo versus a temperatura, como mostrado na figura 3.6, é uma ferramenta crucial para a ciência dos materiais poliméricos e engenharia. Ele fornece um panorama de uma propriedade vital para a engenharia, e é também uma impressão digital da dinâmica molecular disponível para o material. 


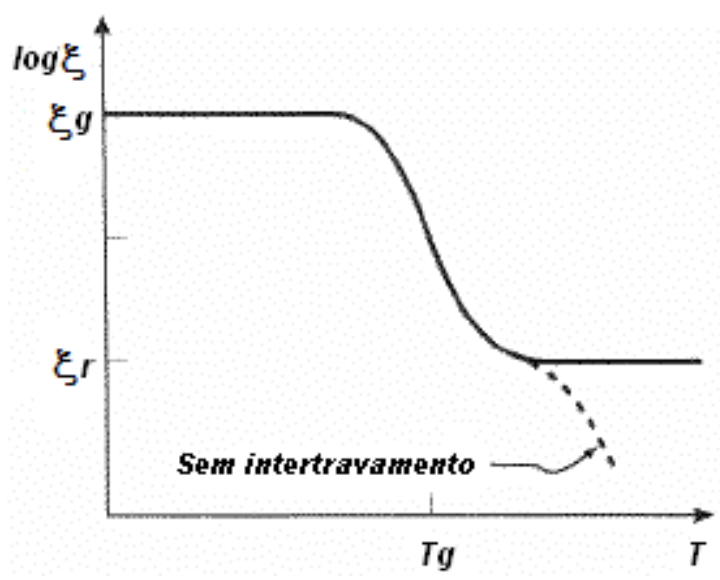

Figura 3.6. Módulo de Elasticidade $\xi$ x Temperatura para polímeros. Fonte: ROYLANCE, 2001

\subsection{CLASSIFICAÇÃO DOS POLÎMEROS}

Os polímeros são utilizados na engenharia sob a forma de materiais puros ou em combinação com uma vasta diversidade de aditivos, orgânicos e inorgânicos. Esses aditivos podem ser os plastificantes que reduzem a rigidez ou a fragilidade do material, as adições que aumentam a resistência ou melhoram o comportamento do plástico na deformação, ou os estabilizantes que protegem os polímeros contra a ação dos raios ultravioletas (IDOL e LEHMAN, 2004).

No universo dos plásticos, existem dois grandes grupos que se podem considerar: os termoplásticos e os termofixos, cuja divisão baseia-se na distinção do seu comportamento térmico durante o processamento. Os polímeros termoplásticos amolecem quando aquecidos, podendo ser remoldados. Esse processo pode ser repetido inúmeras vezes, com um mínimo de degradação da estrutura do polímero. Já os polímeros termofixos não podem ser remoldados pelo aquecimento. Eles são moldáveis em algum estágio do processamento, mas ao final torna-se um sólido rígido e não podem ser aquecidos novamente. Os termofixos, por sua vez, são mais resistentes e rígidos que os termoplásticos (IDOL e LEHMAN, 2004).

\subsubsection{Polímeros Termoplásticos}

Apresentam-se, a seguir, os principais polímeros termoplásticos.

\section{a) Acetais e Poliacetais}

Estes termoplásticos combinam uma alta resistência à ruptura, boa resistência à temperatura e à abrasão, uma excepcional estabilidade dimensional e um baixo coeficiente de expansão térmica. Eles competem com o nylon (mas possui melhores propriedades) e com metais fundidos (porém, mais leves). Possuem uma boa resistência química, com exceção aos ácidos fortes. As suas aplicações típicas são em peças de bombas d'água, tubulações, máquinas de lavar e rodas de engrenagem. 


\section{b) Acrílicos}

São conhecidos por sua transparência e são utilizados sob a forma de chapas, barras e tubos. Distinguem-se por sua dureza e fragilidade e são relativamente resistentes ao intemperismo. São aplicados em lentes óticas, prismas, coberturas transparentes, refletores etc. São encontrados num variado espectro de cores opacas e transparentes.

\section{c) Celulósicos}

O nitrato celulósico é inflamável, tem uma baixa performance contra o calor e a exposição ao sol e possui uma aplicação limitada. O acetato celulósico, por sua vez, tem uma boa resistência a ruptura, rigidez e ductilidade. Existem diversos outros tipos de celulósicos e o seu processamento é feito por moldagem por injeção e a vácuo. São aplicados numa vasta gama de moldes, como isolantes e em brinquedos.

d) Acetato vinil-etileno (EVA)

É um material bastante flexível e que pode ser processado sob diversas temperaturas. O material pode ser enrijecido com adições, compete com o PVC, o polietileno e as borrachas sintéticas. Possui diversas aplicações em embalagens, produtos de uso doméstico e instrumentos médicos.

e) Polietileno Tereftalato (PET)

O PET é um polímero formado a partir da reação entre o ácido tereftálico e o etileno glicol, formando um poliéster que possui alta resistência à ruptura, rigidez, boa resistência química e à abrasão, resistência ao impacto na forma orientada, baixo coeficiente de fricção e fácil reciclabilidade. O seu uso em garrafas de bebidas carbonatadas deve-se ao fato do PET possuir boas propriedades de "barreira", havendo uma mínima absorção de oxigênio. A figura 3.7 mostra uma representação da estrutura química do PET.

As aplicações para o PET são as mais diversas, mas se pode destacar as seguintes: como garrafas para bebidas carbonatadas, óleos vegetais e produtos de limpeza; na forma de fibras para uso na indústria têxtil, apresentando excelente resistência mecânica e ao amassamento; como películas transparentes e altamente resistentes para uso em isolamentos de capacitores, películas cinematográficas, filmes e placas para radiografia (MARCZAK, 2004).

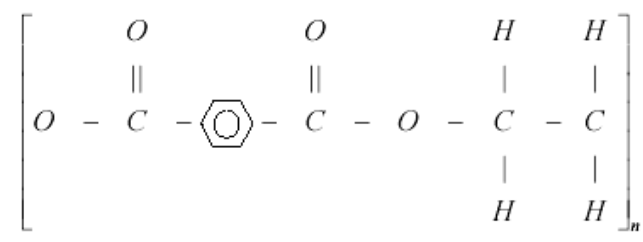

Figura 3.7. Estrutura química do PET. Fonte: MARCZAK, 2004 


\section{f) Poliamidas (náilons)}

As poliamidas são uma família de termoplásticos, por exemplo: nylon 6, nylon 66 e nylon 610. São os plásticos mais dúcteis na engenharia e, dessa forma, possuem uma alta capacidade de absorção de vibrações, resistência à abrasão e uma capacidade de carga para rolamentos de alta rotação. Possuem um baixo coeficiente de atrito e uma boa flexibilidade. Como aplicações, além de rolamentos, são utilizadas em isolantes elétricos, engrenagens, parafusos de fixação e outros fixadores.

\section{g) Polietileno}

Suas principais características são: baixo custo; boa resistência química; baixo coeficiente de atrito; fácil processamento; baixa permeabilidade à água; atóxico e inodoro (MARCZAK, 2004). A figura 3.8 mostra a estrutura química do polietileno.

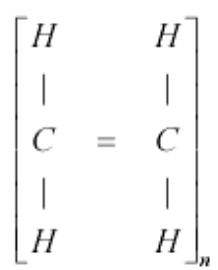

Figura 3.8. Estrutura química do Polietileno. Fonte: MARCZAK, 2004

O polietileno de baixa densidade (PEBD) é utilizado em filmes, camadas protetoras de superfície, tubos, produtos de uso doméstico e isolantes elétricos. O polietileno de alta densidade (PEAD) é utilizado em peças de grande tamanho e é encontrado na forma de chapas, tubos etc. O polietileno é limitado como material de engenharia por causa de sua baixa capacidade de suporte de carga e sua baixa rigidez. No entanto, essa deficiência pode ser atenuada com a adição de fibras de reforço.

\section{h) Poliestireno}

Este material não é muito utilizado como um material de engenharia devido a sua fragilidade, mas é bastante utilizado em brinquedos, isolantes elétricos, partes de refrigeradores e embalagens. É encontrado na forma de uma resina transparente e também em cores opacas. Pode ser obtida uma forma altamente resistente ao impacto quando em composição com o butadieno ou outras resinas emborrachadas. $\mathrm{O}$ poliestireno pode ser estabilizado contra a radiação ultravioleta e pode ser feito numa forma expandida, servindo como isolante térmico. Suas principais características são: fácil processamento; fácil coloração; baixo custo; elevada resistência a ácidos e álcalis; baixa densidade e absorção de umidade; baixa resistência a solventes orgânicos, calor e intempéries (MARCZAK, 2004). 
A figura 3.9 mostra a estrutura química do poliestireno.

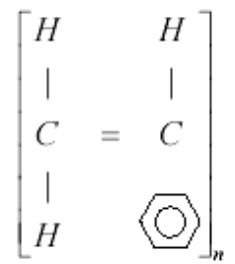

Figura 3.9. Estrutura química do Poliestireno. Fonte: MARCZAK, 2004

\section{i) Cloreto de Polivinila (PVC)}

Este é um dos plásticos mais utilizados. Com a mistura com estabilizantes, lubrificantes, adições, pigmentos e plastificantes, um amplo espectro de propriedades é possível. Vai do flexível ao enrijecido PVC, transparente, opaco e nas formas coloridas. Ele é resiliente, com boa resistência ao ataque de substâncias químicas, boas características a baixas temperaturas e propriedades retardantes de chama. $\mathrm{O}$ PVC, no entanto, não mantém sua boa performance mecânica em temperaturas acima de $80^{\circ} \mathrm{C}$. A figura 3.10 ilustra a sua composição química.

$$
\left[\begin{array}{ccc}
H & & H \\
\mid & \mid \\
C & = & C \\
\mid & \mid \\
H & C l
\end{array}\right]_{n}
$$

Figura 3.10. Estrutura química do PVC. Fonte: MARCZAK, 2004

\section{j) Policarbonato}

O policarbonato é um termoplástico extremamente resiliente, com excelente resistência à ruptura, estabilidade dimensional e propriedades elétricas. É encontrado na forma de lentes transparentes e opacas, em diversas cores. O policarbonato, porém, não possui uma boa resistência aos ataques de substâncias químicas, aspecto evidenciado pelas trincas e fissuras causadas por diversos solventes. Pode ser estabilizado contra a radiação ultravioleta com o uso de aditivos. Podendo ser processado por meio da moldagem por injeção e extrusão, o policarbonato é um importante plástico de engenharia. A sua estrutura química é mostrada na figura 3.11.

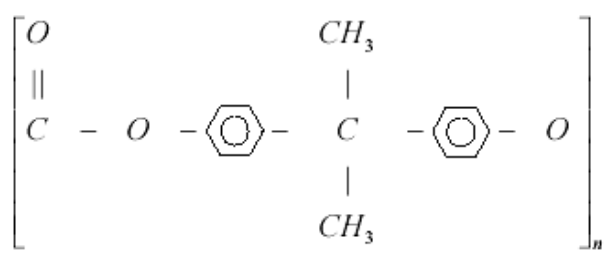

Figura 3.11. Estrutura química do Policarbonato. Fonte: MARCZAK, 2004 


\section{k) Polipropileno}

O polipropileno é um termoplástico de baixa densidade, dúctil, rígido, resistência à fluência e com boa resistência química. Possui ainda uma boa resistência ao intemperismo, baixa absorção de água e possui, relativamente, um baixo custo. É utilizado em embalagens de alimentos e de produtos químicos, utensílios domésticos, móveis, peças automotivas, brinquedos etc. A figura 3.12 mostra a sua estrutura química.

$$
\left[\begin{array}{ccc}
H & & H \\
\mid & & \mid \\
C & = & C \\
\mid & & \mid \\
H & & \mathrm{CH}_{3}
\end{array}\right]_{n}
$$

Figura 3.12. Estrutura química do Polipropileno. Fonte: MARCZAK, 2004

\subsubsection{Polímeros Termofixos}

Os principais polímeros termofixos são indicados a seguir.

\section{a) Aminoplásticos}

São resinas baseadas na reação do formaldeído com a uréia ou a melanina e são aplicados como camadas de proteção superficial, adesivos para laminados e em pó. São usualmente misturados com celulose, pó de madeira e outras adições. A sua resistência à ruptura é alta o suficiente para ser utilizado em componentes submetidos a tensão, apesar de o material ser frágil. Possui boas propriedades elétricas e térmicas.

\section{b) Epóxis}

As resinas epóxicas são extensivamente utilizadas como plásticos de engenharia. Eles podem ser processados a frio sem pressão ou a quente. Adições inertes, plastificantes e expansores proporcionam uma vasta gama de propriedades, desde materiais muito flexíveis a sólidos rígidos. Unindo-se a praticamente todos os materiais, por exemplo, madeira, metais e vidros, possuem excelentes propriedades mecânicas, elétricas e químicas.

Os epóxis são utilizados em todas as áreas da engenharia, incluindo grandes peças, circuitos e outras partes elétricas, estruturas com fibra de carbono e de vidro, pisos, camadas de proteção superficial e adesivos. Um aspecto importante é que, durante a cura do material, ele praticamente não apresenta retração, sendo uma de suas principais vantagens. 


\section{c) Fenólicos (Fenol formaldeído)}

Mais conhecido pelo seu nome original, baquelita, o fenol formaldeído é usualmente preenchido com 50 a $70 \%$ de pó de madeira, para uso em peças não tensionadas ou levemente submetidas à tensão. Outras adições, como mica e fibra de vidro, são utilizadas para peças elétricas e estruturais, respectivamente.

Os fenólicos representam um dos melhores polímeros para aplicações que exigem uma fluência reduzida. O material possui boa resistência à ruptura, bom aspecto visual e boa temperatura de serviço, apesar de ser um pouco frágil.

e) Poliéster

As resinas de poliéster podem ser curadas a temperatura ambiente, com o uso de aditivos especiais, ou sozinhas, a uma temperatura de 70 a $150^{\circ} \mathrm{C}$. É material comumente utilizado em combinação com fibra de vidro.

\section{f) Silicones}

Os silicones também podem ser curados a frio ou a quente, e são utilizados em laminados e peças elétricas submetidas a altas temperaturas.

\subsubsection{Estruturas Poliméricas Laminadas}

Uma vasta gama de estruturas é preparada a partir de resinas poliméricas combinadas com fibras. Essas estruturas consistem de camadas de material fibroso impregnado, usualmente, com uma resina termofixa para a confecção de chapas, barras, tubos etc.

\subsubsection{Elastômeros}

Os elastômeros, ou borrachas, são essencialmente polímeros amorfos com cadeias moleculares lineares com algum tipo de interconexão, que garante elasticidade e retorno do material à sua forma original, quando o carregamento é removido. São caracterizados por largas deformações (tipicamente 100\%) quando submetido a tensões. A borracha sintética estireno butadieno é o elastômero mais utilizado, com a borracha natural em segundo lugar.

A tabela 3.1. mostra, após essa exposição dos termoplásticos e termofixos, algumas das principais propriedades físicas desses dois grupos. Pode-se observar a superioridade dos termofixos quando se trata da resistência à tração e do módulo de elasticidade. Por outro lado, a processabilidade dos termoplásticos é, em geral, melhor que a dos termofixos. O alongamento, que dá uma medida da deformação suportada pelo material antes de sua ruptura, mostra que os termoplásticos são muito mais tenazes, como é o caso do polipropileno, cujo alongamento varia de 200 a $700 \%$ de seu comprimento inicial. 
Tabela 3.1. Propriedades físicas dos polímeros. Fonte: IDOL e LEHMAN, 2004

\begin{tabular}{|c|c|c|c|c|c|}
\hline & $\rho$ & Resist. à Tração & Deformação $^{1}$ & Módulo Easticidade & Trabalhabilidade \\
\hline Propriedades dos plásticos & $(\mathrm{kg} \mathrm{m}-3)$ & $(\mathrm{MPa})$ & $(\%)$ & $(\mathrm{GPa})$ & (Processamento) \\
\hline \multicolumn{6}{|l|}{ Termoplásticos } \\
\hline PVC rígido & 1330 & 48 & 200 & 3,4 & excelente \\
\hline Poliestireno & 1300 & 48 & 3 & 3,4 & regular \\
\hline Polipropileno & 1200 & 27 & $200-700$ & 1,3 & excelente \\
\hline Nylon & 1160 & 60 & 90 & 2,4 & excelente \\
\hline Nitrato celulósico & 1350 & 48 & 40 & 1,4 & excelente \\
\hline Acetato celulósico & 1300 & 40 & $10-60$ & 1,4 & excelente \\
\hline Acrílico & 1190 & 74 & 6 & 3,0 & excelente \\
\hline Polietileno (alta densidade) & 1450 & $20-30$ & $20-100$ & 0,7 & excelente \\
\hline \multicolumn{6}{|l|}{ Termofixos } \\
\hline Resinas epoxícas & $1600-2000$ & $68-200$ & 4 & 20,0 & bom \\
\hline Melamina formaldeído & $1800-2000$ & $60-90$ & - & 7,0 & regular \\
\hline Uréia formaldeído & 1500 & $38-90$ & 1 & $7,0-10,0$ & bom \\
\hline Fenol formaldeído & $1600-1900$ & $38-50$ & 0,5 & $17,0-35,0$ & bom \\
\hline
\end{tabular}

1 - Deformação do plástico, antes da ruptura

\subsection{CARACTERÍSTICAS GERAIS DOS PLÁSTICOS}

Apresentam-se, a seguir, as principais características dos plásticos.

\subsubsection{Peso Molecular}

O peso molecular é uma medida que se relaciona com o comprimento das cadeias poliméricas. Essa propriedade é fundamental porque a processabilidade dos termoplásticos é diretamente influenciada pelo tamanho das cadeias do polímero.

De acordo com Marczak (2004), os polímeros possuem uma unidade de repetição ou um grupo molecular. O número dessas unidades em uma cadeia de polímero é chamado de grau de polimerização. Por exemplo, sendo 60 o peso molecular da unidade de repetição (a soma do peso de todas as moléculas do grupo) e havendo 1000 unidades de repetição, então o polímero tem um peso molecular de 60000 .

Os plásticos têm o seu peso molecular, normalmente, entre $10^{4}$ e $10^{6}$. Quanto maior o peso molecular do polímero, mais difícil é a sua moldagem com aplicação de pressão e calor. O limite prático para permitir uma processabilidade razoável é dado pelo peso molecular de 200000.

\subsubsection{Polîmeros Cristalinos e Amorfos}

Os polímeros podem ser classificados em cristalinos ou amorfos, apesar de atualmente ser mais correto descrever os plásticos pelo seu "grau de cristalização". Os polímeros não podem ser materiais $100 \%$ cristalinos, do contrário não seria possível derretê-lo haja vista a sua estrutura altamente organizada. Dessa maneira, a maioria dos polímeros é considerada semicristalina e com um percentual máximo de $80 \%$ de cristalização. 
Os polímeros que possuem arranjos cristalinos regulares e um padrão de repetição são caracterizados como materiais cristalinos. Uma característica distinta é que esses polímeros possuem um ponto de fusão bem definido, o que permite um controle preciso da matéria prima durante o processo de fabricação, fator preponderante para a indústria. Uma desvantagem é que os polímeros cristalinos se contraem significativamente durante o resfriamento. A teoria que mais se adequa ao comportamento desses tipos de polímeros é a viscoelasticidade linear.

Os polímeros amorfos são aqueles que não possuem esse arranjo cristalino e a sua moldagem não flui tão facilmente quanto a dos materiais cristalinos. A maioria das borrachas convencionais é considerada amorfa. A viscoelasticidade não-linear é uma teoria que rege de forma aproximada o comportamento desses polímeros (MARCZAK, 2004).

Os termoplásticos são amorfos ou semicristalinos. Os polímeros semicristalinos não possuem uma temperatura de transição vítrea bem definida, no entanto, como sua estrutura é composta por regiões cristalinas e amorfas, parte da estrutura sofrerá essa transição. A tabela 3.2 mostra alguns termoplásticos e a sua classificação.

Tabela 3. 2. Termoplásticos amorfos e cristalinos. Fonte: http://www.azom.com

\begin{tabular}{|c|c|}
\hline Am orfo & Sem icris talino \\
\hline Poliamida (amorfo) & Poliamida (6,6 e 11) \\
\hline Cloreto de Polivinila - PVC & Tereftalato de Polietileno - PET \\
\hline Polimetilmetacrilato & Polioximetileno \\
\hline Poliestireno & Polipropileno \\
\hline Poliamideimida & Polietileno de Alta Densidade \\
\hline Poliarilato & Polietileno de Baixa Densidade \\
\hline
\end{tabular}

\subsubsection{Propriedades Térmicas}

A sensibilidade dos plásticos à variação de temperatura representa, ao mesmo tempo, uma grande vantagem e uma grande desvantagem para esses materiais. $O$ seu baixo ponto de fusão representa um gasto reduzido de energia para o seu processamento, refletindo nos custos de produção.

No entanto, os plásticos tendem a mudar consideravelmente suas dimensões em comparação aos outros materiais, como os metais. O coeficiente de expansão térmica dos plásticos é cerca de uma ordem de grandeza maior que o dos metais, e isso representa uma grande problemática que deve ser considerada em projeto.

a) Coeficiente de Expansão Térmica $(\alpha)$

A tabela 3.3 compara o coeficiente de expansão térmica $\alpha$ de alguns plásticos com o de outros materiais. Quando se compara o polietileno com o aço, por exemplo, o primeiro possui um $\alpha$ cerca de 17 vezes maior que o último. Uma forma de atenuar essa influência da variação de temperatura é a adição de fibras, naturais ou sintéticas. 
Tabela 3.3. Valores típicos de coeficiente de expansão térmica. Fonte: MARCZAK, 2004

\begin{tabular}{|l|c|}
\hline \multicolumn{1}{c|}{ Material } & $\alpha$ \\
\cline { 2 - 2 } & $\left(\mathrm{m} / \mathrm{m}^{\circ} \mathrm{C}\right)$ \\
\hline Polietileno & $7,8 \times 10^{-5}$ \\
\hline Acrilico & $3,3 \times 10^{-5}$ \\
\hline Acetal copolímero & $2,6 \times 10^{-5}$ \\
\hline Policarbonato & $2,1 \times 10^{-5}$ \\
\hline Alumínio & $7,2 \times 10^{-6}$ \\
\hline Policarbonato ref. c/ fibra de vidro (30\%) & $5,0 \times 10^{-6}$ \\
\hline Aço & $4,4 \times 10^{-6}$ \\
\hline Vidro & $2,2 \times 10^{-6}$ \\
\hline
\end{tabular}

\section{b) Temperatura de Distorção ao Calor}

Marczak (2004) apresenta este parâmetro, obtido a partir de um ensaio de flexão de três pontos (cargas padronizadas de 456 e 1820N) e medindo o seu deslocamento central. A temperatura é aumentada até que o deslocamento ultrapasse um determinado valor. Essa é a temperatura de distorção ao calor (HDT, do inglês Heat Distortion Temperature), e quando a resistência e o módulo de elasticidade têm seus valores drasticamente reduzidos. A tabela 3.4 mostra o HDT para alguns polímeros.

Tabela 3.4. HDT de alguns plásticos (carga de 1820N). Fonte: MARCZAK, 2004

\begin{tabular}{|l|c|}
\hline \multicolumn{1}{|c|}{ Material } & HDT \\
\hline Silicones & $\left({ }^{\circ} \mathrm{C}\right)$ \\
\hline Nylon ref. c/ fibra de vidro (30\%) & 455 \\
\hline Resina epóxi ref. c/ fibra de vidro & 260 \\
\hline Acetal ref. c/ fibra de vidro & 205 \\
\hline Policarbonato & 165 \\
\hline Nylon de uso geral & 145 \\
\hline Acrilico & 105 \\
\hline Polipropileno & 83 \\
\hline & 60 \\
\hline
\end{tabular}

\section{c) Condutividade Térmica}

Os polímeros, de uma maneira geral, são maus condutores térmicos. Para efeito de comparação, os metais são de 300 a 2500 vezes melhor condutores que os polímeros. Por esse motivo, diversos sistemas de isolamento térmico utilizam o material polimérico, principalmente na forma de espumas.

\subsubsection{Propriedades Elétricas}

Assim como são bons isolantes térmicos, os plásticos também são excelentes isolantes elétricos, daí seu uso extensivo em produtos elétricos. Para que haja fluxo de corrente elétrica, deve haver troca de elétrons. Como os plásticos, de uma maneira geral, têm uma baixíssima densidade de elétrons livres, eles são bons isolantes, tanto térmicos como elétricos (MARCZAK, 2004). 


\subsubsection{Propriedades óticas}

Muitos plásticos possuem transparência e são utilizados em aplicações óticas, em substituição ao vidro. O acrílico, o estireno, o PVC, o policarbonato, o ABS, as resinas epóxicas, dentre outros, são plásticos que podem ser transparentes e são utilizados para esse fim.

\subsection{ALTERAÇÃO DAS PROPRIEDADES DOS PLÂSTICOS}

Os inúmeros produtos que podem ser misturados aos plásticos - aditivos, corantes, cargas e reforços - servem como um "ajuste fino" das propriedades dos polímeros, adequando-os para determinado fim (MARCZAK, 2004). Alguns procedimentos, clássicos, podem ser salientados:

- A adição de cargas inorgânicas inertes reduz o custo de uma peça plástica sem afetar suas propriedades.

- $\quad$ O uso de reforço com fibras ou a adição de cargas minerais podem aumentar a resistência mecânica do compósito resultante.

- Para atenuar o efeito da radiação ultravioleta e aumentar a resistência mecânica, o negro de fumo pode ser utilizado, por exemplo, no caso dos pneus e dos filmes para a agricultura.

- Os plásticos podem se tornar mais ou menos flexíveis e tenazes, desde que sejam utilizados aditivos conhecidos como plastificantes.

- A fabricação de espumas é feita através da adição de agentes expansores, que se transformam em gás no momento da transformação do polímero, quando ele se encontra no estado fundido.

\subsubsection{Aditivos}

Os aditivos são escolhidos tomando-se o cuidado de se manter a compatibilidade do material puro e a sua forma de processamento. Uma observação a ser feita é que, normalmente, quando se tenta melhorar uma determinada propriedade, outras são prejudicadas, mesmo que seja em níveis aceitáveis. Os aditivos mais utilizados são: antioxidantes, agentes anti-eletricidade estática, retardantes de chama, modificadores de resistência ao impacto, agentes expansores, redutores de atrito, fungicidas e estabilizantes UV (MARCZAK, 2004).

\subsubsection{Reforços}

Os reforços mais utilizados são as fibras de carbono e de vidro, mica e aramidas. A finalidade, normalmente, é o aumento da resistência e da rigidez do material. A adição de reforços também permite a utilização dos plásticos sob condições de carga 
e temperatura mais altas, com uma maior estabilidade dimensional. A esses plásticos, em especial, dá-se o nome de compósitos, materiais largamente utilizados nas indústrias automotiva e aeroespacial.

\subsubsection{Corantes}

Apesar da aplicação de corantes não objetivar mudanças diretas nas propriedades mecânicas, a sua escolha deve ser feita levando em consideração a sua compatibilidade com o material base, o tipo de processamento e a aplicação desejada para o produto final. 


\section{Fundamentos Teóricos}

Um projeto de engenharia estrutural exige o conhecimento das propriedades mecânicas, para definir o comportamento e adequar, com mais precisão, técnicas e métodos de análise e previsão do desempenho do material sob as ações de projeto.

Os plásticos se comportam de maneira diferente da madeira, do aço e do concreto. Quando se objetiva viabilizar o plástico como material estrutural, é importante tratar minuciosa e claramente os fundamentos teóricos que tratam das suas propriedades mecânicas e os seus modelos preditivos.

De acordo com Haddad (1995), muitos materiais de engenharia, como os polímeros e os metais, a elevadas temperaturas, fluem quando sujeitos às tensões ou às deformações. Tal fluidez é acompanhada por uma dissipação de energia devida a alguns mecanismos internos de perdas (por exemplo, ruptura das ligações e formação de ligações de reação, deslocamentos e formação de subestruturas nos metais). Materiais desse tipo possuem uma resposta dita viscoelástica. Esse comportamento viscoelástico deve-se ao fato de tais materiais exibirem propriedades viscosas e elásticas.

A figura 4.1 ilustra a diferença do diagrama da deformação ao longo do tempo para espécimes elástico, viscoso e viscoelástico, quando sujeitos a uma tensão constante ao longo do tempo. As tensões são aplicadas no tempo $t=0$ para corposde-prova sem perturbação e mantidas constantes para um tempo de duração $\mathrm{t}_{1}$ (fig. 4.1a). Como mostrado na figura $4.1 \mathrm{~b}$, a resposta da deformação ao longo do tempo de um corpo-de-prova elástico tem a mesma forma da tensão aplicada. Na aplicação da carga, a deformação alcança, instantaneamente, certo valor $\varepsilon_{0}$ e permanece constante.

Para um fluido viscoso (fig. 4.1c), o material flui a uma taxa constante e a resposta da deformação é proporcional ao tempo. Já para o corpo-de-prova viscoelástico (fig. 4.1d), existe um aumento relativamente rápido nas deformações, para pequenos valores de $\mathrm{t}$, imediatamente após a aplicação da carga. Com o aumento de $\mathrm{t}$, a inclinação da tangente à curva diminui $\mathrm{e}$, para $\mathrm{t} \rightarrow \infty$, aproxima-se de zero ou de um valor finito, mantida uma tensão constante. 
Com a remoção da carga no tempo $t_{1}$, as deformações nos corpos-de-prova recuperar-se-ão da maneira mostrada na figura 4.1. O sólido perfeitamente elástico recuperar-se-á instantaneamente após a remoção da carga (fig. 4.1b). Entretanto, com a remoção da carga, o corpo-de-prova viscoelástico recuperará rapidamente a sua deformação elástica; no entanto, a parte retardada da resposta, necessitará de mais tempo para se recuperar (fig. 4.1d).

(a)

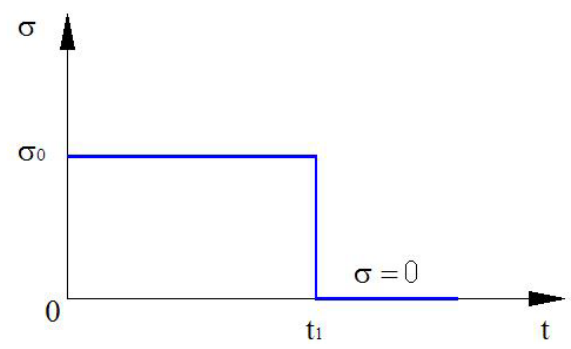

(b)

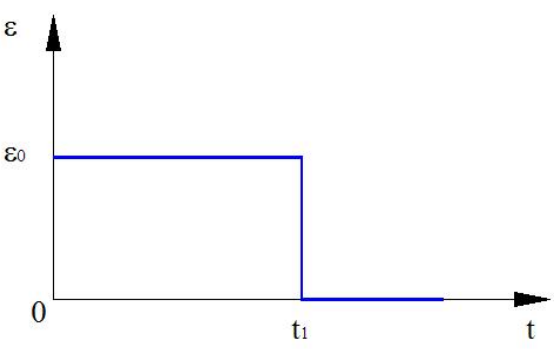

Material Elástico

(c)

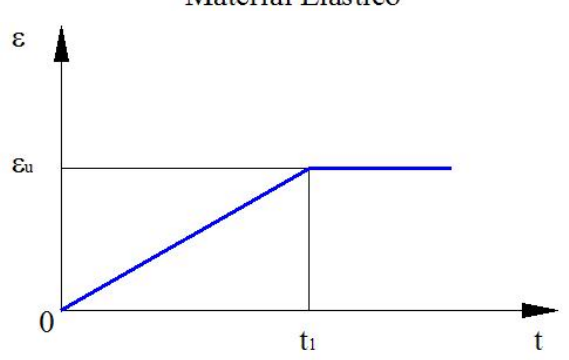

Fluido Viscoso

(d)

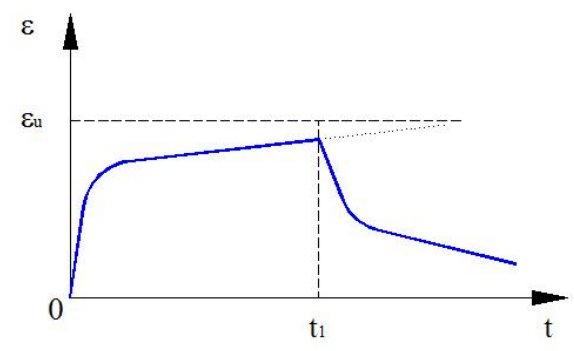

Material Viscoelástico

Figura 4.1. Comparação da deformação para os materiais elástico, viscoso e viscoelástico submetidos a uma tensão constante durante o tempo $\mathrm{t}_{1}$. Fonte: HADDAD, 1995

Num estado de tensão constante, a deformação por fluência de um material viscoelástico pode ser dividido, com referência à figura 4.2, em três componentes (LETHERSICH, 1950 apud HADDAD, 1995): 
(a) Deformação elástica instantânea $\varepsilon_{\mathrm{e}}\left(0^{+}\right)$. Num material polimérico, por exemplo, essa parcela é atribuída às deformações das ligações moleculares, incluindo a deformação das ligações fracas de Van de Waals entre as cadeias moleculares. Essa deformação é reversível e desaparece com a remoção das tensões.

(b) Deformação elástica retardada $\varepsilon_{\mathrm{d}}(\mathrm{t})$. A taxa de crescimento dessa parcela diminui rapidamente com o tempo. Também é elástica, mas, depois da remoção da carga, requer um tempo para uma completa recuperação. É, geralmente, chamada de "fluência primária" ou "efeito elástico posterior". Num material polimérico, a deformação elástica retardada é atribuída, por exemplo, à deformação da cadeia polimérica.

(c) Fluidez viscosa $\varepsilon_{\mathrm{v}}(\mathrm{t})$. Esse é um componente da deformação irreversível que pode ou não aumentar linearmente com a aplicação das tensões. Num material polimérico, é característico do escorregamento intermolecular. É, geralmente, referido como uma "fluência secundária" ou "deformação irreversível".
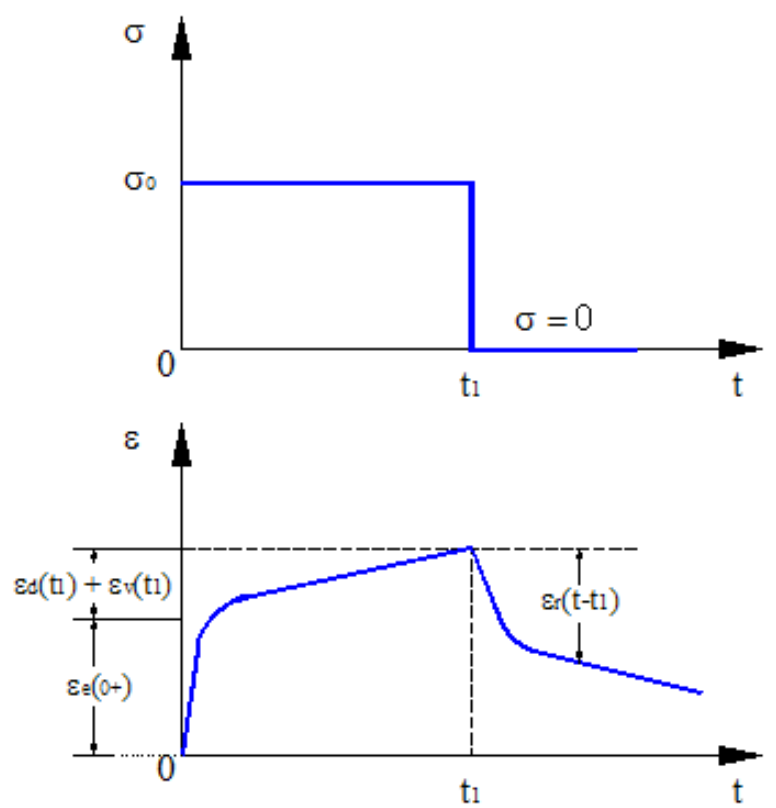

Figura 4.2. Deformação de um material viscoelástico submetido a uma tensão constante durante o tempo $t_{1}$. Fonte: HADDAD, 1995

No descarregamento do corpo-de-prova viscoelástico no tempo $t_{1}$, a resposta elástica instantânea recupera-se rapidamente e a resposta elástica retardada recupera-se gradualmente, mas a fluidez viscosa permanece (WARD, 1983 apud HADDAD, 1995).

\subsection{PROPRIEDADES MECÂNICAS}

Uma propriedade intrínseca aos materiais plásticos é o seu caráter viscoelástico, ou seja, suas propriedades mecânicas agregam as características dos líquidos 
viscosos e dos sólidos elásticos. Essa natureza explica o seu comportamento complexo - dependente do tempo, da temperatura e da taxa de deformação.

As propriedades mecânicas dos materiais plásticos, não obstante suas propriedades viscoelásticas, podem ser descritas por meio do diagrama tensão deformação de um ensaio de curta duração. Esses dados podem servir para uma classificação inicial, mas não devem ser utilizados no projeto de estruturas que exijam um comportamento bem definido em longo prazo (CRAWFORD, 1987).

De uma maneira geral, o diagrama tensão - deformação dos plásticos é equivalente aos dos metais, conforme mostrado na figura 4.3. Para pequenas deformações, há uma fase elástica, em que a relação entre tensão e deformação é proporcional. A partir do limite de proporcionalidade, o material se comporta de maneira não-linear, com a tensão última definida pelo limite de escoamento.

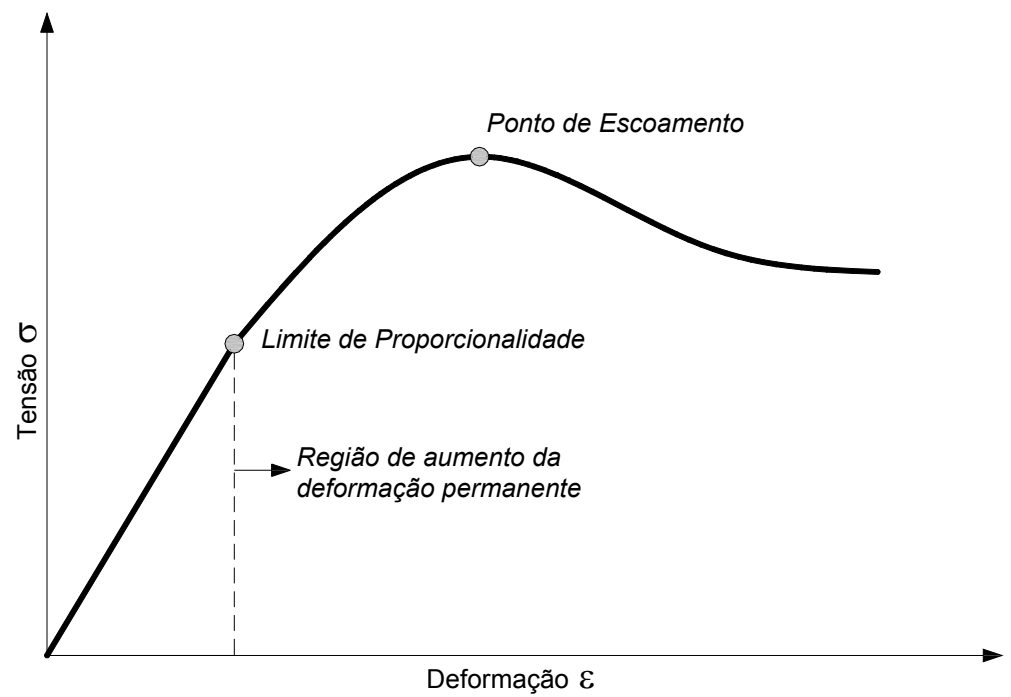

Figura 4.3. Diagrama típico dos materiais plásticos. Fonte: CRAWFORD, 1987

Como já citado anteriormente, a temperatura de exposição do plástico também afeta o seu comportamento, tornando-o mais flexível à medida que a temperatura aumenta, ou seja, deformando-se mais, com níveis de tensões menores. O efeito da temperatura é ilustrado na figura 4.4.

Para os polímeros amorfos (plásticos que possuem a geometria molecular de maneira aleatória), dependendo da temperatura, o comportamento frágil ou dútil é bem definido. Já para os polímeros cristalinos (geometria molecular com arranjos cristalinos regulares) não há uma transição bem clara, e a temperatura de fusão (transição da fase sólida para a fase líquida) é utilizada como parâmetro.

A tensão correspondente ao escoamento dos materiais plásticos também é afetada, consideravelmente, pela temperatura. À medida que a temperatura diminui, a capacidade de resistir aos esforços aumenta. Deve ser verificado também se o comportamento à tração é o mesmo à compressão. 


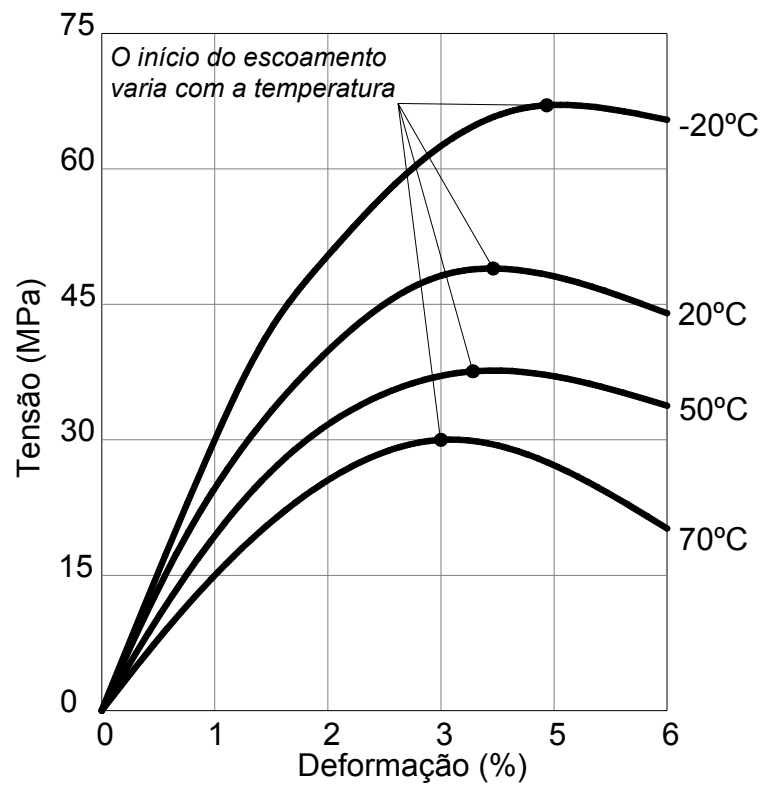

Figura 4.4. Efeito da temperatura no comportamento dos plásticos. Fonte: CRAWFORD, 1987

A figura 4.5 mostra como a velocidade com que se aplica o carregamento também influencia a resposta do material, pois ele é sensível à taxa de deformação.

Um dos critérios de projeto mais relevantes é a rigidez estrutural. Para as estruturas de material termoplástico, essa regra também é válida. A rigidez de um material é normalmente avaliada por meio do seu módulo de elasticidade. A literatura considera, usualmente, como sendo o módulo de elasticidade, a reta tangente à curva tensão - deformação. Mas para os plásticos, esse valor não deve ser tomado como constante para todos os casos de projeto, haja vista o comportamento variável dos plásticos quando submetidos a condições diversas. Na figura 4.6, o módulo de elasticidade tangente é obtido a partir do ponto $A$, o limite de proporcionalidade do material.

Em alguns casos, o módulo tangente é algo difícil de se obter precisamente. Pode-se, então, adotar o conceito de módulo secante, representado por uma deformação de $2 \%$ (ponto $C^{\prime}$ ). $O$ valor do módulo de elasticidade secante é determinado a partir do ponto $\mathrm{C}$ na curva, correspondente à deformação adotada, como ilustra a figura 4.6.

Além da resistência à ruptura, as deformações aceitáveis são um dos fatores mais limitantes no dimensionamento de elementos estruturais. Deseja-se, na maioria dos casos, que o material possua valores altos tanto para a resistência como para o módulo de elasticidade. No entanto, a natureza dos plásticos, quando estes possuem um módulo de elasticidade elevado, é associada a uma baixa dutilidade, ou seja, reduzida capacidade de se deformar antes da ruptura. 


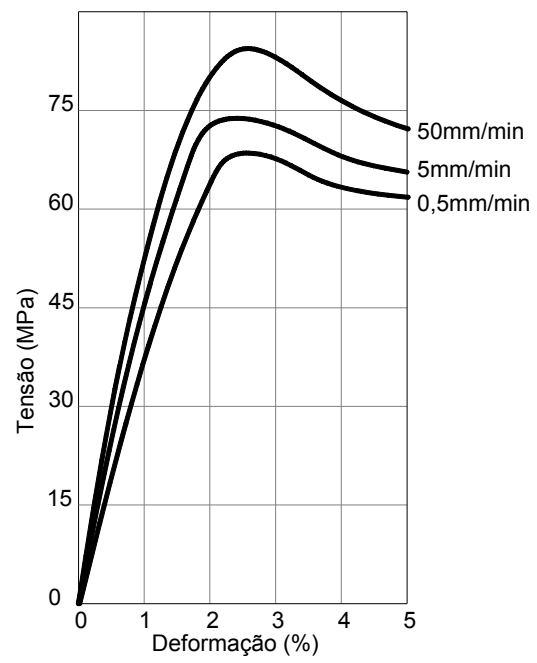

Figura 4.5. Efeito da variação da taxa de deformação nos plásticos. Fonte: CRAWFORD, 1987

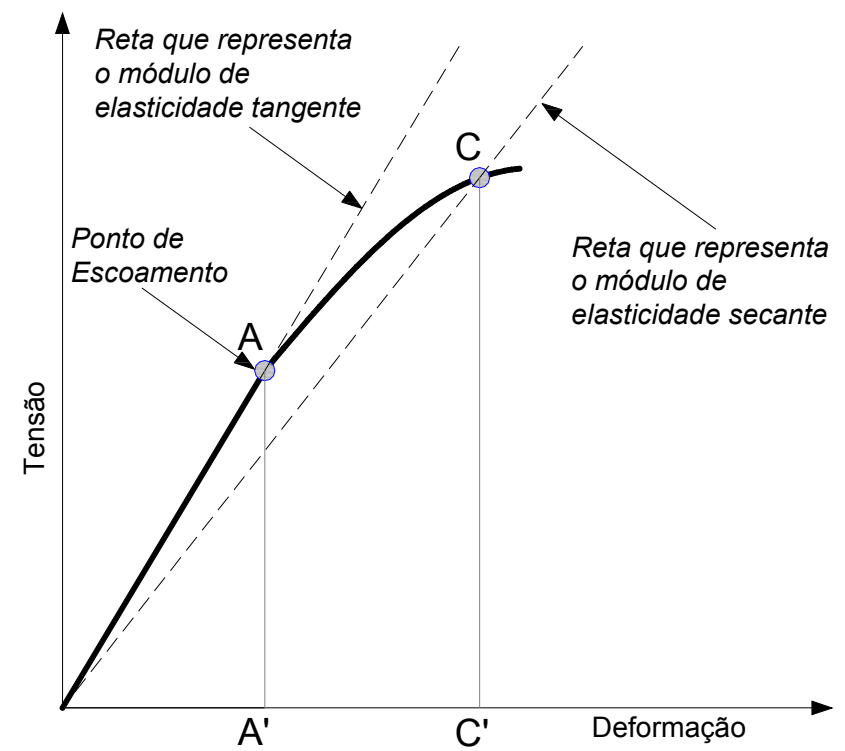

Figura 4.6. Módulos de elasticidade tangente e secante. Fonte: CRAWFORD, 1987

A tabela 4.1 traz as propriedades mecânicas típicas dos plásticos mais importantes, obtidas a partir de ensaios de curta duração. Observa-se que as propriedades variam consideravelmente, havendo plásticos com resistência à tração da ordem de 20 vezes superior a outros. O módulo de elasticidade também varia bastante, sendo a adição de fibras um fator que influencia substancialmente a rigidez.

Os fenômenos da fluência e da relaxação das tensões também são verificados nos plásticos, como conseqüência da sua natureza viscoelástica. A fluência é a denominação dada ao aumento das deformações para um nível de tensões constante. O comportamento restaurador dos plásticos, quando descarregado, tem sua explicação a partir do mesmo princípio da fluência. Já a relaxação, ou seja, mantida uma deformação ao longo do tempo, as tensões necessárias para mantê-la reduzemse ao longo do tempo (CRAWFORD, 1987). 
Tabela 4.1. Propriedades mecânicas de plásticos importantes. Fonte: CRAWFORD, 1987

\begin{tabular}{|c|c|c|c|c|}
\hline \multirow[b]{2}{*}{ Material } & \multirow[b]{2}{*}{$\begin{array}{l}\text { Densidade } \\
\qquad\left(\mathrm{kg} / \mathrm{m}^{3}\right)\end{array}$} & \multicolumn{3}{|c|}{ Módulo de } \\
\hline & & $\begin{array}{l}\text { Resistência à tração } \\
\text { (MPa) }\end{array}$ & $\begin{array}{c}\text { Elasticidade } \\
\qquad(\mathrm{MPa})\end{array}$ & $\begin{array}{c}\text { Deformação }^{1} \\
(\%)\end{array}$ \\
\hline ABS (alto impacto) & 1040 & 38 & 2200 & 8 \\
\hline Acrílico & 1190 & 74 & 3000 & 2 \\
\hline Resinas epóxicas & $1600-2000$ & $68-200$ & 20000 & 4 \\
\hline PEEK $^{2}$ & 1300 & 62 & 3800 & 4 \\
\hline PEEK (30\% carbono) & 1400 & 240 & 14000 & 1,6 \\
\hline PET & 1360 & 75 & 3,00 & 70 \\
\hline PET ( $30 \%$ fibra de vidro) & 1630 & 180 & 12000 & 3 \\
\hline Policarbonato & 1150 & 65 & 2800 & 100 \\
\hline Poliamida & 1420 & 72 & 2500 & 8 \\
\hline Polipropileno & 1200 & 27 & 1300 & $200-700$ \\
\hline Poliestireno & 1300 & 48 & 3400 & 3 \\
\hline Polietileno $\left(\mathrm{BD}^{3}\right)$ & 920 & 10 & 200 & 400 \\
\hline Polietileno $\left(A D^{4}\right)$ & 1450 & $20-30$ & 1200 & $200-100$ \\
\hline PVC rígido & 1330 & 48 & 3400 & 200 \\
\hline PVC flexível & 1300 & 14 & 7 & 300 \\
\hline
\end{tabular}

1 - Deformação do plástico, antes da ruptura; 2 - Resina termoplástica de alta resistência, marca registrada pela empresa VITRECX®; 3 - Baixa densidade; 4 - Alta densidade.

Conforme ilustra a figura 4.7, quando se aplica uma carga, ocorre uma primeira deformação, instantânea, que representa a parcela elástica (intervalo O-A). Com a manutenção das tensões, ocorre o fenômeno da fluência, aumentando as deformações, representado a parcela viscoelástica (intervalo A-B). A restauração das deformações, quando se descarrega o material, ocorre de maneira similar. Tem-se, inicialmente, uma parcela de restauração elástica (intervalo $\mathrm{B}-\mathrm{C}$ ) e, ao longo do tempo, a restauração viscoelástica (intervalo C-D).

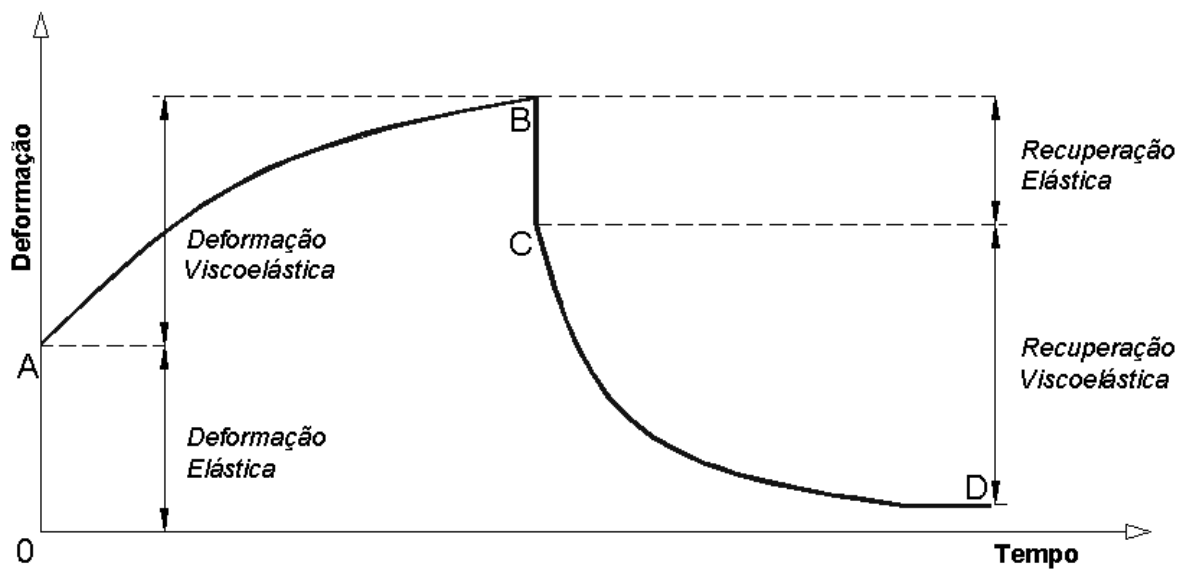

Figura 4.7. Fluência e recuperação de um material plástico. Fonte: CRAWFORD, 1987 
Assim como para os metais, a fadiga dos plásticos também deve ser considerada. O carregamento cíclico pode provocar a degradação do material, fazendo-o chegar à ruptura com cargas inferiores à de um carregamento considerado estático. A fluência pode também levar o material à ruptura, como conseqüência das deformações excessivas. Esse fenômeno é conhecido como fadiga estática (CRAWFORD, 1987).

As propriedades mecânicas supracitadas, no entanto, podem variar em função de vários fatores, tanto externos como intrínsecos ao material. A tabela 4.2 sumariza algumas causas e os efeitos no módulo de elasticidade e na sua dutilidade.

Tabela 4.2. Relações entre a rigidez e a dutilidade. Fonte: CRAWFORD, 1987

\begin{tabular}{lcc}
\hline \multicolumn{1}{c}{ Causa } & \multicolumn{2}{c}{ Efeito } \\
\cline { 2 - 3 } & Módulo de Elasticidade & Dutilidade \\
\hline Redução da temperatura & $\uparrow$ aumenta & $\downarrow$ diminui \\
Aumento da taxa de deformação & $\uparrow$ aumenta & $\downarrow$ diminui \\
Campo multiaxial de tensões & $\uparrow$ aumenta & $\downarrow$ diminui \\
Incorporação de plastificante & $\downarrow$ diminui & $\uparrow$ aumenta \\
Incorporação de material emborrachado & $\downarrow$ diminui & $\uparrow$ aumenta \\
Incorporação de fibras de vidro & $\uparrow$ aumenta & $\downarrow$ diminui \\
Incorporação de material particulado & $\uparrow$ aumenta & $\downarrow$ diminui
\end{tabular}

\subsubsection{O fenômeno da fluência}

A fluência pode se manifestar de diferentes maneiras, a depender do tipo de material e a que condições ele está submetido. A figura 4.8 exibe duas curvas típicas de fluência que podem ocorrer. No eixo das ordenadas tem-se a deformação $\varepsilon=\Delta \mathrm{L} / \mathrm{L}_{0}$, em que $\Delta \mathrm{L}$ é o aumento do comprimento do corpo-de-prova e $\mathrm{L}_{0}$ é o comprimento inicial. No eixo das abscissas, tem-se o tempo t . A partir da deformação inicial $\varepsilon_{0}$, a taxa de deformação por fluência é alta nos primeiros instantes do carregamento e diminui com o passar do tempo (a inclinação da tangente à curva de fluência tem o significado físico da taxa de deformação), sendo este primeiro estágio denominado de fluência primária. O estágio em que a taxa de deformação atinge um valor constante é chamado de fluência secundária. Considerado o estágio mais importante, é nele que se calcula o tempo de ruptura $t_{f}$ na fluência. A fluência terciária, o último estágio, é caracterizada pela fratura interna do material, fluência acelerada e ruptura definitiva (NIX et al., 2001).

O mecanismo de fluência envolve o movimento de escorregamento de átomos ou moléculas uns em relação aos outros. A maioria dos materiais se comporta de acordo com a fluência da curva A. 
Em materiais amorfos, praticamente todos os átomos ou moléculas são livres para escorregar até um determinado limite. Tais materiais descrevem, tipicamente, grandes deformações por fluência inelástica (curva B da figura 4.8). Para os materiais cristalinos, a deformação por fluência também envolve o deslizamento dos átomos, que ocorre somente dentro do núcleo dos cristais. A fluência dos metais e das cerâmicas normalmente é governada por esse tipo de movimento.

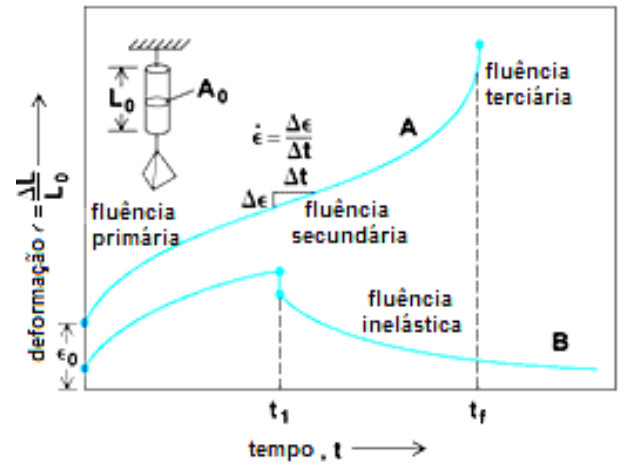

Figura 4.8. Curvas típicas de fluência para os materiais. Fonte: NIX et al., 2001

Em um ensaio de fluência simples, o corpo-de-prova sem perturbação é sujeito, inicialmente, no tempo $\mathrm{t}=0$, a uma tensão $\sigma_{0}=\sigma\left(0^{+}\right)$, que é mantida constante durante o ensaio; entretanto, a deformação dependente do tempo $\varepsilon(\mathrm{t})$ é observada. Neste caso, a deformação por fluência total pode ser considerada como a soma das três parcelas $\varepsilon_{\mathrm{e}}\left(0^{+}\right), \varepsilon_{\mathrm{d}}(\mathrm{t})$ e $\varepsilon_{\mathrm{v}}(\mathrm{t})$, mencionadas anteriormente. Além disso, a magnitude dessas parcelas individuais de deformação é proporcional à magnitude da tensão imposta. Dessa maneira, uma função de conformação (ou função de flexibilidade) da fluência $F_{c r p}(t)$, dependente somente do tempo, pode ser definida, no caso da viscoelasticidade linear, como:

$$
\mathrm{F}_{\text {crp }}(\mathrm{t})=\frac{\varepsilon(\mathrm{t})}{\sigma\left(0^{+}\right)}=\mathrm{F}_{\mathrm{e}}\left(0^{+}\right)+\mathrm{F}_{\mathrm{d}}(\mathrm{t})+\mathrm{F}_{\mathrm{v}}(\mathrm{t})
$$

$\mathrm{Na}$ relação acima, a função de conformação $\mathrm{F}_{\mathrm{v}}(\mathrm{t})$, que define a fluidez newtoniana, pode ser negligenciada para os materiais sólidos com grande viscosidade, por exemplo, polímeros rígidos a temperatura ambiente. Polímeros lineares amorfos, por outro lado, demonstram um valor finito de $F_{v}(t)$ a temperaturas acima da sua transição vítrea. No entanto, a baixas temperaturas, o comportamento viscoelástico destes polímeros pode ser influenciado pelas funções $F_{e}\left(0^{+}\right)$e $F_{d}(t)$. O mesmo vale para o caso de polímeros altamente interconectados e, com uma razoável 
aproximação, para o caso dos polímeros altamente cristalizados. Em geral, a separação da conformação da fluência $F_{c r p}(t)$, para um material particular a qualquer temperatura, nas funções $F_{e}\left(0^{+}\right), F_{d}(t)$ e $F_{v}(t)$ pode não ser uma tarefa tão fácil e pode envolver divisões arbitrárias (HADDAD, 1995).

Ainda com relação à figura 4.2, considere o caso em que a tensão $\sigma_{0}$ é aplicada a um corpo-de-prova sem perturbação no tempo $t=0$ e removida no tempo $t=t_{1}$. Desse modo, na consideração do comportamento viscoelástico linear, a deformação total por fluência $\varepsilon(t)$, em qualquer instante $t>t_{1}$, é dada pela superposição de duas deformações individuais. Por exemplo, considere-se um $\varepsilon_{\mathrm{e}}=\sigma_{0} \mathrm{~F}_{\text {crp }}(\mathrm{t})$ correspondendo a um carregamento no tempo $\mathrm{t}=0$ e $\varepsilon_{\mathrm{r}}=-\sigma_{0} \mathrm{~F}\left(\mathrm{t}-\mathrm{t}_{1}\right)$ correspondendo a um descarregamento no tempo $t=t_{1}$. Dessa forma:

$$
\varepsilon(\mathrm{t})=\sigma_{0} \mathrm{~F}_{\text {crp }}(\mathrm{t})-\sigma_{0} \mathrm{~F}_{\text {crp }}\left(\mathrm{t}-\mathrm{t}_{1}\right)
$$

A recuperação $\varepsilon_{\mathrm{r}}\left(\mathrm{t}-\mathrm{t}_{1}\right)$ é definida como a diferença entre a fluência antecipada devida à tensão inicial e a atual medida da fluência (HADDAD, 1995).

Uma forma típica de apresentação da função de conformação da fluência $F_{\text {crp }}(t)$ é mostrada na figura 4.9, com a abscissa sendo o logaritmo do tempo. Dessa maneira, a forma a curva muda drasticamente, alongando a porção de curta duração e compactando a região de longa duração. O valor ao longo da abscissa denominado " $\log \tau$ " marca a inflexão da curva e $\tau$ é chamado de "tempo de relaxação" do processo de fluência (ROYLANCE, 2001).

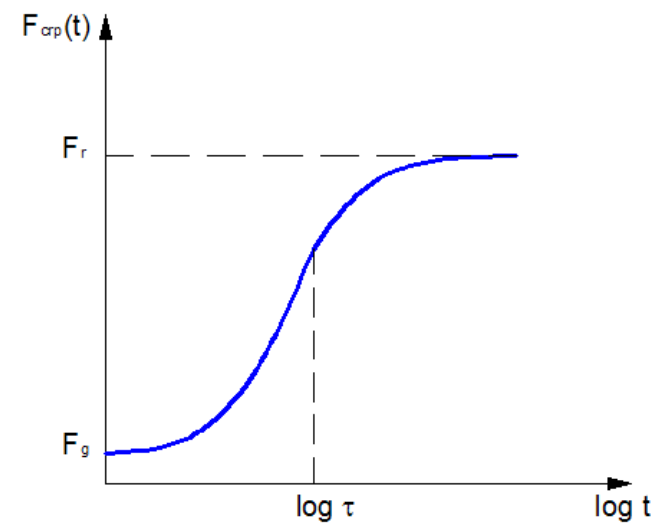

Figura 4.9. Curva de conformação da fluência $F_{\text {crp }}(t)$. Fonte: ROYLANCE, 2001

\subsubsection{O fenômeno da relaxação}

Para um material viscoelástico submetido a um estado de deformação constante, o fenômeno de diminuição das tensões ao longo do tempo é chamado de relaxação 
(vide figura 4.10). Na hipótese de um comportamento viscoelástico linear, um módulo de relaxação das tensões, uma função do tempo somente, pode ser definida como:

$$
\xi_{\text {rel }}(\mathrm{t})=\frac{\sigma(\mathrm{t})}{\varepsilon\left(0^{+}\right)}
$$

Num ensaio de relaxação, a fluidez viscosa interfere no valor limite das tensões. $\mathrm{Na}$ consideração da fluidez viscosa, a tensão pode cair para zero, em grandes períodos de tempo. Por outro lado, se não existe a fluidez viscosa, a tensão decai para um valor finito. Isso resultaria no equilíbrio ou módulo relaxado $\xi_{\infty}=\xi(\infty)$ no tempo infinito (LOCKETT, 1972; GITTUS, 1975 apud HADDAD, 1995).
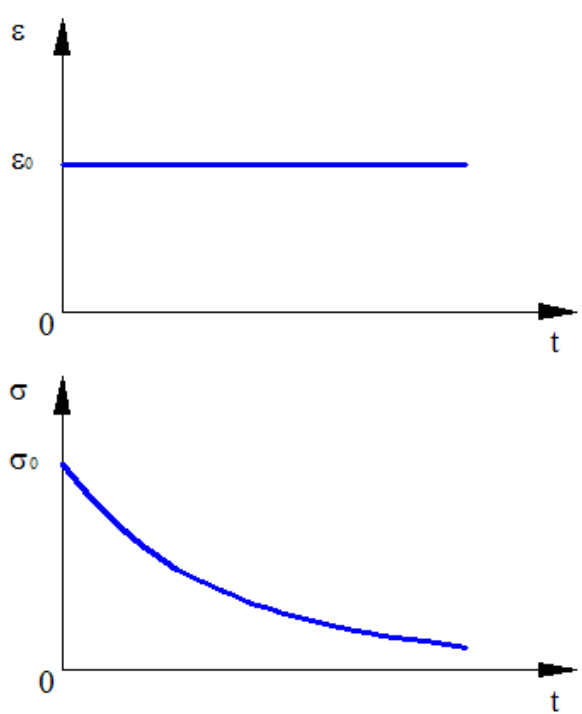

Figura 4.10. Relaxação das tensões de um material viscoelástico sujeito a uma deformação constante. Fonte: HADDAD, 1995

A natureza particular da classe de materiais viscoelásticos considerados prova a existência de uma propriedade, denominada "resistência passiva", em tais materiais. Isto vai de encontro à resposta instantânea e a reversibilidade que caracteriza o comportamento elástico puro. Essa resistência passiva é de natureza viscosa e reflete o que é usualmente chamado de propriedade de "resposta hereditária" do material. Isto é, o estado presente da resposta depende não somente do estado presente do carregamento imposto, mas também dos estados anteriores. Esta propriedade é revelada experimentalmente, em diferentes fenômenos dependentes do tempo como a fluência, a relaxação das tensões e a atenuação intrínseca de propagação das ondas.

Analogamente à conformação da fluência, podem-se superpor as curvas de relaxação por meio do módulo de relaxação $\xi_{\text {rel }}(\mathrm{t})$, com a abscissa sendo o logaritmo do tempo, conforme a figura 4.11. Para curta duração, a tensão situa-se num platô correspondente a um módulo vítreo $\xi_{\mathrm{g}}$ e, em seguida, cai exponencialmente para um 
módulo "emborrachado" $\xi_{\mathrm{r}}$, com as moléculas poliméricas gradualmente acomodando as deformações pelo alongamento conformacional (ROYLANCE, 2001).

Tanto a fluência como a relaxação são manifestações do mesmo mecanismo molecular, e espera-se que $F_{\text {crp }}(t)$ e $\xi_{\text {rel }}(t)$ estejam relacionados. No entanto, ainda que $\xi_{\mathrm{g}}=1 / \mathrm{F}_{\mathrm{g}}$ e $\xi_{\mathrm{r}}=1 / \mathrm{F}_{\mathrm{r}}$, em geral, $\xi_{\text {rel }}(\mathrm{t}) \neq 1 / \mathrm{F}_{\text {crp }}(\mathrm{t})$. Em particular, a resposta $\mathrm{da}$ relaxação é mais rápida que a resposta da fluência (ROYLANCE, 2001).

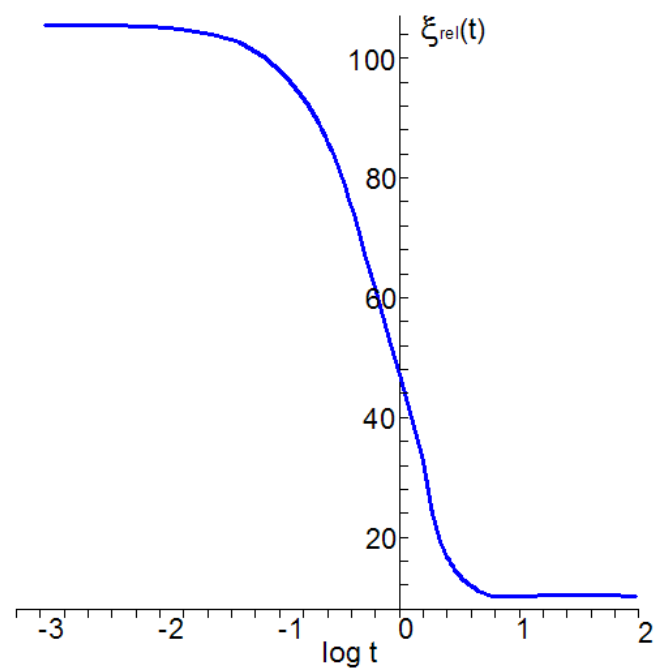

Figura 4.11. Curva do módulo de relaxação $\xi_{\text {rel }}(\mathrm{t})$. Fonte: ROYLANCE, 2001

\subsubsection{Comparação com outros materiais}

Os diversos comportamentos possíveis para o plástico podem tornar difícil uma comparação deste com outros materiais. Ao mesmo tempo, as relações entre a rigidez, a resistência, a densidade, a temperatura são uma forma bastante eficaz de se analisar e comparar um material com os demais.

A figura 4.12 mostra um panorama da relação entre a resistência (à tração e à compressão) para diversos materiais, entre eles, os plásticos ou polímeros. Observase que os plásticos podem ser tão resistentes quanto a madeira e até mesmo alguns metais e ligas, com uma densidade inferior, se comparada à dos metais. Pode haver tanto plásticos com resistência próxima a $100 \mathrm{MPa}$, como também inferior a $10 \mathrm{MPa}$. $\mathrm{A}$ densidade, por sua vez, não varia na mesma proporção, havendo plásticos com menos de $1000 \mathrm{~kg} / \mathrm{m}^{3} \mathrm{e}$, até, com aproximadamente $3000 \mathrm{~kg} / \mathrm{m}^{3}$.

A baixa rigidez dos materiais plásticos talvez seja a sua maior deficiência. Apesar de uma resistência mecânica satisfatória, a grande deformabilidade inviabiliza o uso em diversas aplicações. Uma solução já consagrada, que pode atenuar essa deficiência, é a adição de fibras. Há um significativo ganho de rigidez, o que é comprovado em várias pesquisas: NOSKER e RENFREE (1999a e 1999b); CARROLL et al. (2001); CORREA et al. (2003); SELKE e WICHMAN (2004). 
Os diagramas das figuras 4.12 a 4.15 foram adaptados de figuras retiradas do sítio eletrônico do Departamento de Engenharia da Universidade de Cambridge, a partir do trabalho do pesquisador Michael Ashby, intitulado Materials selection in mechanical design, de 1992.

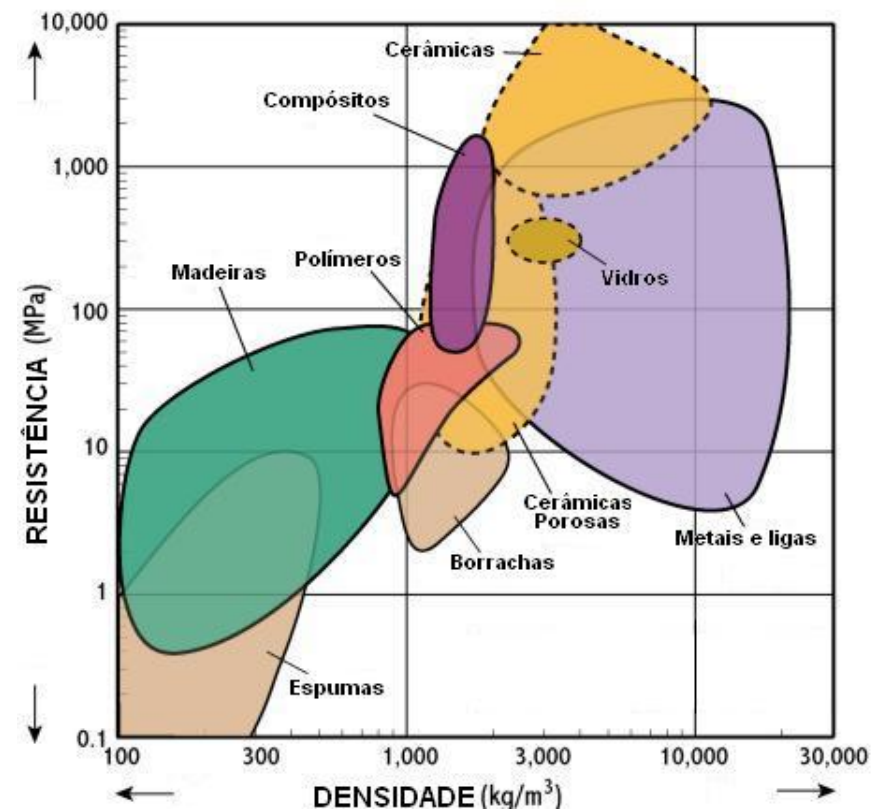

Figura 4.12. Relação entre densidade e resistência para diversos materiais

A figura 4.13 mostra, para diversos materiais, a relação entre rigidez e resistência específicas. Analisando-a, verifica-se a baixa rigidez dos polímeros, se comparados com a madeira e os metais. Já para os compósitos, esses alcançam resistências e rigidezes equivalentes à da madeira e dos metais.

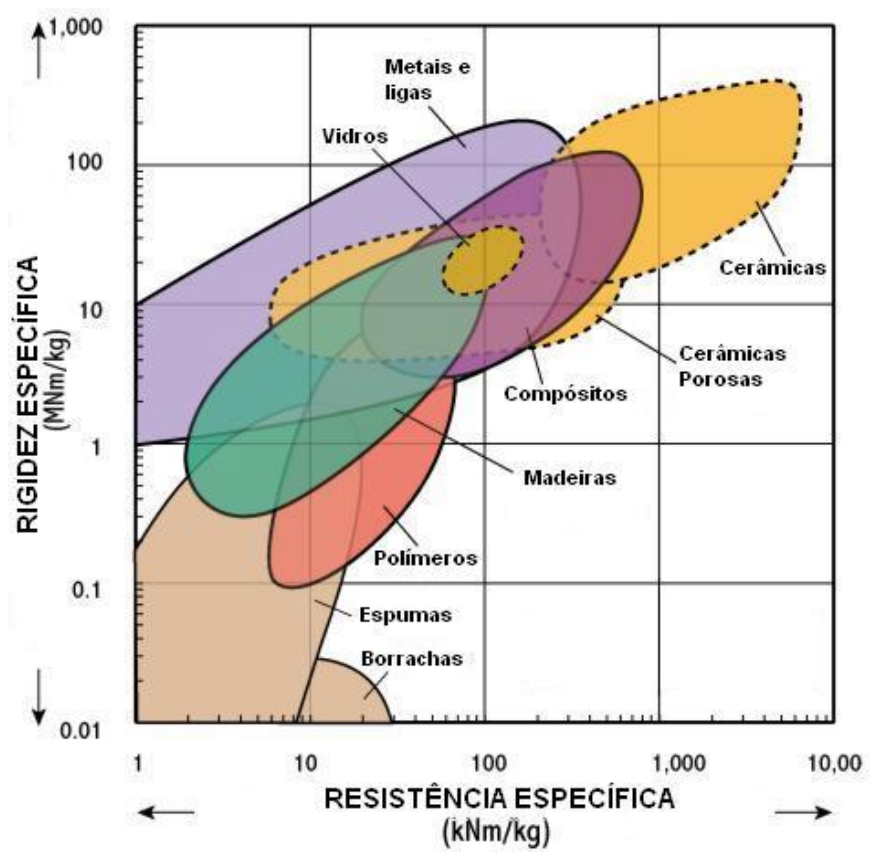

Figura 4.13. Relação entre rigidez e resistência específicas para diversos materiais 
Outra relação entre resistência mecânica e alongamento antes da ruptura é mostrada na figura 4.14. Como previsto, os polímeros, por serem mais dúcteis, alongam-se mais que a maioria das madeiras e dos metais, com uma resistência equivalente à da madeira, mas inferior à dos metais.

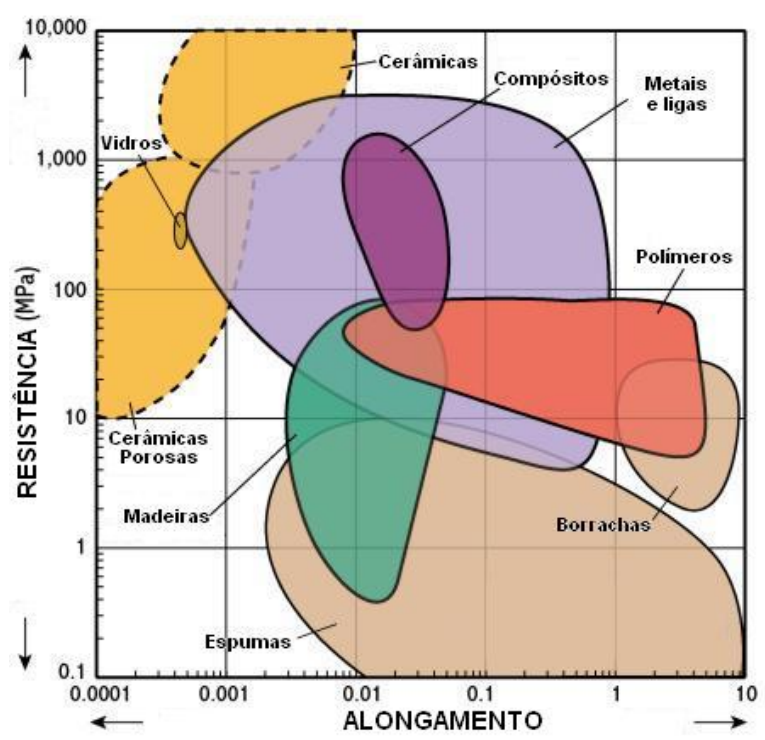

Figura 4.14. Relação entre resistência e alongamento para diversos materiais

Um aspecto crítico do uso dos plásticos é a sua sensibilidade à temperatura. Os plásticos possuem um baixo desempenho quando submetidos a temperaturas mais altas, o que pode ser observado na figura 4.15. Esse diagrama relaciona a resistência do material à sua máxima temperatura de serviço. Nesse aspecto, os metais possuem uma grande vantagem em relação aos outros materiais, pois reúnem altas resistências a também altas temperaturas de serviço.

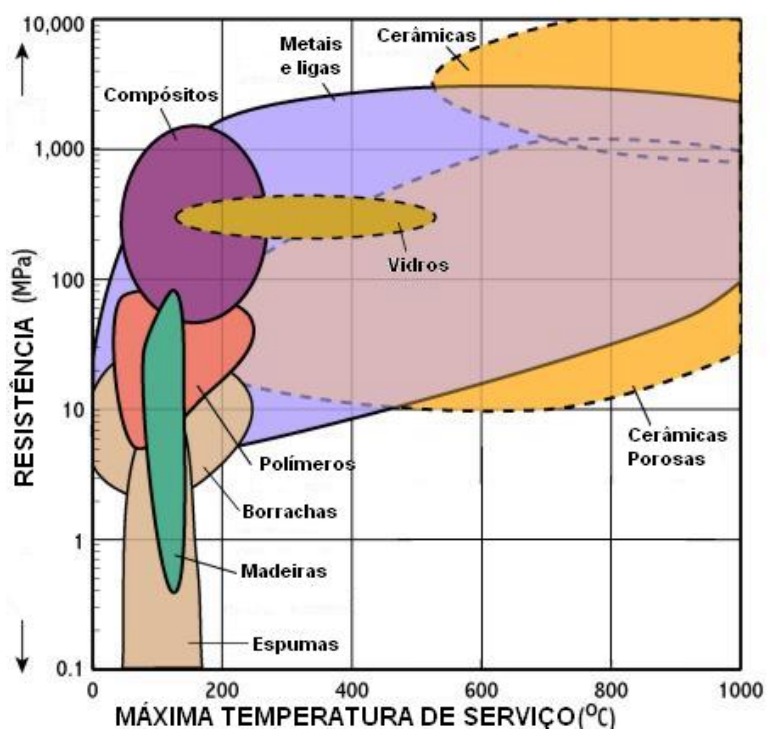

Figura 4.15. Relação entre resistência e máxima temperatura de serviço para diversos materiais 


\subsection{MODELOS DE PREVISÃO DO COMPORTAMENTO VISCOELÁSTICO}

Para um material perfeitamente elástico, as tensões $\sigma$ se correspondem às deformações $\varepsilon$ de maneira diretamente proporcional, e a equação para o caso de tensão uniaxial pode ser expressa da seguinte forma:

$\sigma=\xi \cdot \varepsilon$

$\xi$ é uma constante que representa o módulo de elasticidade do material.

Para um fluido perfeitamente viscoso (newtoniano), as tensões cisalhantes $\tau$ são diretamente proporcionais à taxa de deformação $\dot{\gamma}$. A equação para um fluido newtoniano é descrita a seguir:

$$
\sigma=\eta \cdot \dot{\gamma}
$$

$\eta$ é uma constante referida como a viscosidade do fluido.

O comportamento viscoelástico dos materiais plásticos pode ser simulado utilizando modelos físicos de previsão, por meio da associação em série e em paralelo de molas e amortecedores. Nesses modelos, o comportamento dos sólidos elásticos é representado pela mola e o comportamento viscoso pelo amortecedor (CRAWFORD, 1987).

\subsubsection{Representação Diferencial da Viscoelasticidade Linear}

A seguinte relação diferencial linear é, geralmente, utilizada como uma equação constitutiva da viscoelasticidade linear, relacionando as tensões com as deformações.

$$
\mathrm{P} \sigma(\mathrm{t})=\mathrm{Q} \varepsilon(\mathrm{t})
$$

$\mathrm{P}$ e Q são operadores diferenciais lineares com relação ao tempo t. Numa forma geral, esses operadores são expressos como:

$$
\begin{aligned}
& P=\sum_{i=0}^{p} a_{i} \frac{\partial^{i}}{\partial t^{i}} \\
& Q=\sum_{i=0}^{q} b_{i} \frac{\partial^{i}}{\partial t^{i}}
\end{aligned}
$$

$a_{i}$ e $b_{i}$ são constantes do material. $\mathrm{O}$ número de constantes dependerá da resposta viscoelástica de um material particular em consideração. Combinando as equações (4.6), (4.7) e (4.8), a equação resultante pode ser escrita na seguinte forma:

$$
\mathrm{a}_{0} \sigma+\mathrm{a}_{1} \frac{\mathrm{d} \sigma}{\mathrm{dt}}+\mathrm{a}_{2} \frac{\mathrm{d}^{2} \sigma}{\mathrm{dt}^{2}}+\ldots=\mathrm{b}_{0} \varepsilon+\mathrm{b}_{1} \frac{\mathrm{d} \varepsilon}{\mathrm{dt}}+\mathrm{b}_{2} \frac{\mathrm{d}^{2} \varepsilon}{\mathrm{dt}^{2}}+\ldots
$$

No entanto, pode ser suficiente representar a resposta viscoelástica numa escala de tempo limitada, considerando somente dois termos da cada lado da equação (4.9). Isto seria, dessa forma, equivalente a uma descrição do comportamento viscoelástico 
linear por meio de modelos contínuos, obtidos a partir de elementos elásticos lineares, que obedecem à Lei de Hooke, e amortecedores viscosos, que obedecem à Lei da Viscosidade de Newton. Portanto, o comportamento viscoelástico do material, em geral, pode ser investigado pelo uso de modelos mecânicos que consistem em associações entre molas e amortecedores. Existem, também, modelos elétricos correspondentes contendo resistências e capacitâncias que podem ser usados. A invenção de modelos mecânicos para a identificação da resposta viscoelástica dos materiais data de antes do século XIX e coincide com a primeira introdução de polímeros manufaturados pelo homem. Esses modelos dão uma indicação do significado dos parâmetros internos, representados pela respostas dos elementos do modelo (HADDAD, 1995).

\subsubsection{Modelos Simples Unidimensionais}

a) Modelo de Maxwell

O Modelo de Maxwell é uma idealização da resposta viscoelástica e um dos modelos mais simples. Consiste em uma mola linear e um amortecedor em série, conforme a figura 4.16. O amortecedor é visualizado como um pistão movendo-se num fluido viscoso. Sob a ação de uma tensão uniaxial, ocorre uma deformação instantânea da mola. Esta é a resposta elástica do modelo. Ao mesmo tempo, o fluido no amortecedor passa, lentamente, por um orifício no pistão, resultando numa deformação do comprimento total do amortecedor. Esta é uma fluidez viscosa que se refere a uma resposta dependente do tempo, do Modelo de Maxwell. Como a mola e o amortecedor estão em série, as deformações elástica e viscosa são aditivas.

As relações constitutivas são representadas pelas equações (4.10) e (4.11).

$$
\begin{aligned}
& \sigma_{\mathrm{s}}=\xi \cdot \varepsilon_{\mathrm{s}} \\
& \sigma_{\mathrm{d}}=\eta \cdot \dot{\varepsilon}_{\mathrm{d}}
\end{aligned}
$$

$\sigma_{\mathrm{s}}$ e $\sigma_{\mathrm{d}}$ são as tensões na mola e no amortecedor, respectivamente,

$\varepsilon_{\mathrm{s}}$ é a parcela de deformação da mola,

$\dot{\varepsilon}_{\mathrm{d}}$ é a taxa de deformação correspondente ao amortecedor.

Para que haja o equilíbrio do sistema de mola e amortecedor em série, assumindo uma área da seção transversal constante, as tensões aplicadas devem ser iguais, ou seja, $\sigma=\sigma_{\mathrm{s}}=\sigma_{\mathrm{d}}$.

A equação da deformação total do sistema é dada pela soma das parcelas da mola e do amortecedor, conforme a equação (4.12).

$$
\varepsilon=\varepsilon_{\mathrm{s}}+\varepsilon_{\mathrm{d}}
$$



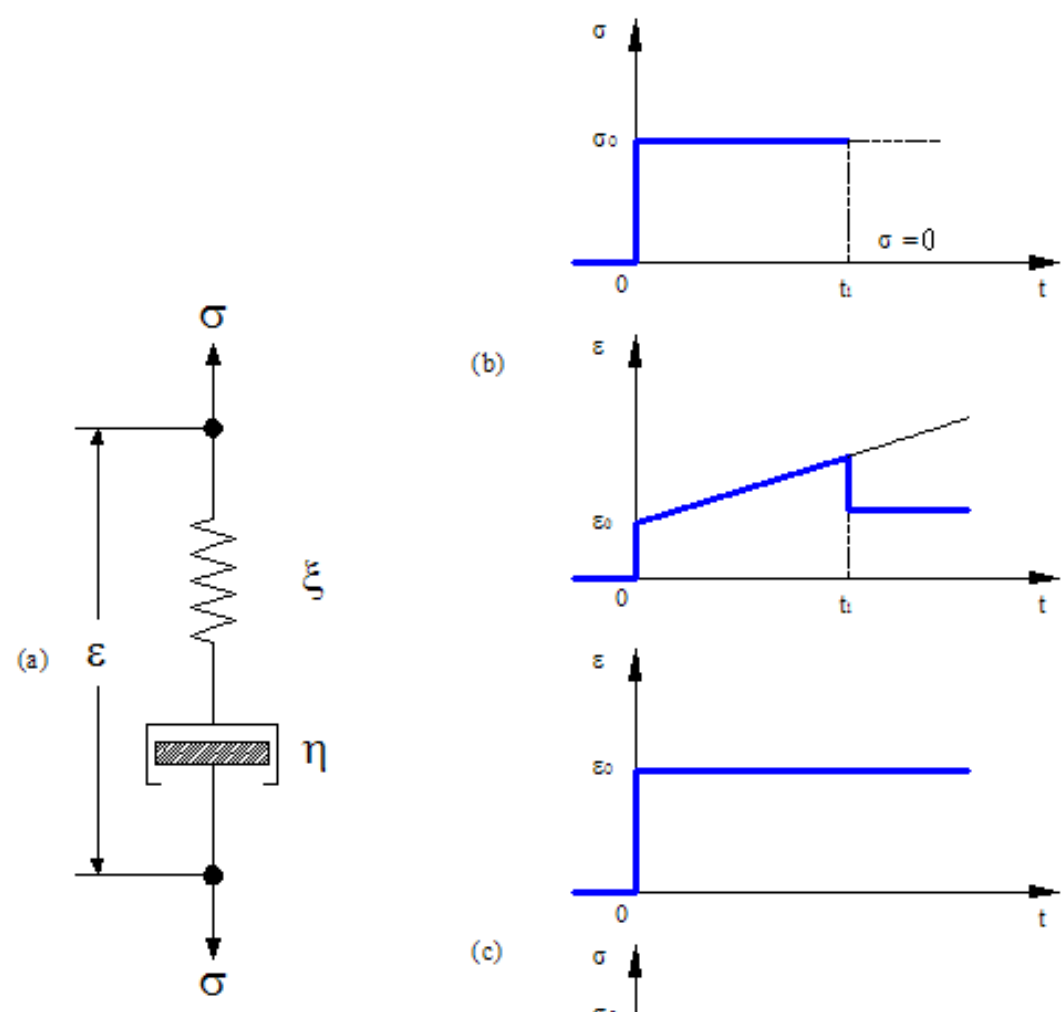

(b)
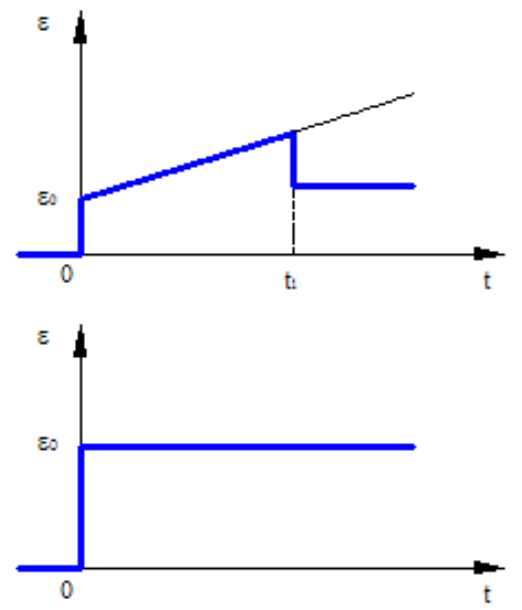

(c)

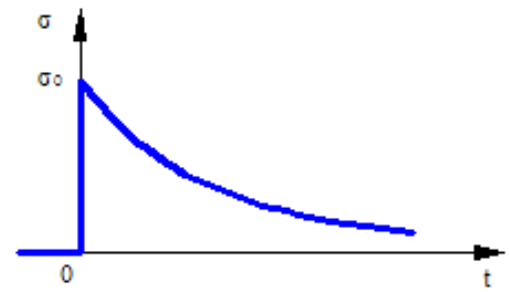

Figura 4.16. Modelo de Maxwell: (a) modelo físico; (b) resposta da fluência; (c) resposta da relaxação. Fonte: HADDAD, 1995

A equação (4.12) pode ser escrita em função das propriedades do material, explicitadas nas equações (4.10) e (4.11).

$$
\sigma+\lambda \cdot \dot{\sigma}=\eta \cdot \dot{\varepsilon}
$$

$\lambda=\eta / \xi$

É considerado que a equação da resposta do Modelo de Maxwell é conectada à resposta da relação diferencial (4.9), por meio de:

$$
\begin{aligned}
& \mathrm{p}=1, \mathrm{a}_{0}=1 / \eta, \mathrm{a}_{1}=1 / \xi \\
& \mathrm{q}=1, \mathrm{~b}_{0}=0, \mathrm{~b}_{1}=1
\end{aligned}
$$

Os fenômenos da fluência e da relaxação são característicos do comportamento dos materiais plásticos, que exibem uma deformação dependente do tempo. O aumento da deformação ao longo da aplicação de uma tensão constante é denominado como fluência (CRAWFORD, 1987).

No ensaio de fluência, aplica-se no tempo $t=0$ uma tensão constante $\sigma=\sigma_{0} \mathrm{e}$ objetiva-se obter a função da fluência dependente do tempo $\varepsilon(\mathrm{t})$. Dessa forma, a equação (4.3) é uma equação diferencial para $\varepsilon$ e tem a seguinte solução: 


$$
\varepsilon(\mathrm{t})=\frac{\sigma_{0}}{\eta} \mathrm{t}+\mathrm{c}
$$

$c$ é uma constante de integração. A incógnita pode ser obtida por meio de uma condição inicial no tempo $t=0$, por exemplo:

$$
\varepsilon_{0}=\varepsilon(0)=\sigma_{0} / \xi
$$

Essa deformação inicial é correspondente à resposta elástica instantânea do elemento de mola. Dessa forma, o valor da constante é determinado:

$$
\mathrm{c}=\varepsilon_{0}=\sigma_{0} / \xi
$$

Substituindo na equação (4.16) o valor da constante da equação (4.18), obtémse a equação constitutiva da fluência para o Modelo de Maxwell:

$$
\varepsilon(\mathrm{t})=\frac{\sigma_{0}}{\xi}\left(1+\frac{\mathrm{t}}{\lambda}\right)=\sigma_{0} \cdot \mathrm{F}(\mathrm{t})
$$

$F(t)$ é a função conformação da fluência ou, simplesmente, "função fluência", que tem, a partir da equação (4.19), para o Modelo de Maxwell, a seguinte forma:

$$
\mathrm{F}(\mathrm{t})=\xi^{-1}\left(1+\frac{\mathrm{t}}{\lambda}\right)
$$

A equação (4.19) da resposta da fluência é ilustrada na figura 16b para $0 \leq t \leq t_{1}$. Ainda com referência a essa figura, a equação (4.19) mostra que a resposta instantânea no tempo $\mathrm{t}=0^{+}$(isto é, imediatamente após a aplicação da carga) do Modelo de Maxwell é elástica, com módulo de elasticidade $\xi$. Este último é a constante elástica da mola. Além disso, pode-se observar que o Modelo de Maxwell mostra uma propriedade típica dos fluidos, por exemplo, a capacidade ilimitada de deformação sob a atuação de uma tensão finita. Isto é ilustrado na figura $4.16 \mathrm{~b}$ pelas linhas tracejadas.

Tal desempenho pode se constituir numa desvantagem limitante na tentativa de se adotar ao Modelo de Maxwell na previsão do comportamento à fluência, dos materiais viscoelásticos reais. Além do mais, este modelo não pode demonstrar a recuperação viscoelástica dependente do tempo que ocorre num material viscoelástico real se, durante a fluência, as tensões impostas forem removidas. O que ocorre é apenas uma recuperação elástica, como resultado da contração da mola. Não haverá nenhuma recuperação dependente do tempo, pois não há força alguma agindo no pistão para movê-lo para trás quando as tensões forem removidas (GITTUS, 1975 apud HADDAD, 1995). 
Por outro lado, se for aplicado no tempo $t=0$ uma deformação constante, por exemplo, $\varepsilon(\mathrm{t})=0$ para $\mathrm{t}<0$ e $\varepsilon(\mathrm{t})=\varepsilon_{0}$ para $\mathrm{t} \geq 0$, que corresponde a um ensaio de relaxação das tensões. Dessa maneira, com referência à equação (4.13), segue que:

$$
\sigma+\lambda \cdot \dot{\sigma}=0
$$

Integrando esta equação com relação ao tempo e considerando a condição inicial de $\sigma=\sigma_{0}$ no tempo $\mathrm{t}=0$, obtém-se:

$$
\sigma(\mathrm{t})=\sigma_{0} \exp (-\mathrm{t} / \lambda)
$$

A equação (4.22) indica que num ensaio de relaxação das tensões, estas decaem exponencialmente com um parâmetro característico do tempo $\lambda=\eta / \xi$; portanto, este parâmetro é relacionado com um "tempo de relaxação" do Modelo de Maxwell, para uma deformação constante.

A relaxação é outra conseqüência da natureza viscoelástica, e consiste na redução das tensões aplicadas, quando se submete o material plástico a uma deformação constante ao longo do tempo (CRAWFORD, 1987).

O procedimento para a obtenção da resposta da relaxação é, de certa forma, análogo ao da fluência. No ensaio de relaxação, aplica-se no tempo $t=0$ uma deformação constante $\varepsilon=\varepsilon_{0}$ e objetiva-se obter a função da tensão dependente do tempo $\sigma(\mathrm{t})$.

A relaxação é obtida a partir da integração da equação (4.13) e da imposição das condições iniciais, resultando na equação (4.23):

$$
\sigma(\mathrm{t})=\varepsilon_{0} \cdot \mathrm{R}(\mathrm{t})
$$

$\varepsilon_{0}=\varepsilon\left(0^{+}\right)$e $\mathrm{R}(\mathrm{t})$ estão relacionados com módulo de relaxação das tensões ou "função relaxação". $\mathrm{R}(\mathrm{t})$ é dado por:

$$
\mathrm{R}(\mathrm{t})=\xi \cdot \exp (-\mathrm{t} / \lambda)
$$

Um defeito adicional do Modelo de Maxwell torna-se aparente quando se examina a forma da função relaxação $R(t)$, que contém somente um termo de decaimento exponencial. Isto pode não ser suficiente para a representação do comportamento da relaxação das tensões, para os materiais viscoelásticos reais. $O$ comportamento real pode, não necessariamente, decair até zero para um tempo infinito, como a equação (4.24) sugere (HADDAD, 1995).

Apesar de ser um modelo bastante simplificado, que pode ser aceito como uma aproximação inicial do comportamento viscoelástico, os resultados obtidos não representam de maneira correta os fenômenos de natureza viscoelástica. A 
recuperação do material, quando as tensões são removidas, comporta-se de maneira semelhante à de um material elástico. O Modelo de Maxwell apenas considera a recuperação instantânea, não havendo dependência do tempo, como pode ser observado na figura $4.16 \mathrm{~b}$.

\section{b) Modelo de Kelvin-Voigt}

Este modelo consiste na associação em paralelo de mola e do amortecedor, expressando o comportamento retardado dos materiais viscoelásticos. As relações entre tensão e deformação são semelhantes ao modelo de Maxwell [equações (4.10) e (4.11)].

Por causa do arranjo em paralelo e do amortecedor, este modelo exibirá uma fluência primária (retardamento) quando carregado. Isto se deve ao fato da mola poder se estender somente tão rapidamente quanto o amortecedor. Portanto, este modelo não pode exibir um estado de fluência contínua. Pela mesma razão, também não pode demonstrar um estado de relaxação contínua das tensões. Por outro lado, se após um período de tensão uniaxial a tensão for retirada, a mola tentará retornar para o seu comprimento inicial, exercendo, dessa forma, compressão no amortecedor durante o processo. O amortecedor retrairá lentamente, sob essa tensão, para o comprimento original, permitindo que a mola se retraia (HADDAD, 1995).

Portanto, a fluência à compressão, sob tensões nulas, ocorrerá e, eventualmente, após um tempo infinito, permitirá que deformação por fluência seja totalmente recuperada. Tal propriedade (contração viscoelástica) pode ser significativa no comportamento à fluência para uma larga gama de materiais viscoelásticos. Como pode ser observada, a contração viscoelástica, como descrita acima, não ocorre no modelo de Maxwell.

O equilíbrio de forças do sistema é dado pela mola e pelo amortecedor, de acordo com a equação (4.25).

$$
\sigma=\sigma_{\mathrm{s}}+\sigma_{\mathrm{d}}
$$

A compatibilidade das deformações, para o sistema mola-amortecedor em paralelo, traduz-se em deformação total igual às deformações na mola e no amortecedor, ou seja, $\varepsilon=\varepsilon_{\mathrm{s}}=\varepsilon_{\mathrm{d}}$.

A partir das equações constitutivas e da equação (4.25), obtém-se:

$$
\sigma=\xi \cdot \varepsilon+\eta \cdot \dot{\varepsilon}
$$

Esta relação está conectada com a equação da resposta diferencial [equação (4.9)] através dos seguintes parâmetros:

$$
\mathrm{p}=0, \mathrm{a}_{0}=1, \mathrm{q}=1, \mathrm{~b}_{0}=\xi, \mathrm{b}_{1}=\eta
$$


Se for aplicada uma tensão constante $\sigma_{0}$, para $\mathrm{t} \geq 0^{+}$, como num ensaio de fluência, a equação (4.26) tem a solução a seguir:

$$
\varepsilon(\mathrm{t})=\frac{\sigma_{0}}{\xi}+\mathrm{C} \cdot \exp (-\mathrm{t} / \lambda)
$$

A constante de integração dada é sujeita às seguintes condições de contorno iniciais: $\varepsilon_{0}=\varepsilon(0)=0$. Dessa maneira, $\mathrm{C}=-\sigma_{0} / \xi$ e a equação constitutiva da fluência, para o Modelo de Kelvin-Voigt, é dada pela equação (4.29).

$$
\begin{aligned}
& \varepsilon(t)=\frac{\sigma_{0}}{\xi} \cdot[1-\exp (-t / \lambda)]=\sigma_{0} \cdot F(t) \\
& F(t)=\xi^{-1}[1-\exp (-t / \lambda)]
\end{aligned}
$$

A equação (4.30) é a função fluência para o Modelo de Kelvin-Voigt

A resposta da fluência do Modelo de Kelvin-Voigt é mostrada na figura 4.17. Para um tempo $\mathrm{t} \rightarrow \infty$, a deformação aproxima-se, gradualmente, de um valor limite. Este valor é proporcional à tensão imposta, com um módulo assintótico $\mathrm{E}_{\infty}$, em que,

$$
\varepsilon_{\infty}=\varepsilon(\infty)=\sigma_{0} / \xi_{\infty}
$$

Este comportamento é descrito como "elástico retardado" e, portanto, o Modelo de Kelvin representa o comportamento à fluência de materiais reais para uma primeira aproximação.

Por outro lado, durante o ensaio de relaxação, a deformação aplicada é constante, isto é, $\varepsilon(\mathrm{t})=\varepsilon_{0}=\varepsilon\left(0^{+}\right)$para $\mathrm{t} \geq 0$. Com o arranjo dos elementos em paralelo para o Modelo de Kelvin-Voigt, é observado que o modelo não é sensível à relaxação das tensões quando a deformação é aplicada no tempo $t=0^{+}$e mantida constante. Como mostrado na figura 4.17b, quando a deformação é estabilizada no tempo $\mathrm{t}=\mathrm{t}_{1}$, as tensões são relaxadas imediatamente para certo valor e, então, permanece constante.

A recuperação do material, quando removidas as tensões atuantes, é obtida a partir da integração da equação (4.26), para uma tensão nula. A equação (4.32) é o resultado dessa integração e a figura 4.18 ilustra a recuperação para o modelo em questão.

$$
\varepsilon(\mathrm{t})=\varepsilon^{\prime} \cdot \exp \left(-\frac{\xi}{\eta}\right) \mathrm{t}
$$



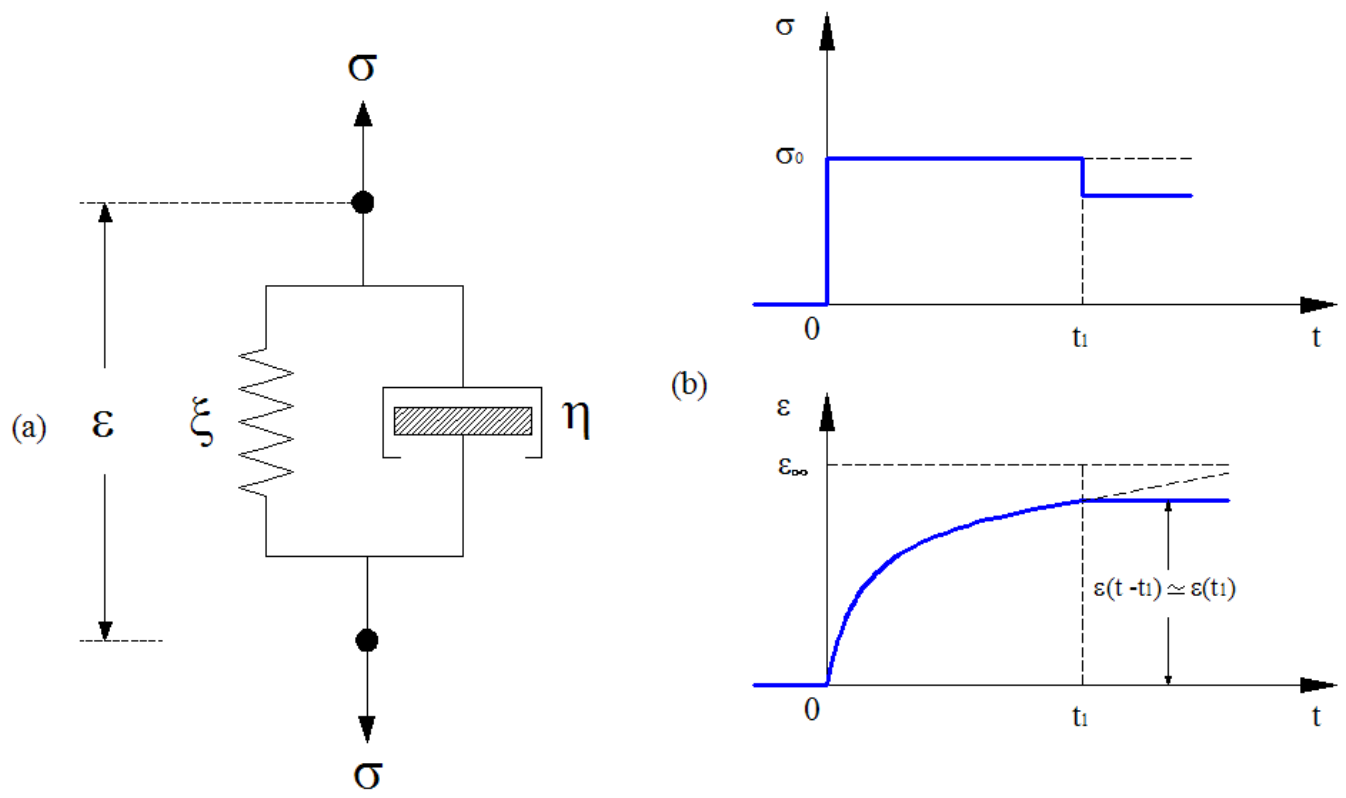

(b)

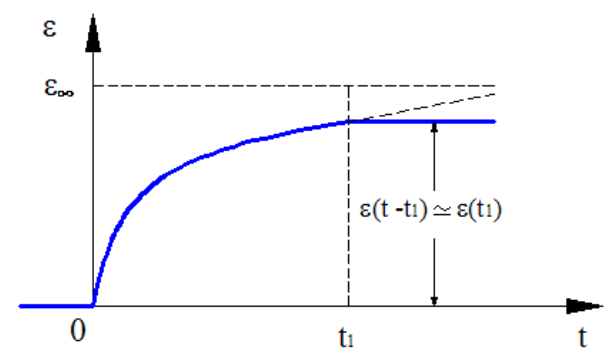

Figura 4.17. Modelo de Kelvin-Voigt: (a)modelo físico; (b)resposta da fluência e relaxação incompleta para $\mathrm{t}>\mathrm{t}_{1}$. Fonte: HADDAD, 1995

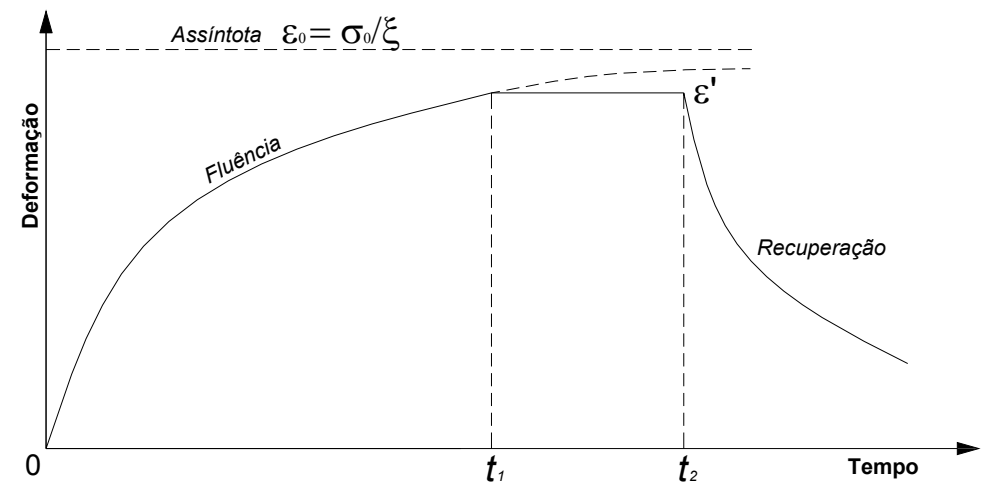

Figura 4.18. Recuperação para o Modelo de Kelvin-Voigt. Fonte: CRAWFORD, 1987

c) Modelo de Três Elementos (M.T.E.)

Este modelo consiste em uma mola em série com o elemento Kelvin-Voigt. A figura 19a esquematiza o modelo físico.

Com referência à figura $4.19 a$, as respostas de ambas as partes do modelo são expressas como:

$$
\sigma=\xi \cdot \varepsilon_{\mathrm{s}}, \sigma=\xi^{\prime} \cdot \varepsilon_{\mathrm{d}}^{\prime}+\eta \cdot \dot{\varepsilon}_{\mathrm{d}}
$$

A partir da equação (4.33) e utilizando a transformada de Laplace, a seguinte equação é obtida:

$$
\left(\xi+\xi^{\prime}\right) \sigma+\eta \dot{\sigma}=\xi \xi^{\prime} \varepsilon+\xi \eta \dot{\varepsilon}
$$




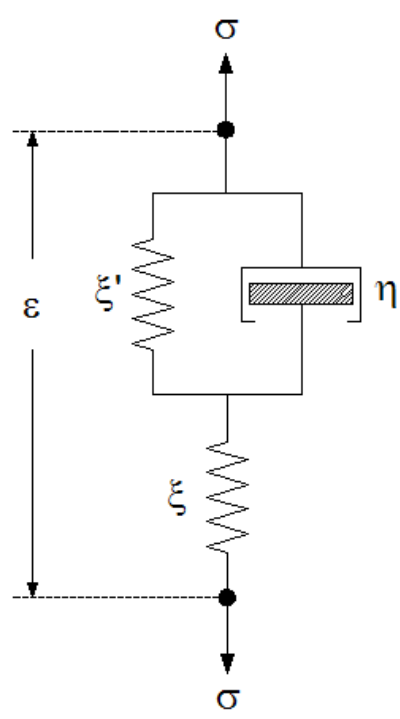

(a)
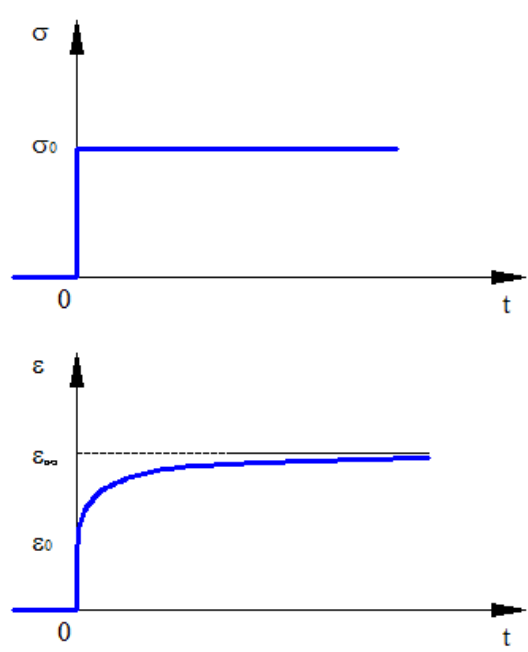

(b)

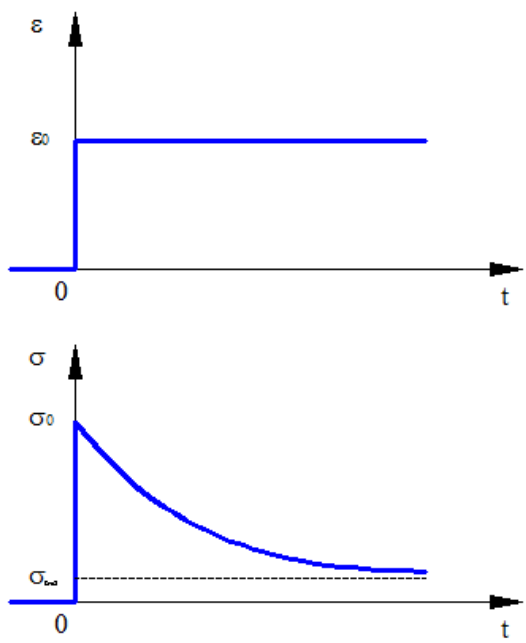

(c)

Figura 4.19. M.T.E.: (a) modelo físico; (b) fluência; (c) relaxação. Fonte: HADDAD, 1987

Na fase de fluência, pode ser mostrado que:

$$
\begin{aligned}
& \varepsilon(\mathrm{t})=\frac{\sigma_{0}}{\zeta_{1}}\left\{\lambda[1-\exp (-\mathrm{t} / \lambda)]+\zeta_{2} \exp (-\mathrm{t} / \lambda)\right\} \\
& \zeta_{1}=\frac{\xi \eta}{\xi+\xi^{\prime}}, \zeta_{2}=\frac{\eta}{\xi+\xi^{\prime}}
\end{aligned}
$$

A resposta da fluência do M.T.E. é demonstrada na figura 4.19b. O modelo descreve uma elasticidade instantânea como mostrada na equação (4.37).

$$
\varepsilon_{0}=\varepsilon\left(0^{+}\right)=\frac{\sigma_{0} \zeta_{2}}{\zeta_{1}}=\frac{\sigma_{0}}{\xi}
$$

Em seguida, tem-se um comportamento elástico assintótico dado por:

$$
\begin{aligned}
& \varepsilon_{\infty}=\varepsilon(\infty)=\frac{\sigma_{0}}{\xi_{\infty}} \\
& \xi_{\infty}=\frac{\xi \xi^{\prime}}{\xi+\xi^{\prime}}
\end{aligned}
$$

Para a fase de relaxação, a equação (4.33) assume, utilizando a transformada de Laplace, a seguinte expressão:

$$
\begin{aligned}
& \sigma(t)=\xi_{\infty} \varepsilon_{0}\left[1-\exp \left(-t / \lambda^{\prime}\right)\right]+\sigma_{0} \exp \left(-t / \lambda^{\prime}\right) \\
& \lambda^{\prime}=\frac{\eta}{\xi+\xi^{\prime}}
\end{aligned}
$$

Como ilustrado na figura 4.19c, o modelo relaxa gradualmente para o valor de:

$\sigma_{\infty}=\sigma(\infty)=\xi_{\infty} \varepsilon$ 
d) Modelo Associado: Maxwell e Kelvin-Voigt em série

Os modelos (a) e (b) descritos anteriormente são uma aproximação inicial do comportamento viscoelástico. No entanto, a simplicidade leva-os a deficiências na descrição de fenômenos como fluência, relaxação e recuperação do material.

O Modelo de Maxwell, apesar de apresentar uma descrição razoável da relaxação dos plásticos, é bastante pobre na representação da fluência e da recuperação do material. Já o Modelo de Kelvin não considera a relaxação, mas apresenta, de forma aceitável, os fenômenos da fluência e da recuperação (CRAWFORD, 1987).

Uma maneira de obter um modelo de previsão mais próximo do comportamento real é a associação de dois ou mais modelos. Com esse intuito, associou-se em série - Modelo de Maxwell ao de Kelvin, garantindo uma representação aceitável dos fenômenos comuns aos materiais plásticos - a fluência, a relaxação e a recuperação do material. As figuras 4.20 (a, b) ilustram o modelo associado e os diagramas correspondentes à deformação por fluência, à relaxação das tensões e à recuperação do material ao longo do tempo.

As relações constitutivas permanecem iguais às mostradas nas equações (4.3) e (4.4). A deformação total do sistema é dada a seguir.

$\varepsilon=\varepsilon_{\mathrm{s}}+\varepsilon_{\mathrm{d}}+\varepsilon_{\mathrm{k}}$

$\varepsilon_{\mathrm{s}}$ é a deformação correspondente à mola do Modelo de Maxwell,

$\varepsilon_{\mathrm{d}}$ é a deformação correspondente ao amortecedor do modelo de Maxwell e

$\varepsilon_{\mathrm{k}}$ é a deformação correspondente ao modelo de Kelvin.

A equação que representa o fenômeno da fluência, quando o material é submetido a uma tensão constante $\sigma_{0}$, é a soma das parcelas de deformação por fluência do Modelo de Maxwell e do Modelo de Kelvin-Voigt. Seguem as equações. (4.19) e (4.29) reescritas para o Modelo Associado.

$$
\begin{aligned}
& \varepsilon_{M}(t)=\frac{\sigma_{0}}{\xi}\left(1+\frac{t}{\lambda}\right) \\
& \varepsilon_{K}(t)=\frac{\sigma_{0}}{\xi^{\prime}} \cdot\left[1-\exp \left(-t / \lambda^{\prime \prime}\right)\right] \\
& \lambda^{\prime \prime}=\eta^{\prime} / \xi^{\prime}
\end{aligned}
$$

Dessa forma, a equação da deformação por fluência é dada por:

$$
\varepsilon(\mathrm{t})=\frac{\sigma_{0}}{\xi}\left(1+\frac{\mathrm{t}}{\lambda}\right)+\frac{\sigma_{0}}{\xi^{\prime}} \cdot\left[1-\exp \left(-\mathrm{t} / \lambda^{\prime \prime}\right)\right]
$$




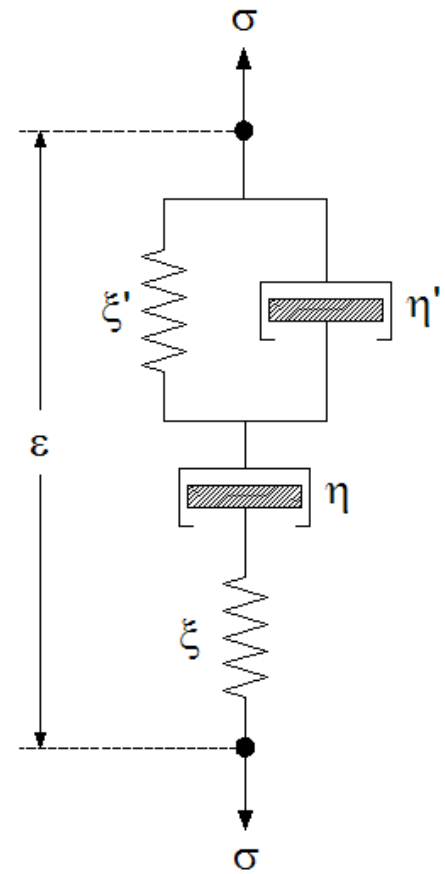

(a)
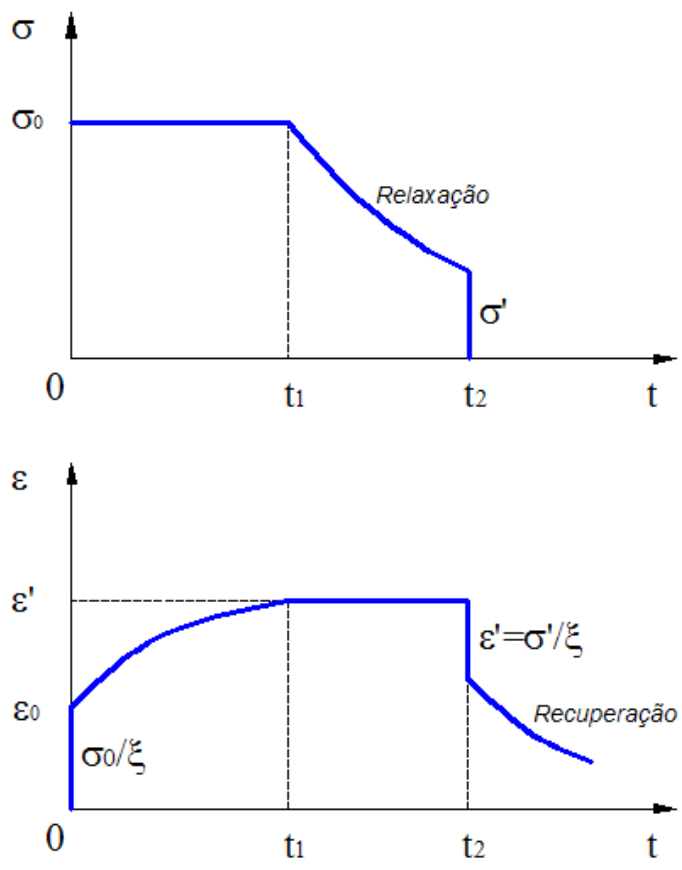

(b)

Figura 4.20. Modelo de Maxwell e de Kelvin em série. Fonte: CRAWFORD, 1987

Assim como a fluência, a recuperação e a relaxação do material são uma soma dos efeitos obtidos nos modelos de Maxwell e de Kelvin. Dessa forma, as equações que representam a recuperação e a relaxação são mostradas nas equações (4.47) e (4.48), respectivamente.

$$
\begin{aligned}
& \varepsilon(\mathrm{t})=\varepsilon^{\prime} \cdot\left[1+\exp \left(-\mathrm{t} / \lambda^{\prime \prime}\right)\right] \\
& \sigma(\mathrm{t})=\sigma_{0} \cdot \exp (-\mathrm{t} / \lambda) \\
& \varepsilon^{\prime}=\sigma^{\prime} / \xi \text { é a deformação elástica instantânea do modelo resultante do }
\end{aligned}
$$

descarregamento da tensão $\sigma^{\prime}$. No caso da figura $4.20 \mathrm{~b}$, corresponde à deformação elástica no tempo $t_{2}$.

Segundo Crawford (1987), a resposta exponencial de previsão dos modelos não é uma representação verdadeira da complexa resposta viscoelástica dos materiais poliméricos. No entanto, é uma aproximação aceitável do comportamento real. Outros elementos podem ser adicionados ao modelo, tornando melhor a aproximação e, ao mesmo tempo, tornando-se matematicamente mais complexo.

\subsubsection{Modelos Mecânicos Generalizados}

a) Modelo Generalizado de Maxwell

Neste caso, as unidades básicas de Maxwell são associadas em paralelo, como mostrado na figura 4.21 . 
Com referência à figura 4.21, considera-se um Modelo Generalizado de Maxwell com $\mathrm{N}$ diferentes elementos de Maxwel arranjados em paralelo. Fazendo $\mathrm{i}=1,2, \ldots, \mathrm{N}$ denotar uma unidade de Maxwell, a deformação total no modelo generalizado é dada por:

$$
\varepsilon=\varepsilon_{\mathrm{i}}
$$

A tensão total é dada por:

$$
\sigma=\sum_{\mathrm{i}=1}^{\mathrm{N}} \sigma_{\mathrm{i}}
$$

A tensão não é dividida igualmente, isto é, $\sigma_{1} \neq \sigma_{2} \neq \sigma_{3} \neq \ldots \neq \sigma_{\mathrm{N}}$. A partir das equações (4.13) e (4.49), pode ser mostrado que:

$\dot{\varepsilon}_{\mathrm{i}}(\mathrm{t})=\xi_{\mathrm{i}}^{-1}\left(\mathrm{~d}_{\mathrm{t}}+\lambda_{\mathrm{i}}^{-1}\right) \sigma_{\mathrm{i}}=\dot{\varepsilon}(\mathrm{t})$

$d_{t}$ designa o operador de derivação no tempo, isto é, $d_{t}=d / d t$ e

$\lambda_{\mathrm{i}}=\eta_{\mathrm{i}} / \xi_{\mathrm{i}}$

Dessa forma,

$$
\sigma(\mathrm{t})=\sum_{\mathrm{i}=1}^{\mathrm{N}} \xi_{\mathrm{i}}\left(\mathrm{d}_{\mathrm{t}}+\lambda_{\mathrm{i}}^{-1}\right)^{-1} \dot{\varepsilon}(\mathrm{t})
$$

Além disso, a função relaxação para o Modelo Generalizado de Maxwell é dada por:

$$
R(t)=\sum_{i=1}^{N} \xi_{i} \exp \left(-t / \lambda_{i}\right)
$$

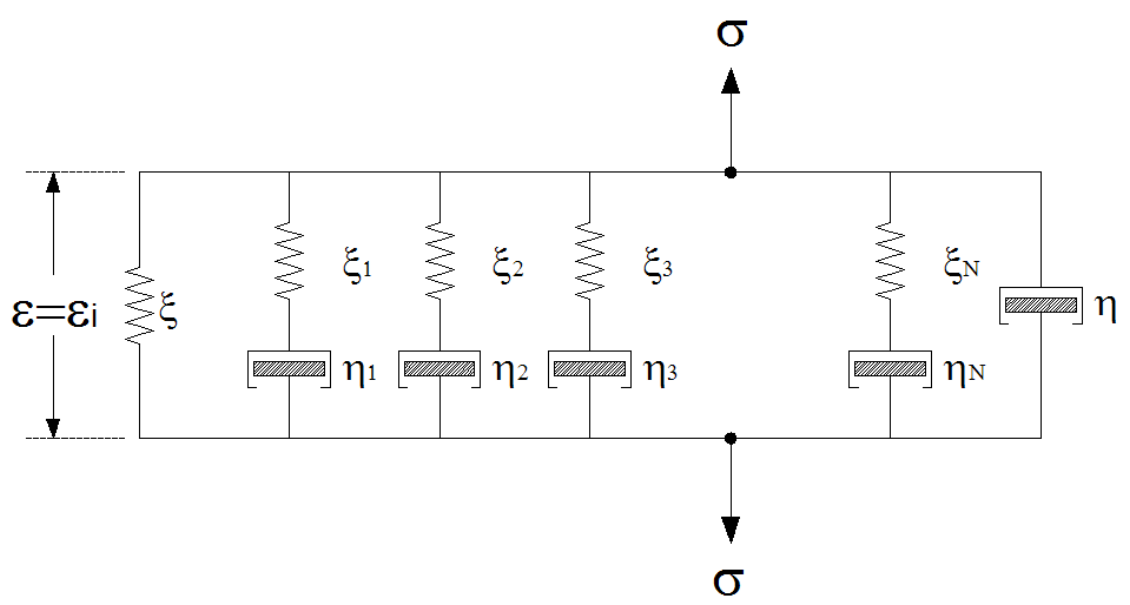

Figura 4.21. Modelo Generalizado de Maxwell. Fonte: HADDAD, 1995

b) Modelo Generalizado de Kelvin-Voigt

$\mathrm{Na}$ figura 4.22, N elementos de Kelvin-Voigt são associados em série para formar o Modelo Generalizado de Kelvin-Voigt. 


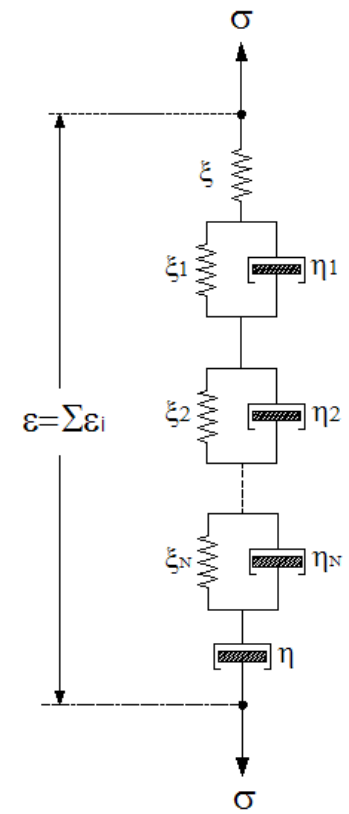

Figura 4.22. Modelo Generalizado de Kelvin-Voigt. Fonte: HADDAD, 1995

Neste caso, a tensão em cada elemento é a mesma, isto é, $\sigma_{1}=\sigma_{2}=\sigma_{3}=\ldots=\sigma_{\mathrm{N}}$. Deste modo, pode ser mostrado, com referência à equação (4.26), que:

$$
\begin{aligned}
& \sigma(\mathrm{t})=\xi_{\mathrm{i}}\left(1+\mathrm{d}_{\mathrm{t}} \lambda_{\mathrm{i}}\right) \varepsilon_{\mathrm{i}}(\mathrm{t}) \\
& \varepsilon(\mathrm{t})=\sigma(\mathrm{t}) \sum_{\mathrm{i}=1}^{\mathrm{N}} \xi_{\mathrm{i}}^{-1}\left(1+\mathrm{d}_{\mathrm{t}} \lambda_{\mathrm{i}}\right)^{-1}
\end{aligned}
$$

Além do mais, com referência à equação (4.30), a função fluência do Modelo Generalizado de Kelvin-Voigt pode ser escrito como:

$$
\mathrm{F}(\mathrm{t})=\sum_{\mathrm{i}=1}^{\mathrm{N}} \xi^{-1}\left[1-\exp \left(-\mathrm{t} / \lambda_{\mathrm{i}}\right)\right]
$$

\subsubsection{O Princípio da Superposição de Williams, Landel e Ferry}

Williams, Landel e Ferry imaginaram que um comportamento viscoelástico equivalente dos plásticos podia ser obtido quando se aumentava a temperatura para um mesmo carregamento ou quando se aumentava o carregamento e mantinha-se a temperatura. Eles, então, postularam um princípio de superposição baseado no tempo e nas tensões solicitantes. No entanto, este método somente corrigia curvas de fluência de referência já existentes para curvas novas, para diferentes temperaturas ou carregamentos. O modelo também era limitado, pois não era possível modelar o aumento da deformação por fluência com o tempo (LAl e BAKKER, 1995).

A equação de WLF é, tipicamente, aplicada em polímeros amorfos na região entre $T_{g}$ e $T_{g}+100^{\circ} \mathrm{C}$. A equação para a correção do tempo a diferentes temperaturas, pode ser representada como: 


$$
\log \mathrm{a}_{\mathrm{T}}=\frac{-\mathrm{c}_{1}\left(\mathrm{~T}-\mathrm{T}_{\text {ref }}\right)}{\mathrm{c}_{2}+\mathrm{T}-\mathrm{T}_{\mathrm{ref}}}
$$

$\mathrm{a}_{\mathrm{T}}$ é o fator de correção do tempo, $\mathrm{T}_{\text {ref }}$ é a temperatura de referência e $\mathrm{T}$ é a temperatura para a qual o fator de correção é desejado. As constantes $c_{1}$ e $c_{2}$ são dependentes do material.

Num modelo viscoelástico, os dois principais elementos utilizados são a mola, um componente elástico que obedece à lei de Hooke, e um amortecedor, um componente dependente do tempo que obedece à lei de Newton da viscosidade. $\mathrm{O}$ modelo mais simples, que é sensível a todos os fenômenos da viscoelasticidade, é o Modelo de Bürger, ou Modelo Associado, consistindo de um elemento de Maxwell em paralelo a um elemento de Kelvin-Voigt. Assume-se, para as tensões e deformações transientes, uma correspondência linear. A relação entre as tensões e as deformações é obtida a partir da função de conformação da fluência, $F(t)$, mostrada a seguir.

$$
\mathrm{F}(\mathrm{t})=\left[\frac{1}{\xi_{\mathrm{m}}}+\frac{\mathrm{t}}{\eta_{\mathrm{m}}}+\frac{1}{\xi_{\mathrm{k}}}\left(1-\mathrm{e}^{-\mathrm{t} / \lambda_{\mathrm{k}}}\right)\right]
$$

Um procedimento simples para a determinação das constantes é obtido a partir da análise de uma curva da função conformação da fluência versus tempo. $O$ procedimento é descrito a seguir e esquematicamente mostrado na figura 4.23.

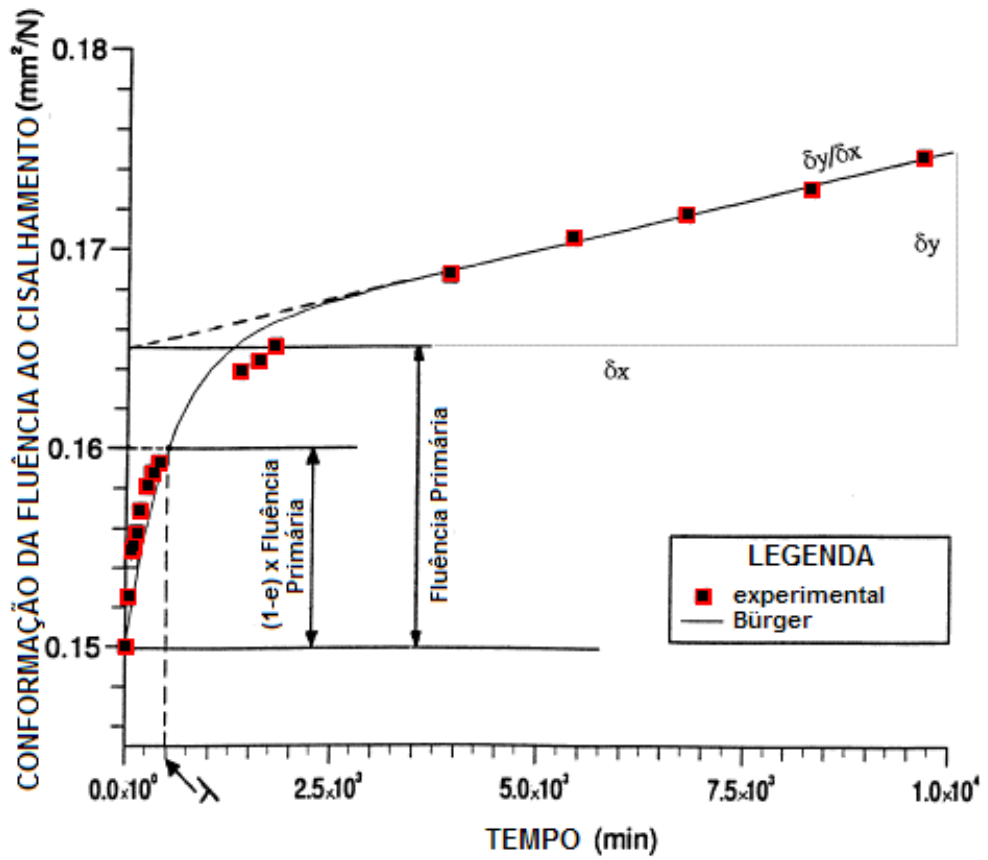

Figura 4.23. Curva conformação da fluência ao cisalhamento versus tempo. 
No tempo $t=0$, a função conformação da fluência é igual ao valor da conformação estática e $\mathrm{F}(\mathrm{t})=1 / \xi_{\mathrm{m}}$. A tangente da curva no estágio linear da fluência determina a constante $\eta_{\mathrm{m}}$, sendo a tangente igual a $1 / \eta_{\mathrm{m}}$. A constante $\xi_{\mathrm{k}}$ pode ser determinada estendendo a reta da fluência linear até o eixo vertical com $t=0$. $O$ valor correspondente à diferença entre a conformação da fluência estática e o ponto onde toca a reta estendida da fluência linear equivale ao valor de $1 / \xi_{\mathrm{k}}$.

O valor de $\lambda_{\mathrm{k}}=\eta_{\mathrm{k}} / \xi_{\mathrm{k}}$ pode ser obtido a partir do tempo de relaxação $\lambda_{\mathrm{k}}$. Como o valor de $\left(1-\mathrm{e}^{\lambda / \lambda}\right)$ é sempre igual a 0,632 , e a fluência primária é correspondente ao componente Kelvin-Voigt, o tempo equivalente a, aproximadamente, 63,2\% dessa fluência é igual a $\lambda_{k}$. A figura 1 ilustra melhor a obtenção dessa constante.

O Modelo de Bürger é linear viscoelástico, o que implica que, para qualquer nível de tensão ou tempo de fluência, as constantes viscoelásticas permanecem as mesmas. Para as aplicações não-lineares, Bürger pode ser utilizado se for conhecida a variação das constantes para um determinado nível de tensões. Por isso, é necessária uma família de curvas experimentais de fluência, cobrindo uma variedade de níveis de carregamento, para determinar as constantes de viscoelasticidade. Pode ser observado que a resposta instantânea governada pela constante $\xi_{\mathrm{m}}$ é constante, enquanto as tensões solicitantes aumentam consistentemente, de acordo com a teoria linear estática da viga. O tempo de retardação $\lambda$ pode ser considerado constante enquanto $\xi_{\mathrm{k}}$ e $\eta_{\mathrm{m}}$ possuem valores que mudam significativamente com as tensões solicitantes. Equações cúbicas foram calibradas para perceber essa variação das constantes. Deve ser enfatizado que imprecisões são observadas quando as constantes são utilizadas para prever deformações em longos períodos de tempo. Essas constantes são válidas somente para aqueles tempos de fluência para mesma ordem de magnitude para os quais foram determinados (LAl e BAKKER, 1995).

Através de observações em ensaios de flexão em polímeros, foram observadas não-linearidades e, em função disso, decidiu-se investigá-las utilizando um modelo não-linear de energia, com o objetivo de observar se há uma correlação com o Modelo de Bürger. Uma forma geral da Lei de Energia, proposta por Findley $(1976,1960)$ apud Kobbe (1995), é mostrada a seguir, em termos das deformações devidas à tração.

$$
\varepsilon(\mathrm{t})=\varepsilon_{0}+\mathrm{m}\left(\frac{\mathrm{t}}{\mathrm{t}_{0}}\right)^{\mathrm{n}}
$$

$\varepsilon(\mathrm{t})$ é a deformação por fluência dependente do tempo; $\varepsilon_{0}$ é a deformação 
instantânea; m é coeficiente da deformação dependente do tempo; t é o tempo após o carregamento $\mathrm{e}_{0}$ a unidade de tempo. Dessa maneira, ambos $\varepsilon_{0}$ e $\mathrm{m}$ são dependentes das tensões aplicadas, enquanto assume-se que o exponente $\mathrm{n}$ é constante, independentemente das tensões atuantes, apesar de Dillard et al. encontrarem evidências que, para alguns materiais, essa consideração não é verdadeira. Pode-se observar que a resposta da deformação estática instantânea $\varepsilon_{0}$ é aproximadamente linear até próximo do valor da tensão de ruptura.

Adequando as constantes da Lei de Energia aos dados experimentais, observouse que o coeficiente m varia, aproximadamente, com as tensões, de acordo com uma função seno hiperbólico. Para descrever o comportamento à fluência do material para qualquer nível de tensão, os parâmetros dos modelos dependentes das tensões $\left(\varepsilon_{0}, \mathrm{~m}\right)$ podem ser substituídos por funções hiperbólicas (FINDLEY, 1960 apud KOBBE, 2005).

$$
\begin{aligned}
& \varepsilon_{0}=\varepsilon_{0}^{\prime} \operatorname{senh}\left(\frac{\sigma}{\sigma_{\varepsilon}}\right) \\
& m=m^{\prime} \operatorname{senh}\left(\frac{\sigma}{\sigma_{\mathrm{m}}}\right)
\end{aligned}
$$

$\varepsilon_{0}^{\prime}$ é a deformação instantânea referente ao nível de tensão $\sigma_{\varepsilon} ; \sigma$ é a tensão aplicada; m' é o parâmetro de fluência $m$ no nível de tensões de referência $\sigma_{m}$. Substituindo $\left(\varepsilon_{0}, \mathrm{~m}\right)$ na equação da Lei de Energia, por essas expressões hiperbólicas, a equação resultante pode ser escrita na forma a seguir.

$$
\varepsilon(\mathrm{t})=\varepsilon_{0}^{\prime} \operatorname{senh}\left(\frac{\sigma}{\sigma_{\varepsilon}}\right)+m^{\prime} \operatorname{senh}\left(\frac{\sigma}{\sigma_{\mathrm{m}}}\right)\left(\frac{\mathrm{t}}{\mathrm{t}_{0}}\right)^{\mathrm{n}}
$$

As constantes $\varepsilon_{0}^{\prime}, \sigma_{\varepsilon}, \mathrm{m}^{\prime}$ e $\sigma_{\mathrm{m}}$ são determinadas empiricamente a partir de dados coletados em diferentes níveis de tensão. Os valores de $\sigma_{\varepsilon}$ e $\sigma_{\mathrm{m}}$ são determinados com a linearização das curvas para $\varepsilon_{0}$ e $\mathrm{m}$, obtidas em ensaios para um espectro de tensões. Observa-se que esses parâmetros são independentes e, portanto, não necessariamente iguais. Os valores para $\varepsilon_{0}^{\prime}$ e m' são obtidos a partir da reta tangente da fluência referente aos dados de ensaios, por meio do procedimento da Lei dos Mínimos Quadrados. Os valores de $\varepsilon_{0}^{\prime}, \sigma_{\varepsilon}, \mathrm{m}^{\prime}, \sigma_{\mathrm{m}}$ e $\mathrm{n}$ são constantes independentes das tensões, deformações e tempo, mas permanecem função do material, temperatura, umidade e outros fatores ambientais. 
A Lei de Energia de Findley é somente válida para materiais que sofreram uma fluência primária, caracterizada pela diminuição da taxa de deformação por fluência ao longo do tempo. Para altos níveis de tensão, a taxa de fluência alcança um estado monotônico ou aumenta, passando para os estágios secundário e terciário da fluência, respectivamente.

Dessa maneira, a função seno hiperbólico pode ser utilizada para descrever essa dependência somente para valores moderados das tensões. A Lei de Energia de Findley tem-se mostrado um modelo adequado, para materiais similares àqueles já investigados, até cerca de $50-60 \%$ da resistência última.

\subsubsection{Séries de Prony}

As propriedades mecânicas de um material linear viscoelástico são usualmente determinadas a partir de ensaios de laboratório com uma excitação transiente ou senoidal.

A explícita representação analítica dessas propriedades é justificada para várias análises de engenharia. Por exemplo, na análise das tensões de um corpo-de-prova viscoelástico ou na interconversão das funções do material viscoelástico linear, nas funções de expressões analíticas viscoelásticas relevantes.

Várias expressões analíticas do comportamento viscoelástico são disponíveis. Dentre estas, são amplamente utilizadas representações utilizando séries de decaimento exponencial, comumente referidas como "Prony" ou "Dirichlet", são amplamente utilizadas.

A popularidade deve-se à excepcional eficiência computacional associada a essas funções de base exponencial. A representação do comportamento de um material viscoelástico por meio de séries de Prony tem sua base física na teoria dos modelos mecânicos de molas e amortecedores associados (POOLER, 2001).

Têm sido propostos diferentes métodos de adaptação de séries de Prony para os dados disponíveis. Schapery (1961) utiliza um "método de colocação" para ajustar as funções das séries de Prony para os dados de ensaios viscoelásticos. Cost e Becker (1970) apresentaram o método "multidados" e utilizaram-no para ajustar as funções das séries de Prony para os dados no domínio da Transformada de Laplace.

Embora esses métodos sejam simples e diretos, uma deficiência é que, geralmente, eles fornecem coeficientes das séries negativos (ou resistências mecânicas), o que é fisicamente irrealista. Coeficientes negativos são a causa primária da oscilação indesejável na reconstrução da curva da função do material. O problema de coeficientes negativos ou oscilações ocorrem especialmente quando os dados possuem uma variação significante (POOLER, 2001). 


\subsubsection{Representação das Séries de Prony}

Séries de Prony são amplamente utilizadas para representações analíticas das funções dos materiais viscoelásticos. Por exemplo, a função conformação da fluência de um sólido linearmente viscoelástico pode ser expresso como:

$$
\mathrm{F}(\mathrm{t})=\mathrm{F}_{\mathrm{g}}+\sum_{\mathrm{i}=1}^{\mathrm{N}} \mathrm{F}_{\mathrm{i}}\left(1-\mathrm{e}^{-\mathrm{t} / \mathrm{\lambda}_{\mathrm{i}}}\right)
$$

$\mathrm{F}_{\mathrm{g}}, \mathrm{F}_{\mathrm{i}}$ e $\lambda_{\mathrm{i}}$ são constantes relacionadas com uma função de conformação vítrea, uma retardação da resistência e um tempo de retardação, respectivamente. Aqui, a conformação vítrea representa o comportamento de curta duração da conformação, isto é, $F_{g}=\lim _{t \rightarrow 0} F(t)$.

A expressão matemática anterior está relacionada a um modelo mecânico conhecido por Modelo de Voigt Generalizado, que compreende molas e amortecedores lineares conectados em paralelo (Findley et al., 1976).

As vantagens do uso de séries de Prony incluem a capacidade de descrever um vasto espectro de materiais viscoelásticos e a eficiência computacional associada às funções de base exponencial (POOLER, 2001). 


\section{Análise dos Modelos de Previsão}

A seguir será feita uma comparação entre três modelos matemáticos de previsão apresentados no capítulo anterior: Maxwell, Kelvin-Voigt e Associado. Cada modelo possui uma determinada sensibilidade aos diversos fenômenos pertinentes ao comportamento viscoelástico. Essa comparação, a partir da análise de um mesmo material, fornecerá um quadro geral para a análise desses modelos de previsão.

O material utilizado para a comparação é o acrílico, um termoplástico conhecido por sua transparência e que é utilizado sob a forma de chapas, barras e tubos. É relativamente resistente ao descoloramento e ao intemperismo, sendo aplicado em lentes óticas, prismas, coberturas transparentes e refletores. A figura 5.1 mostra a sua família de curvas de fluência, necessária à obtenção das constantes dos modelos físicos adotados e foi retirada do livro Plastics Engineering (CRAWFORD, 1987)

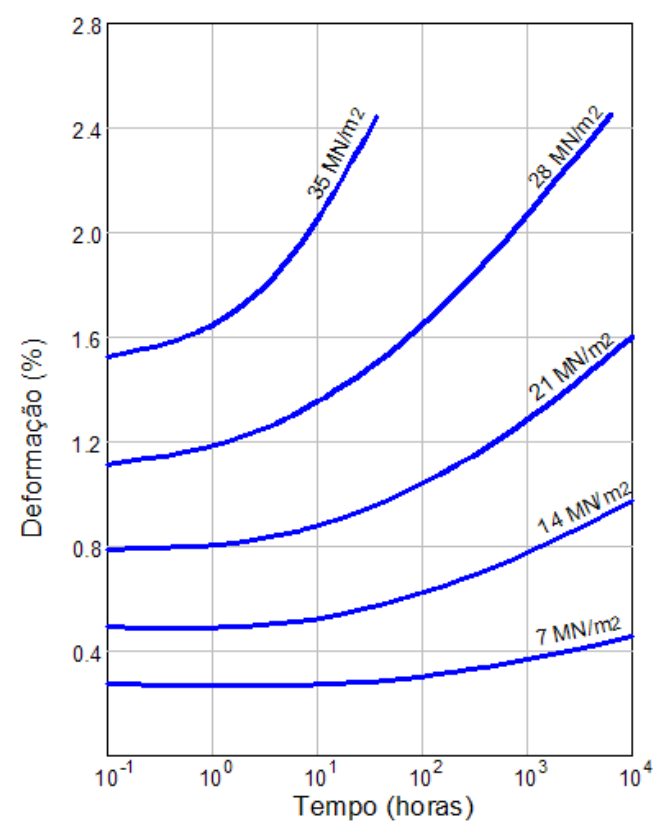

Figura 5.1. Curvas de fluência para o acrílico a $20^{\circ} \mathrm{C}$. Fonte: CRAWFORD, 1987

Ainda será feita a consideração de que o material está sendo solicitado por uma tensão de $14 \mathrm{MPa}$, a segunda curva, de baixo para cima, mostrada na figura 5.1. Se esta curva for replotada numa escala linear de tempo, sua configuração é dada na figura 5.2 . 


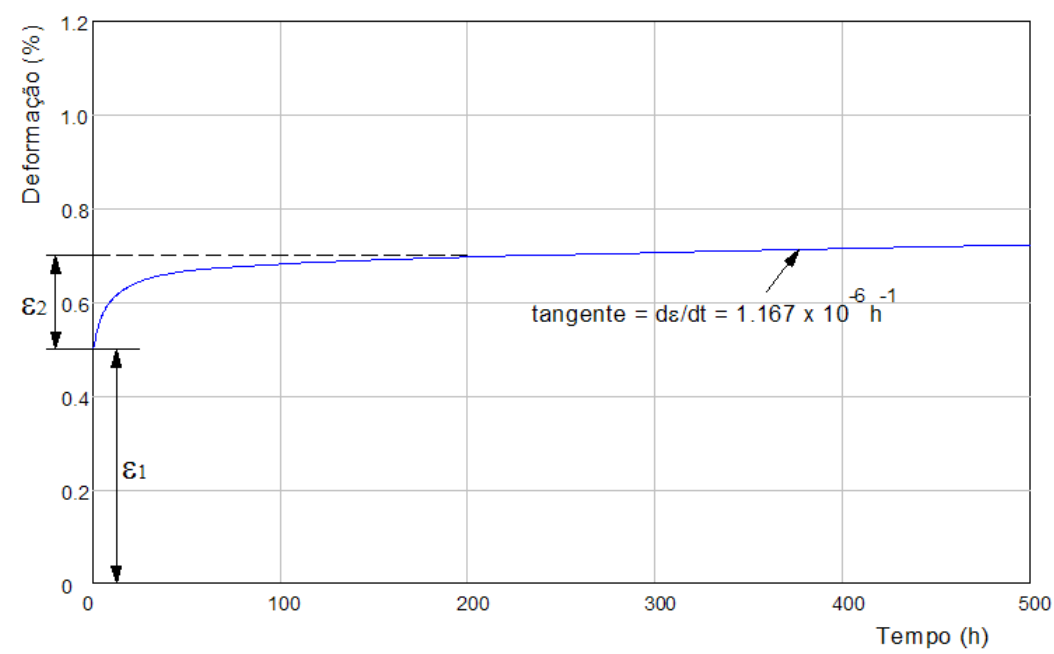

Figura 5.2. Curva de fluência para o acrílico a $20^{\circ} \mathrm{C}$ e $\sigma=14 \mathrm{MPa}$. Fonte: CRAWFORD, 1987

\subsection{MODELO DE MAXWELL}

A partir do modelo mais simples para o comportamento viscoelástico, representado por uma mola e um amortecedor em série, obtêm-se as seguintes equações para a fluência e relaxação, respectivamente.

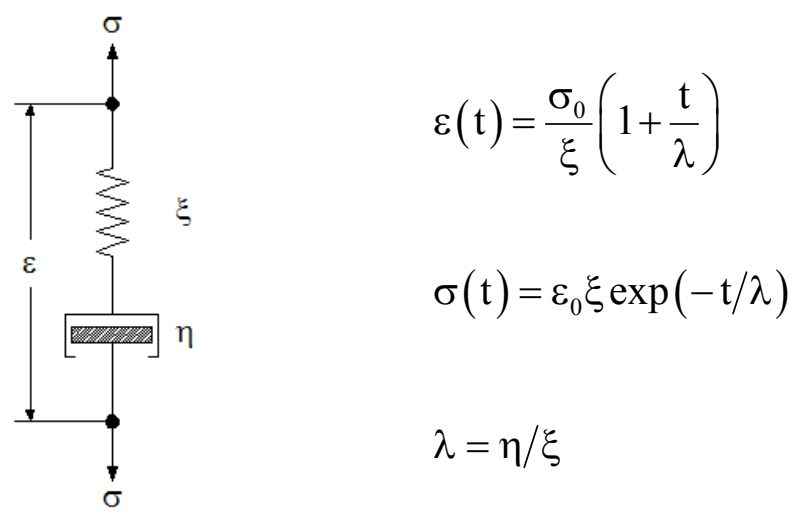

A simplicidade do Modelo de Maxwell torna-se explícita quando se analisa a sensibilidade do modelo à recuperação do material. Quando as tensões são removidas, comporta-se de maneira semelhante à de um material elástico. Apenas é considerada a recuperação instantânea, não havendo uma dependência do tempo.

\subsubsection{Obtenção das constantes do Modelo de Maxwell}

Interessa saber, para as condições impostas no início do capítulo, quais são as constantes do modelo, ou seja, quais são os valores de $\xi$ e $\eta$, respectivamente, a constante elástica da mola e o coeficiente de viscosidade do amortecedor.

Como a mola é responsável pela totalidade da deformação instantânea, o valor de $\xi$ é obtido diretamente da substituição dos valores para a equação constitutiva para uma mola ideal (mola "hookeana"), ou substituindo os valores da equação da fluência para um tempo $t=0$. 
A deformação inicial $\varepsilon_{1}$, de $0,5 \%$, levaria a valores muito imprecisos para a deformação devido à fluência. Como a resposta da fluência para esse modelo é linear, a reta da deformação dependente do tempo partiria de $\varepsilon_{1}$ e seguiria paralela e abaixo da reta aproximada mostrada na figura 5.2, cuja tangente é igual a $1,167 \cdot 10^{-6} \mathrm{~h}^{-1}$.

Uma maneira de calibrar o Modelo de Maxwell é considerando a deformação inicial como a soma de $\varepsilon_{1}$ e $\varepsilon_{2}$, ou seja, $0,667 \%$. Dessa maneira, o valor de $\xi$ é:

$$
\xi=\frac{\sigma_{0}}{\varepsilon_{1}}=\frac{14}{0,00667} \rightarrow \xi=2098 \mathrm{MN} / \mathrm{m}^{2}
$$

O valor de $\eta$, responsável pela totalidade da deformação dependente do tempo, pode ser obtido a partir do conhecimento da taxa de deformação correspondente a longos períodos de tempo. No caso estudado, a taxa de deformação é a tangente da reta aproximada da figura 5.2 .

$$
\frac{\mathrm{d} \varepsilon}{\mathrm{dt}}=1,167 \cdot 10^{-6} \mathrm{~h}^{-1}
$$

A viscosidade do amortecedor $\eta$ é obtida, então, a partir da substituição dos valores da equação constitutiva de um amortecedor newtoniano:

$$
\eta=\frac{\sigma_{0}}{\dot{\varepsilon}}=\frac{14}{1,167 \cdot 10^{-6}} \rightarrow \eta=1,2 \cdot 10^{7} \mathrm{MN} \cdot \mathrm{h} / \mathrm{m}^{2}
$$

Substituindo na equação (5.1) os valores obtidos de $\xi$ e $\eta$, resulta:

$$
\varepsilon(t)=\frac{14}{2098}\left(1+\frac{t}{5720}\right) \text { e } \sigma(t)=14 \cdot \exp (-t / 5720)
$$

$\varepsilon(\mathrm{t})$ é um valor adimensional e $\sigma(\mathrm{t})$, dado em $\mathrm{MN} / \mathrm{m}^{2}$.

Para posterior comparação, haverá um descarregamento total no tempo $\mathrm{t}=250 \mathrm{~h}$. A deformação nesse tempo, considerando a fluência é:

$$
\varepsilon(250)=\frac{14}{2098}\left(1+\frac{250}{5720}\right) \rightarrow \varepsilon(250)=0,00696
$$

A deformação residual $\varepsilon_{\text {resd }}$ é a subtração da deformação no tempo $t=250 \mathrm{~h}$ pela recuperação total da deformação elástica, ou seja:

$\varepsilon_{\text {resd }}=0,00696-0,00667=0,00029$ ou $0,029 \%$

Já para a relaxação, a equação que rege o fenômeno, de acordo com as considerações do Modelo de Maxwell, é mostrada a seguir.

$$
\sigma(\mathrm{t})=14 \cdot \exp \left(-\frac{\mathrm{t}}{5720}\right)
$$




\subsubsection{Curvas representativas do Modelo de Maxwell}

As figuras 5.3, 5.4 e 5.5 mostram, respectivamente, os comportamentos à fluência e à relaxação e a recuperação do material, para as condições dadas.

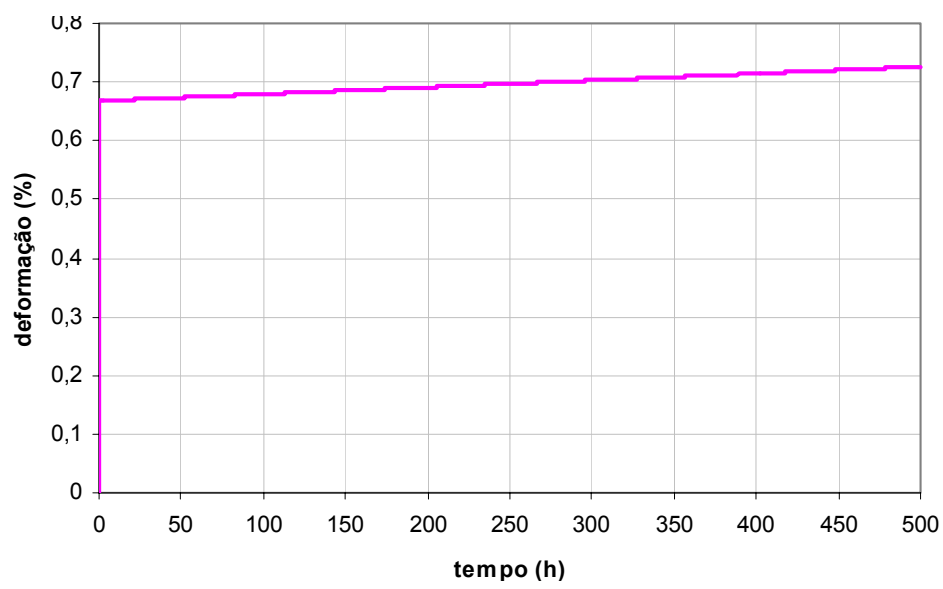

Figura 5.3. Fluência do acrílico pelo Modelo de Maxwell

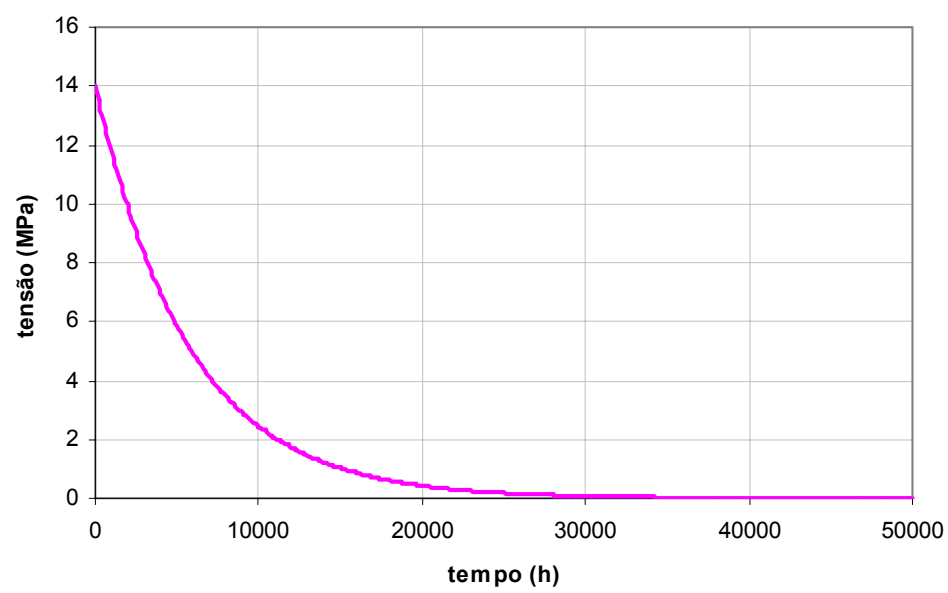

Figura 5.4. Relaxação do acrílico pelo Modelo de Maxwell

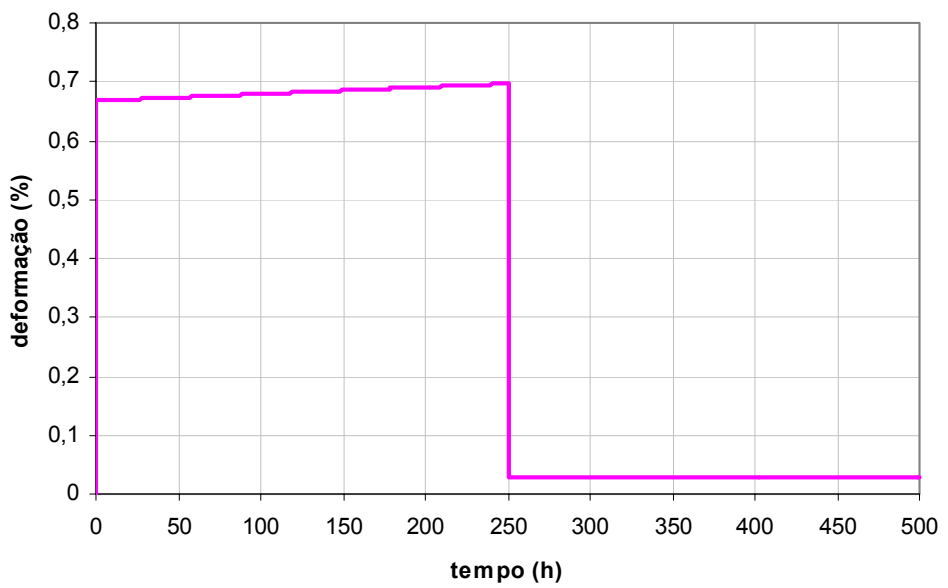

Figura 5.5. Recuperação do acrílico pelo Modelo de Maxwell 


\subsection{MODELO DE KELVIN-VOIGT}

A determinação dos valores das constantes para este modelo não se diferencia da relativa ao modelo anterior. Consistindo numa associação em paralelo da mola e do amortecedor, o Modelo de Kelvin-Voigt expressa com mais fidelidade 0 comportamento retardado dos materiais viscoelásticos.

Como já citado no capítulo 4, o arranjo em paralelo fará com que o modelo exiba uma fluência primária (retardamento) quando carregado. Isto se deve ao fato da mola poder se estender somente tão rapidamente quanto o amortecedor. Portanto, este modelo não pode exibir um estado de fluência contínua. Também não pode demonstrar um estado de relaxação contínua das tensões. Por outro lado, se após um período de tensão uniaxial houver um descarregamento total, a mola retornará ao seu comprimento inicial, comprimindo o amortecedor durante o processo.

As equações (5.3) e (5.4) demonstram, respectivamente, os fenômenos da fluência e da recuperação para o Modelo de Kelvin-Voigt.

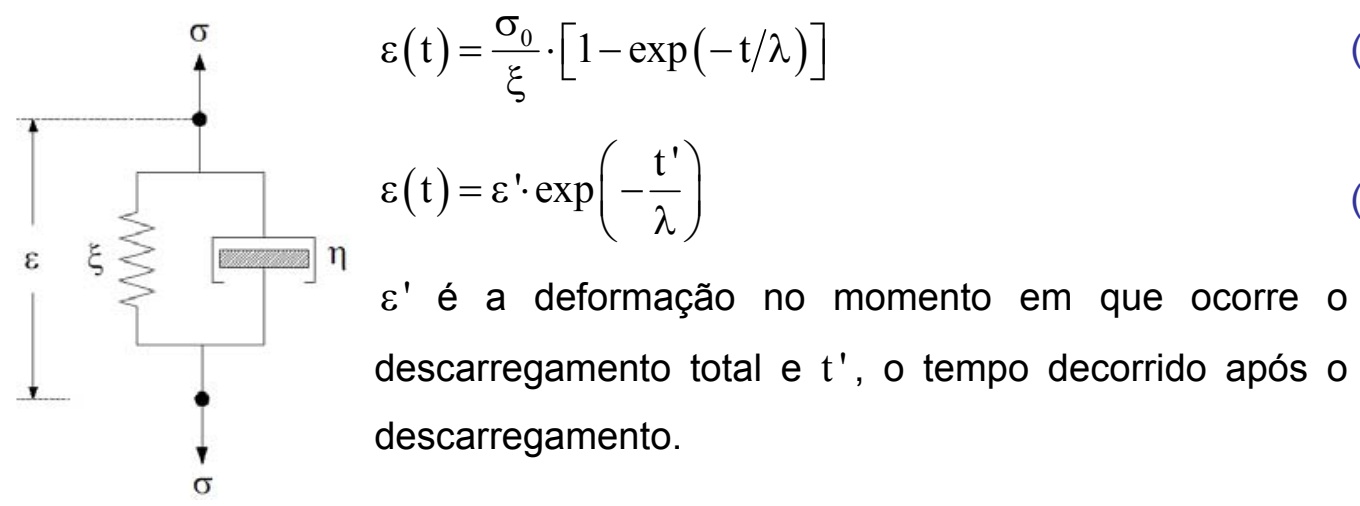

A relaxação, por sua vez, não é "percebida" pelo Modelo de Kelvin-Voigt. Ou seja, mantendo-se a deformação constante, não há a suavização das tensões, fenômeno intrínseco aos polímeros, como resultado do escorregamento das cadeias moleculares.

\subsubsection{Obtenção das constantes do Modelo de Kelvin-Voigt}

Assim como para o Modelo de Maxwell, é necessário obter as duas constantes, $\xi$ e $\eta$. As condições impostas também são as mesmas, ou seja, $\sigma=14 \mathrm{MPa}$ a uma temperatura de $20^{\circ} \mathrm{C}$.

Como a mola e o amortecedor encontram-se em paralelo, não há uma deformação elástica instantânea, quando uma tensão $\sigma_{0}$ é imposta. A configuração da curva é uma assíntota que tende ao valor de $\sigma_{0} / \xi$, quando $t \rightarrow \infty$.

Sendo a deformação elástica retardada, o valor de $\xi$ é obtido a partir da 
equação constitutiva da mola "hookeana" para a máxima deformação obtida. Ou seja, no tempo $\mathrm{t} \rightarrow \infty$, a deformação do acrílico tende ao valor de $0,7 \%$, resultando:

$$
\xi=\frac{\sigma_{0}}{\varepsilon_{\max }}=\frac{14}{0,007} \rightarrow \xi=2000 \mathrm{MN} / \mathrm{m}^{2}
$$

A constante $\eta$ do amortecedor pode ser obtida selecionando-se um par de coordenadas tempo/deformação (figura 5.2) na região em que a elasticidade retardada predomina (correspondente à região que vai do $\mathrm{t}=0$ até, aproximadamente, $\mathrm{t}=50 \mathrm{~h}$ ) e substituindo na equação da fluência. Para um $t=10 \mathrm{~h}$ tem-se uma deformação de $0,605 \%$. Substituindo na equação (5.3) os valores, obtém-se $\eta$.

$$
\varepsilon(10)=\frac{14}{2000} \cdot\left[1-\exp \left(-\frac{10 \cdot 2000}{\eta}\right)\right]=0,00605 \rightarrow \eta=10014 \mathrm{MN} \cdot \mathrm{hr} / \mathrm{m}^{2}
$$

Dessa forma, a equação para a fluência pode ser escrita em função dos valores de suas constantes:

$$
\varepsilon(\mathrm{t})=\frac{14}{2000} \cdot\left[1-\exp \left(-\frac{2000}{10014} \mathrm{t}\right)\right]
$$

Para posterior comparação, haverá um descarregamento total no tempo $\mathrm{t}=250 \mathrm{~h}$ (aproximadamente 10 dias). Considerando a fluência, a deformação nesse tempo é:

$$
\varepsilon(250)=\frac{14}{2000} \cdot\left[1-\exp \left(-\frac{2000}{10014} \cdot 250\right)\right] \rightarrow \varepsilon(250)=0,007
$$

Decorrido uma hora após o descarregamento, ou seja, $t^{\prime}=1 \mathrm{~h}$, a recuperação do material foi de:

$$
\varepsilon(1)=0,007 \cdot \exp \left(-\frac{2000}{10014}\right) \rightarrow \varepsilon(1)=0,00573
$$

A deformação residual $\varepsilon_{\text {resd }}$ é a parcela da deformação que ainda permanece, ou seja, após uma hora, ainda ocorre aproximadamente $82 \%$ da deformação total $(\varepsilon=0,007)$ ainda permanece.

\subsubsection{Curvas representativas do Modelo de Kelvin-Voigt}

As figuras 5.6, 5.7 e 5.8 mostram, respectivamente, os comportamentos à fluência e à relaxação e a recuperação do material, para as condições dadas. 


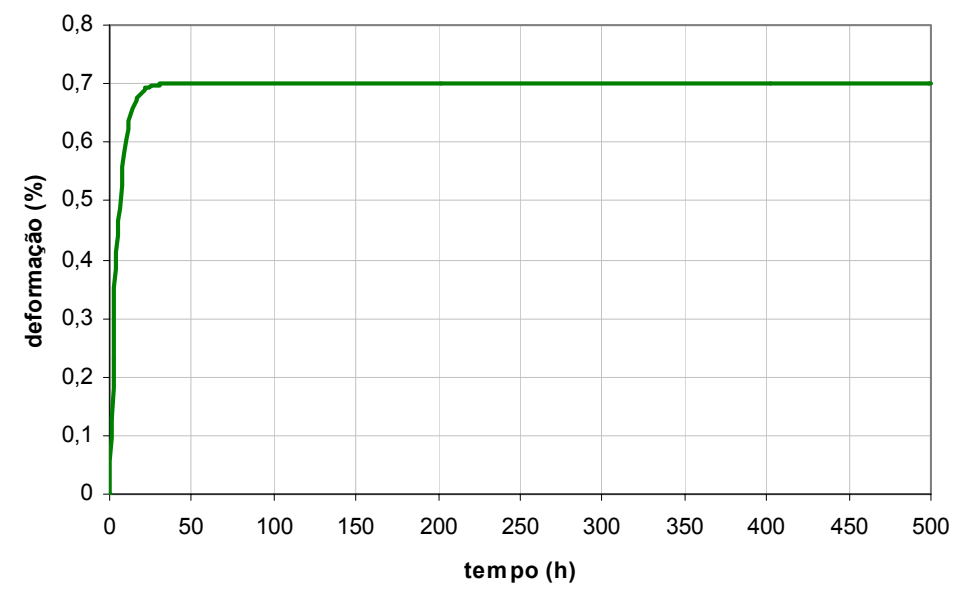

Figura 5.6. Fluência pelo Modelo de Kelvin-Voigt

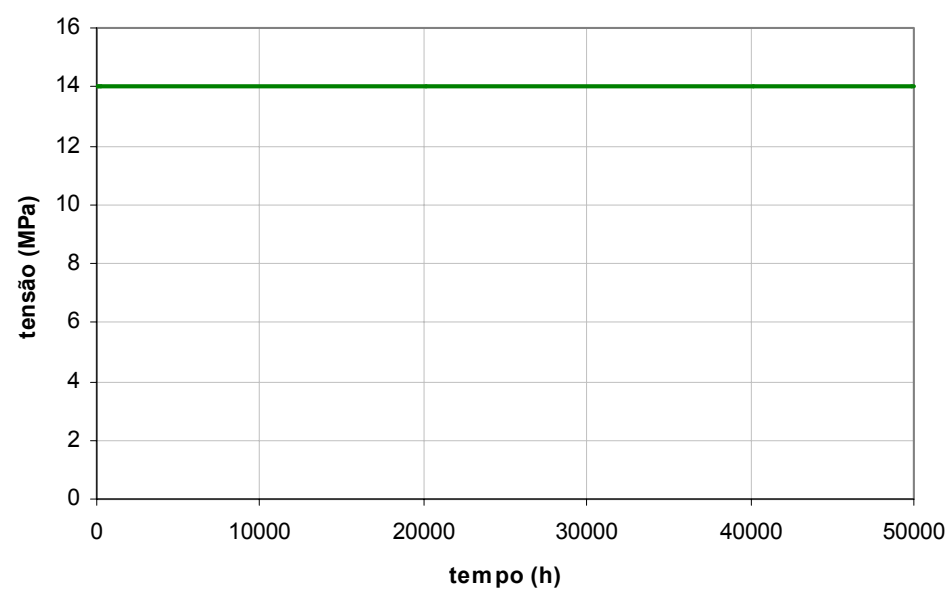

Figura 5.7. Relaxação nula pelo Modelo de Kelvin-Voigt

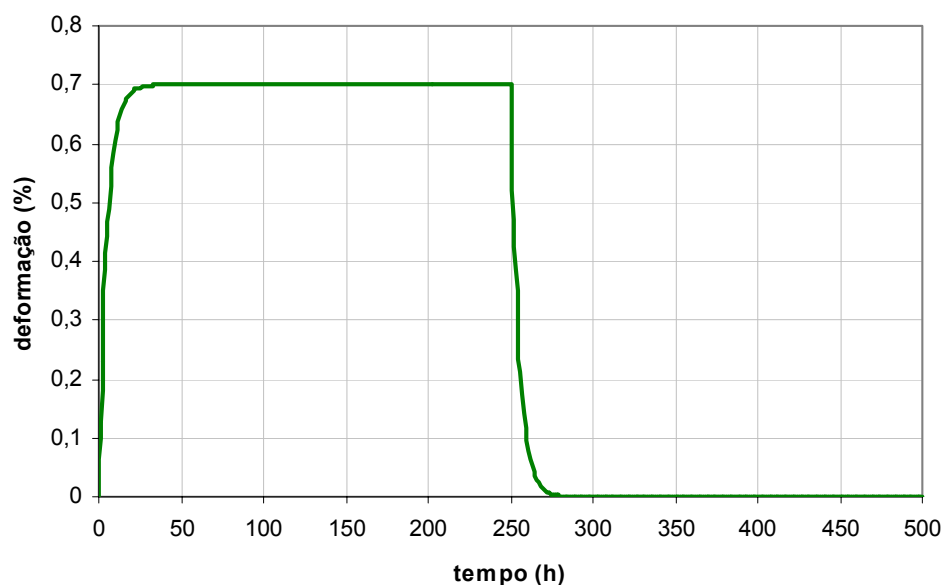

Figura 5.8. Recuperação pelo Modelo de Kelvin-Voigt

\subsection{MODELO ASSOCIADO: Maxwell e Kelvin-Voigt em série}

A equação que representa o fenômeno da fluência, quando o material é submetido a uma tensão constante $\sigma_{0}$, é a soma das parcelas de deformação por fluência do Modelo de Maxwell e do Modelo de Kelvin-Voigt. A equação (5.7) mostra a equação da fluência reescrita para o Modelo Associado. 


$$
\begin{aligned}
& \varepsilon_{M}(t)=\frac{\sigma_{0}}{\xi}\left(1+\frac{t}{\lambda}\right) \\
& \varepsilon_{K}(t)=\frac{\sigma_{0}}{\xi^{\prime}} \cdot\left[1-\exp \left(-t / \lambda^{\prime \prime}\right)\right] \\
& \lambda^{\prime \prime}=\eta^{\prime} / \xi^{\prime}
\end{aligned}
$$

Dessa forma, a equação da deformação por fluência é dada a seguir.

$$
\varepsilon(\mathrm{t})=\frac{\sigma_{0}}{\xi}\left(1+\frac{\mathrm{t}}{\lambda}\right)+\frac{\sigma_{0}}{\xi^{\prime}} \cdot\left[1-\exp \left(-\mathrm{t} / \lambda^{\prime \prime}\right)\right]
$$

As equações que representam a recuperação e a relaxação são mostradas nas equações (5.8) e (5.9), respectivamente.

$$
\begin{aligned}
& \varepsilon(\mathrm{t})=\varepsilon^{\prime} \cdot\left[1+\exp \left(-\mathrm{t} / \lambda^{\prime \prime}\right)\right] \\
& \sigma(\mathrm{t})=\sigma_{0} \cdot \exp (-\mathrm{t} / \lambda) \\
& \varepsilon^{\prime}=\sigma^{\prime} / \xi \text { é a deformação elástica instantânea do modelo resultante do } \\
& \text { descarregamento da tensão } \sigma^{\prime} \text {. }
\end{aligned}
$$

A figura 5.9 ilustra o modelo físico adotado no Modelo Associado.

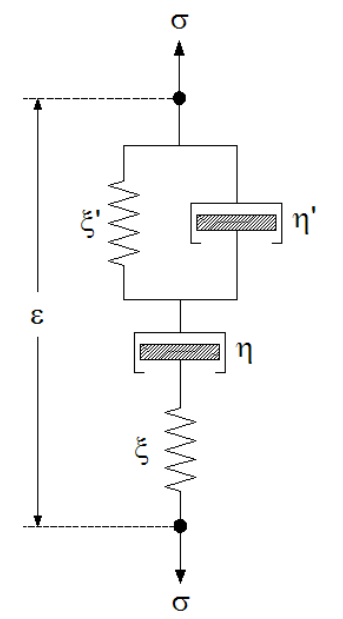

(a)

Figura 5.9. Modelo Associado

\subsubsection{Obtenção das constantes do Modelo Associado}

Para o Modelo Associado, são quatro as constantes a serem determinadas: $\xi$, $\eta, \xi^{\prime}$ e $\eta^{\prime}$.

Como o modelo é sensível à deformação instantânea, o valor de $\xi$ é obtido a partir da equação constitutiva da mola "hookeana". No gráfico da figura 5.2 , a deformação instantânea é igual a 0,5\%. 


$$
\xi=\frac{\sigma_{0}}{\varepsilon_{1}}=\frac{14}{0,005} \rightarrow \xi=2800 \mathrm{MN} / \mathrm{m}^{2}
$$

A constante $\eta$ é obtida a partir da tangente $\mathrm{d} \varepsilon / \mathrm{dt}$ na figura 5.2. No caso:

$$
\begin{aligned}
& \frac{\mathrm{d} \varepsilon}{\mathrm{dt}}=1,167 \cdot 10^{-6} \mathrm{~h}^{-1} \\
& \eta=\frac{\sigma_{0}}{\dot{\varepsilon}}=\frac{14}{1.167 \cdot 10^{-6}} \rightarrow \eta=1,2 \cdot 10^{7} \mathrm{MN} \cdot \mathrm{h} / \mathrm{m}^{2}
\end{aligned}
$$

A constante da mola $\xi^{\prime}$ do elemento Kelvin-Voigt é obtida a partir da máxima deformação retardada, como mostra a figura 5.2, igual a $0,2 \%$.

$$
\xi^{\prime}=\frac{\sigma_{0}}{\varepsilon_{2}}=\frac{14}{(0,7-0,5) \cdot 10^{-2}} \rightarrow \xi^{\prime}=7000 \mathrm{MN} / \mathrm{m}^{2}
$$

Por fim, a constante do amortecedor do elemento Kelvin-Voigt, $\eta^{\prime}$, pode ser determinada selecionando-se um par de coordenadas tempo/deformação da curva de fluência da figura 5.2, numa região onde predomina a elasticidade retardada.

Para o mesmo par utilizado no Modelo de Kelvin-Voigt, ou seja, $t=10 \mathrm{~h}$ e $\varepsilon(10)=0,605 \%$, tem-se:

$$
\begin{aligned}
& \varepsilon(10)=\frac{14}{2800}+\frac{14 \cdot 10}{1.2 \cdot 10^{7}}+\frac{14}{7000} \cdot\left[1-\exp \left(-\frac{10 \cdot 7000}{\eta^{\prime}}\right)\right]=0,0056 \\
& \eta^{\prime}=200932 \mathrm{MN} \cdot \mathrm{h} / \mathrm{m}^{2}
\end{aligned}
$$

Dessa maneira, a equações para a fluência pode ser escrita em função dos valores numéricos das constantes determinadas:

$$
\varepsilon(t)=\frac{14}{2800}\left(1+\frac{2,8 \cdot t}{12000}\right)+\frac{14}{7000}\left[1-\exp \left(-\frac{7 \cdot t}{200932}\right)\right]
$$

A equação da recuperação será obtida levando em consideração um descarregamento total no tempo $t=250 \mathrm{~h}$. Nesse instante, a deformação, considerando a fluência, possui o seguinte valor:

$$
\begin{aligned}
& \varepsilon(\mathrm{t})=\frac{14}{2800}\left(1+\frac{2,8 \cdot 250}{12000}\right)+\frac{14}{7000}\left[1-\exp \left(-\frac{7000 \cdot 250}{200932}\right)\right] \rightarrow \\
& \varepsilon(\mathrm{t})=0,00729
\end{aligned}
$$

A equação para a recuperação, nesse instante, é mostrada a seguir:

$$
\varepsilon(\mathrm{t})=0,00729 \cdot \exp \left(-\frac{7000 \cdot \mathrm{t}^{\prime}}{200932}\right)
$$

Decorrida uma hora após o descarregamento, a recuperação do material foi de: 


$$
\varepsilon(1)=0,00729 \cdot \exp \left(-\frac{7000}{200932}\right)=0,00704
$$

A deformação residual $\varepsilon_{\text {resd }}$ é a parcela da deformação que ainda permanece, ou seja, após uma hora, ainda ocorre aproximadamente $97 \%$ da deformação total $(\varepsilon=0,00729)$ ainda permanece.

Por fim, o fenômeno da relaxação é regido pela equação a seguir, de acordo com o Modelo Associado:

$$
\sigma(\mathrm{t})=14 \cdot \exp \left(-\frac{2,8 \cdot \mathrm{t}}{12000}\right)
$$

A equação da relaxação para o Modelo Associado é equivalente à do Modelo de Maxwell, haja vista que o Modelo de Kelvin-Voigt não é sensível a esse fenômeno.

\subsubsection{Curvas representativas do Modelo Associado}

As figuras 5.10, 5.11 e 5.12 mostram, respectivamente, as curvas de fluência, de relaxação e de recuperação do material, para as condições dadas.

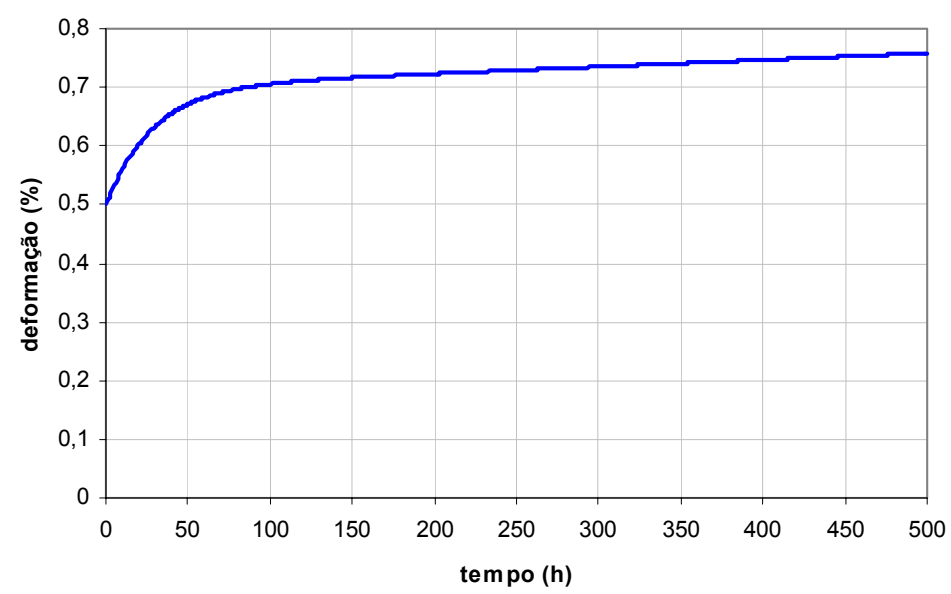

Figura 5.10. Fluência do acrílico pelo Modelo Associado

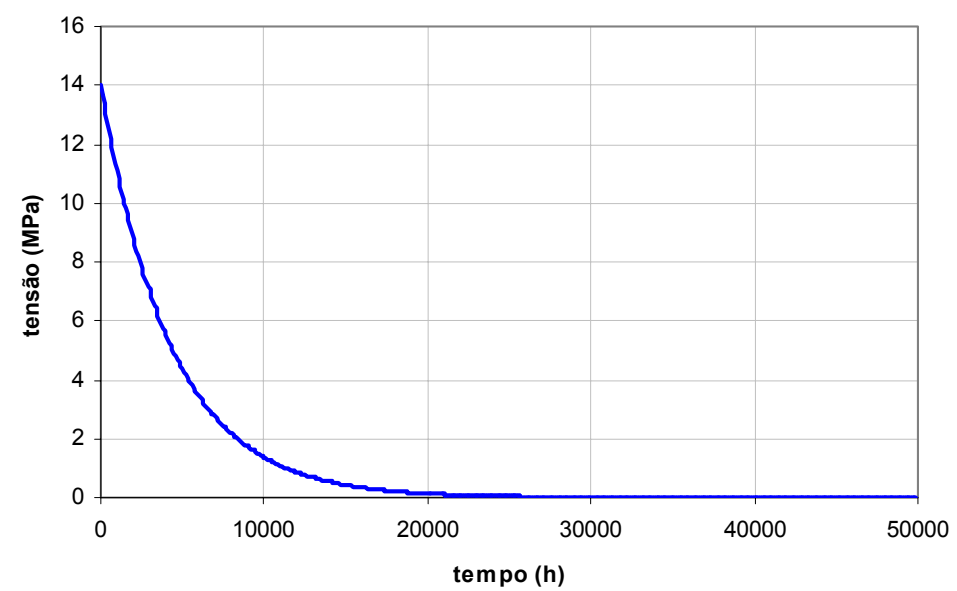

Figura 5.11. Relaxação do acrílico pelo Modelo Associado 


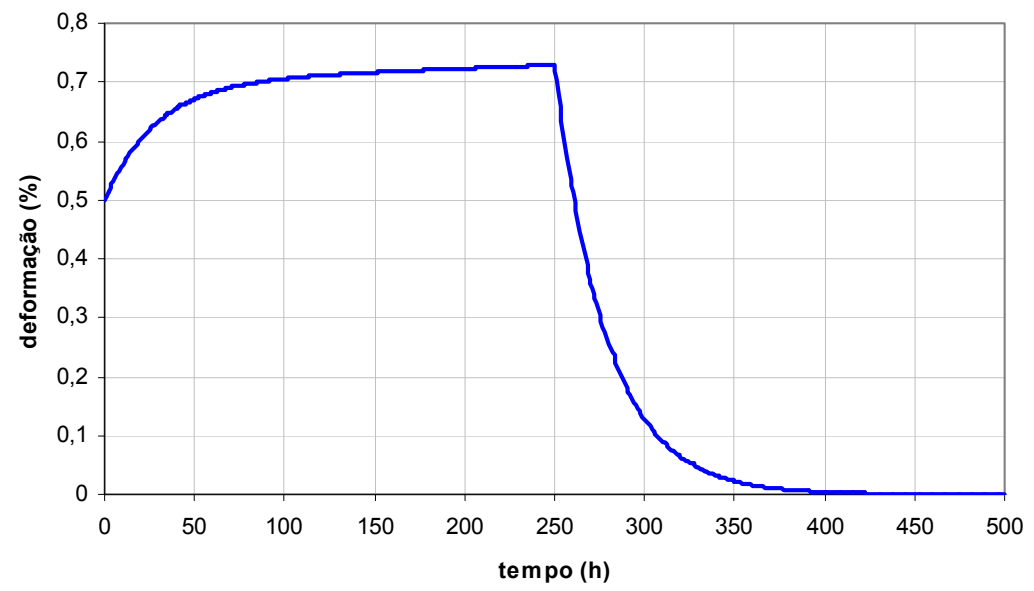

Figura 5.12. Recuperação do acrílico pelo Modelo Associado

\subsection{COMPARAÇÃO: MAXWELL, KELVIN-VOIGT E ASSOCIADO}

Os gráficos das figuras 5.13, 5.14 e 5.15 permitem uma comparação entre os modelos desenvolvidos anteriormente.
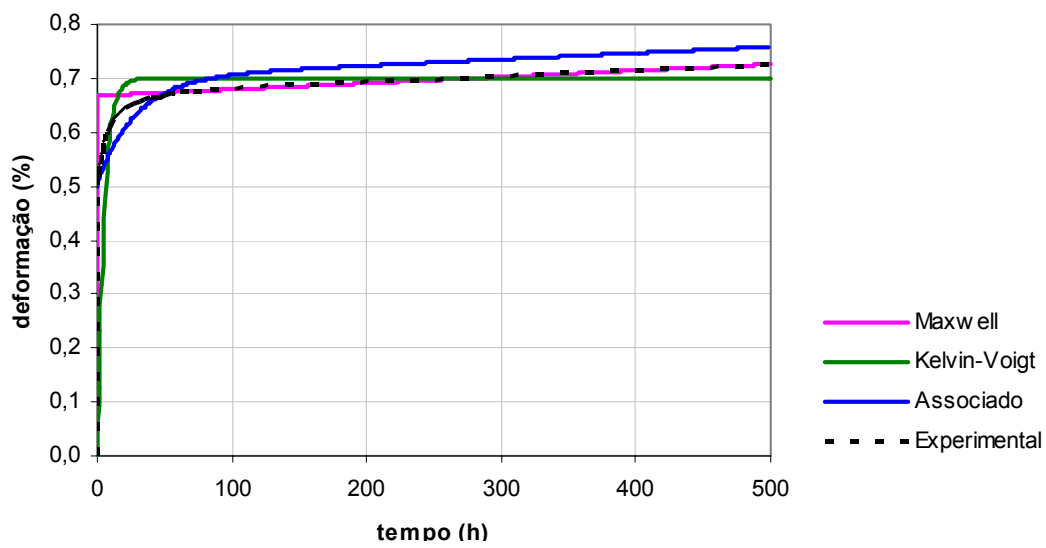

Figura 5.13. Curvas de fluência para o acrílico
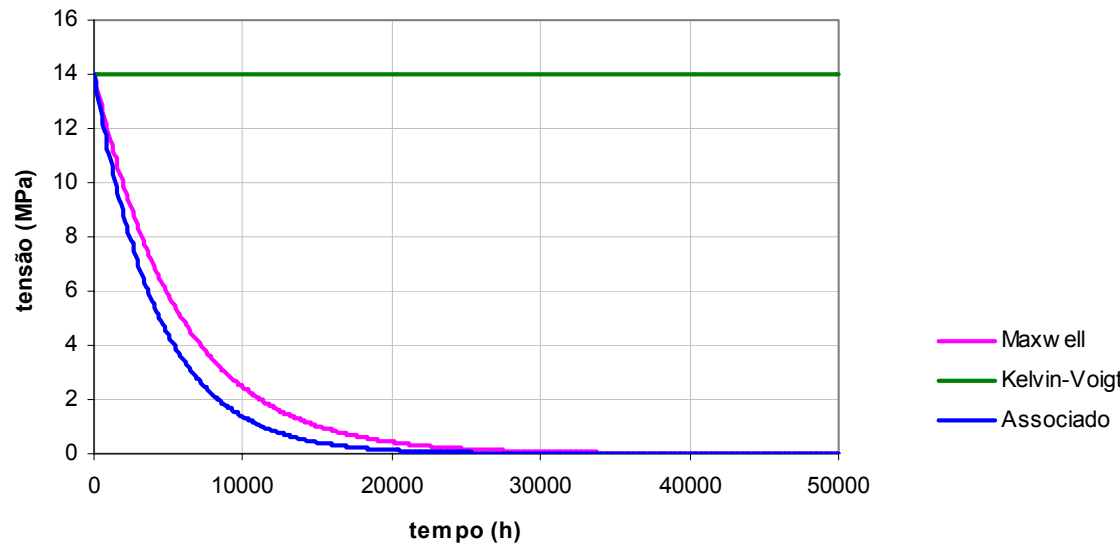

Figura 5.14. Curvas de relaxação para o acrílico 


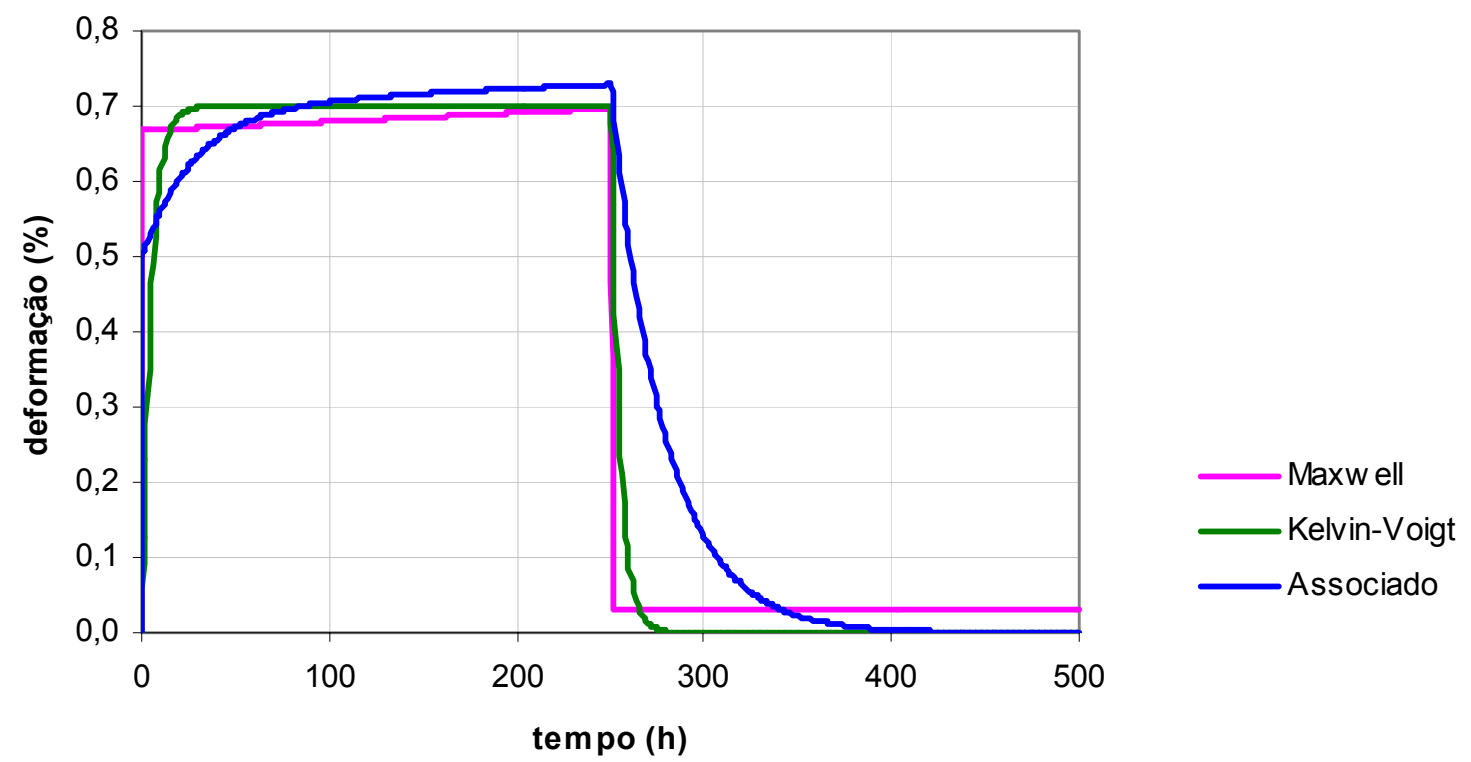

Figura 5.15. Curvas de recuperação para o acrílico

Da comparação entre os três modelos, pode-se fazer as seguintes observações:

- Quando se analisa a fluência, o Modelo de Maxwell possui uma deformação imediata elástica e, posteriormente, um crescimento linear da deformação. Isso mostra uma aproximação grosseira da realidade, cuja deformação, para longos períodos de tempo, assume um valor aproximadamente constante. O Modelo de Kelvin-Voigt, apesar de melhor representar o comportamento viscoelástico, é um modelo que rapidamente estabiliza-se num patamar, o que não ocorre na realidade, conforme os dados experimentais mostrados na figura 5.2. Este modelo também não é sensível a uma deformação instantânea, o que ocorre na realidade. Dessa maneira, o Modelo Associado é o que melhor representa o comportamento à fluência do polímero estudado, o acrílico. Por ser uma associação em série dos modelos de Maxwell e Kelvin-Voigt, é um modelo que sana algumas das deficiências dos modelos anteriores. Ou seja, possui uma deformação instantânea, que cresce ao longo do tempo, possuindo a sua curva uma aproximação bastante razoável com relação à curva de ensaio de fluência do acrílico.

- Com relação à relaxação, o Modelo de Kelvin-Voigt não a percebe, em virtude da disposição em paralelo da mola e do amortecedor. Dessa forma, não há atenuação das tensões para este modelo. Já o Modelo Associado e o Modelo de Maxwell possuem curvas equivalentes, haja vista que a sensibilidade do Modelo Associado deve-se ao elemento de Maxwell. O decaimento exponencial representa uma razoável aproximação para o fenômeno. 
- A recuperação do Modelo de Maxwell é bastante precária, pois leva em consideração somente a parcela elástica, sendo a parcela viscoelástica uma deformação irreversível, o que não ocorre na realidade. Já os modelos de Maxwell e Associado possuem suas curvas de decaimento das deformações bastante equivalentes, devendo-se também ao componente de Kelvin-Voigt no Modelo Associado.

- De uma maneira geral, os modelos possuem curvas que, apesar do traçado, tem seus valores equivalentes. São modelos que, em função da simplicidade de sua formulação, são utilizados para a composição de modelos mais complexos, como os modelos generalizados. Estes modelos são um refinamento dos modelos mais simples, pois contam com componentes de Kelvin-Voigt e/ou Maxwell em série ou em paralelo, podendo seus parâmetros serem melhor calibrados em função dos dados experimentais. 


\section{Considerações Sobre as Estruturas de Plástico}

Neste capítulo serão discutidos alguns aspectos pertinentes a um Projeto de Engenharia e, posteriormente, apresentados alguns conceitos e considerações específicos a um projeto de estruturas de material plástico.

\subsection{O PROJETO DE ENGENHARIA}

De maneira generalizada, a Engenharia é entendida como a criação de sistemas, dispositivos e processos que são concebidos para usufruto e benefício da sociedade. O meio pelos quais esses objetivos são alcançados é denominado Projeto de Engenharia. Tanto para o caso específico dos elementos estruturais de material plástico reciclado como algo mais genérico, o projeto pode ser esquematizado como uma seqüência de eventos ilustrada na figura 6.1. Pode ser observado que um projeto é um processo cíclico, em que cada etapa é alimentada e alimenta as etapas anteriores e posteriores. O objetivo mostrado na figura pode ser entendido como a realização ou satisfação de uma determinada necessidade ou desejo humano.

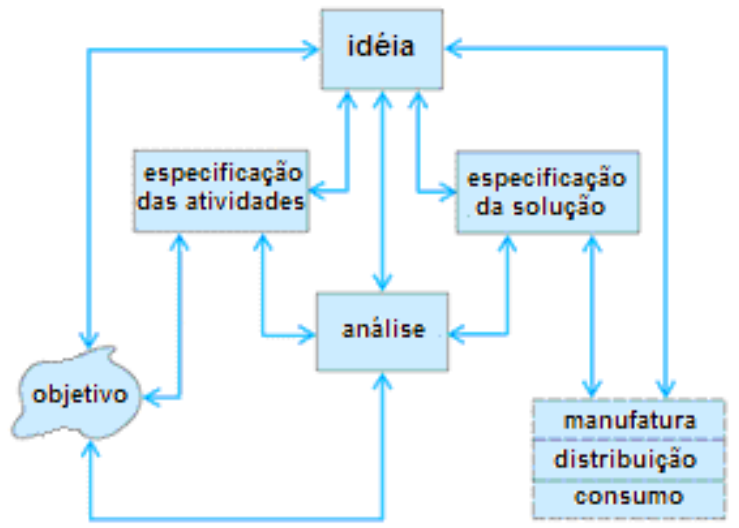

Figura 6.1. Seqüência de eventos de um projeto de engenharia. Fonte: MANN, 2002

\subsection{A DINÂMICA DE UM PROJETO DE ENGENHARIA}

Uma outra dimensão da dinâmica de um Projeto de Engenharia é o tempo dispensado em cada etapa, no desenvolvimento e elaboração do projeto. A figura 6.2 mostra o tempo como abscissa e os recursos como ordenada. Os vários estágios ou etapas de um Projeto de Engenharia estão mostrados em seqüência da esquerda para a direita. 


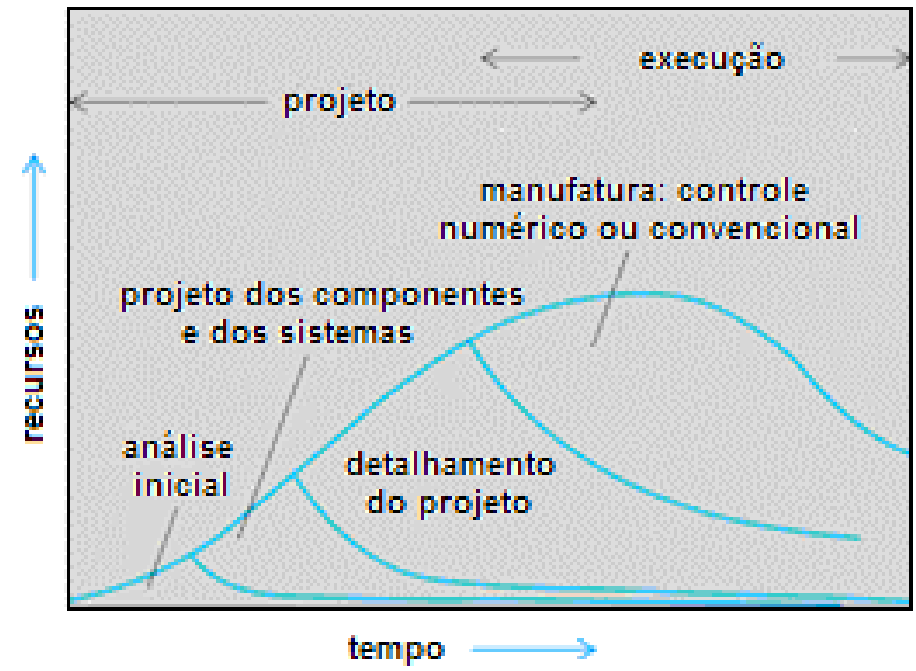

Figura 6.2. Gráfico recursos versus tempo para um projeto estrutural. Fonte: MANN, 2002

\subsection{O CONCEITO DE MATERIAL ESTRUTURAL}

Levando-se em conta o ambiente a que está submetido, um material estrutural deve ser entendido como aquele capaz de suportar forças externas por um período indefinido, mantendo, de maneira satisfatória, a sua estabilidade dimensional e o equilíbrio das forças. Não pode ser considerado um grupo bem definido e sim um espectro de possibilidades, haja vista que um material pode ser estrutural numa aplicação, mas não em outra. Por exemplo, a madeira, amplamente utilizada na construção civil, não é utilizada estruturalmente na indústria aeroespacial.

\subsection{A ESCOLHA DO MATERIAL ESTRUTURAL}

Basicamente, a escolha do material é fundamentada nos seguintes aspectos, não necessariamente na ordem apresentada:

- Técnico: o material deve possuir as propriedades mecânicas exigidas no projeto como, por exemplo, resistência à tração, à flexão, à compressão e ao impacto. As propriedades físicas como resistência à corrosão, ao ataque de microorganismos, impermeabilidade e inflamabilidade também devem ser consideradas.

- Financeiro: além da performance frente às solicitações, o material tem que ser financeiramente viável, no entanto, esse é um aspecto que pode variar bastante, a depender da importância da estrutura e da confiabilidade esperada da estrutura, bem como outros fatores subjetivos.

- Estético: outro fator preponderante, pois além da funcionalidade, uma estrutura deve ser esteticamente agradável e possibilitar um design leve e integrado com o espaço em que está inserido. No então, esse é um aspecto subjetivo, a depender da preferência do usuário. 
- Ambiental: um material deve garantir, antes de tudo, o menor impacto possível ao meio ambiente e aos usuários. Atualmente tem-se levado bastante em consideração a questão da sustentabilidade. As facilidades e benefícios que o material proporciona não mais justificam os malefícios à natureza.

- Disponibilidade: condicionado aos fatores financeiro e ambiental, a utilização de um determinado material deve levar em conta a sua abundância e/ou facilidade de extração e manufatura. Por exemplo, a disponibilidade e abundância de matéria-prima para a composição do cimento e do concreto no Brasil têm relação direta com o uso maciço de estruturas de concreto no país.

- Cultural: apesar de ter uma importância menor que os aspectos já citados, a escolha do material também é condicionada ao aspecto cultural de uma determinada sociedade, tendo como principal motivador o fator histórico.

\subsection{O PROJETO DE ENGENHARIA DE ESTRUTURAS}

Quando se introduz um novo material estrutural, deve-se sempre observar o impacto que este tem sobre o espaço em que será inserido, as especificidades do dimensionamento dos elementos estruturais e do sistema estrutural como um todo e as mudanças no processo executivo.

Por estrutura entende-se como o conjunto de elementos responsáveis pela estabilidade, pela sustentação de uma determinada edificação. Define-se como o conjunto de elementos resistentes que, diante de uma ação externa, geram reações entre si, permanecendo em equilíbrio. Se os elementos estão unidos por vínculos que transmitem tensões, de forma que por ação e reação todos os elementos resistem solidários ao esforço externo, o conjunto é uma estrutura.

O sistema estrutural, o conjunto de elementos com função estrutural pode ser considerado um sistema de transmissão de forças que permite o caminhamento de forças, utilizando-se de mecanismos internos capazes de transportar cargas desde a cobertura até as fundações.

Dessa forma, pode ser entendido como projeto estrutural a seleção dos materiais, a escolha do sistema estrutural, a definição das cargas atuantes, o dimensionamento e o detalhamento da estrutura, levando-se em conta a segurança e a funcionalidade. As fases de um projeto estrutural não seguem uma progressão rígida, mas normalmente parte-se de uma estimativa e por meio de diversos ciclos de análise e redimensionamento para se chegar ao projeto final (TOMASETTI e JOSEPH, 2002). 
De acordo com Pinheiro (2005), a concepção estrutural deve levar em consideração a finalidade da edificação e o atendimento das condições impostas pela arquitetura. O projeto arquitetônico representa, de fato, a base para a elaboração do projeto estrutural. Este deve prever o posicionamento dos elementos de forma a respeitar a distribuição dos diferentes ambientes nos diversos pavimentos ou níveis existentes.

O projeto estrutural deve ainda estar em harmonia com os demais projetos, tais como: de instalações elétricas, hidráulicas, telefonia, segurança, som, televisão, ar condicionado, computador e outros, de modo a permitir a coexistência, com qualidade, de todos os sistemas (PINHEIRO, 2005).

\subsection{O PROJETO DE ESTRUTURAS DE MATERIAL PLÁSTICO}

A proposição de um novo sistema estrutural ou a substituição parcial de elementos tradicionais por elementos de plástico reciclado deve vir seguida do estudo da mudança da arquitetura que será necessária, até para definir em quais soluções o plástico pode ser aplicado. Talvez um dos fatores mais importantes a se considerar é o vão que pode ser alcançado com essa estrutura. De certa forma, é um problema de natureza arquitetônica, e que evidencia a dependência óbvia entre estrutura e arquitetura.

Além de manter a estabilidade da edificação, o novo material deve também atender às condições de serviço a que será submetido. No caso particular dos plásticos, o fator que talvez seja o mais limitante é a temperatura. Nos materiais viscoelásticos, à medida que se aumenta a temperatura, diminui o seu módulo de elasticidade. Em se tratando de materiais estruturais, a perda de rigidez torna-se crítica, pois é indesejável o surgimento de deformações excessivas, causando desconforto aos usuários e até mesmo o colapso da estrutura.

O uso de materiais combinados ou compósitos poliméricos contorna algumas deficiências dos plásticos, como a baixa rigidez e a suscetibilidade à variação de temperatura. Esses compósitos, antes aplicados exclusivamente na indústria aeronáutica e aeroespacial, passam a ser cada vez mais utilizados na construção civil, atendendo aos desafios impostos pelas arquiteturas cada vez mais arrojadas e aos requisitos de alta performance e de durabilidade.

O uso de reforços é um conceito que tem sido extensivamente aplicado pelos projetistas, e com os materiais plásticos não é diferente. Desde o uso de fibras naturais como reforço em estruturas de argila pelos egípcios, os materiais compósitos atendem às demandas por soluções na área da construção. Por exemplo, a combinação do aço e do concreto, formando o concreto armado, tem sido a base para 
inúmeros sistemas estruturais adotados no século $X X$. Os projetistas, contudo, continuam a desenvolver e adotar novos materiais, com o intuito de tornar a estrutura mais resistente, maior, mais durável, energeticamente eficiente e esteticamente agradável (LOPEZ-ANIDO e NAIK, 2000).

\subsubsection{Propriedades mecânicas do plástico relevantes a um projeto estrutural}

Para uma correta concepção da estrutura, visando o aproveitamento das vantagens do material plástico, certas propriedades físicas e mecânicas devem ser observadas, a depender do fim a que se destina a estrutura, pois devem ser levadas em consideração as peculiaridades desse material, cujo comportamento é bastante diferente dos relativos aos metais, à madeira e ao concreto. A seguir são mostradas as propriedades mais relevantes em um projeto estrutural.

- Resistência à tração;

- Resistência à compressão;

- $\quad$ Resistência à flexão;

- $\quad$ Módulo de Elasticidade (para diversas temperaturas);

- $\quad$ Coeficiente de Poisson;

- Resistência à fadiga;

- $\quad$ Fluência;

- Relaxação;

- $\quad$ Resistência ao impacto;

- $\quad$ Absorção de água;

- Temperatura de transição vítrea - $\mathrm{T}_{\mathrm{g}}$;

- Coeficiente de expansão térmica.

O projetista que deseja dimensionar elementos estruturais deve fazer, durante o desenvolvimento do projeto estrutural, as seguintes perguntas:

- Qual o nível de tensões a que o material será submetido?

- Qual a solicitação predominante (tração, compressão, flexão, torção)?

- Qual a vida útil esperada para a estrutura?

- Será a estrutura submetida ao impacto?

- $\quad$ Será a estrutura submetida a um carregamento cíclico (fadiga)?

- Qual é a deformação admissível para a estrutura em questão?

- Qual a máxima temperatura a que o plástico será submetido?

- Será o plástico exposto à umidade e a substâncias químicas? 


\subsubsection{Limitações de uma estrutura de material plástico}

A seguir são mostradas algumas das principais limitações do uso do material plástico em elementos estruturais.

a) A inflamabilidade e a influência da temperatura no desempenho das estruturas

Para que o material plástico possa ser utilizado com segurança em edificações, pode-se utilizar de normas específicas que prevêem o cuidado com a inflamabilidade das estruturas. A adição de produtos químicos retardantes de chama, durante a manufatura dos plásticos, é uma forma de se evitar o perigo de incêndio em estruturas com elementos de material plástico.

O dimensionamento de uma estrutura de plástico, em função de sua baixa rigidez, deverá ser regido pelo estado limite de serviço, sendo a deformação o fator limitante de projeto. A perda da rigidez dos plásticos com a diminuição de seu módulo de elasticidade, à medida que se aumenta a temperatura, deve ser considerada em projeto.

Por exemplo, um plástico como o poliestireno possui quatro estágios de deformação com o aumento da temperatura, como mostra a figura 6.3. O impacto da variação de temperatura sobre os plásticos é, talvez, o maior entrave à sua aplicação em estruturas de sustentação, apesar das fibras reduzirem bastante essa influência.

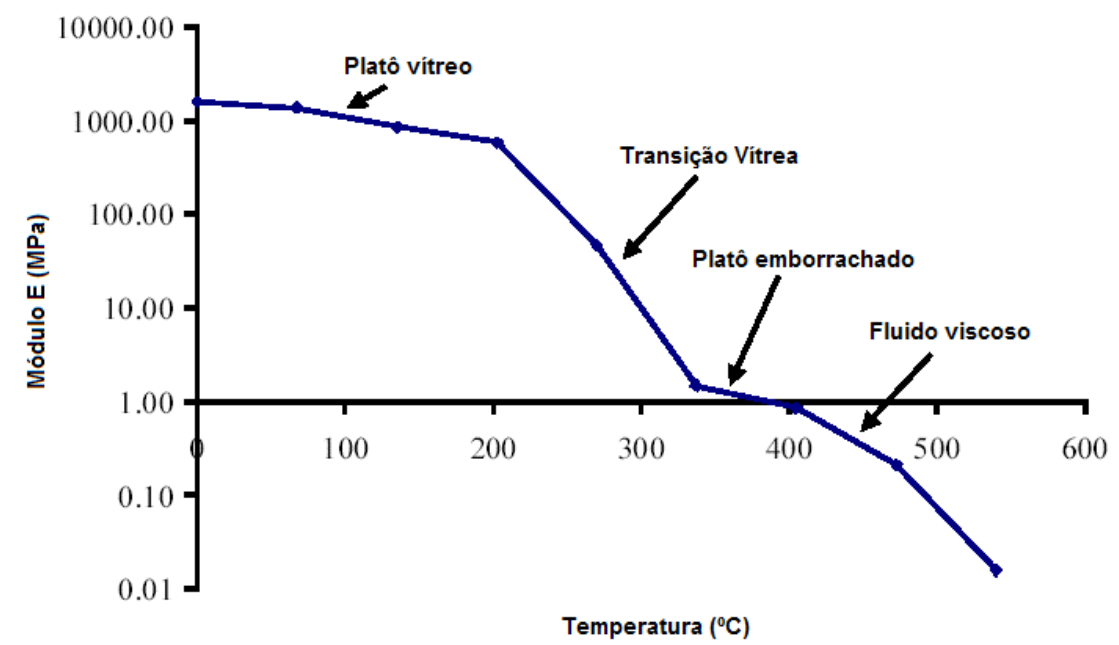

Figura 6.3. Módulo de Elasticidade E versus temperatura. Fonte: PRINGLE e BAKER, 2000

b) Estabilidade aos raios ultravioletas (UV)

Ao ser aplicado em elementos estruturais que, porventura, estarão expostos ao sol, deve-se observar a resistência dos plásticos aos efeitos dessa exposição. Isso porque a radiação ultravioleta pode tornar o plástico, antes durável e resistente, num material que se quebra ou se rompe sob uma força aplicada, e este é um processo irreversível (PRINGLE e BAKER, 2000). 
Como a deterioração em função dos raios UV é bastante lenta, ensaios utilizando luz artificial para acelerar o processo são realizados para se medir essa estabilidade. Existem, no entanto, produtos químicos chamados de estabilizantes que retardam o efeito da radiação, minimizando bastante os efeitos maléficos que podem vir a surgir. Os plásticos reciclados podem conter estabilizantes UV, mas não é possível ter essa certeza, a não ser que sejam realizados ensaios que possam detectar essas substâncias, o que não é prático. De qualquer forma, raramente é possível se determinar a quantidade de estabilizante utilizado e qual a degradação que esse plástico já sofreu. Por isso, em algumas aplicações, para se garantir uma maior vida útil à peça, utiliza-se uma proporção de material virgem com o material reciclado (PRINGLE e BAKER, 2000).

Lynch et al. (2001), por meios de ensaios mecânicos, verificaram quais foram as mudanças nas propriedades mecânicas de elementos estruturais de material plástico reciclado, mais precisamente polietileno de alta densidade (PEAD), expostos ao sol e às intempéries por 11 anos. Os resultados, contudo, mostram um prognóstico positivo para a utilização de plástico reciclado, ao menos para o tipo de plástico estudado, o PEAD.

Houve um clareamento superficial em função da radiação UV no lado que estava exposto ao sol. A radiação UV ainda provocou uma minúscula degradação da superfície do PEAD, da ordem de 0,075mm/ano. No entanto, o clareamento e a minúscula degradação superficial não afetaram as propriedades mecânicas do material. A figura 6.4 mostra a comparação entre os lados do elemento estrutural, sendo o de cima o lado exposto ao sol, e o de baixo que não foi submetido a essa exposição.

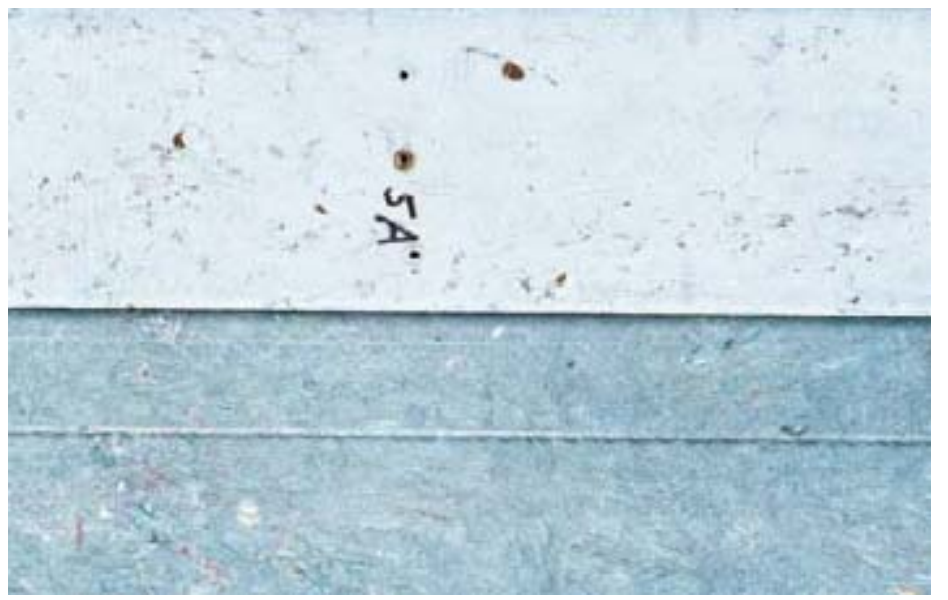

Figura 6.4. Clareamento do PEAD como resultado da radiação UV. Fonte: LYNCH et al., 2001

A figura 6.5 mostra a estrutura, uma passarela, de onde foram retirados os exemplares para os ensaios. 
Lynch et al. (2001) concluíram, após verificar um aumento de 3\% no módulo de elasticidade e na resistência à flexão, que as mudanças climáticas ocorridas ao longo dos 11 anos aumentaram o grau de cristalização do plástico, e que essa redução das regiões amorfas contribuíram para o aumento da rigidez e da resistência do PEAD reciclado.

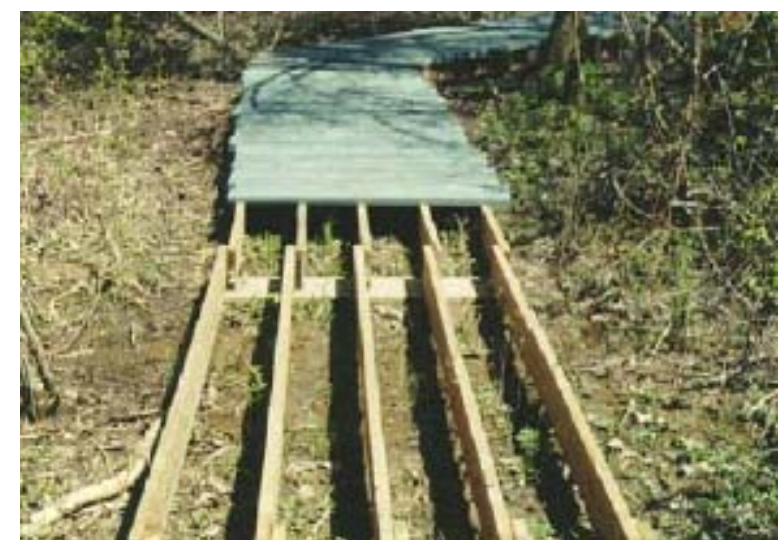

Figura 6.5. Passarela de onde foram retirados os exemplares para ensaio. Fonte: LYNCH et al., 2001

\section{c) Resistência aos solventes}

Em algumas aplicações deve-se verificar se o plástico será exposto a solventes, como, por exemplo, o contato com combustíveis ou outros derivados do petróleo, haja vista que isso pode comprometer a sua integridade. O mesmo cuidado deve ser dado aos plásticos reciclados e, caso necessário, o material deve ser processado de forma a melhorar sua resistência frente aos solventes (PRINGLE e BAKER, 2000). 


\section{Conformação dos Plásticos}

Uma das maiores vantagens dos plásticos é a facilidade com que eles podem ser conformados. Em alguns casos, para outros materiais, artigos semi-acabados como chapas e barras são produzidos e, subseqüentemente, fabricados nas mais diversas formas utilizando métodos convencionais como a soldagem e a usinagem. No entanto, o artigo acabado de material plástico, que pode ter sua forma relativamente complexa, pode ser produzido numa única operação. Os estágios da conformação como o aquecimento, moldagem e resfriamento podem ser contínuos (por exemplo, a fabricação de tubos por extrusão) ou um ciclo repetido de eventos (por exemplo, a fabricação da carcaça de um monitor por injeção no molde), mas, na maioria dos casos, os processos podem ser automatizados e, portanto, são adaptados para a produção em massa (CRAWFORD, 1987).

Ainda de acordo com Crawford (1987), existe uma vasta gama de métodos de conformação que podem ser utilizados para os plásticos. Na maioria dos casos, a escolha do método é baseada na forma do componente e se é um termoplástico ou não. É importante, no entanto, durante a escolha do melhor processo, que o projetista tenha um entendimento básico dos diversos métodos de conformação para os plásticos, pois uma forma mal concebida ou um detalhe de projeto podem limitar a escolha do método de moldagem.

O projetista de estruturas de concreto deve, ao menos, possuir um conhecimento elementar do processo executivo dessa estrutura. Com esse conhecimento, o engenheiro terá um maior desprendimento para definir qual a resistência a ser adotada no concreto, pois essa escolha não depende somente do cálculo, mas também da dimensão da obra, do controle de qualidade, da qualificação da mão-de-obra, da viabilidade econômica, do tempo disponível para a execução da estrutura, enfim, diversos outros fatores que vão além da Engenharia de Estruturas em si.

Da mesma forma, o projetista de estruturas de material plástico deve conhecer quais as formas de conformação a que o plástico pode ser submetido. Dessa maneira, pode-se tirar um maior proveito das propriedades mecânicas e das vantagens do material plástico, obtendo, ao final, uma estrutura eficiente e otimizada. 
A seguir serão apresentados os tipos de conformação mais utilizados e, para cada um deles, quais aplicações a que se destinam e qual a sua influência nas características do produto final. Afora as citações explícitas, utilizou-se como referência básica a apostila de Processamento de Polímeros, organizada pela Universidade Federal de Santa Catarina - UFSC.

\subsection{MOLDAGEM POR COMPRESSÃO}

A moldagem por compressão é um processo de conformação utilizado principalmente para os termofixos (por exemplo, resinas fenol-formaldeído, uréiaformaldeído, melanina-formaldeído, epóxies e fenólicas) e consiste na compactação da matéria prima (resina, aditivos, pigmentos, catalisadores) entre moldes préaquecidos.

O molde, montado geralmente sobre uma prensa hidráulica, é aquecido até a temperatura especificada para o serviço, que depende das características do material que nele será moldado. A prensa é então acionada, abrindo o molde para se colocar a matéria-prima.

O material de moldagem, em forma de pó, flocos, esferas, tabletes ou pré-forma é depositado na cavidade do molde. A prensa é então acionada, iniciando um movimento suave e que vai aumentando a pressão progressivamente sobre o material, até o fechamento do molde.

Na moldagem de grandes peças é comum a retirada momentânea da pressão para permitir a liberação de gases que, porventura, tenham sido liberados durante o processo.

Passado o tempo de cura - que também depende do material - a prensa é acionada novamente, abrindo o molde e retirando o moldado, num processo conhecido como desmoldagem. A figura 7.1 ilustra um processo de moldagem por compressão, de maneira simplificada.

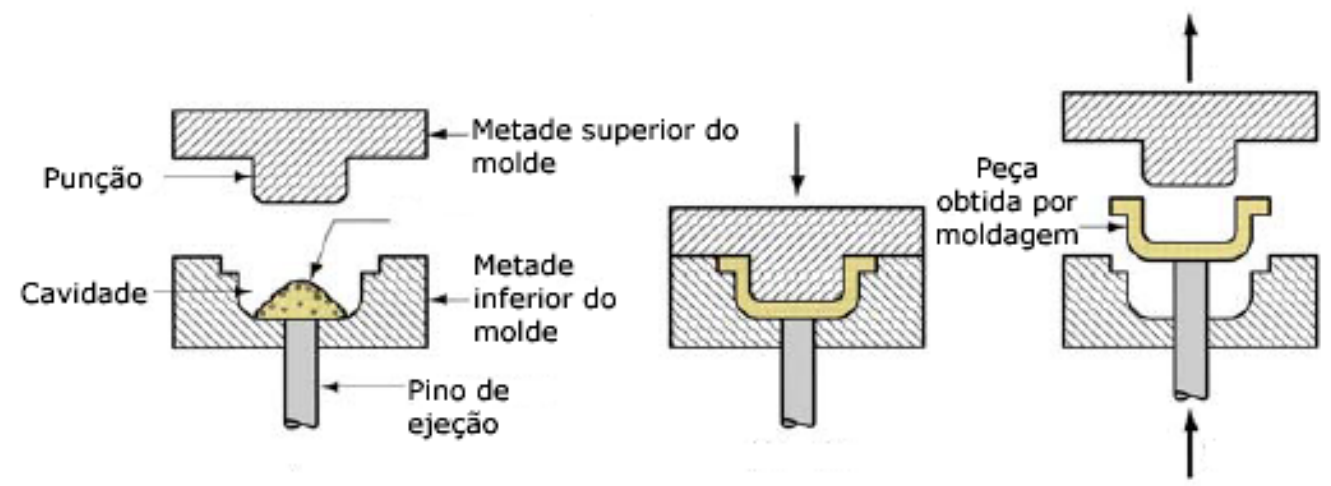

Figura 7.1. Moldagem por compressão 
Essa seqüência de operações, ou ciclo de moldagem, dependendo das instalações, pode ser realizada de maneira manual, semi-automática ou automática.

A prensa pode ser aquecida de várias maneiras, dependendo do tamanho da peça a ser moldada. Para chapas e peças delgadas, normalmente utiliza-se vapor, óleo quente ou resistências elétricas. O aquecimento é um fator crítico, pois toda a superfície deve estar corretamente aquecida para garantir uma cura adequada e uma boa qualidade do produto acabado.

A moldagem por compressão é uma forma de processamento muito simples e utilizada há bastante tempo. A seguir são descritas algumas das vantagens e desvantagens dessa técnica.

\section{Vantagens}

- Devido à sua simplicidade, os custos de fabricação dos moldes são baixos;

- O fluxo relativamente baixo do material reduz o desgaste e a abrasão dos moldes;

- A produção de peças de grandes dimensões é mais exeqüível;

- São possíveis moldes mais compactos devido à sua simplicidade.

\section{Desvantagens}

- Peças com geometria complexa são difíceis de serem produzidas;

- Limitada precisão dos componentes produzidos com essa técnica;

- É necessário retirar o excesso de material das peças moldadas, reduzindo a eficiência.

As condições de moldagem para alguns plásticos (resinas termofixas) são mostradas na tabela 7.1. O processo de moldagem por compressão na conformação de termoplásticos foi praticado no passado, mas se encontra em desuso hoje.

Tabela 7.1. Condições para a moldagem por compressão

Material

Fenólicos

Fenólicos com pó de madeira

Fenólicos com carga de tecido

Uréia - formaldeído

Melamina - formaldeído

Alquídicos
Temperatura $\left({ }^{\circ} \mathrm{C}\right)$

$149-177$

$116-160$

$135-182$

150
Pressão (MPa)

$12-50$

16

$33-50$

$24-47$

$15-47$

$4-8$

\subsection{MOLDAGEM POR TRANSFERÊNCIA}

A moldagem por compressão possui um custo reduzido, mas apresenta alguns inconvenientes, além dos que já foram citados: moldados de parede espessa geralmente resultam em núcleos mal curados, ou então exigem um tempo excessivo de moldagem; quando existem grandes variações de espessura nas paredes de uma 
peça, as paredes mais finas podem ficar sobrecuradas; inserções delicadas em moldes complexos são sujeitas a se quebrar facilmente.

A moldagem por transferência pode contornar satisfatoriamente esses inconvenientes e é uma técnica que consiste, basicamente, em forçar o material termoendurecível por meio de um êmbolo ou de uma cavidade de carga através de um canal alimentador, a uma cavidade de moldagem aquecida. Esse processo é formalmente similar ao processo de moldagem por injeção utilizado para materiais termoplásticos. Apresenta, sobre a moldagem por compressão, a vantagem de introduzir no molde o material já plastificado, num estado que lhe permita, mediante pressão, preencher cada canto do molde, sem forçar excessivamente insertos e saliências do molde, como ocorre quando se comprime o pó ainda frio. Além disso, a movimentação do material na câmara e no canal de alimentação assegura a uniformização de temperatura e elimina as diferenças no estado de cura, em regiões de paredes delgadas ou espessas. Tem-se, ainda: menores solicitações sobre as zonas críticas do molde; menores tempos de cura, menores ciclos de moldagem e a produção de moldados de melhor qualidade, especialmente nas geometrias complexas.

A figura 7.2 ilustra o processo de moldagem por transferência, de maneira simplificada.
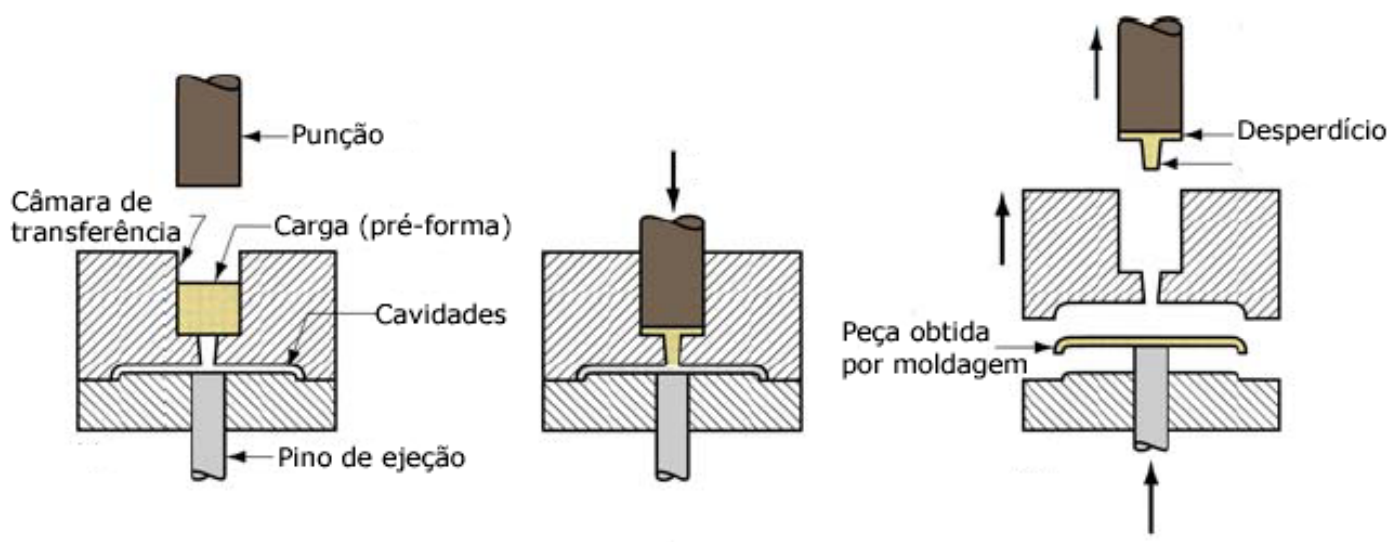

Figura 7.2. Moldagem por transferência

As temperaturas recomendadas para a moldagem são as mesmas empregadas na moldagem por compressão (vide tabela 7.1). Para moldados com geometria mais complexa é empregada menor temperatura, a fim de permitir que o material encha completamente o molde. Os tempos de cura são aproximadamente os mesmos recomendados para a moldagem por compressão, para moldados de parede delgada. Para espessuras maiores adotam-se substanciais reduções no tempo de cura.

A pressão necessária é maior para a moldagem por transferência, variando, geralmente, entre 80 e 160 MPa na seção transversal do êmbolo da prensa. 


\subsection{MOLDAGEM DOS PLÁSTICOS REFORÇADOS}

As propriedades mecânicas dos plásticos reforçados dependem do efeito combinado da quantidade de material fibroso de reforço e de sua disposição no composto acabado. Já as propriedades químicas, elétricas e térmicas são influenciadas, principalmente, pela resina polimérica empregada. Por outro lado, o processo de fabricação adequado depende dos requisitos de materiais, projeto e produção e afeta também o custo do produto.

Os três tipos de fibras sintéticas mais utilizadas para reforçar os plásticos são

- Fibra de vidro (a mais barata dentre as três e a mais empregada);

- Fibra de carbono (apresenta resistência mecânica elevada e baixa densidade e, apesar de seu alto custo, é bastante utilizada);

- Fibra de aramida (mais conhecida pelo seu nome comercial, kevlar).

Diversos são os processos que podem ser utilizados para confeccionar o plástico reforçado, com a combinação desejada de desempenho do projeto e do custo de produção. A seguir são apresentados os principais processos de fabricação de peças de plástico reforçado.

(a) Moldes abertos: constam de uma única cavidade, macho ou fêmea, e são usados quando se requer pouca ou nenhuma pressão. As características dos moldados assim obtidos são: acabamento de uma só face, possibilidade de conformação de geometrias complexas e de peças grandes. A confecção em moldes abertos pode ser manual, por pistola, câmara de vácuo, câmara de pressão, autoclave, fundição centrifugada, enrolamento de filamentos ou outros.

(b) Moldes fechados: possuem duas cavidades, macho e fêmea, permitindo a obtenção de acabamentos superficiais controlados, em duas faces, e com excelente reprodução de aspectos superficiais de peça a peça. A fabricação em moldes fechados pode ser por matrizes combinadas, por injeção, ou por laminação contínua.

(c) Molde manual ou por contato: é o mais antigo e simples dos processos de moldagem de plásticos reforçados com materiais fibrosos. Fibras e resina são depositadas sobre o molde e o ar aprisionado é removido com pincéis ou roletes. As camadas de fibra e resina são adicionadas até se atingir a espessura de projeto. Para se obter uma superfície de boa qualidade, começa-se com a aplicação de uma camada gelatinosa (resina de superfície e pigmento). O conjunto cura à temperatura ambiente; eventualmente se usam aquecedores para acelerar a cura. A superfície exposta é geralmente áspera, mas pode ser melhorada superpondo uma camada de celofane ou outra película adequada. A moldagem manual é usualmente empregada com poliésteres ou resinas epoxídicas. 
(d) Moldagem por pistola: nesse processo a resina e o material fibroso são simultaneamente projetados sobre a superfície do molde, por meio de um equipamento especial. A fibra em feixes é alimentada através de um cortador e lançada num fluxo composto de resina e catalisador. Eventualmente a alimentação da fibra pode ser realizada através de uma segunda pistola. Após a deposição, a mistura é trabalhada com pincéis ou roletes para remover o ar aprisionado, orientar as fibras e alisar a superfície. A cura se dá à temperatura ambiente, podendo ser acelerada por aquecimento. A moldagem por pistola também é empregada predominantemente para resinas poliésteres e epoxídicas.

(e) Moldagem em câmara de vácuo: é um refinamento da moldagem manual, envolvendo o uso de vácuo para eliminar vazios, liberar o ar aprisionado e expulsar o excesso de resina. Uma película adequada (celofane, álcool polivinílico ou náilon) é colocada sobre o moldado, presa pelas bordas e vedada com um composto vedante. Feito vácuo na câmara sob a película, permite-se, em seguida, a cura.

(f) Moldagem em câmara de pressão: é uma variante do processo anterior. Uma camada de borracha é colocada sobre o moldado e, mediante ar comprimido ou vapor, eliminam-se vazios, ar aprisionado ou excesso de resina.

(g) Moldagem em autoclave: é outra variante da moldagem em câmara de pressão. Permite o controle da pressão $(0,35$ ou $0,7 \mathrm{MPa})$ para produzir a qualidade desejada.

(h) Enrolamento de filamentos: permite usar reforço contínuo para obter uma aplicação mais eficiente da fibra. Feixes de fibra são alimentados de carretéis através de um banho de resina e enrolados sobre um mandril de forma adequada. Máquinas especiais permitem o enrolamento segundo padrões determinados que assegurem a máxima resistência na direção requerida. Ao ser atingido o número desejado de camadas, o mandril é posto a curar ao ambiente ou em um forno.

(i) Fundição centrifugada: é o processo usado na moldagem de objetos redondos ou tubulares. Uma manta de fibra picada é posicionada no interior de um mandril oco, que é posto a girar. Um tubo central alimenta a resina e a força centrífuga pressiona a resina e as fibras contra a parede do mandril. A cura se faz ao ar ou em forno.

(j) Moldagem em matrizes combinadas: é um processo de produção em massa. Malhas, tecidos ou pré-formas de fibras são combinados com a resina e colocados sobre um molde. Uma contra-matriz de metal é prensada contra o molde e a cura se faz sob pressão e temperatura selecionadas. Dependendo do tamanho e da forma da peça, bem como das características da resina, os ciclos de cura podem ser de um a cinco minutos. 
(k) Moldagem por injeção: é um processo de alta produção usado com materiais termoplásticos. As fibras picadas e a resina são misturadas e introduzidas numa câmara de aquecimento, onde a resina amolece. A massa amolecida é então injetada na cavidade do molde, que é mantido a uma temperatura inferior à de amolecimento.

(I) Laminação contínua: neste processo, camadas de tecido ou manta passam através de um banho de resina e penetram entre duas camadas de celofane. $O$ conjunto é então aquecido e a resina cura. A espessura do laminado e o teor de resina são controlados através de roletes, quando os vários elementos são reunidos.

$\mathrm{Na}$ figura 7.3 são apresentados alguns dos mais conhecidos processos de moldagem de materiais poliméricos reforçados.

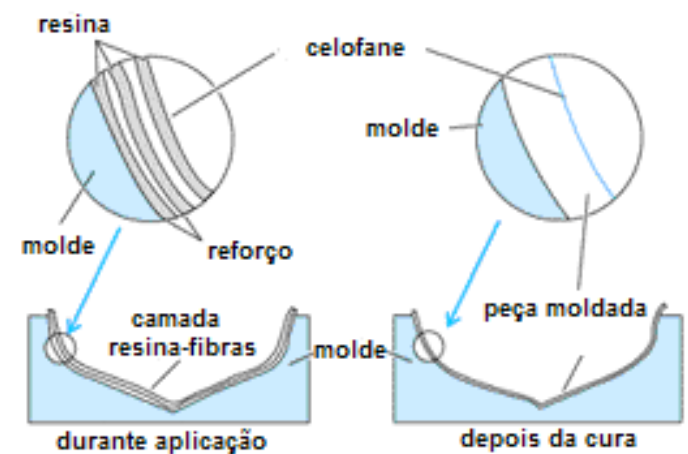

(a)

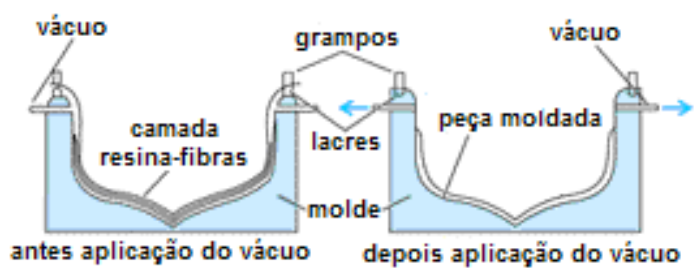

(b)

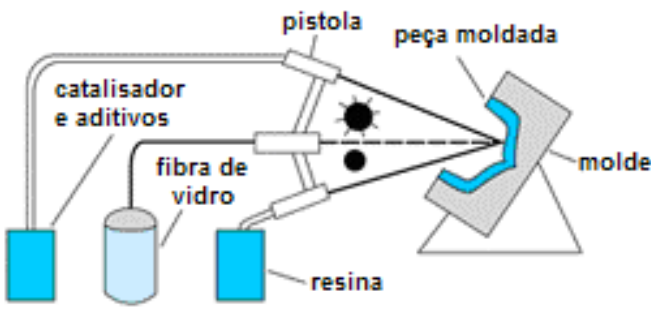

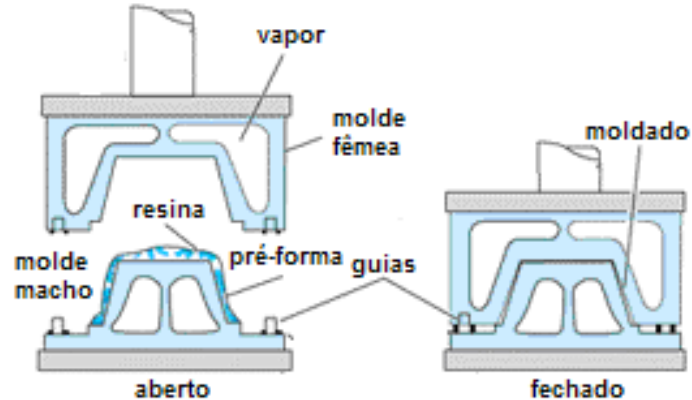

(d)

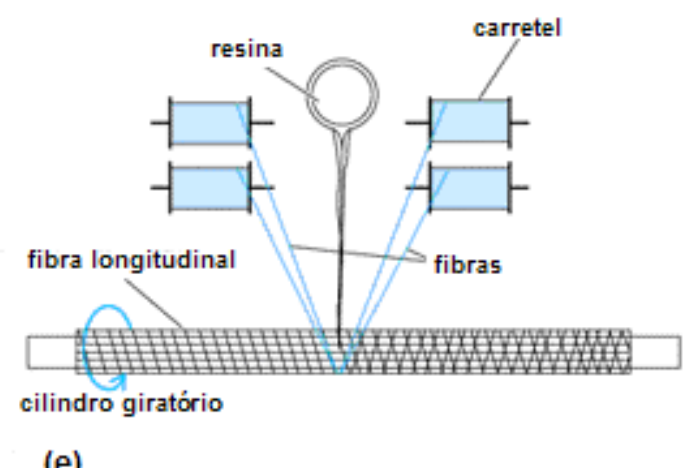

(c)

Figura 7.3. Técnicas de moldagem de plásticos reforçados: (a) moldagem manual; (b) moldagem por câmara de vácuo; (c) moldagem em câmara de vácuo; (d) moldagem em câmara de pressão; (e) enrolamento de filamentos. Fonte: GOODMAN, 2002

\subsection{MOLDAGEM POR INJEÇÃO}

Os termoplásticos, aqueles polímeros que podem ser fundidos diversas vezes sem perda significativa de suas características, se fossem conformados pelo processo da moldagem por compressão, demandariam muito tempo e calor, pois seria 
necessário aquecer o material a um estado de fluidez, conformá-lo na cavidade de um molde, para então resfriá-lo enquanto estiver contido no molde.

Em função disso, a moldagem por injeção - uma adaptação do processo de fundição sob pressão, utilizado para metais leves - apresenta-se como um dos processos mais importantes de conformação dos termoplásticos.

Consiste em forçar uma carga de material plástico aquecido, por meio de um êmbolo (equipamentos mais antigos) ou rosca, em uma prensa-cilindro aquecida, através de um bocal até um molde frio ou pouco aquecido, no qual o material preenche as cavidades ali alojadas. O material frio, granulado ou em pó, é alimentado ao cilindro, onde é aquecido até amolecer, para então ser forçado sob pressão (injetado) no molde frio, de onde é posteriormente extraído.

Existem quatro tipos principais de prensas para moldes por injeção:

- Manuais: o êmbolo é empurrado através do cilindro, por força manual exercida através de uma alavanca;

- Hidráulicas: o êmbolo é acionado por uma alavanca hidráulica de dupla ação;

- Pneumáticas: o acionamento do êmbolo é feito por um pistão pneumático;

- De potência: o êmbolo é acionado por uma manivela, incorporando uma pesada mola para o caso do êmbolo prender-se no cilindro.

As prensas de injeção podem ser de operação horizontal ou vertical, sendo as primeiras de emprego muito mais generalizado. No entanto, a variedade de modelos construtivos é enorme.

O equipamento é composto por dois componentes principais, como mostra a figura 4:

- Unidade de injeção: funde e transporta o material até a próxima unidade;

- Unidade de fixação: onde se localiza o molde, que abre e fecha a cada ciclo de injeção.

Ainda de acordo com a figura 7.4, podem ser observadas as seguintes partes essenciais:

- Tremonha: mecanismo para dosagem da carga e alimentação do equipamento;

- Cilindro: recebe o material da tremonha e nele se dá a plastificação ou o amolecimento;

- Rosca ou parafuso: opera no cilindro, aplicando pressão ao material e transportando-o ao molde;

- Molde: consiste de duas ou mais partes, que podem ser separadas para extrair o moldado. 


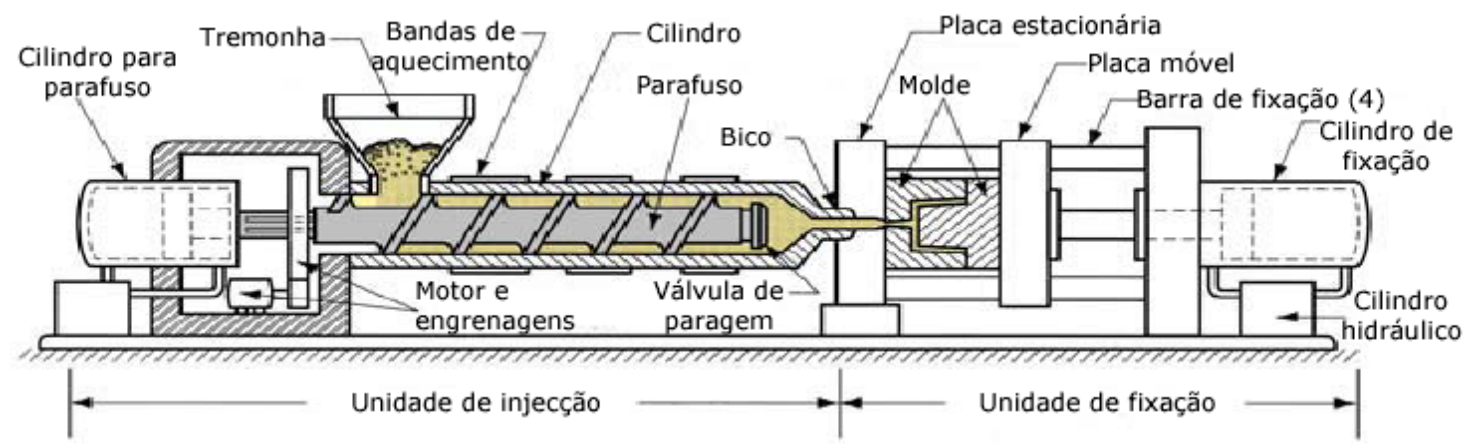

Figura 7.4. Moldagem por injeção

A figura 7.5 mostra um ciclo básico de operações, durante a moldagem por injeção, e compreende as seguintes etapas:

(a) Fechamento do molde;

(b) A rosca gira, exercendo pressão e transportando o material, injetando no molde;

(c) Fase de solidificação, o molde permanece fechado até que o moldado tenha resfriado o suficiente para que possa ser removido sem distorsão. A duração dessa etapa é pré-determinada pela natureza do material e pelo tamanho e forma do moldado;

(d) o molde é aberto e a peça é extraída, podendo se dar início a um novo ciclo de operações.

O desenvolvimento da moldagem por injeção com reação (RIM - Reaction injection molding) permitiu a fabricação com redução de tempo, para os materiais líquidos. Neste processo, que pode ser à temperatura ambiente ou aquecido, dois materiais reagentes, com baixo peso molecular e baixa viscosidade, são transportados, primeiramente, a um misturador, e logo em seguida injetados num molde previamente aquecido, onde a reação de solidificação é completada. A polimerização e o encadeamento molecular ocorrem no molde. Essa técnica tem se mostrado bastante eficiente para a conformação a altas velocidades, para materiais como os poliuretanos, epóxies, poliésteres e náilons.

A moldagem por injeção, por sua possibilidade de automatização, é uma das formas de processamento mais empregadas em todo o mundo. A seguir são descritas algumas das vantagens e desvantagens dessa técnica. 


\section{Vantagens}

- Podem-se produzir peças de elevada qualidade e com alta velocidade de produção;

- O processo tem custos de fabrico relativamente baixos;

- Pode produzir-se um bom acabamento superficial na peça moldada;

- O processo pode ser automatizado;

- Podem-se produzir peças com geometria complexa, sem perda de qualidade.

\section{Desvantagens}

- O elevado custo do equipamento faz com que seja necessário produzir um grande volume de peças, para compensar o custo inicial;

- Todo o processo tem de ser rigorosamente controlado, para que se obtenha um produto de qualidade.

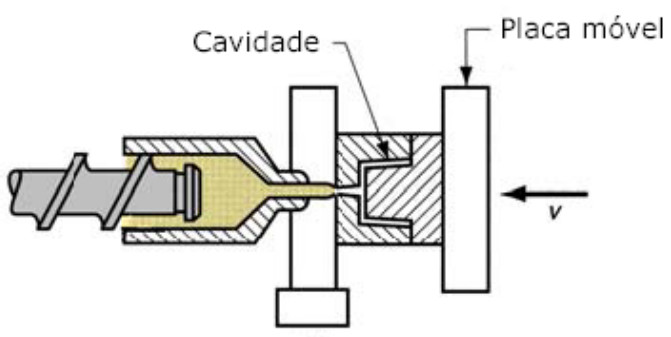

(a)

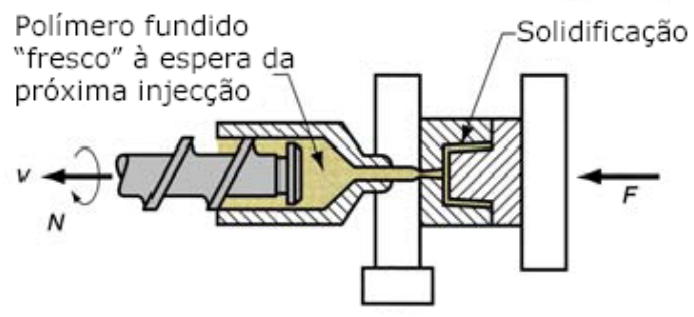

(c)

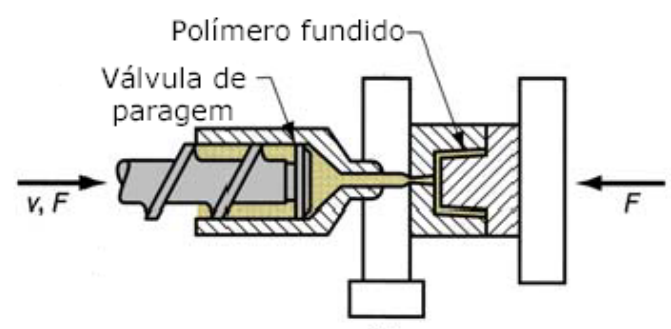

(b)

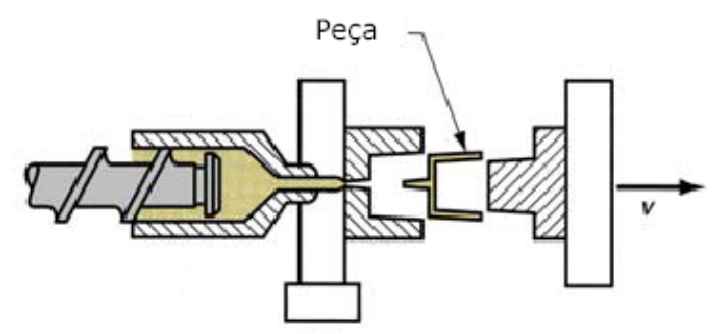

(d)

Figura 7.5. Ciclo básico da moldagem por injeção

\subsection{MOLDAGEM POR EXTRUSÃO}

A moldagem por extrusão é um dos mais importantes processos de conformação dos termoplásticos, sendo utilizado tanto para a confecção de produtos acabados (barras, fitas, mangueiras, tubos e perfilados) como, e principalmente, para a produção de semimanufaturados, que devem sofrer novo processamento.

Tratando-se especificamente da conformação de elementos estruturais de plástico reciclado, que muito provavelmente terão a forma de perfis, a moldagem por extrusão, dentre todos os outros processos, aparece como o mais provável a ser utilizado. A pultrusão, que também se destaca, possui praticamente a mesma filosofia da extrusão, com exceção à adição de fibras. 
$\mathrm{Na}$ moldagem por extrusão, péletes ou grãos plásticos são fluidificados, homogeneizados e continuamente moldados, e essa técnica apresenta uma característica essencial, que a distingue dos processos anteriormente apresentados: é um processo contínuo. E, por isso mesmo, é empregado na produção de produtos lineares, como os descritos anteriormente, que podem ser usados como produtos finais ou matéria-prima para outros processos de moldagem. A figura 7.6 mostra, esquematicamente, uma extrusora de rosca única.

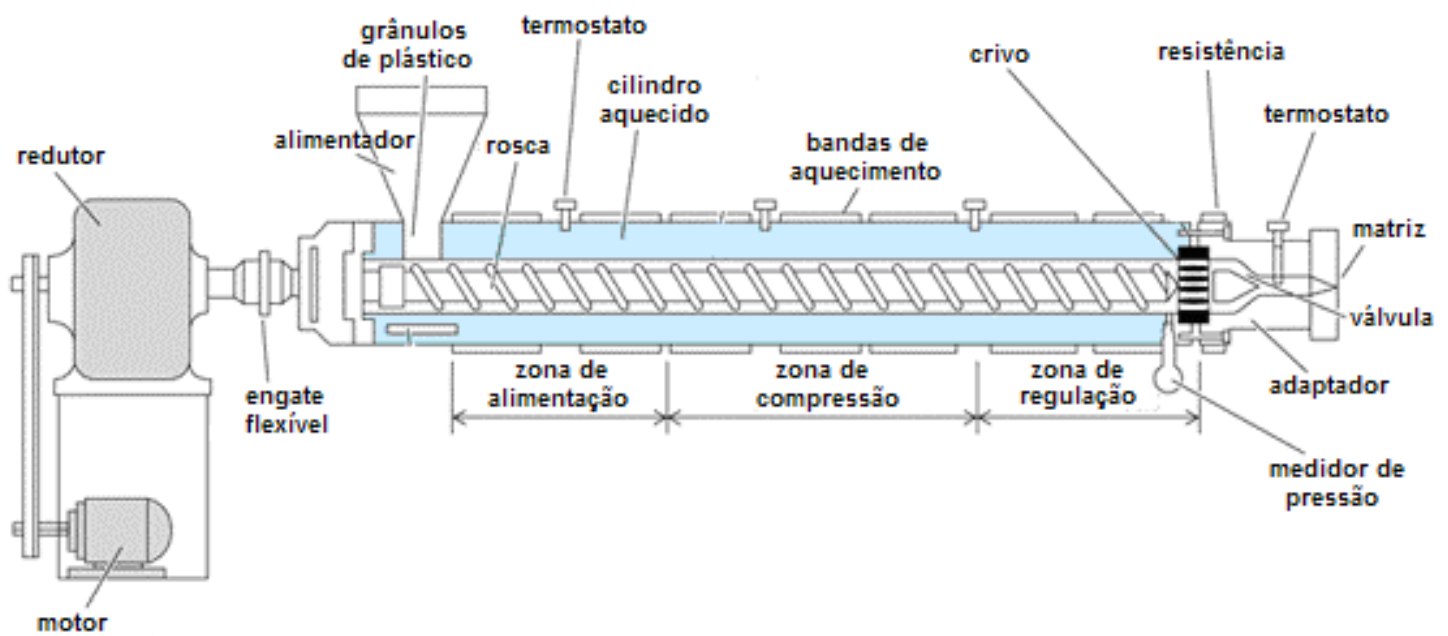

Figura 7.6. Moldagem por extrusão. Fonte: GOODMAN, 2002

Basicamente, uma extrusora de rosca, como a mostrada na figura 7.6, possui três diferentes zonas (CRAWFORD, 1987):

Zona de alimentação: a função desta zona é pré-aquecer o plástico e transportálo para as zonas subseqüentes. O projeto da seção da rosca é importante, pois uma profundidade constante dos canais deve suprir a zona de regulação com material suficiente, de forma a preenchê-la minimamente, mas também sem sobrecarregá-la. $O$ projeto ótimo está relacionado com a natureza e forma da matéria-prima, a geometria da rosca e o atrito entre essa rosca e o material plástico. $\mathrm{O}$ atrito da matéria-prima tem uma considerável influência na taxa de fluidez que pode ser implementada.

Zona de compressão: nesta zona, a profundidade dos canais da rosca diminui gradualmente, para compactar o plástico. Essa compactação tem a dupla função de reduzir as bolhas de ar aprisionadas na zona de alimentação, comprimindo-as, e permitir uma melhor transferência de calor, com a redução da espessura do material.

Zona de regulação: nesta seção da rosca, a profundidade é, novamente, constante, mas muito menor que na zona de alimentação. Na zona de regulação o plástico derretido é homogeneizado para fornecer, a uma taxa constante, um material com temperatura e pressão uniformes para a matriz. Esta zona é a que permite uma aferição e análise mais direta, pois envolve um fluido ao longo de um canal uniforme. 
A pressão exercida no material ao longo da rosca é ilustrada na figura 7.7. O comprimento das zonas de uma rosca em particular depende do material a ser extrusado. Com o náilon, por exemplo, o derretimento ocorre rapidamente, de forma que a compressão pode ser aplicada com apenas um passo de rosca. O PVC, por outro lado, possui uma sensibilidade muito grande ao calor, e é preferível uma rosca com uma zona de compressão que compreenda toda a sua extensão.

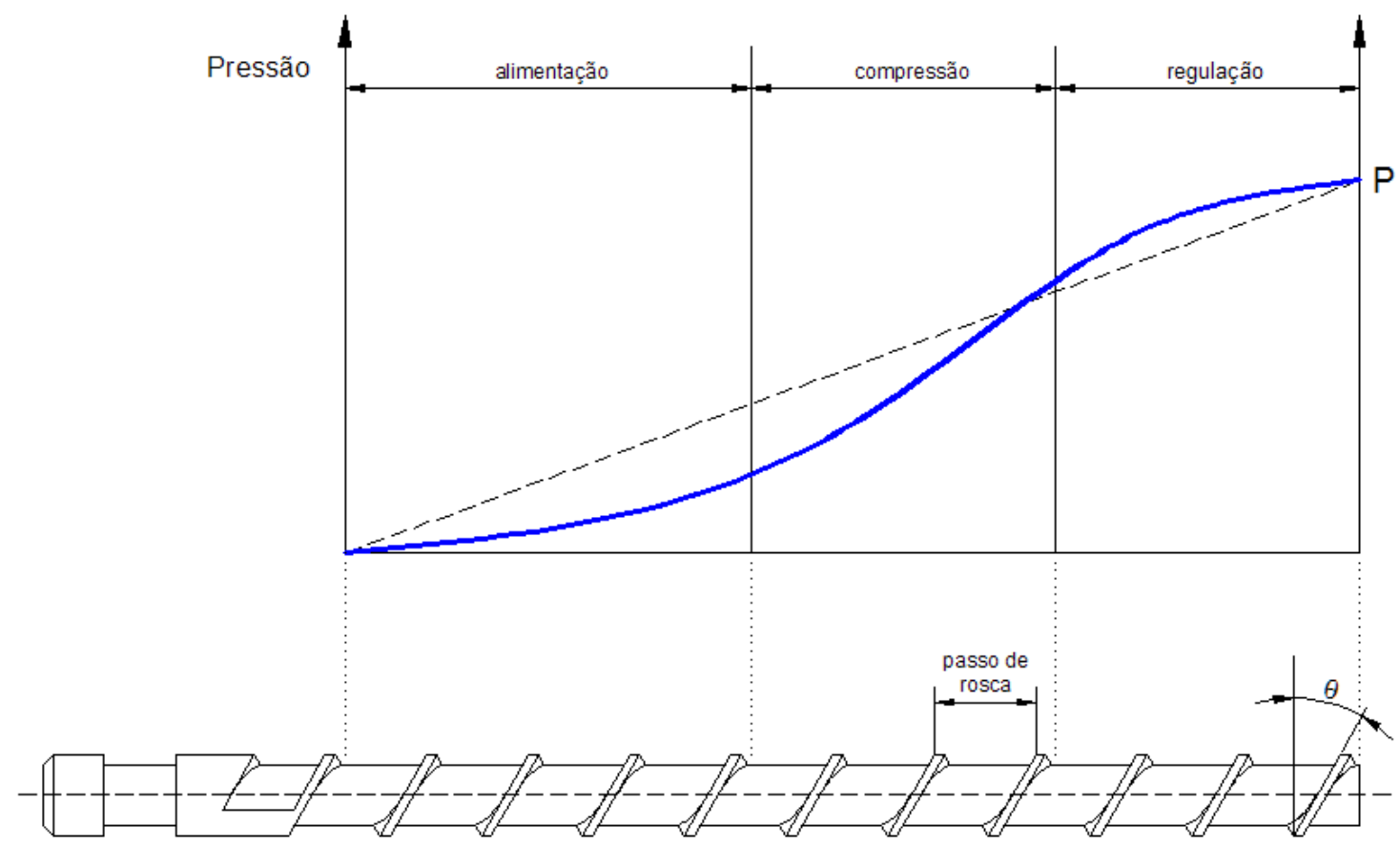

Figura 7.7. Zonas típicas de uma extrusora de rosca. Fonte: CRAWFORD, 1987

Em algumas extrusoras também existem uma zona de ventilação. Essa zona fazse necessária porque alguns plásticos são higroscópicos, ou seja, eles absorvem umidade do meio ambiente. Se esses materiais são extrusados com água absorvida, num equipamento convencional, a qualidade do produto final é prejudicada devido ao vapor d'água aprisionado no plástico derretido. Uma possibilidade é secar previamente a matéria prima, mas esse processo torna-se oneroso e passível de contaminação. Em função disso, tubos cilíndricos de ventilação foram desenvolvidos para esse fim (CRAWFORD, 1987).

A geometria do produto que sai da extrusora é definida pela matriz, que se localiza na extremidade final do equipamento. A figura 7.8 mostra um exemplo de matriz e o produto obtido: corpos-de-prova para ensaios de compressão.

Algumas regras usuais são adotadas no projeto de matrizes (CRAWFORD, 1987): 
(a) A resistência devida ao atrito que apresentam os materiais termoplásticos na passagem pelo orifício de uma matriz tende a ser proporcional ao comprimento da guia prismática desse orifício. Assim, devem ser usados comprimentos variados para diferentes regiões da seção transversal do orifício. Comprimentos maiores geram mais atrito e reduzem a espessura dos extrusados.

(b) É possível afirmar, a partir da equação de Poiseuille, que a quantidade de material que escoa, em condições ideais, através do orifício da matriz, varia diretamente com a quarta potência da abertura e inversamente com seu comprimento e com a viscosidade do plástico.

(c) Diferenças de espessura tornam mais difícil o controle das dimensões dos perfis moldados, em virtude das variações que introduz na taxa de resfriamento. Esse efeito pode ser, às vezes, compensado por meio de um jato de ar frio lançado sobre as partes que requerem mais tempo para resfriar.
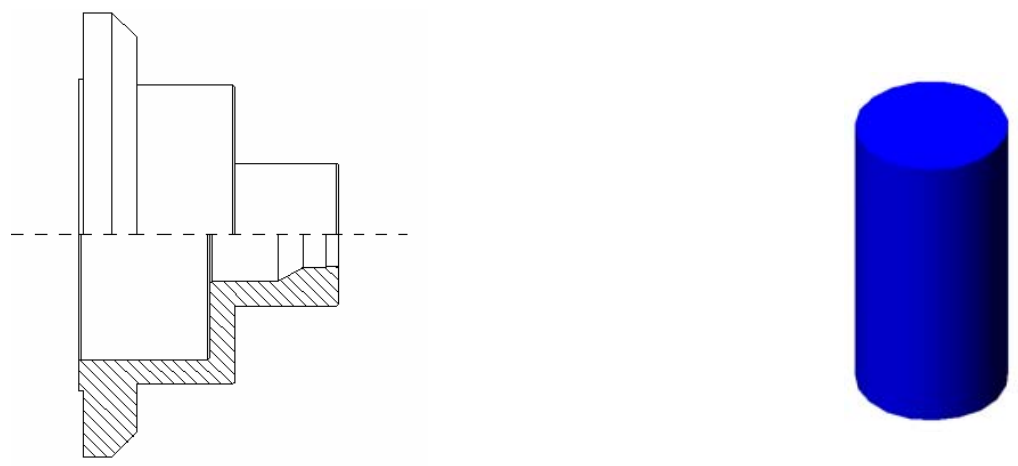

Figura 7.8. Matriz (à esquerda) e o corpo-de-prova produto da extrusão

A principal vantagem da extrusão e sua característica mais importante é o seu processo contínuo de alimentação e produção de elementos perfilados, tornando-o mais produtivo em relação aos outros processos de conformação. No entanto, tratando-se de elementos estruturais de plástico reciclado, alguns pontos devem salientados: a extrusora a ser utilizada deverá ser bastante robusta e potente, haja vista a produtividade e a dimensão dos elementos; tratando-se de plástico reciclado, deverá ser considerado um maior desgasta da rosca e da camisa, em função das impurezas do material. Uma tela localizada no crivo, mostrado na figura 7.6 deverá ser bastante solicitada, pois barrará impurezas maiores, sendo fundamental para a qualidade final do produto; no projeto dessa extrusora deverá ser considerado também dispositivos de ventilação para a liberação dos gases gerados durante o aquecimento do material. 


\subsection{MOLDAGEM POR PULTRUSÃO}

De acordo com Goodman (2002), a pultrusão é um termo adotado para descrever o processo de extrusão contínua de perfis de plástico reforçado. Fibras de reforço, sob a forma de fios, são puxadas através de um reservatório (banheira) para a impregnação da resina polimérica de uma matriz e finalmente o perfil passa por uma zona de cura. A figura 7.9 esquematiza essa técnica de conformação.

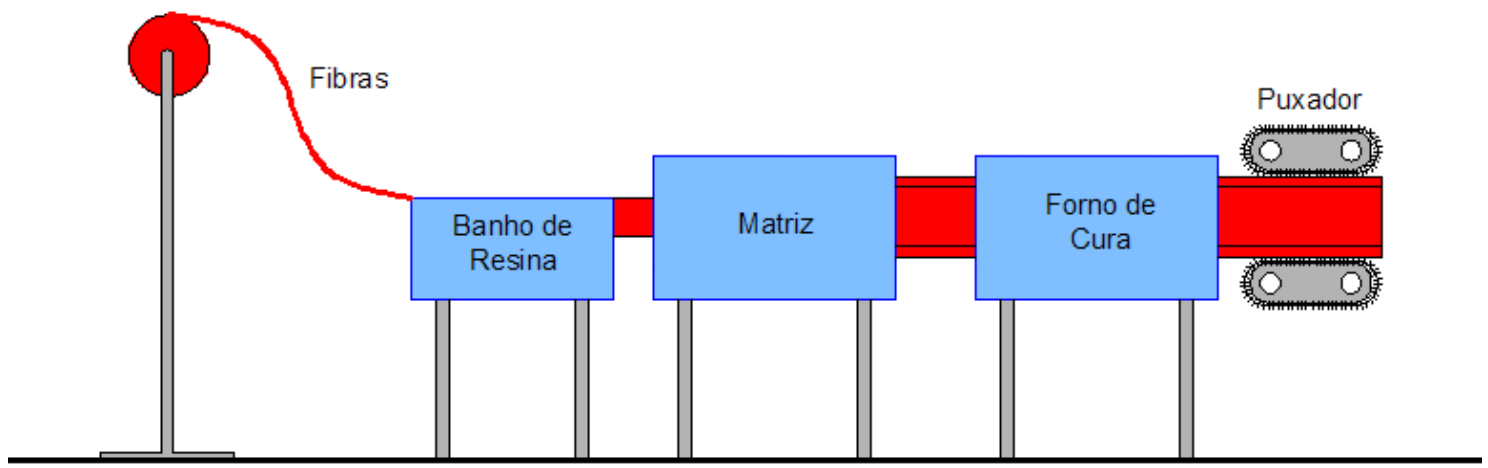

Figura 7.9. Modelo esquemático da pultrusão

A pultrusão é empregada na conformação de perfis com fins estruturais, pois a grande concentração de fibras e a sua disposição, paralelas ao eixo do perfilado, permite que as peças alcancem elevadas resistências mecânicas. A figura 7.10 mostra um perfil duplo I obtido a partir dessa técnica.

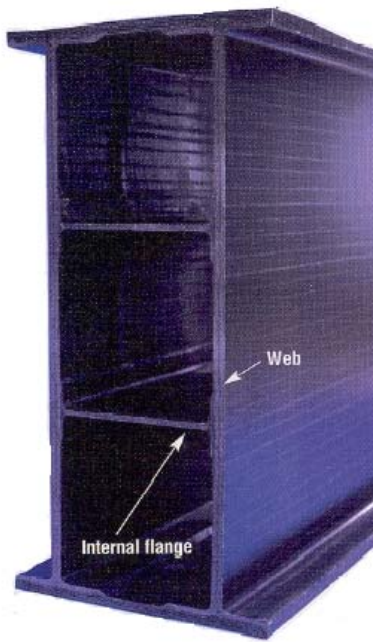

Figura 7.10. Perfil duplo I obtido por pultrusão. Fonte: www.me.gatech.edu

Diversos são os filamentos e mantas utilizados para o reforço na peça pultrusada. A figura 7.11 mostra algumas formas em que a fibra de vidro pode estar disposta, como, por exemplo, sob a forma de fios, de tramas formando uma manta, e também de maneira aleatória. 

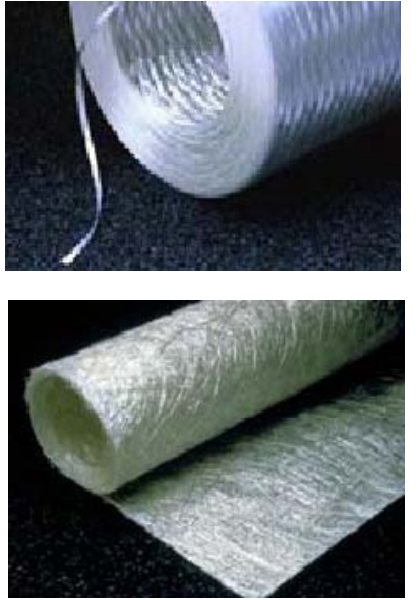
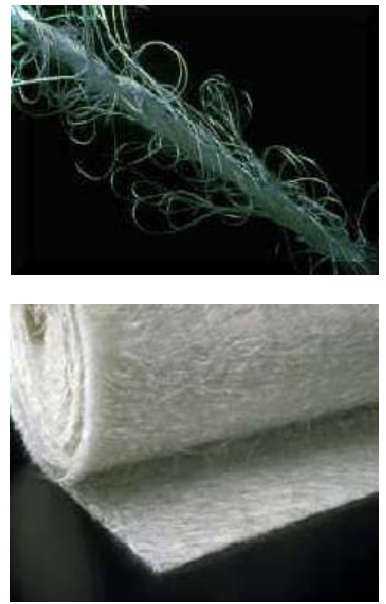

Figura 7.11. Disposição das fibras de vidro utilizadas na moldagem por pultrusão Fonte: www.me.gatech.edu

\subsection{CONFORMAÇÃO DE CHAPAS PLÂSTICAS}

Predominantemente, existem quatro processos utilizados na moldagem de chapas plásticas, sendo que todos envolvem o amolecimento por aquecimento da placa. Envolvem também a impulsão da chapa aquecida e flexível contra os contornos de um molde. Esses processos são:

- $\quad$ Conformação em moldes combinados;

- $\quad$ Conformação por escorregamento;

- $\quad$ Moldagem em ar comprimido;

- Moldagem a vácuo.

\subsubsection{Conformação em moldes combinados}

Neste processo a chapa é aquecida até o amolecimento e prensada em um par de moldes. A pressão pode ser aplicada hidráulica ou pneumaticamente, ficando sua magnitude situada no intervalo de 0,03 a $1 \mathrm{MPa}$. A figura 7.12 ilustra este processo.

Dentre os processos citados, este é o mais oneroso, devido à necessidade de se utilizarem dois moldes. Além disso, os moldes devem ser feitos de aço, alumínio reforçado ou certas ligas.

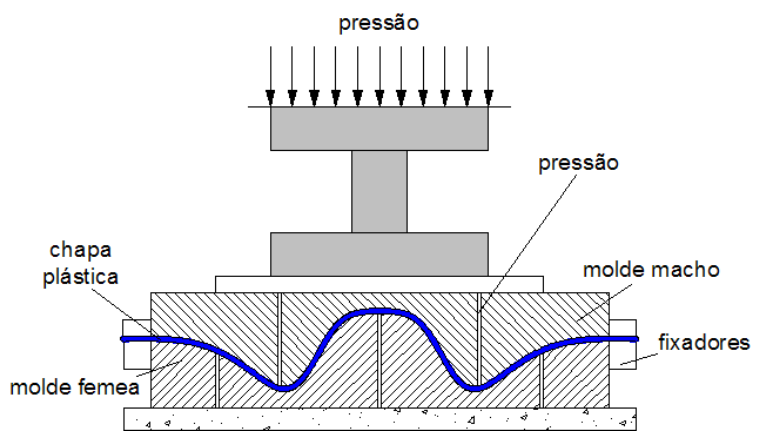

Figura 7.12. Conformação de chapas plásticas em moldes combinados 


\subsubsection{Conformação por escorregamento}

Neste processo a placa termoplástica aquecida é conformada mecanicamente ao redor de um molde macho, por meio de uma prensa hidráulica de duplo efeito.

O processo compreende duas etapas, de aquecimento e fechamento da prensa. A chapa é fixada apenas levemente pelas bordas, podendo escorregar sob as garras, que são deslizadas por sobre a placa, que vai assumindo a geometria do molde.

Esse processo é utilizado quando se deseja evitar ou minimizar o afinamento excessivo na moldagem de peças embutidas.

\subsubsection{Moldagem a ar comprimido}

Neste processo a chapa plástica é novamente aquecida e comprimida contra uma cavidade fêmea por meio de ar comprimido, a pressões de até $1 \mathrm{MPa}$.

\subsubsection{Moldagem a vácuo}

Consiste na fixação da chapa termoplástica, sobre um molde, aquecendo-a a uma temperatura de conformação e removendo-se o ar contido entre a chapa e o molde. A pressão atmosférica, então, força a chapa de encontro aos contornos do molde. Após o endurecimento, a chapa pode ser removida do molde.

Dentre o processo de conformação de chapas plásticas, este é, possivelmente, o mais barato, pois as baixas pressões empregadas permitem moldes leves e equipamentos simples. Essa vantagem levou à popularidade da técnica e à difusão de variantes no processo, dentre as quais podemos citar: conformação em molde fêmea, em molde macho, por repulsão, livre a vácuo, por revestimento, moldagem a vácuo com êmbolo e moldagem com colchão de ar.

As figuras 7.13 e 7.14 ilustram duas dessas técnicas de moldagem a vácuo, respectivamente com moldes macho e fêmea.

Nas duas figuras, na parte (a) a chapa plástica é fixada e aquecida até a temperatura de conformação; na (b) a chapa é impulsionada, forçada a entrar em contato com o molde e, então, selada. O vácuo é então aplicado e a chapa adquire a forma do molde; na parte (c) a peça é, então, desmoldada e adquire uma espessura homogênea. 


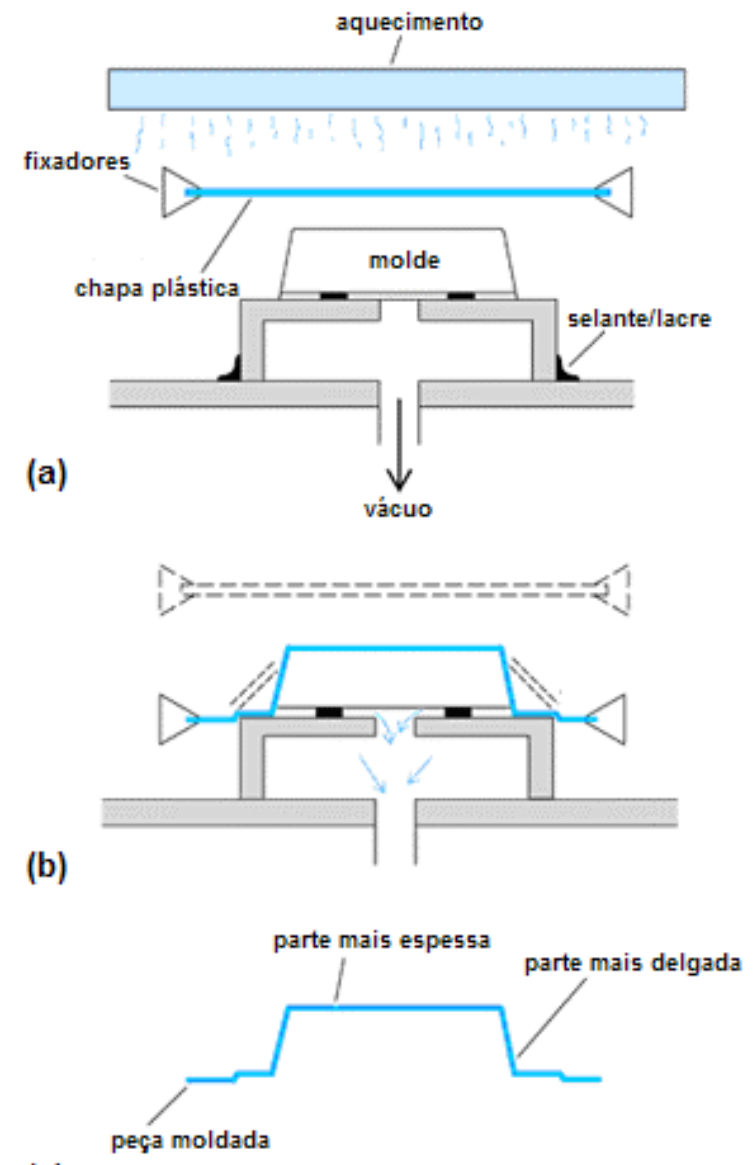

(c)

Figura 7.13. Moldagem a vácuo em molde macho. Fonte: GOODMAN, 2002

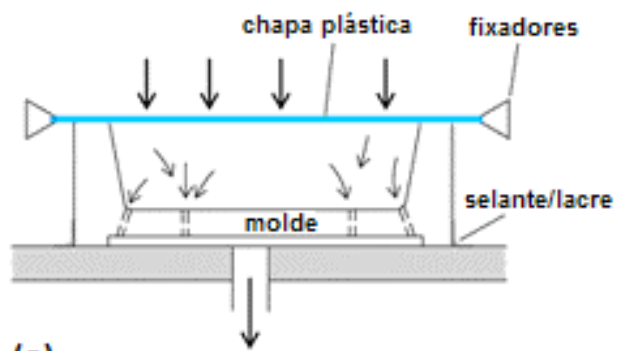

(a)
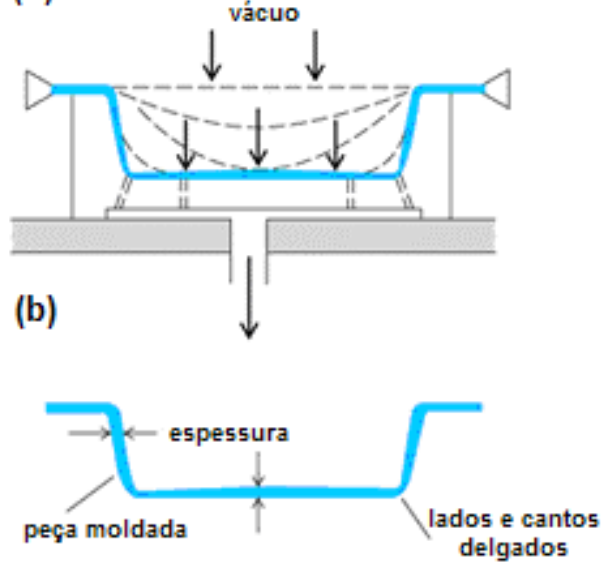

(c)

Figura 7.14. Moldagem a vácuo em molde fêmea. Fonte: GOODMAN, 2002 


\section{Reciclagem dos Plásticos}

Um dos aspectos relevantes para a viabilidade do uso do material plástico reciclado em elementos estruturais é a determinação, com segurança, de suas propriedades mecânicas. Se o fabrico de elementos estruturais exige o manejo de grandes volumes, esse material deve possuir uma homogeneidade que permita a previsão de seu comportamento quando solicitado por ações externas.

Não é significativo, portanto, garantir o comportamento de um determinado material, se ele não for uma amostra representativa do todo. Em se tratando do plástico reciclado, é de fundamental importância o conhecimento e o entendimento do processo de reciclagem.

Os termoplásticos, teoricamente, podem ser reciclados indefinidamente. No entanto, é sabido que há uma alteração nas características desse plástico, como resultado de diversos fatores: intempéries a que se expôs, contaminação, falhas na coleta e na triagem, degradação e quebra das cadeias poliméricas que compõem o plástico, dentre outros.

O plástico produzido em escala comercial já está presente na sociedade há mais de um século. A sua reciclagem, no entanto, apesar de ser realizada pelas indústrias para o reaproveitamento das perdas de produção, é um fenômeno recente quando se trata do volume de material plástico que atualmente é reciclado.

O paradigma de uma sociedade preocupada somente com o custo, o tempo e a qualidade tem cedido espaço para um pensamento baseado na sustentabilidade. Esse neologismo pode ser entendido como o conhecimento das necessidades e aspirações humanas no presente, sem esquecer o compromisso de permitir às futuras gerações conhecer as suas necessidades e aspirações, como foi definido pela WCED (World Commission on Environment and Development,1987).

A figura 8.1 mostra esse novo paradigma sob a forma de dois triângulos, sendo que antigo não foi totalmente descartado, haja vista que o custo, o tempo e qualidade devem sempre ser levados em consideração. No entanto, eles foram englobados por uma idéia maior, em que se considera a satisfação humana, o mínimo consumo de energia e o mínimo impacto ao meio ambiente. 


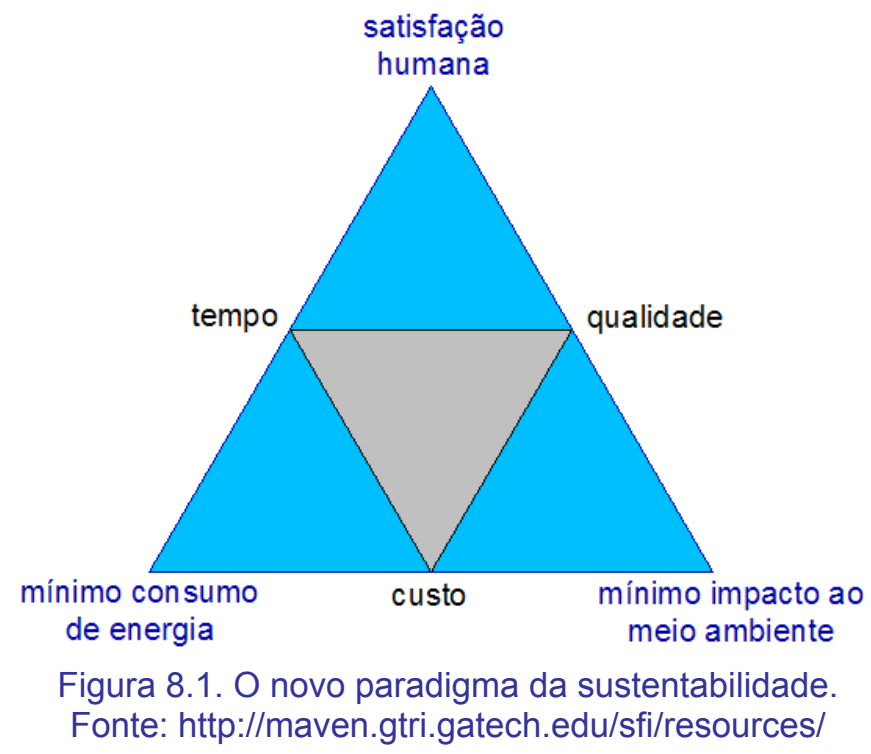

A seguir serão apresentados algumas definições e conceitos sobre a reciclagem, bem como dados que exemplificam e mensuram essa atividade, dentro do contexto nacional e do mundo.

\subsection{O QUE É RECICLAGEM?}

A reciclagem pode ser entendida como o termo que designa uma série de atividades que incluem a coleta de materiais descartados pela sociedade, a triagem, o processamento e a transformação desses materiais em matéria-prima para a manufatura de novos produtos.

De uma maneira geral, a reciclagem pode ser dividida nas seguintes etapas:

- Coleta: etapa importante que está fundamentalmente ligada a políticas públicas de conscientização, campanhas de esclarecimento e infra-estrutura para coleta e armazenamento do resíduo a ser reaproveitado;

- Separação ou triagem: triagem por tipos de material (papel, plásticos, madeiras, metais etc.). No caso dos plásticos, deve ser feita a triagem por tipo de plástico (PVC, polietileno, polipropileno etc.);

- Revalorização: etapa intermediária que prepara o material coletado e separado para a comercialização e/ou etapa de transformação;

- Transformação: processamento do material para a geração de novos materiais ou produtos, agregando-Ihes valor. Para os plásticos, trata-se dos tipos de processamento já citados no cap. 7, como: extrusão, pultrusão, moldagem por injeção, moldagem por transferência, moldagem por compressão, dentre outros. 


\subsection{CLASSIFICAÇÃO DOS PLÁSTICOS}

Nem todos os plásticos podem ser reciclados, e dentre os recicláveis foi criada uma classificação com o objetivo de auxiliar na identificação feita no trabalho de triagem. Consiste numa numeração de 1 a 7 , como mostrada a seguir, adotado pela ABNT na Norma Brasileira 13230 - Reciclabilidade e identificação de materiais plásticos (NBR 13230, 1994).

(1) PET - politereftalato de etileno

2. PEAD - polietileno de alta densidade

(3) PVC - policloreto de vinila

(4) PEBD - polietileno de baixa densidade

(5) PP - polipropileno

(6) PS - poliestireno

(7) Outros

\subsection{TIPO S DE RECICLAGEM}

De acordo com o Instituto Sócio-ambiental dos Plásticos PLASTVIDA (www.plastvida.org.br), pode-se classificar a reciclagem em três tipos, que serão detalhados a seguir.

\subsubsection{Reciclagem Química}

Neste processo os plásticos são transformados em petroquímicos básicos: monômeros ou misturas de hidrocarbonetos que servem como matéria-prima, em refinarias ou centrais petroquímicas, para a obtenção de produtos nobres de elevada qualidade.

Tem como objetivo a recuperação dos componentes químicos individuais para serem reutilizados como produtos químicos ou para a produção de novos plásticos.

Essa reciclagem permite tratar a mistura de plásticos, reduzindo custos de prétratamento, custos de coleta e seleção. Além disso, permite produzir plásticos novos com a mesma qualidade de um polímero original.

Existem vários processos de reciclagem química, dentre os quais, pode-se citar:

- Hidrogenação: as cadeias são quebradas mediante o tratamento com calor e hidrogênio, gerando produtos capazes de serem processados em refinarias;

- Gaseificação: os plásticos são aquecidos com ar ou oxigênio, gerando-se gás de síntese contendo monóxido de carbono e hidrogênio; 
- Quimólise: consiste na quebra parcial ou total dos plásticos em monômeros, na presença de glicol/metanol e água;

- $\quad$ Pirólise: é a quebra das moléculas pela ação do calor, na ausência de oxigênio. Este processo gera frações de hidrocarbonetos capazes de serem processados em refinarias.

A figura 8.2 mostra, esquematicamente, o processo da reciclagem química.

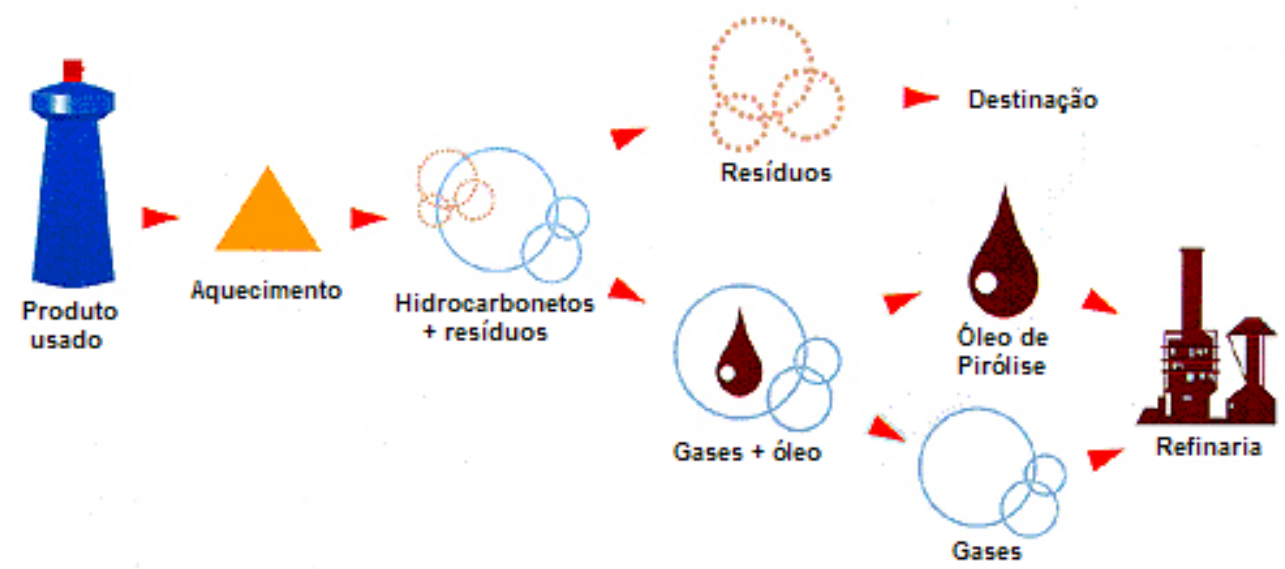

Figura 8.2. O processo da reciclagem química. Fonte: www.plastvida.org.br

\subsubsection{Reciclagem Mecânica}

É o tipo de reciclagem mais difundido e utilizado. Consiste na conversão dos resíduos plásticos pós-industriais ou pós-consumo em grânulos que podem ser reutilizados na produção de outros produtos, como sacos de lixo, solados, pisos, conduítes, mangueiras, componentes de automóveis, fibras, embalagens, dentre outros.

Essa reciclagem possibilita a obtenção de produtos compostos por um único tipo de plástico, ou produtos a partir de misturas de diferentes plásticos em determinadas proporções. Estima-se que no Brasil $15 \%$ do resíduo plástico pós-consumo sejam reciclados dessa maneira.

A seguir são apresentadas as etapas básicas desse processo:

- Separação: é a feita a triagem dos diferentes tipos de plásticos, de acordo com a identificação ou com o aspecto visual. Nesta etapa são separados também rótulos de materiais diferentes, tampas de garrafas e produtos compostos por mais de um tipo de plástico, embalagens metalizadas, grampos etc. Por ser uma etapa geralmente manual, a eficiência depende diretamente da prática das pessoas que executam esta tarefa. Outro fator determinante da qualidade é a fonte do material a ser separado, sendo que aquele oriundo da coleta seletiva é mais limpo em relação ao material proveniente dos lixões ou aterros; 
- Moagem: após a triagem, o plástico é moído e fragmentado em pequenos pedaços;

- Lavagem: o plástico passa por uma etapa de lavagem com água para a retirada dos contaminantes. É necessário que a água de lavagem receba um tratamento para a sua reutilização ou emissão como efluente. Em função desse impacto ambiental do descarte da água contaminada, alguns processos estão sendo propostos sem a etapa da lavagem.

- Aglutinação: Após a secagem, o material é compactado no aglutinador, reduzindo-se assim o volume que será enviado ao equipamento que fará o processamento final, que normalmente é uma extrusora. $O$ atrito dos fragmentos contra a parede do equipamento rotativo provoca elevação da temperatura, levando à formação de uma massa plástica. O aglutinador também é utilizado para incorporação de aditivos, como cargas, pigmentos e lubrificantes.

- Processamento: A extrusora funde e torna a massa plástica homogênea. $\mathrm{Na}$ saída da extrusora, encontra-se o cabeçote, do qual saem filamentos contínuos, que é resfriado num reservatório com água. Em seguida, são picotados num granulador e transformados em péletes (grãos plásticos).

A figura 8.3 mostra, passo a passo, o processo da reciclagem mecânica.

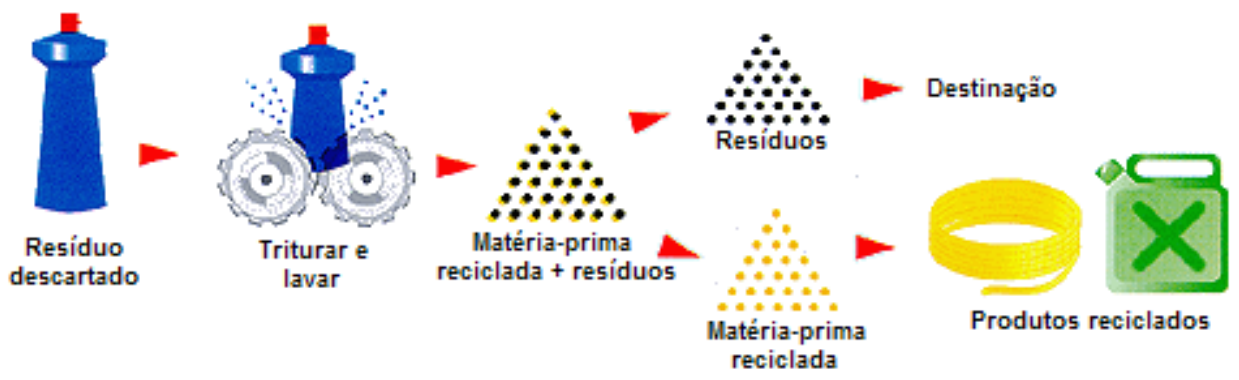

Figura 8.3. As etapas da reciclagem mecânica. Fonte: www.plastvida.org.br

\subsubsection{Reciclagem Energética}

É o processo que aproveita o resíduo plástico para a geração de energia através de processos térmicos e já representa $15 \%$ da reciclagem dos países da Europa Ocidental.

É importante ressaltar que essa reciclagem distingue-se da incineração, por utilizar os resíduos plásticos como combustível na geração de energia elétrica. Já a simples incineração não reaproveita a energia dos materiais.

Para efeito de comparação, pode-se afirmar que $1 \mathrm{~kg}$ de plástico possui uma capacidade de gerar energia equivalente à contida em $1 \mathrm{~kg}$ de óleo combustível. 
Além da economia e reaproveitamento da energia obtidas, ainda há uma redução de 70 a $90 \%$ da massa do material, restando apenas um resíduo inerte esterilizado. $O$ fluxograma da reciclagem elétrica é mostrado na figura 8.4

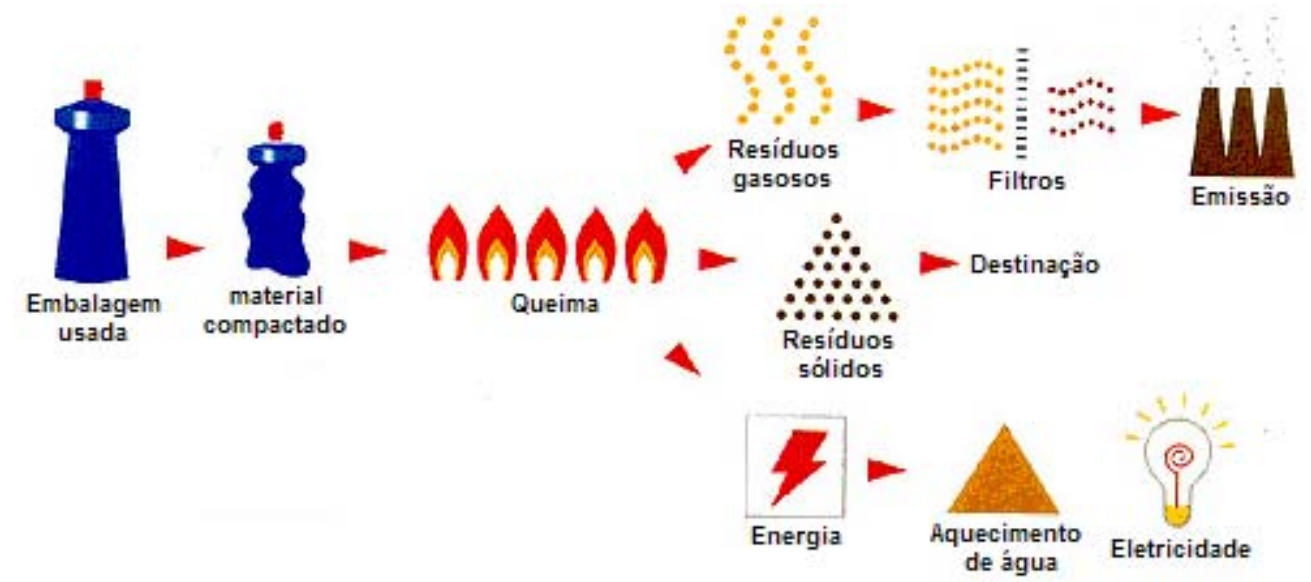

Figura 8.4. Fluxograma das etapas da reciclagem elétrica. Fonte: www. plastvida.org.br

\subsection{PERSPECTIVAS DA RECICLAGEM DOS PLÁSTICOS}

O mercado de reciclagem, apesar de já estar lidando com um grande volume de material, tem ainda margem para crescer bastante e mostra-se bastante promissor.

O gráfico da figura 8.5 exemplifica esse potencial de crescimento em nível mundial, mostrando o índice de reciclagem (em porcentagem) de diversos países da Europa, a partir de um estudo feito pela APME (Association of Plastics Manufactures in Europe) em 2002.

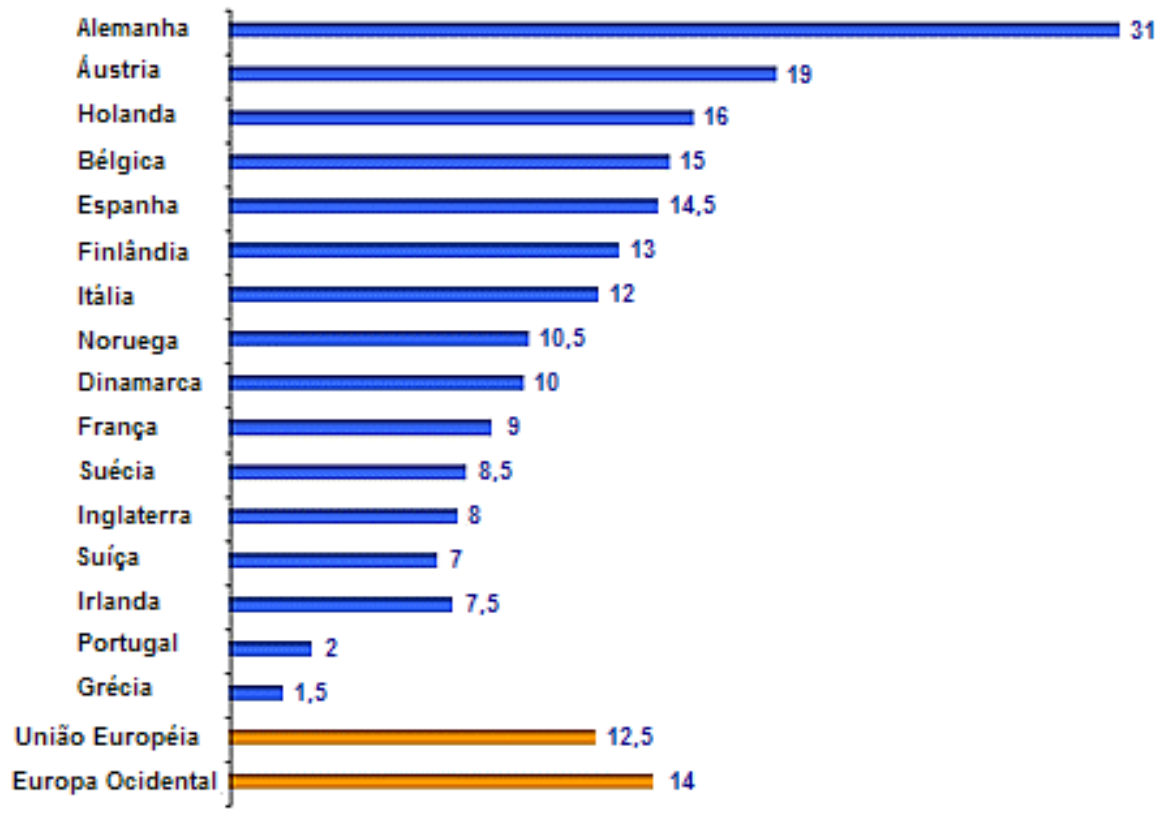

Figura 8.5. Índice de reciclagem para diversos países europeus. Fonte: www.plastvida.org.br 
Entende-se por índice de reciclagem a razão entre a quantidade total de produtos reciclados e a quantidade total de resíduos sólidos gerados.

Índice de Reciclagem $=\frac{\text { Quantidade de produtos reciclados }}{\text { Quantidade de resíduos sólidos gerados }} \cdot 100$

Juntamente com o conceito de sustentabilidade, que reforça o comprometimento e a responsabilidade da sociedade para com o meio ambiente, o resíduo descartado já não é mais visto como um material sem valor. Um exemplo é preço do polietileno de alta densidade (PEAD), cujo quilo do produto reciclado é comercializado por cerca de dois reais no mercado nacional (pouco menos de um dólar). Cerca de cinco anos atrás, o mesmo material podia ser obtido pela metade desse valor (MARCZAK, 2004).

Uma maneira de compreender o mercado da reciclagem é acompanhar a análise realizada pelo Instituto PLASTVIDA sobre uma pesquisa do IBGE (Instituto Brasileiro de Geografia e Estatística), denominada "Elaboração e Monitoramento dos Índices de Reciclagem Mecânica dos Plásticos no Brasil", desenvolvida no ano de 2004, com base nos resultados de 2003. A seguir será apresentado um resumo dos dados obtidos por essa pesquisa.

A composição média (porcentagem em peso) do lixo obtido pela coleta seletiva, nas cidades em que possui esse sistema, é mostrada no gráfico da figura 8.6.

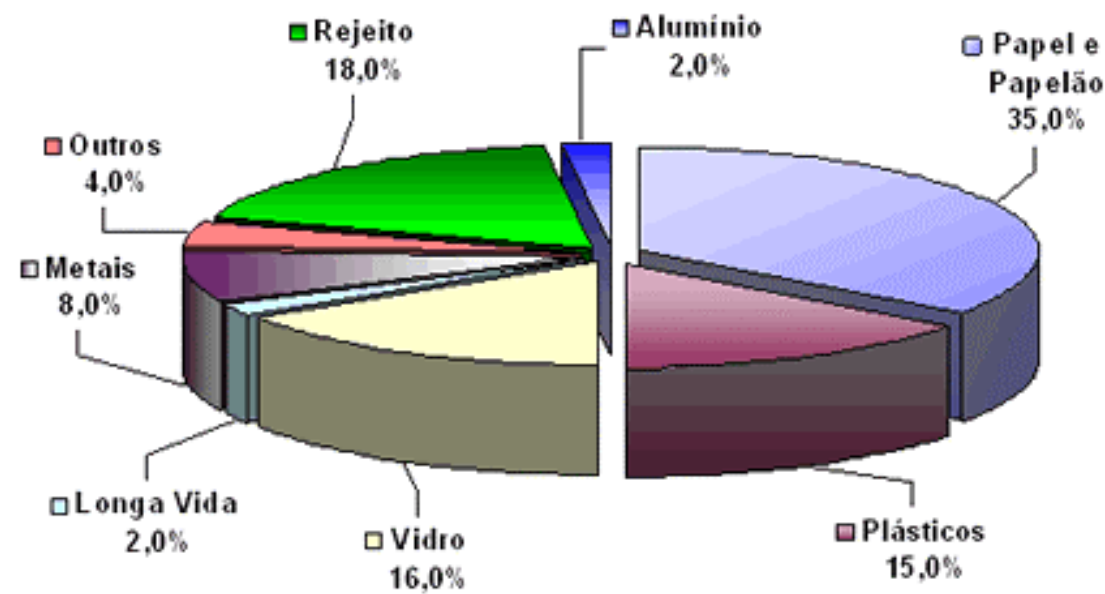

Figura 8.6. Composição média do lixo da coleta seletiva. Fonte: www.plastvida.org.br

De acordo com o Instituto PLASTIVIDA, o mercado da reciclagem de material plástico participa de praticamente todos os setores da indústria que possuem o plástico como matéria-prima.

A tabela 8.1 mostra os dados da quantidade de plástico reciclado utilizado no Brasil e a sua porcentagem, por diversos segmentos de mercado. 
Tabela 8.1. Mercados consumidores do plástico reciclado. Fonte: www.plastvida.org.br

\begin{tabular}{lcc} 
Segmentos de Mercado & \multicolumn{2}{c}{ Total } \\
& (ton) & $\%$ \\
\hline Utilidades domésticas & 166.245 & 23,6 \\
Construção civil & 97.860 & 13,9 \\
Têxtil & 74.957 & 10,7 \\
Descartáveis & 63.084 & 9 \\
Agropecuária & 55.389 & 7,9 \\
Calçados & 41.510 & 5,9 \\
Eletroeletrônico & 37.224 & 5,3 \\
Limpeza doméstica & 31.455 & 4,5 \\
Industrial & 30.694 & 4,4 \\
Automobilístico & 19.168 & 2,7 \\
Móveis & 12.649 & 1,8 \\
Outros & 72.761 & 10,3 \\
TOTAL & 702.997 & 100
\end{tabular}

As tabelas 8.2, 8.3 e 8.4 servem como base para o cálculo do Índice de Reciclagem no Brasil, de acordo com os dados da pesquisa do IBGE supracitada.

Tabela 8.2. Geração de plástico pós-consumo (ton/ano). Fonte: www.plastvida.org.br

\begin{tabular}{lcccccc} 
& Centro-oeste & Norte & Nordeste & Sul & Sudeste & Brasil \\
\hline PET & 24.979 & 22.903 & 84.953 & 59.747 & 187.816 & 380.397 \\
PEAD & 24.714 & 22.660 & 84.053 & 59.113 & 185.824 & 376.364 \\
PVC & 6.772 & 6.209 & 23.030 & 16.197 & 50.916 & 103.123 \\
PEBD/ PELBD & 39.851 & 36.539 & 135.534 & 95.320 & 299.641 & 606.885 \\
PP & 32.935 & 30.197 & 112.012 & 78.777 & 247.637 & 501558 \\
PS & 8.807 & 8.075 & 29.952 & 21.065 & 66.217 & 134.115 \\
Outros tipos & 4.948 & 4.537 & 16.829 & 11.836 & 37.207 & 75.357 \\
TOTAL & 143.005 & 131.119 & 486.364 & 342.054 & 1.075 .257 & 2.177 .799
\end{tabular}

Tabela 8.3. Reciclagem de plástico pós-consumo (ton/ano). Fonte: www.plastvida.org.br

\begin{tabular}{lcccccc} 
& Centro-oeste & Norte & Nordeste & Sul & Sudeste & Brasil \\
\hline PET & 0 & 0 & 23.221 & 37.472 & 88.615 & 149.307 \\
PEAD & 3.742 & 0 & 10.817 & 14.177 & 33.871 & 62.606 \\
PVC & 0 & 0 & 4.903 & 4.669 & 7.481 & 17.054 \\
PEBD/ PELBD & 3.575 & 0 & 5.796 & 24.198 & 46.272 & 79.841 \\
PP & 1.618 & 0 & 7.480 & 5.383 & 26.558 & 41.038 \\
PS & 0 & 0 & 0 & 2.753 & 3.550 & 6.303 \\
Outros tipos & 0 & 0 & 0 & 925 & 2.058 & 2.983 \\
TOTAL & 8.935 & 0 & 52.217 & 89.576 & 208.405 & 359.133
\end{tabular}

Tabela 8.4. Índice de reciclagem de plástico pós-consumo (\%). Fonte: www.plastvida.org.br

\begin{tabular}{lcccccc} 
& Centro-oeste & Norte & Nordeste & Sul & Sudeste & Brasil \\
\hline PET & 0 & 0 & 27,3 & 62,7 & 47,2 & 39,3 \\
PEAD & 15,1 & 0 & 12,9 & 24 & 18,2 & 16,6 \\
PVC & 0 & 0 & 21,3 & 28,8 & 14,7 & 16,5 \\
PEBD/ PELBD & 9 & 0 & 4,3 & 25,4 & 15,4 & 13,2 \\
PP & 4,9 & 0 & 6,7 & 6,8 & 10,7 & 8,2 \\
PS & 0 & 0 & 0 & 13,1 & 5,4 & 4,7 \\
Outros tipos & 0 & 0 & 0 & 7,8 & 5,5 & 4 \\
TOTAL & 6,2 & 0 & 10,7 & 26,2 & 19,4 & 16,5
\end{tabular}


De acordo com os dados analisados pelo Instituto PLASTVIDA, chega-se a um Índice de Reciclagem de 16,5\% para o Brasil, o que o coloca entre os primeiros países do mundo em reciclagem de plástico pós-consumo, analisando a figura 8.5. É válido lembrar, no entanto, que os dados dessa figura referem-se a 2002, ao passo que a pesquisa do IBGE é de 2003.

A campeã nacional de reciclagem de plástico pós-consumo é a região Sudeste, com $58 \%$. Em seguida vem a região Sul com $24,9 \%$ e, posteriormente, a região Nordeste com $14,5 \%$. É pertinente lembrar que isso não seria possível sem a imensa população de cerca de 500 mil catadores informais, que recolhem os resíduos e os revendem. 


\section{Considerações Finais e Conclusões}

\subsection{CONSIDERAÇÕES FINAIS}

Esta pesquisa é um trabalho inaugural sobre o tema no Departamento de Estruturas da EESC/USP e, portanto, um dos principais objetivos - que se acredita ter sido alcançado - é lançar a base do que pode ser uma nova área de estudo nesse departamento: os elementos estruturais de plástico reciclado. Por conseqüência, ao introduzir um material estrutural alternativo, desmistifica-se para a comunidade científica e para a sociedade o seu potencial e as suas vantagens que, dentre as várias, pode-se citar: o forte apelo ecológico, o baixo peso específico, a indiferença à deterioração por decomposição e ataque de microorganismos, a alta resistência à corrosão, o fácil processamento e o reduzido custo de manutenção.

Espera-se também ter contribuído para o aumento da reciclagem dos plásticos no País, dando um uso mais nobre a esses resíduos e agregando-lhe valor. Dessa forma, desoneram-se os aterros sanitários e lixões de um material que pode levar mais de 450 anos para se degradar, além de contribuir para o surgimento de novo mercado. É importante salientar, contudo, que deve haver uma contrapartida por parte da iniciativa privada, apoiando pesquisas na área e investindo esforços e recursos para que isso se torne realidade.

A abundância de material plástico reciclado a baixo custo é uma alternativa a ser explorada na Engenharia de Estruturas e não deve mais ser desconsiderada. A pesquisa sobre o tema no Brasil é incipiente e a escassez de uma bibliografia nacional evidencia esse atraso. No entanto, em países como Estados Unidos, Japão e Canadá, os avanços na área são notáveis, tornando exeqüível a construção de pontes, passarelas, deques, ferrovias e marinas, com elementos de sustentação de plástico, reciclado ou não.

\subsection{CONCLUSÕES}

Com base no que foi pesquisado sobre o emprego do material plástico reciclado em elementos estruturais, pode-se fazer as seguintes observações: 
Dentre os plásticos descartados, o que representa o maior percentual é o polietileno, com 37\% (PIVA e WIEBECK, 2004). Como a manufatura de elementos estruturais de plástico exige um grande volume de material disponível, essa abundância coloca-o em vantagem em relação aos outros plásticos, e deve ser posto em evidência quando da escolha do tipo de plástico.

A pesquisa de Martins et al. (1999) também aponta alguma das vantagens do polietileno reciclado. Tal trabalho contém resultados que apontam melhorias nas suas propriedades mecânicas quando exposto às radiações ionizantes. Apesar de ter havido um endurecimento por deformação (strain hardening), houve um aumento da ordem de $15 \%$ no limite de resistência à tração e de aproximadamente $24 \%$ na rigidez, quando submetido a uma irradiação ao ar de $2000 \mathrm{kGy} / \mathrm{h}$. Esse comportamento tem como causa a formação de ligações cruzadas entre as cadeias moleculares, a partir da reticulação provocada pela irradiação.

O polietileno, assim como outros termoplásticos, possue uma baixa rigidez quando comparado com os materiais de construção tradicionais, como a madeira, o aço e o concreto. A figura 9.1 mostra o módulo de elasticidade para alguns plásticos, para o concreto e a para a madeira.

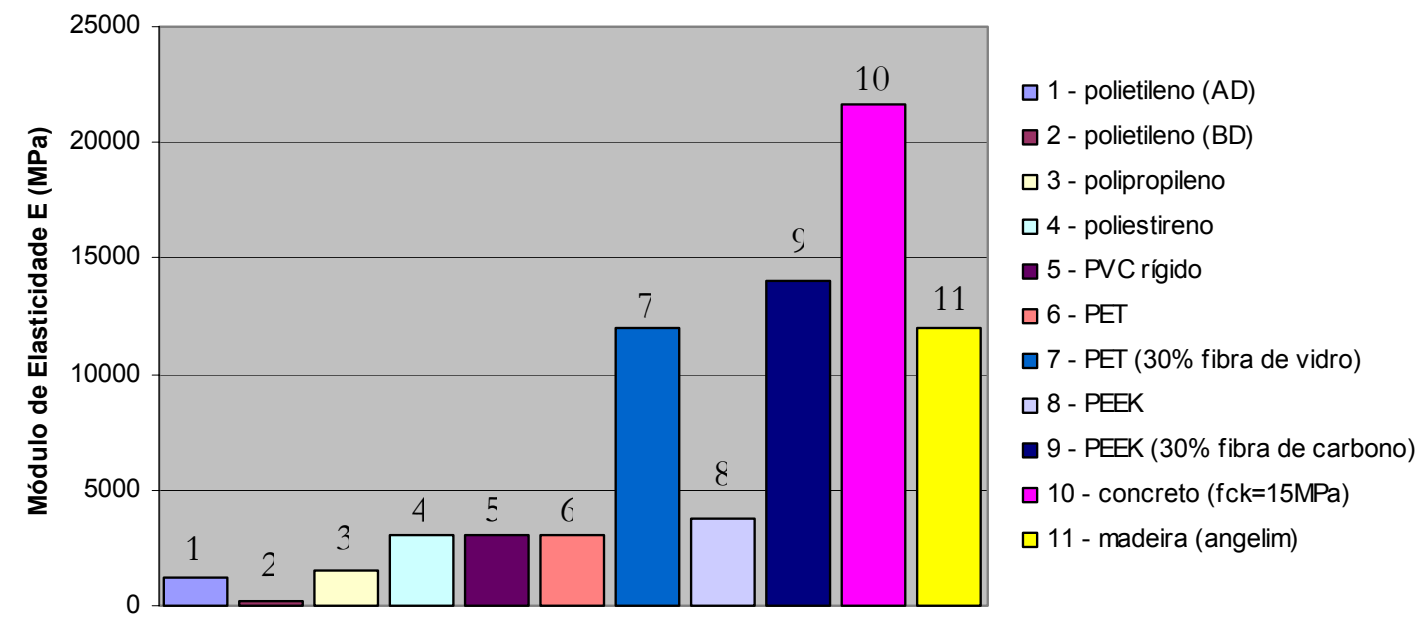

Figura 9.1. Módulo de elasticidade para diversos materiais.

Fontes: CRAWFORD, 1987; NBR 6118, 2003; http://www.ipt.br/areas/dpf/propriedades

Como pode ser observado, a adição de fibras aumenta substancialmente o módulo de elasticidade, como é o caso do PET e do PEEK (resina termoplástica de alta resistência, VITRECX) que, formando compósitos, com $30 \%$ de fibra de vidro e $30 \%$ de fibra de carbono, respectivamente, mais do que dobraram suas rigidezes. Além disso, a adição de fibras nos plásticos pode também para atenuar os fenômenos dependentes do tempo, como a fluência e a relaxação. Dessa forma, vê-se o 
desenvolvimento dos elementos estruturais de plástico, inevitavelmente passando pela adição de fibras e pelo domínio da tecnologia dos materiais compósitos.

A baixa rigidez também pode ser compensada também com o emprego de armaduras protendidas ou com o desenvolvimento de geometrias ótimas, aproveitando a alta relação resistência/densidade desses materiais.

Uma das principais vantagens dos plásticos, quando comparados aos materiais tradicionais, é a sua possibilidade de ser moldado nas mais diversas formas, não exigindo soldas e outras formas de conformação para a obtenção do produto final. Enquanto um perfil metálico possui diversas etapas para a sua manufatura, um perfil de material plástico pode ser confeccionado numa única etapa.

A relação resistência/densidade para os materiais plásticos, principalmente os compósitos poliméricos, é superior à dos materiais tradicionais. Esse peso reduzido permite um melhor aproveitamento da capacidade estrutural do elemento e a adoção de um sistema estrutural mais eficiente.

As características de um plástico podem ser desenvolvidas a partir das necessidades de projeto, sendo esta uma diferença básica perante os materiais tradicionais, que normalmente têm seu projeto baseado nas propriedades disponíveis.

Os plásticos possuem comportamento dependente da temperatura e da taxa de deformação. A temperatura pode ser considerada um fator limitante, pois à medida que se aumenta a temperatura, diminui-se o módulo de elasticidade. Em se tratando de materiais estruturais, a perda de rigidez torna-se crítica, pois é indesejável o surgimento de deformações excessivas, causando desconforto aos usuários e até mesmo o colapso da estrutura. Antes de se projetar uma estrutura de plástico, deve-se observar com que intensidade os elementos estruturais estarão expostos ao calor, fazendo-se o dimensionamento para a pior condição possível, ou seja, a maior temperatura.

A inflamabilidade dos plásticos deve ser considerada. Para que o material possa ser utilizado com segurança em edificações, devem ser utilizadas normas que prevejam o cuidado com a inflamabilidade dessas estruturas e até mesmo o emprego de instalações especiais de combate ao incêndio. A adição de produtos químicos retardantes de chama, durante a manufatura, é uma forma de se atenuar o perigo de incêndio em estruturas com elementos de material plástico. Outra solução é a utilização de uma camada protetora de material isolante. 
Os modelos viscoelásticos mais simples são o Modelo de Maxwell e o de KelvinVoigt. Por possuírem sua formulação bastante simples, eles possuem deficiências, tais como:

(a) O Modelo de Maxwell não é sensível à recuperação viscoelástica quando sofre um descarregamento;

(b) O Modelo de Maxwell possui uma deformação à fluência linear muito diferente da realidade;

(c) O Modelo de Kelvin-Voigt não é sensível à relaxação, permanecendo constantes as tensões quando mantidas constantes as deformações;

(d) A evolução exponencial das funções que representam os fenômenos viscoelásticos para os dois modelos é uma aproximação razoável, mas as curvas dos ensaios experimentais se adequam mais às funções seno hiperbólicas.

O Modelo Associado é o mais simples que possui sensibilidade aos fenômenos viscoelásticos mais importantes: a fluência, a relaxação e a recuperação. Uma desvantagem é que, a partir de uma curva de fluência experimental, é possível fazer uma análise do comportamento dependente do tempo somente para o nível de tensões da ordem de magnitude dos dados dos ensaios. Para uma análise envolvendo vários níveis de tensões, seria necessária uma família de curvas de fluência. Isso torna o método pouco funcional, haja vista que um projeto estrutural deve ser concebido para diversas situações.

\subsection{SUGESTÕES PARA PESQUISAS FUTURAS}

Este trabalho é apenas o primeiro de uma série que se pretende realizar no Departamento de Estruturas da EESC/USP. A seguir são apresentadas algumas sugestões de pesquisa que são fundamentais para a consolidação desta nova área de pesquisa.

(a) Caracterização do plástico reciclado a ser adotado como material estrutural. Inicialmente, esta pesquisa propunha-se a realizar também ensaios experimentais de caracterização do material plástico. Seriam ensaios de curta duração (tração, compressão e flexão) balizados por roteiros em conformidade com as normas da ASTM. As matrizes, necessárias à extrusão dos corpos-deprova, foram desenvolvidas em parceria com o Departamento de Engenharia Mecânica desta Escola e serão utilizadas pelos pesquisadores que darão continuidade a essa linha de pesquisa, no âmbito do mestrado e do doutorado. $\mathrm{O}$ anexo A apresenta o projeto das matrizes e um roteiro resumido dos ensaios supracitados; 
(b) A influência da adição de fibras nas propriedades mecânicas, para adequação do plástico reciclado para uso em elementos estruturais;

(c) Análise experimental e numérica de elementos estruturais de plástico reciclado;

(d) Otimização da geometria das estruturas de plástico reciclado;

(e) Estudo das ligações em sistemas estruturais de plástico reciclado;

(f) Estudo dos modelos viscoelásticos de previsão mais sofisticados e sua implementação computacional;

(g) Desenvolvimento de métodos de dimensionamento simplificado para as estruturas de plástico reciclado;

(h) O estudo dos fenômenos de instabilidade, como a flambagem, nos elementos estruturais de plástico reciclado. 


\section{Referências Bibliográficas}

AGNELLI, J. A. M. (200?). Verbetes em polímeros. Departamento de Engenharia de Materiais - UFSCar.

ALBANO, C.; SANCHEZ, G. (1999). Study of mechanical, thermal and thermodegradative properties of virgin PP with recycled and non-recycled HDPE. Polymer Engineering and Science, v. 39, Agosto 1999.

Anônimo (1985). Apostila de processamento de polímeros. Florianópolis: Impressa Universitária da UFSC.

AMERICAN SOCIETY FOR TESTING AND MATERIALS (1994). D5592-94: Standard guide for material properties needed in engineering design using plastics;

ASSOCIAÇÃO BRASILEIRA DE NORMAS TÉCNICAS (1994). NB 13230: Reciclabilidade e identificação de materiais plásticos. Rio de Janeiro.

BASTOS, P. S. S. (1989). Análise experimental de dormentes de concreto protendido reforçados com fibras de aço. 256p. Tese (Doutorado). Universidade de São Paulo, São Carlos. 1999.

CARROLL, D. R.; STONE, R. B.; SIRIGNANO, A. M.; SAINDON. R. M.; GOSE, S. C.; FRIEDMAN, M. A. (2001). Structural properties of recycled plastic/sawdust lumber decking planks. ELSEVIER: Resources, Conservation \& Recycling. Disponível em: <http://www.elsevier.com/locate/resconrec>. Acesso em 15 Dez 2004.

CORREA, C. A. F.; FONSECA, S. N.; RAZZINO, C. A.; HAGE JR, E. (2003). Compósitos termoplásticos com madeira. Polímeros: Ciência e Tecnologia, v.13, n.3, p.154-165, 2003.

CORREIA, J. R.; BRANCO, F. A.; FERREIRA, J. G. (2005a). Structural behavior of GFRPconcrete hybrid beams. Composites in Construction 2005 - Third International Conference, Lyon, France, Jul 2005.

CORREIA, J. R.; CABRAL-FONSECA, S.; BRANCO, F. A.; FERREIRA, J. G.; EUSÉBIO, M. I.; RODRIGUES, M. P. (2005b). Durability of glass fibre reinforced polyester (GFRP) pultruded profiles used in civil engineering applications. Composites in Construction 2005 Third International Conference, Lyon, France, Jul 2005. 
CRAWFORD, R. J. (1987). Plastics engineering. 2nd Edition. Belfast: Pergamon Press.

DONATO, M. (1972). O mundo do plástico: o plástico na história, o plástico no mundo, o plástico no Brasil. São Paulo: Goyana S.A. - Indústrias Brasileiras de Matérias Plásticas.

DOWNS, J. (2002). Your recycled plastic may build a bridge. The Philadelphia Inquirer, 21 Jul 2002.

ELLIOTT, C. D. (1994). The development of materials and systems for buildings - technics and architecture. Cambridge: MIT Press.

ENCICLOPÉDIA VIRTUAL ABOUT.COM. The history of construction materials. Disponivel em: <http://inventors.about.com/library/inventors/blconstructionmaterials .htm>. Acesso em 23 Fev 2005.

FOLHA ONLINE CIÊNCIA: Brasil recicla menos de 5\% do seu lixo urbano. Disponível em: < http://www1.folha.uol.com.br/folha/ciencia/ult306u9268.shtml>. Acesso em 26 Jan 2005.

FOLHA ONLINE COTIDIANO: Coleta de lixo e limpeza são precárias no Brasil, mostra pesquisa. Disponível em: <http://www1.folha.uol.com.br/folha/cotidiano/ ult95u102617>. Acesso em 26 Jan 2005.

GALIOTO, C. E. (2004). Researchers develop plastic lumber. University - The Daily Targum, 21 Out 2004.

GOODMAN, S. H. (2002). Plastics processing. Disponível em: <http://www.accessscience. com, DOI 10.1036/1097-8542.526800>. Acesso em 15 Ago 2005.

GUTERMAN, L. (2003). One world: plastics - a group of researchers defies wisdom with polymer blends. The Chronicle of Higher Education, 28 Fev 2003.

HADDAD, Y. M. (1995). Viscoelasticity of engineering materials. 1st. Ed. London: Chapman \& Hall.

IDOL, J. D.; LEHMAN, R. L. (2004). The CRC handbook of mechanical engineering. 2nd. Ed. Nova lorque: CRC.

JACOBSON, L. (2003). N.J. Bridge puts recycled plastic to unusual use. The Washington Post, Washington, 8 Dez 2003.

JOSHI, J.; LEHMAN, R.; NOSKER, T. (2004). Selected physical characteristics of polystyrene/high density polyethylene composites prepared from virgin and recycled materials. Disponível em: <http://www.amipp.rutgers.edu/html/scholarly_pub.html>. Acesso em 20 Fev 2005. 
KRISHNASWAMY, P. (2001a). Feature-recycled plastic lumber standards. Disponível em: <http://www.astm.org/SNEWS/DECEMBER_2001/>. Acesso em 4 Fev 2005.

KRISHNASWAMY, P.; MIELE, C. R.; FRANCINI, R. B.; YURACKO, K.; YERACE, P. (1997). Field evaluation of recycled plastic lumber pallets. Departamento de Recursos Naturais de Ohio. Columbus: Battelle

KRISHNASWAMY, P.; MCLAREN, M. G.; ASSIS, G.; PENSIERO, J.; MELEWSKI, P. M.; LASHWAY, K. F. (2001b). Introducing to the first recycled plastic bridge in the world. Disponível em: <http://www.maclaren.com/IBC\%20Paper.htm>. Acesso em 4 Fev 2005.

LAI, J., BAKKER, A. (1995). Analysis of the non-linear creep of high-density polyethylene. Polymer, vol. 36, n. 1.

LAMPO, R.; NOSKER T. (2001). An estimate of the effect of greenhouse gases by using recycled plastics as a substitute for treated wood railroad croosties. Disponível em: <http://www.epa.gov/reg5rcra/wptdiv/solidwaste/RR-Ties-GHG-report\%20final.pdf>. Acesso em 24 Fev 2005.

LOPEZ-ANIDO, A.; NAIK, T. R. (2000). Emerging materials for civil infrastructure - state of the art. Reston: ASCE (American Society of Civil Engineers).

LYNCH, J. K.; NOSKER, T. J.; RENFREE, R. (2001). Weathering effects on mechanical properties of recycled HDPE based plastic lumber. Disponível em: <http://www.amipp.rutgers.edu/html/scholarly_pub.html>. Acesso em 20 Fev 2005.

MANN, R. W. (2002). Engineering design, Disponível em: <http://www.accessscience. com, DOI 10.1036/1097-8542.233800>, Acesso em 11 Nov 2005.

MARCZAK, R. J. (2004). Polímeros como materiais de engenharia. Porto Alegre. UFRGS. MARTINS, A. F.; SUAREZ, J. C. M.; MANO, E. B., (1999). Polímeros poliolefínicos reciclados com desempenho superior aos materiais virgens correspondentes. Polímeros: Ciência e Tecnologia, Out/Dez 1999.

MEHTA P. K.; MONTEIRO, P. J. M. (1994). Concreto: estrutura, propriedades e materiais. São Paulo: Editora PINI.

MENEZES, M. S. (1989). Plástico reciclado: possibilidades de uso na construção e no mobiliário. 257p. Dissertação (Mestrado). Universidade de São Paulo, São Carlos. 1989. MCRUM, N. G. (1987). Principles of polymer engineering, 1st. Ed., Oxford Public. 
NIELSEN, L. E.; LANDEL, R. F. (1994). Mechanical properties of polymers ands composites. Nova lorque: Marcel Dekker.

NIX, W. D.; GIBELING, J. C.; HEMKER, K. J. (2001). Creep materials. Disponível em: <http://www.accesscience.com/, DOI 10.1036/1097-8542.167300>, Acesso em 4 Nov 2005.

NOSKER, T.; RENFREE, R. (1993). The use of commingled plastic lumber as construction materials. Disponível em: < http://www.amipp.rutgers.edu/html/scholarly_pub.html>. Acesso em 20 Fev 2005.

NOSKER, T.; RENFREE, R.; MORROW, D. R. (1994). Physical characteristics of the dual phase region in mixtures of recycled polystyrene/curbside tailings materials. Disponível em: <http://www.amipp. rutgers.edu/html/scholarly_pub.html>. Acesso em 20 Fev 2005.

NOSKER, T.; RENFREE, R. (1999a). Developing a recycled plastic composite railroad tie. Plastics Engineering, v. 55, Abril 1999.

NOSKER, T.; RENFREE, R. (1999b). Fiber orientation and the creation of structural plastic lumber. Plastics Engineering, v. 55, Junho 1999.

PINHEIRO, L. M. (2005). Fundamentos do concreto e projeto de edifícios. São Carlos. Disponível em: < http://www.set.eesc.usp.br> (Mat. didático on line). Acesso em 10 Nov 2005.

PIVA, A. M.; WIEBECK, H. (2004). Reciclagem do plástico - como fazer da reciclagem um negócio lucrativo. São Paulo: Editora Artliber.

PLÁSTICO REFORÇADO E COMPÓSITOS. As vantagens do plástico reforçado. Ano VI, v. 40, Novembro/Dezembro 2004. São Paulo: Editora do Administrador.

POOLER, D. J. (2001). The temperature dependent non-linear response of a wood plastic composite. Dissertação (Mestrado). Washington State University, Washington. 2001.

PRINGLE, B; BARKER, M. (2000). Starting a waste plastics recycling business. Disponível em: <http://www1.sac.ac.uk/info/External/Publications/WasteRecycling/>. Acesso em 15 Dez 2004.

RODRIGUES, C. A. (2001). Contribuição ao planejamento da manutenção preditiva da superestrutura ferroviária. 260p. Tese (Doutorado). Universidade Federal do Rio de Janeiro COPPE, Rio de Janeiro. 2001.

ROYLANCE, D. (2001). Engineering viscoelasticity. Cambridge: Massachusetts Institute of Technology. 24 out 2001. 
SAWYER, T. (2003). New extrusion process gives plastic beams greater strength. The Engineering News Record, 24 Fev 2003.

SELKE, S. E.; WICHMAN, I. (2003). Wood fiber/polyolefin composites. ELSEVIER: Composites: part A - applied science and manufacturing. Disponível em:

<http://www.elsevier.com/locate/compositesa>. Acesso em 15 Dez 2004.

SCHUT, J. H. (2004). They've been working on the railroad. Disponível em:

<http://www.plastictechnology.com/article/200404fa3.html>. Acesso em 4 Fev 2005.

SHENOI, R. A.; ALLEN, H. G.; CLARK, S. D. (1997). Cyclic creep and creep-fatigue interaction in sandwich beams. Journal of Strain Analysis, v. 32, n. 1.

Sítio eletrônico da Escola de Engenharia Mecânica da Universidade da Geórgia, EUA. Disponível em: <www.me.gatech.edu>. Acesso em 5 Dez 2005

Sítio eletrônico do Departamento de Engenharia, da Universidade de Cambridge. Disponível em : <http://www-materials.eng.cam.ac.uk>. Acesso em 10 Mar 2005.

Sítio eletrônico do Departamento de Engenharia de Materiais da Universidade da Virgínia. Disponível em : <http://www.people.virginia.edu/ Iz2n/mse209>. Acesso em 12 Mar 2005.

Sítio eletrônico do Instituto de Pesquisas Tecnológicas - IPT. Disponível em:

<http://www.ipt.br/areas/dpf/propriedades>. Acesso em 9 Jan 2006.

Sítio eletrônico do Instituto de Tecnologia da Geórgia, EUA. Disponível em:

<http://maven.gtri.gatech.edu/sfi/resources/>. Acesso em 12 Dez 2005.

Sítio eletrônico do Instituto PLASTVIDA. Disponível em: <www.plastvida.org.br>. Acesso em 14 Dez 2005

Sítio eletrônico do Ministério do Planejamento, Orçamento e Gestão, do Governo Federal. Disponível em : <http://www.planejamento.gov.br/planejamento_investimento>. Acesso em 20 Mar 2005.

Sítio eletrônico oficial da Torre Eiffel. Le site officiel de la Tour Eiffel. Disponível em: <http://www.tour-eiffel.fr/>. Acesso em 24 Fev 2005.

Sítio eletrônico sobre a arquitetura e arte romana. Disponível em:

< http://harpy.uccs.edu/roman/>. Acesso em 25 Nov 2005.

Sítio eletrônico sobre cactos. Disponível em: <http://www.cactos.com.br>. Acesso em 24 Nov 2005. 
SULLIVAN, H.W.; WOLFGANG, A.M. (1999). Polymeric compositions and methods for making construction materials from them. United States Patent. Patent Number: 5.886.078. 23 Mar 1999.

Sítio Eletrônico da U.S. Plastic Lumber. Disponível em:

<http://www.usplasticlumber.com/ index.php>. Acesso em 10 Fev 2006.

TOMASETTI, R. L.; JOSEPH, L. M. (2002) Structural design. Disponível em:

<www.accessscience.com, DOI 10.1036/1097-8542.662250>. Acesso em: 16 Nov 2005.

UNITED STATES PATENT (1999). SULLIVAN, H.W.; WOLFGANG, A.M. Polymeric compositions and methods for making construction materials from them. Patent Number: 5.886.078, 23 Mar 1999.

UNITED STATES PATENT (Brunswick, NJ) (1998). NOSKER, T.; RENFREE, R. W. Composite buildings materials from recyclable waste. Patent number: 5789477, 4 Ago 1998.

UNITED STATES PATENT (Brunswick, NJ) (1999). NOSKER, T. e RENFREE, R. W. Composite buildings materials from recyclable waste. Patent number: 5916932, 29 Jun 1999.

UNITED STATES PATENT (Piscataway, NJ) (1999). NOSKER, T. et al. Method of recycling post-consumer plastic waste. Patent number: 5951940, 14 Set 1999.

UNITED STATES PATENT (Piscataway, NJ) (1994). MORROW, D. R. et al. Method of derving polystyrene and polyolefin plastics composite from recycled plastics. Patent number: 5298214, 29 Mar 1994.

WIGOTSKY, V. (1993). Plastics vs. metals. Plastics Engineering, v.49, Dezembro 1993. 


\section{Glossário}

Blenda polimérica: terminologia adotada para representar as misturas físicas ou misturas mecânicas de dois ou mais polímeros, de forma que entre as cadeias moleculares dos polímeros diferentes só exista interação intermolecular secundária ou que não haja um elevado grau de reação química entre as cadeias moleculares dos polímeros diferentes.

Compósito: material conjugado formado por pelo menos duas fases ou dois componentes, sendo geralmente uma matriz polimérica e uma fase de reforço, normalmente na forma de fibras. Para a formação do material compósito ou do material conjugado é necessário haver uma interação química ou física da matriz polimérica com o reforço fibroso, proporcionando a transferência de esforços mecânicos da matriz polimérica para os reforços fibrosos.

Degradação (em polímeros): reações químicas destrutivas dos plásticos ou das borrachas, que podem ser causadas por agentes físicos, como a radiação solar, a temperatura, o atrito mecânico intenso ou por agentes químicos. A degradação é qualquer fenômeno que provoque alterações estruturais em um polímero, causando uma modificação irreversível nas suas propriedades físico-mecânicas, evidenciada pela variação indesejável dessas propriedades.

Extrusão: A moldagem por extrusão, ou simplesmente extrusão, é um dos mais importantes processos de conformação dos termoplásticos, sendo utilizado tanto para a confecção de produtos acabados como, e principalmente, para a produção de semimanufaturados, que devem sofrer novo processamento. Na extrusão, péletes ou grãos plásticos são fluidificados, homogeneizados e continuamente moldados, e essa técnica apresenta uma característica essencial, que a distingue dos processos anteriormente apresentados: é um processo contínuo.

Fibras de reforço (em polîmeros): são materiais fibrosos que quando adequadamente incorporados aos polímeros aumentam muito a sua resistência mecânica, tendo também influência em outras propriedades. Para terem grande influência no reforço de polímeros, as fibras precisam ser incorporadas em misturadores adequados e o processamento do compósito ou material conjugado deve ser feito corretamente, para evitar drásticas reduções nos comprimentos das fibras. 
Fadiga: na Ciência dos Materiais, é o processo de perda da capacidade resistente de uma material quando submetido a uma carga cíclica.

Fadiga estática: fenômeno que leva o material à ruptura, como conseqüência das deformações excessivas provocadas pela fluência.

Fluência: denominação dada ao aumento das deformações para um nível de tensões constante.

Mero: unidade de repetição do polímero, ou seja, é a unidade estrutural que se repete na cadeia macromolecular do polímero.

Polimerização: é a síntese de um polímero. A polimerização é o conjunto das reações que provocam a união de pequenas moléculas, por ligação covalente, para a formação das muitas cadeias macromoleculares que compõem um material polimérico; a polimerização consiste em reagir um ou mais monômeros para a obtenção de polímeros;

Polímero: material orgânico ou inorgânico, natural ou sintético, de alto peso molecular, formado por muitas macromoléculas, sendo que cada uma dessas macromoléculas deve possuir uma estrutura interna onde há a repetição de pequenas unidades chamadas meros. O termo polímero é massivo, sendo utilizado para designar o material cuja composição é baseada em um conjunto de cadeias poliméricas, e cada uma das muitas cadeias poliméricas que formam o polímero é uma macromolécula formada por união de moléculas simples ligadas por covalência.

Poliolefinas: polímeros obtidos a partir de monômeros que são olefinas, isto é, hidrocarbonetos alifáticos insaturados contendo uma dupla ligação carbono-carbono por molécula do monômero. As principais poliolefinas são: o polietileno de baixa densidade, o polietileno de alta densidade e o polipropileno.

Processamento (de polímeros): o mesmo que moldagem; processamento é a transformação de um polímero, como matéria-prima, em um produto final; a escolha do tipo de processo de transformação de um polímero em um produto polimérico é feita com base nas características intrínsecas do polímero, na geometria do produto a ser moldado e na quantidade do produto que será produzida. 
Pultrusão: a pultrusão é um termo adotado para descrever o processo de extrusão contínua de perfis de plástico reforçado. Fibras de reforço, sob a forma de fios, são puxadas através de um reservatório (banheira) para a impregnação da resina polimérica de uma matriz e finalmente o perfil passa por uma zona de cura.

Reciclagem: pode ser entendida como uma série de atividades que incluem a coleta de materiais descartados pela sociedade, a triagem, o processamento e a transformação desses materiais em matéria-prima para a manufatura de novos produtos.

Relaxação: denominação dada ao fenômeno de decaimento das tensões ao longo do tempo, com a manutenção de uma determinada deformação.

Resiliência: propriedade que um material possui de resistir ao impacto sem se deformar definitivamente (deformação plástica).

Resina: termo atualmente empregado para representar qualquer matéria-prima polimérica no estado termoplástico, sendo fusíveis, insolúveis em água, mas solúveis em outros meios líquidos.

Sustentabilidade: pode ser entendido como o conhecimento das necessidades e aspirações humanas no presente, sem esquecer o compromisso de permitir às futuras gerações conhecer as suas necessidades e aspirações (WCED - World Commission on Environment and Development,1987)

Termofixos: são plásticos que quando curados, com ou sem aquecimento, não podem ser amolecidos novamente por um próximo aquecimento. Estruturalmente, os termofixos têm como componentes fundamentais polímeros com cadeias moleculares contendo muitas ligações químicas primárias entre as cadeias diferentes (ligações cruzadas) que geram o comportamento dos termofixos, que podem também ser chamados polímeros reticulados ou polímeros com muitas ligações cruzadas.

Termoplásticos: são polímeros capazes de ser repetidamente amolecidos pelo aumento da temperatura e endurecidos pela diminuição da temperatura. Essa alteração reversível é física e não química, mas pode provocar alguma degradação no termoplástico, para um número elevado de ciclos de aquecimento e de resfriamento. Estruturalmente, os componentes fundamentais dos termoplásticos são polímeros com cadeias lineares ou ramificadas, sem ligações cruzadas, isto é, entre as cadeias poliméricas diferentes só existem interações intermoleculares secundárias, reversíveis com a temperatura. 
Viscoelasticidade: Comportamento mecânico de alguns materiais que combinam propriedades viscosas e elásticas, apresentando dependência do tempo, da temperatura, das tensões e da taxa de deformação.

Viscosidade: Resistência interna que as partículas de uma substância oferecem ao escorregamento de uma sobre as outras. Propriedade dos fluidos correspondente ao transporte microscópico de quantidade de movimento por difusão molecular. Ou seja, quanto maior a viscosidade, menor a velocidade em que o fluido se movimenta.

Vulcanização (em borrachas): é o processo químico de maior importância para as borrachas, introduzindo a elasticidade, melhorando a resistência mecânica e reduzindo a sensibilidade às variações de temperatura. As reações de vulcanização, que podem empregar aceleradores e ativadores, além do agente de vulcanização, introduzem uma pequena quantidade de ligações cruzadas ou ligações químicas primárias entre as diferentes cadeias poliméricas das borrachas. Essas ligações cruzadas amarrando as cadeias poliméricas são responsáveis pela elasticidade das borrachas vulcanizadas. 


\section{Anexo A - Roteiro Básico de Ensaios Experimentais e Projeto das Matrizes para Extrusão dos Corpos-de-Prova}

\section{A.1. NORMAS UTILIZADAS}

Os parâmetros para o ensaio de materiais plásticos foram retirados das normas da ASTM (American Society for Testing and Materials) citadas abaixo.

- D695-96: Método de ensaio padrão para propriedades compressivas dos plásticos rígidos (Standard Test Method for Compressive Properties of Rigid Plastics);

- D638-96: Método de ensaio padrão para propriedades de tração dos plásticos (Standard Test Method for Tensile Properties of Plastics);

- D5943-96: Método de ensaio padrão para determinação das propriedades de flexão dos plásticos (Standard Test Method for Determining Flexural Properties of Plastics).

\section{A.1.1. Ensaio de compressão: D695-96}

(a) Corpos-de-prova

Os corpos-de-prova devem ser processados cuidadosamente para que tenham superfícies regulares. Devem ser tomadas precauções com as extremidades para que sejam regulares e planas, com cantos bem definidos e perpendiculares ao eixo da peça.

O corpo-de-prova padronizado deve possuir a forma de um cilindro ou prisma reto, em que sua altura seja o dobro da largura principal ou diâmetro. As dimensões preferíveis são:

Prisma: 12,7mm (lado da seção transversal) x 25,4mm (altura)

Cilindro: $12,7 \mathrm{~mm}$ (diâmetro) x 25,4mm (altura)

A figura A.1 mostra as geometrias possíveis e as dimensões dos corpos-deprova recomendadas pela norma D695-96. As dimensões estão expressas em milímetros. 

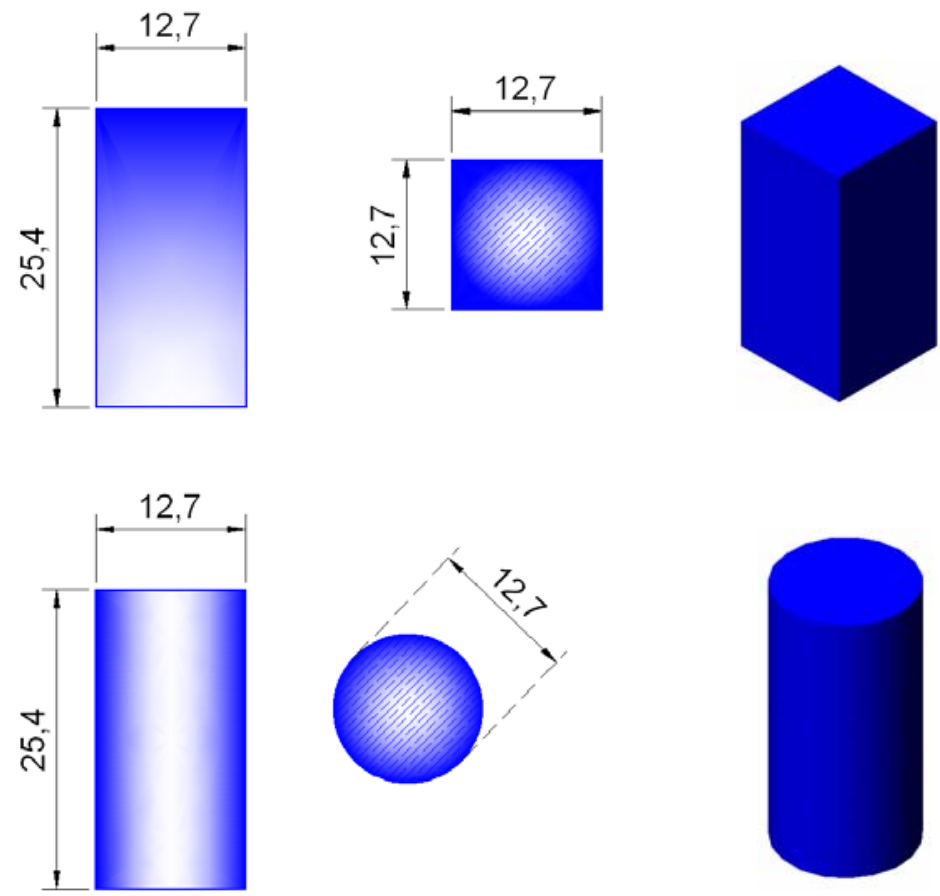

Figura A.1. Corpos-de-prova para o ensaio de compressão (dimensões em mm)

(b) Tamanho da amostra

Ao menos cinco exemplares devem ser ensaiados, no caso dos materiais isotrópicos.

(c) Velocidade do ensaio

A velocidade sugerida para o ensaio de compressão deve ser de $1,3+/-0,3$ $\mathrm{mm} / \mathrm{min}$.

\section{A.1.2. Ensaio de tração: D638-96}

(a) Corpos-de-prova

Os corpos-de-prova devem estar de acordo com a geometria mostrada na figura A.2 e as dimensões explicitadas na tabela A.1. O tipo I é preferível quando o corpo-deprova possui uma espessura de $7 \mathrm{~mm}$ ou menos. O tipo II pode ser utilizado quando 0 material não rompe na seção delgada. O tipo III deve ser utilizado para todos os materiais com espessura maior ou igual a $7 \mathrm{~mm}$, mas não superior a $14 \mathrm{~mm}$. O tipo IV é utilizado quando se deseja comparar materiais com diferentes casos de rigidez. $\mathrm{O}$ tipo $V$ deve utilizado quando o material tiver uma limitação de espessura de $4 \mathrm{~mm}$ ou menos ou quando se tem um grande número de corpos-de-prova a ser ensaiado. 
Todas as superfícies devem estar livres de falhas, ranhuras ou imperfeições visíveis. Marcas grosseiras deixadas por operações de processamento devem ser cuidadosamente removidas com uma lima fina ou um abrasivo. As superfícies lixadas devem ser alisadas com um papel abrasivo (ASTM: D638-96. $\mathrm{N}^{\circ} 0$ ou mais fina). As ranhuras do acabamento devem estar dispostas na direção paralela ao eixo longitudinal da peça. Todas as sobras e lascas devem ser removidas.

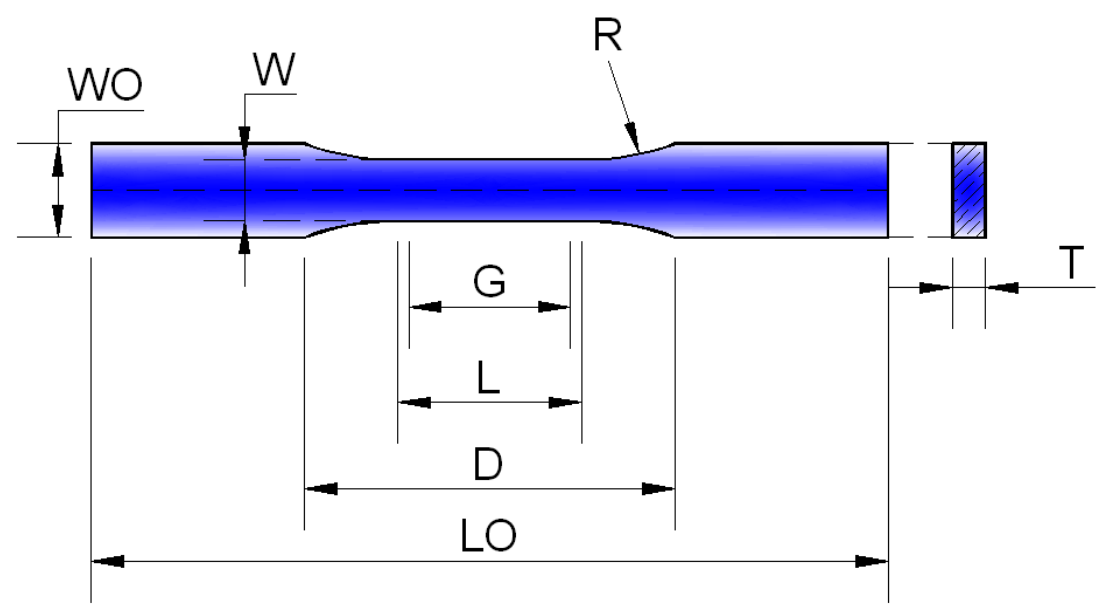

Figura A.2. Corpo-de-prova para ensaio de tração

Tabela A.1. Dimensões do corpo-de-prova para ensaio de tração.

\begin{tabular}{lccc} 
& \multicolumn{2}{c}{$\mathbf{T}=\mathbf{7 , 0} \mathbf{~ m m}$ ou menor } & $\mathbf{T}=\mathbf{7 , 0}-\mathbf{1 4 , 0} \mathbf{~ m m}$ \\
\cline { 2 - 4 } Dimensões (mm) & Tipo I & Tipo II & Tipo III \\
\hline W - Largura da seção delgada & 13 & 6 & 19 \\
L - Comprimento da seção delgada & 57 & 57 & 57 \\
WO - Largura total & 19 & 19 & 29 \\
LO - Comprimento total & 185 & 183 & 246 \\
G - Comprimento p/ instrumentação & 50 & 50 & 50 \\
D - Distância entre garras & 115 & 135 & 115 \\
R - raio & 76 & 76 & 76
\end{tabular}

(b) Tamanho da amostra

Ao menos cinco exemplares devem ser ensaiados, no caso dos materiais isotrópicos.

(c) Velocidade do ensaio D638-96).

A velocidade é obtida após consulta à tabela A.1 (Tabela 1 da norma ASTM 
Tabela A.2. Designação da velocidade de ensaio ${ }^{1}$.

\begin{tabular}{cccc} 
Classificação $^{2}$ & $\begin{array}{c}\text { Tipo do } \\
\text { corpo-de-prova }\end{array}$ & $\begin{array}{c}\text { Velocidade do ensaio } \\
(\mathbf{m m} / \mathbf{m i n})\end{array}$ & $\begin{array}{c}\text { Taxa de deformação } \\
\text { no início do ensaio }\end{array}$ \\
\hline & I, II, III barras e & $5+/-25 \%$ & 0,1 \\
& tubos & $50+/-10 \%$ & 1 \\
Rígidos e & & $500+/-10 \%$ & 10 \\
semi-rígidos & IV & $50+/-25 \%$ & 0,15 \\
& & $500+/-10 \%$ & 1,5 \\
& V & $10+/-25 \%$ & 15 \\
& & $100+/-25 \%$ & 0,1 \\
Flexíveis & III & $50+/-10 \%$ & 1 \\
& \multirow{2}{*}{ IV } & $500+/-10 \%$ & 1 \\
& $50+/-10 \%$ & 10 \\
& $500+/-10 \%$ & 1,5 \\
\end{tabular}

1- Selecionar a menor velocidade que leva o corpo-de-prova à ruptura, com a geometria especificada, no período de $1 / 2$ a $5 \mathrm{~min} ; 2$ - Ver a terminologia das definições na norma ASTM D 883.

\section{A.3.1. Ensaio de flexão: D5943-96}

\section{(a) Corpos-de-Prova}

As dimensões preferíveis para o corpo-de-prova a ser ensaiado são descritas a seguir:

Comprimento: $\mathrm{L}=80+/-2 \mathrm{~mm}$.

Largura: $B=10+/-0,2 \mathrm{~mm}$.

Espessura (altura): $\mathrm{H}=4+/-0,2 \mathrm{~mm}$.

Quando não for possível utilizar as dimensões acima, os seguintes limites podem ser aplicados:

$\frac{L}{H}=20 \pm 1$

A largura B pode ser determinada com o auxílio da tabela A.3.

Tabela A.3. Obtenção da largura B do corpo-de-prova.
Espessura Nominal H
Largura B (+/- 0,5)

\begin{tabular}{cc}
$(\mathrm{mm})$ & $(\mathrm{mm})$ \\
\hline $1<\mathrm{H} \leq 3$ & 25 \\
$3<\mathrm{H} \leq 5$ & 10 \\
$5<\mathrm{H} \leq 10$ & 15 \\
$10<\mathrm{H} \leq 20$ & 20 \\
$20<\mathrm{H} \leq 35$ & 35 \\
$35<\mathrm{H} \leq 50$ & 50
\end{tabular}


A figura A.3. mostra a geometria do corpo-de-prova, recomendada pela norma ASTM D683-96.

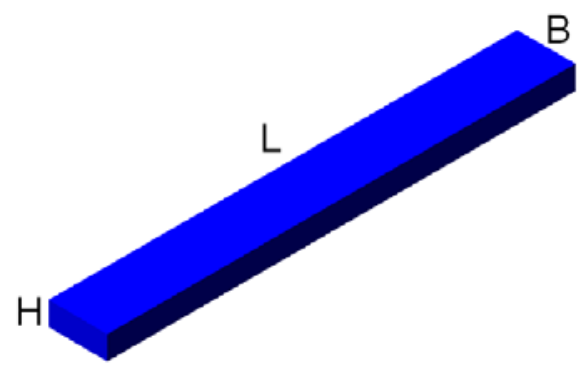

Figura A.3. Corpo-de-prova para ensaio de flexão

(b) Tamanho da Amostra

Ao menos cinco exemplares devem ser ensaiados no caso dos materiais isotrópicos. Se for requerida uma precisão maior do valor médio, deve-se aumentar o tamanho da amostra.

(c) Velocidade do Ensaio

A velocidade sugerida para o ensaio de compressão é de $2,0 \mathrm{~mm} / \mathrm{min}$.

\section{A.2. PROJETO DAS MATRIZES PARA EXTRUSÃO DOS CORPOS-DE-PROVA}

Para a fabricação dos corpos-de-prova, por meio de moldagem por extrusão, fezse necessária a confecção de matrizes, que atendessem aos requisitos geométricos impostos pelas normas da ASTM, já citadas.

A figura A.4, A.5 e A.6 mostram o projeto da matriz e dos adaptadores necessários ao correto acoplamento à extrusora.

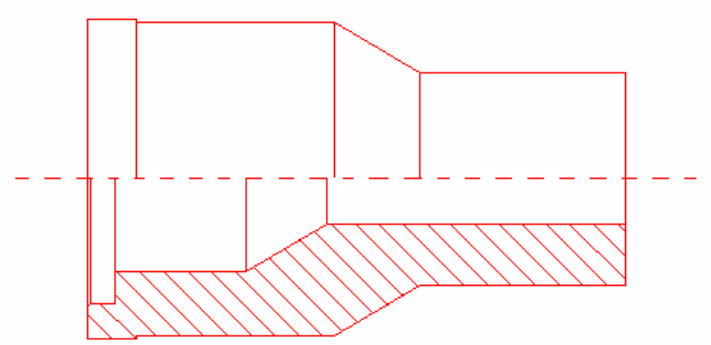

Figura A.4. Matriz para extrusão dos corpos-de-prova 


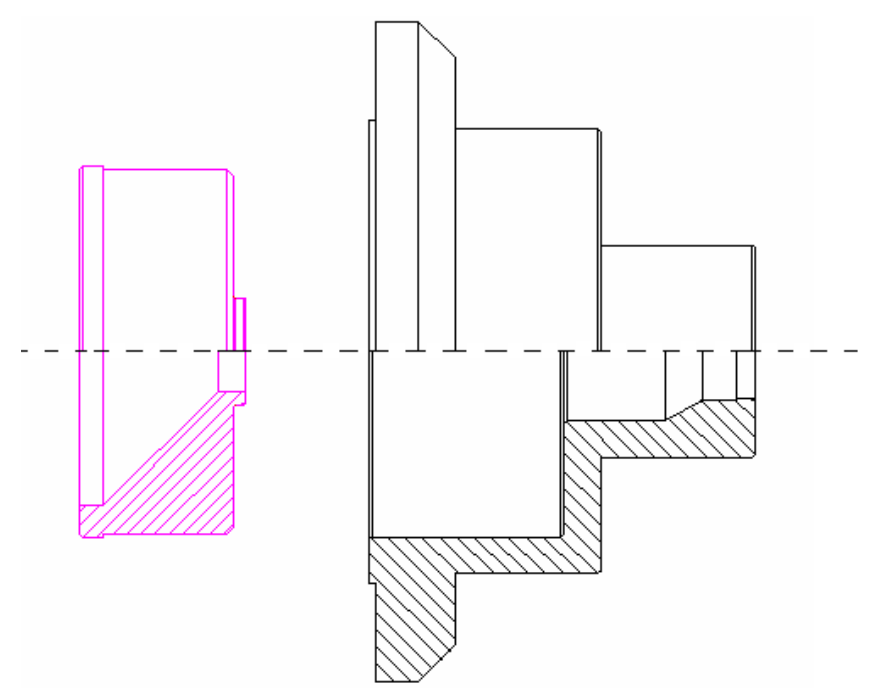

Figura A.5. Adaptadores da matriz, necessários ao acoplamento à extrusora
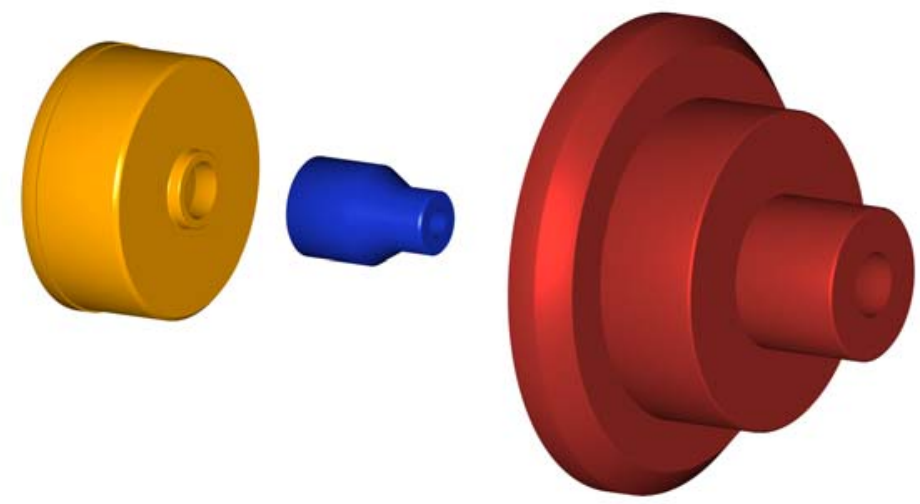

Figura A.6. Matriz e adaptadores em desenho tridimensional

As matrizes e os adaptadores confeccionados durante esta pesquisa serão utilizados nas pesquisas subseqüentes, que darão continuidade ao estudo da viabilidade do plástico reciclado como material estrutural. 